\title{
Neuroautonome Regulation und deren emotionale Modulation bei Mäusen
}

\author{
Dissertation \\ zur Erlangung des Doktorgrades \\ der Mathematisch-Naturwissenschaftlichen Fakultäten \\ der Georg-August-Universität zu Göttingen
}

vorgelegt von

Philip Tovote

aus Gelsenkirchen

Göttingen 2005 
D 7

Referent: $\quad$ Prof. Dr. Rüdiger Hardeland

Korreferent: Prof. Dr. Andreas Stumpner

Tag der mündlichen Prüfung: 26.4.2005 


\section{$1 \quad$ Einleitung}

\subsection{Physiologische und ethologische Anpassungsmechanismen in aver- siven emotionalen Situationen}

Bei Säugetieren und niederen Vertebraten sind viszeromotorische (neuroautonome) Funktionen der direkten, willentlichen Kontrolle weitgehend entzogen und werden im Wesentlichen von subkortikalen Teilen des Zentralnervensystems (ZNS) wie dem Hypothalamus und dem Hirnstamm reguliert. Zur Anpassung an schnell wechselnde Umweltbedingungen bzw. potentielle Gefahren wird die Modulation dieser Grundfunktionen (Homöostase) über komplexe Regulationsmechanismen notwendig. Diese umfassen normalerweise Anpassungsprozesse des somatomotorischen (Verhaltens-), des viszeromotorischen (neuroautonomen) und des endokrinen Systems (Folkow, 2001). Die Erfahrung einer äußeren Bedrohung, wird über die Sinnesorgane (Sehsinn, Gehör, Geruchssinn, Tast- bzw. Schmerzsinn) zum Zentralnervensystem weitergeleitet (s. Abb. 1.1). Die dortige Aktivierung neuronaler, für die Verarbeitung von Emotionen zuständiger Netzwerke führt zu Antwortmustern, die letztendlich dem Schutz des Organismus dienen (LeDoux, 1996).

In der vorliegenden Arbeit wurden diese Regulationsprozesse nach der Präsentation exogener Stimuli mit unterschiedlicher emotionaler Bedeutung auf den genannten drei Ebenen im Mausmodell untersucht. Das Schwergewicht lag dabei auf den durch konditionierte Furcht ausgelösten, neuroautonomen bzw. kardiovaskulären Antworten. Zusätzlich wurde der Beitrag des Kortikotropin-freisetzenden Hormons (corticotropin-releasing factor: CRF)-Systems zur neuroautonomen Regulation und deren emotionaler Modulation untersucht.

\subsubsection{Verhaltensanpassung}

Vertebraten reagieren mit verschiedenen Verhaltensrepertoires auf äußere Bedrohungen (nach Koolhaas et al., 1999). Bei Mäusen ist dies typischerweise Defensiv-Verhalten (defensive behavior). Charakteristische Verhaltensmuster sind dabei Avoidance (Vermeidung) oder Freezing, das als das Fehlen jeglicher Körperbewegung mit Ausnahme von Atembewegungen definiert wird (Fendt \& Fanselow, 1999). Dieses Verhalten ist Teil einer 
Aufmerksamkeitsreaktion (Vigilance), mit der Nagetiere auf mögliche Bedrohung durch Fressfeinde reagieren. Diese ist zudem durch eine umfassende Reduktion der lokomotorischen Aktivität und erniedrigtes Explorationsverhalten geprägt (Blanchard et al., 1991). Durch die Bewegungslosigkeit wird den auf Bewegung reagierenden Angreifern der Schlüsselreiz entzogen. Jedoch ist ein schnelles Umschalten des Verhaltensmusters auf Flucht- oder Gegenwehrreaktionen (fight or flight; (Cannon, 1929)) unter natürlichen Bedingungen jederzeit möglich und oftmals die Alternative mit den größeren Überlebenschancen. In einer neuen Umgebung (Novelty) wird zudem erhöhtes Lokomotions-
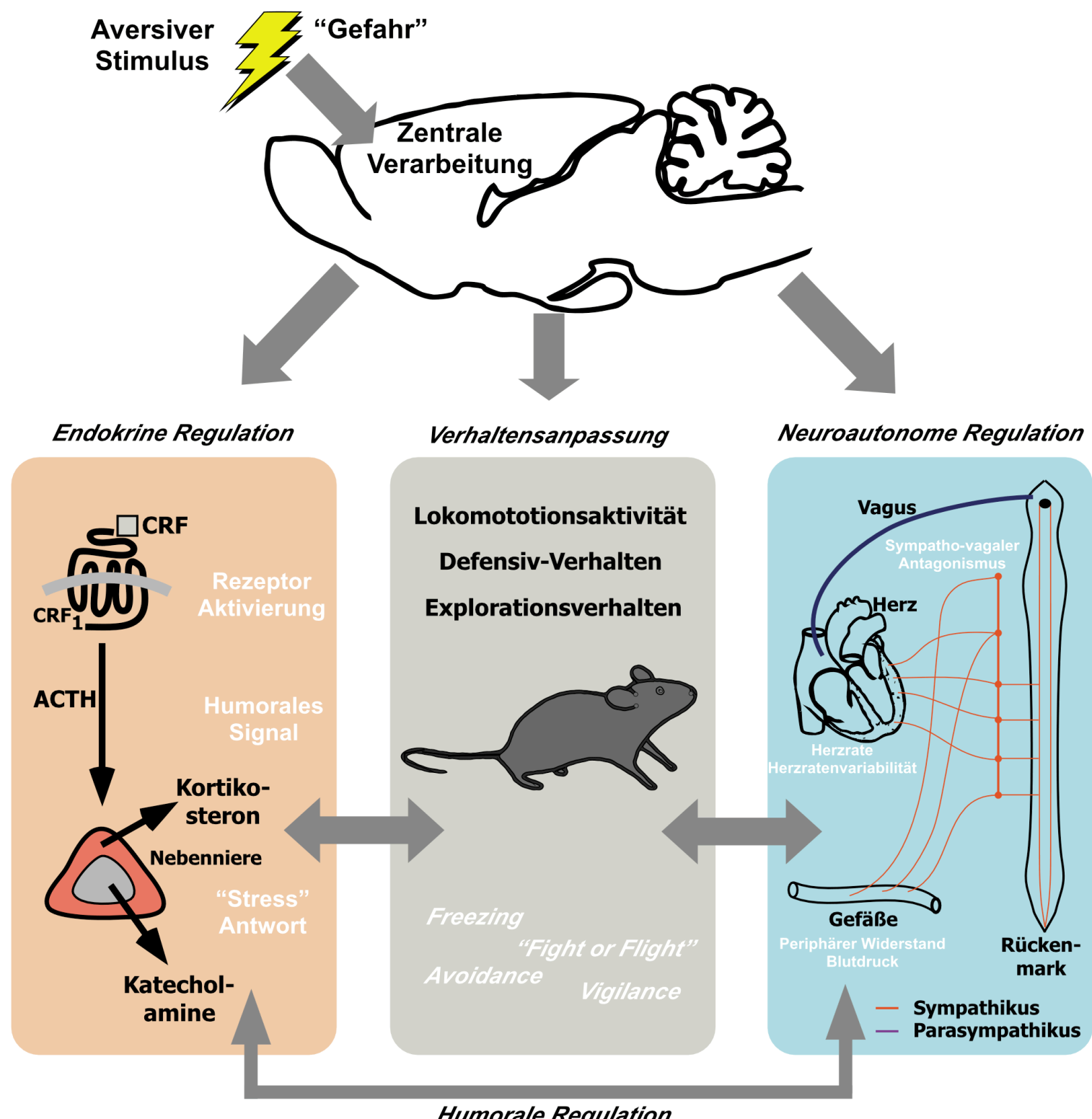

Abb. 1.1: Schematische Darstellung der Hauptregulationsmechanismen als Anpassung an externe aversive Stimuli. $\mathrm{CRF}=$ Corticotropin-releasing-factor, $\mathrm{CRF}_{1}=$ CRF Rezeptor $\mathrm{l}$, $\mathrm{ACTH}=$ adrenokortikotropes Hormon. 
bzw. Explorationsverhalten beobachtet, was als Teil einer Alarmreaktion auf die potentielle Gefahr der unbekannten Umgebung interpretiert wird (Crusio, 2001). Diese hohe Bandbreite der Verhaltensänderungen ist von schneller zeitlicher Dynamik charakterisiert.

\subsubsection{Autonome Regulation}

$\mathrm{Zu}$ den wichtigsten physiologischen Grundfunktionen gehört bei Vertebraten die HirnHerz Interaktion. Sie ermöglicht zum einen die Aufrechterhaltung der homöostatischen Funktion des Herz-Kreislaufsystems, zum anderen die kardiovaskuläre Adaptation an wechselnde Umweltbedingungen als Antwort auf exogene Stimuli. Schnittstellen bzw. Kommunikationsmittel sind endokrines System, Blutkreislauf und das autonome Nervensystem, gegliedert in die funktionell antagonistischen Systeme von Sympathikus und Parasympathikus. Mittels des autonomen Nervensystems und durch Modulation der Balance von Sympathikus und Parasympathikus kann das ZNS auf externe Reize, wie z.B. Bedrohungen, reagieren.

Das in höchstem Maße von Blutzucker und Blutsauerstoff abhängige ZNS übernimmt bei höheren Vertebraten zunehmend als Kontrollinstanz die Regulation der Herztätigkeit und des Blutkreislaufs. Mit steigender Komplexität des ZNS bei Säugetieren im Zuge evolvierter Flexibilität und Anpassungsfähigkeit an wechselnde Umweltbedingungen, werden HerzKreislauffunktionen verstärkt auch von übergeordneten Hirnzentren moduliert. Dabei spielen Emotionen verarbeitende Strukturen, insbesondere die Amygdala eine wichtige Rolle (LeDoux, 1996; reviewed von Ter Horst, 2000). In emotionalen Situationen wie bei der Erfahrung einer äußeren Bedrohung werden spezifische neuronale Netzwerke für Furcht aktiviert (reviewed von Cannistraro \& Rauch, 2003). Emotionale Zustände wie Furcht oder Angst modulieren kardiovaskuläre Funktionen (reviewed von Berntson et al., 1998). Während potenziell lebensentscheidender Verhaltensreaktionen ist maximale lokomotorische Aktivität notwendig, die wiederum hohe Sauerstoffversorgung des Skelettmuskelsystems erfordert. Dies geschieht durch erhöhten Blutfluss, der durch größere Auswurfleistung des Herzens erreicht wird. Die autorhythmische Herztätigkeit wird von den intrinsischen Schrittmacherzentren des Herzens bestimmt, unterliegt jedoch der Kontrolle des autonomen Nervensystems. Die neuroautonome Reaktion auf einen emotionalen Stimulus besteht bei Mäusen in sympathischer Aktivierung und Zurücknahme des im basalen Zustand dominanten parasympathischen Tonus (Stiedl \& Spiess, 1997). Dies führt zu Steigerung der Herz- 
schlagfrequenz (Herzrate: HR), Erniedrigung der Herzratenvariabilität (HRV) und Erhöhung des Blutdrucks (blood pressure: BP). Während HR und HRV durch direkte neuronale Innervierung relativ schnell reguliert werden, ist die überwiegend humorale Vermittlung der Blutdruckregulation über periphere vasomotorische Prozesse durch langsamere zeitliche Dynamik charakterisiert. Die schnellste Regulation des Blutdrucks erfolgt über den Barorezeptorreflex unter Bedingungen erhöhten oder erniedrigten Blutdrucks (Guyton et al., 1972). Andere Anpassungsprozesse des autonomen Systems umfassen einen Anstieg der Körpertemperatur, die Stress induzierte Hyperthermie (Bouwknecht et al., 2000), gesteigerte Defäkation und Erniedrigung des Hautwiderstandes infolge von Transpiration.

\subsubsection{Endokrine Reaktion}

Zusätzlich zu afferenten und efferenten Nervenfasern tragen auch viele humorale Faktoren zur Kommunikation von Herz und Gehirn und zu Anpassungsprozessen auf emotionale Stimuli bei. Sympatische Aktivierung führt zur Freisetzung von Katecholaminen aus sympathischen Nervenendungen und aus dem Nebennierenmark, die u.a. vasokonstriktorische Funktion ausüben und an der Blutdruckregulation beteiligt sind (Busse, 2000). Wichtiger Bestandteil der Stressreaktion ist die endokrine Aktivierung der HypothalamusHypophysen-Nebennieren (HHN)-Achse. Die initiale Aktivierung wird im paraventrikulären Nukleus des Hypothalamus vom Kortikotropin-freisetzenden Hormon (corticotropinreleasing factor: CRF) vermittelt, und führt zur Ausschüttung des adrenokortikotropen Hormons (adrenocorticotropic hormone: ACTH) in den Blutkreislauf (Vale et al., 1981). ACTH vermittelt wiederum die Freisetzung von Glukokortikoiden, vor allem Kortisol (bei Mäusen: Kortikosteron), aus der Nebennierenrinde. Diese haben entzündungshemmende Wirkung und üben permissiven Einfluss auf die vom Nebennierenmark ausgeschütteten Katecholamineffekte (Vasokonstriktion) an der Gefäßmuskulatur aus. In hohen Konzentrationen werden zusätzlich über die Bindung an Minearalokortikoid-Rezeptoren Vasokonstriktion und erhöhtes Blutvolumen infolge Salzretention vermittelt (Wuttke, 2000). Eine wichtige Rolle besteht außerdem in der Rückregulierung der Stressreaktion (Munck et al., 1984). Diese über den Blutkreislauf vermittelten Prozesse weisen relativ langsame zeitliche Dynamik und stereotypische Antwortmuster auf. Langzeiteffekte von chronischer Aktivierung zentraler Glukokortikoidrezeptoren werden in Zusammenhang mit Psychopathologien gebracht (reviewed von Korte, 2001). 


\subsection{Physiologische Eigenschaften kardiovaskulärer Antworten auf konditio- nierte und unkonditionierte emotionale Stimuli}

Nicht nur die Erfahrung einer äußeren Bedrohung bzw. eines aversiven, d.h. emotional bedeutsamen Reizes, sondern auch die Antizipation eines solchen Stimulus kann autonome Anpassungsmechanismen auslösen. Die emotionale Bedeutung möglicher Reize kann sowohl angeboren sein als auch erlernt werden (Blanchard et al., 1991) und ist bei Verhaltens- oder pharmakologischen Versuchen von den experimentellen Bedingungen abhängig. Die zeitlichen Dynamiken der kardiovaskulären Anpassungsmechanismen vom basalen Zustand bis zum Erreichen maximaler Werte und anschließender Rejustierung sind in Mäusen aufgrund fehlender Langzeitmessungen noch nicht untersucht worden.

Die Regulation der autonomen kardiovaskulären Funktionen erfolgt mit unterschiedlichen zeitlichen Dynamiken. Die schnellste Regulation der Herzrate findet durch direkte phasische Modulation der tonischen parasympathischen Kontrolle, gefolgt von einem phasischen Beitrag des sympathischen Systems statt. Im Gegensatz hierzu ist die Regulation des systemischen Blutdrucks ein vom autonomen System gering beeinflusster komplexer Prozess, der sowohl neuronale als auch hormonale und humorale Signalwege einschließt (Guyton et al., 1972). Sympathische Fasern üben tonische neuronale Kontrolle über $\alpha$-adrenerge Rezeptoren an der Gefäßmuskulatur aus. Kurzzeitige Blutdruckregulation erfolgt überwiegend durch eine Baroreflex-vermittelte De- oder Akzeleration der Herzrate unter Bedingungen von stark erhöhtem bzw. erniedrigtem Blutdruck (reviewed von Kumada et al., 1990). Zirkulierende Hormone der Nebennieren (Katecholamine, Kortikoide) beeinflussen den Blutdruck überwiegend in längeren Zeiträumen. Auf der Basis dieser Information wurde die Hypothese einer zeitlichen Dissoziation der Dynamiken der Herzraten- bzw. Blutdruckantworten auf Furcht auslösende Stimuli aufgestellt. Es ist somit unklar, ob die zuvor beschriebene, schnelle und transiente hypertonische Antwort nur Sekunden nach dem Einsetzen des Ton-CS im Gedächtnistest der Furchtkonditionierung (Iwata \& LeDoux, 1988; LeDoux et al., 1988) oder nach akustischer Startle-Stimulation spezifisch einer konditionierten Furchtantwort zuzuordnen ist. Ein Ziel der vorliegenden Arbeit war die experimentelle Überprüfung ob Herzraten- wie auch Blutdruckantworten Indikatoren für konditionierte Furcht sind. Des Weiteren sollte auf die Hypothese von schneller Herzratenund langsamer Blutdruckregulation getestet werden und die zeitliche Dynamik der kardiovaskulären Anpassungen während der Retention konditionierter Furcht untersucht werden. Um konditionierte und unkonditionierte Antworten auf potenziell aversive akustische 
Stimuli bei der Furchtkonditionierung zu vergleichen, wurden Herzraten und Blutdruckeffekte zusätzlich in Startle-Experimenten untersucht. Diese Experimente sollten klären, ob akustische Startle-Stimuli unkonditionierte aversive Stressoren unter den gegebenen stressfreien Bedingungen darstellen, um reflektorisch bedingte Änderungen mit möglicher kurzer Latenz nachweisen zu können.

\subsubsection{Auditorische Furchtkonditionierung}

Auditorische Furchtkonditionierung ist ein validierter experimenteller Verhaltenstest, der genutzt wurde um die neurochemischen und neuroanatomischen Grundlagen konditionierter Antworten auf aversive Stimuli zu untersuchen (reviewed in Fendt \& Fanselow, 1999; Koch, 1999). Die konditionierte Furchtreaktion umfasst die Aktivierung des autonomen Nervensystems (Baudrie et al., 1997; LeDoux, 1993; Stiedl \& Spiess, 1997). Die auditorische Furchtkonditionierung basiert auf der definierten zeitlichen Kopplung eines zunächst neutralen Ton-Reizes (konditionierter Stimulus, CS) mit einem aversiven, elektrischen FußschockReiz (unkonditionierter Stimulus, US) im Training. Die durch den aversiven Reiz ausgelöste Reaktion (unkonditionierte Antwort, UR) kann nach dem Lernvorgang durch die Assoziation der beiden Reize allein durch Präsentation des jetzt aversiv assoziierten Stimulus im Ton abhängigen Gedächtnistest ausgelöst (konditionierte Antwort, CR) werden (Thompson, 2001). Sie drückt sich unter anderem in Änderungen des Verhaltens und einer Tachykardie (Herzratenanstieg) aus (Stiedl et al., 1997; Stiedl \& Spiess, 1997). Der emotionale Lernprozess nach einmaliger Präsentation von CS und US führt zu lang anhaltenden, aversiv assoziierten Gedächtnisinhalten. Dies ist auch von Menschen bekannt, bei denen traumatische Erlebnisse ein Leben lang erinnert werden können (Rosen \& Schulkin, 1998). Werden in der Trainingsprozedur US und CS zeitlich durch Intervalle von $60 \mathrm{~s}$ oder länger voneinander getrennt, so werden sie von C57BL/6J Mäusen nicht mehr aversiv miteinander assoziiert. Dem CS werden somit keine aversiven Eigenschaften zugeschrieben und im Gedächtnistest wird durch ihn keine konditionierte Reaktion ausgelöst. Stattdessen werden milde und transiente Antworten auf autonomer Ebene beobachtet welche auch dann auftreten, wenn im Training US oder CS weggelassen werden und die als Erregungs- oder Attentionsreaktionen gedeutet werden (Stiedl \& Spiess, 1997).

Mit Hilfe neu entwickelter Radiotelemetriesender (Brockway, 1998; Kramer et al., 1993; Mills et al., 2000) können kardiovaskuläre Parameter wie Herzrate und Blutdruck im 
Heimkäfig freibeweglicher Mäuse aufgenommen werden (Tovote, 2001). Dabei werden ungewollte Störungen der Tiere durch Präsentation einer neuen Umgebung (Novelty), manuelles Interferieren (Handling) oder Einschränkung der Bewegungsfreiheit wie z.B. bei Blutdruckmessungen mit Schwanzklemmen (Kurtz et al., 2005) vermieden. Unter solchen relativ stressfreien Bedingungen sind Herzraten-Antworten im Furchtkonditionierungsparadigma eingehend untersucht worden (Stiedl et al., 1999b; Stiedl \& Spiess, 1997). Bei Mäusen führt sympathische Aktivierung nach CS-Präsentation zu einer unmittelbar einsetzenden Beschleunigung der Herzrate bis hin zu maximalen physiologischen Werten von ca. 800 Schlägen pro Minute (beats per minute: bpm) (Stiedl et al., 1999b; Stiedl \& Spiess, 1997). Für das Ausbilden dieser CS induzierten Tachykardie ist die Langzeitgedächtnisfunktion notwendig, die von de novo Proteinsynthese zur Konsolidierung der Erinnerung abhängt (Stiedl et al., 1999a).

\subsubsection{Akustische Startle Experimente}

Bei Startle-Experimenten mit akustischer Stimulation löst ein unvermitteltes, sehr kurzes auditorisches Signal (20-50 ms) mit hoher Intensität (100-110 dB SPL) eine schnelle reflexive Antwort aus, die aus einer koordinierten Muskelkontraktion der Augenlider, des Nackens und der Extremitäten besteht. Diese unwillkürliche Startle-Reaktion wird als Ausdruck reflexiver Abwehrmechanismen angesehen (reviewed in Koch, 1999). Die Amplitude des akustischen Startle-Reflexes und ihre Potenzierung durch konditionierte Furcht sind validierte Paradigmen für die Bewertung konditionierter Furcht in Säugetieren (z.B. Davis, 1997; Falls et al., 1997). Standardmäßig werden Startle-Experimente jedoch unter potentiell stressvollen Bedingungen außerhalb des Heimkäfigs der Versuchstiere durchgeführt (Bouwknecht et al., 2000). Neuere Untersuchungen an Mäusen zeigen, dass der multisensorische Stimulus der unbekannten Umgebung selbst lang anhaltende, kardiovaskuläre Aktivierung mit Herzratenbeschleunigung (Tachykardie) und Blutdruckerhöhung (Hypertonie) bewirkt (Stiedl \& Meyer, 2002; Stiedl et al., 2003). Akustische Startle-Stimuli verursachen eine Blutdruckerhöhung von ca. $25 \mathrm{mmHg}$ in Ratten, welche auf sympathische Aktivierung zurückgeführt wird (Baudrie et al., 1997; Quigley \& Berntson, 1990). 


\subsubsection{Kontextuelle Furchtkonditionierung}

Bei kontextueller (Kontext abhängiger) Furchtkonditionierung wird ein aversiver Stimulus in einer bestimmten Umgebung (Kontext) präsentiert. Die Erinnerung an den Kontext setzt sich aus der Gesamtheit der sensorischen (auditorischen, visuellen, olfaktorischen, taktilen) Erfahrungen zusammen. Diese werden im Gedächtnistest aversiv assoziiert und führen zu kontextuellen Furchtreaktionen. Die Bewertung kontextueller Furcht in Mäusen beschränkt sich normalerweise auf Verhaltensmessungen mit besonderem Schwergewicht auf Freezing, dessen Bewertung durch einen subjektiven Experimentator und anschließende Interpretation Schwächen birgt (McNish et al., 2000). Abhängig von der Mauslinie beeinflussen unterschiedliche Verhaltensmuster die Expression von Furcht (Koolhaas et al., 1999). In der vorliegenden Arbeit sollten Messungen der objektiven Messgrößen HR und HRV aufgrund der Möglichkeit einer verlässlichen Datenaquisition und deren Interpretation die Verhaltensmessungen im Hinblick auf Kontext abhängige Furcht komplementieren. Im Gegensatz zur auditorischen Furchtkonditionierung erfordert die kontextuelle Furchtkonditionierung jedoch ein manuelles Interferieren (Handling, s.u.) mit den Versuchstieren vor der Messung, da die Retention der konditionierten Furcht im konditionierten Kontext stattfindet.

\subsubsection{Handling, Novelty und olfaktorische Stimulation}

Für Nagetiere stellen Menschen mögliche Predatoren und damit angeborene aversive Stimuli dar. Jegliches manuelle Interferieren (Handling) mit den Versuchstieren, wie in den meisten Verhaltenstests gefordert, ist somit eine emotionale Stimulation, die Auswirkungen auf die neuroautonome Regulation hat (Stiedl \& Spiess, 1997). Um mögliche Einflüsse dieser Effekte auf die Versuchsergebnisse zu vermeiden, gehen bei vielen Verhaltenstests Habituierungsphasen, in denen die Tiere an das Handling gewöhnt werden, der eigentlichen Testphase voraus (Yang et al., 2004). Allerdings konnte selbst nach intensiver Habituierung über 12 Tage hinweg noch eine signifikante Erhöhung der HR durch Handling gefunden werden (Kramer et al., 2004). Die zeitliche Dynamik der Effekte einer einzelnen HandlingProzedur auf HR ist aufgrund fehlender kontinuierlicher Messungen bislang unklar. Ebenso hat für Mäuse eine neue Umgebung (Novelty) potentiell aversive Eigenschaften. Die Tiere begegnen dieser Stimulation mit der angeborenen Tendenz die neue Ungebung zu erkunden. 
Novelty gilt somit als Test für emotionale Responsivität und Furcht (Crawley \& Goodwin, 1980). Die Dynamik neuroautonomer Anpassungsprozesse während Novelty ist bislang unklar.

Gerüche sind Teilaspekte von Novelty, vermitteln jedoch auch Informationen über potenzielle Gefahrenquellen und besitzen für Nagetiere teilweise aversive Eigenschaften. Olfaktorische Reize bieten aufgrund ihrer „natürlichen“, angeborenen Eigenschaften als Furcht auslösende Stimuli im Vergleich z.B. mit Elektroschocks daher ethologisch relevante Versuchsbedingungen (Blanchard et al., 2001). Die Präsentation spezifischer Gerüche von Predatoren wie Katze oder Fuchs löst bei naiven Ratten Furchtreaktionen auf Verhaltens(gesteigertes Vermeidungsverhalten), neuroautonomer (erhöhter Blutdruck) und endokriner (erhöhte Kortikosteronwerte) Ebene aus (Blanchard et al., 1990; Dielenberg et al., 2001; Dielenberg \& McGregor, 2001; Morrow et al., 2000). Auf der Basis erhöhten Freezings wurde synthetischer Fuchsgeruch als unkonditionierter aversiver Stimulus in Ratten beschrieben (Wallace \& Rosen, 2000) und löst Furchtverhalten bei Mäusen im Light-Dark Test aus (Hebb et al., 2002). In der vorliegenden Arbeit wurde die Herzratendynamik von Mäusen vor, während und nach der Präsentation synthetischen Fuchsgeruchs untersucht. Bislang wurden dazu keine Untersuchungen angestellt.

\subsection{CRF-System und kardiovaskuläre Regulation}

Das Kortikotropin-freisetzende Hormon (corticotropin-releasing factor: CRF) ist ein Peptid mit 41 Aminosäuren (Spiess et al., 1981) und wurde als ein entscheidender Faktor bei der zentralen Regulation von Verhaltens-, Immun-, und kardiovaskulären Antworten während Stress charakterisiert (Bale \& Vale, 2004; Eckart et al., 1999; Heinrichs et al., 1995; Koob \& Heinrichs, 1999;

Abb. 1.2: Schematische Darstellung der Interaktion von Liganden und CRF-Rezeptoren. oCRF= Kortikotropin-freisetzendes Hormon (vom Schaf); $\mathrm{CRF}_{1}=\mathrm{CRF}_{-}$-Rezeptor I; $\mathrm{CRF}_{2}=$ CRF-Rezeptor 2; $C R F B P=C R F-B i n d e p r o t e i n ; U C N=U r o k o r t i n$.

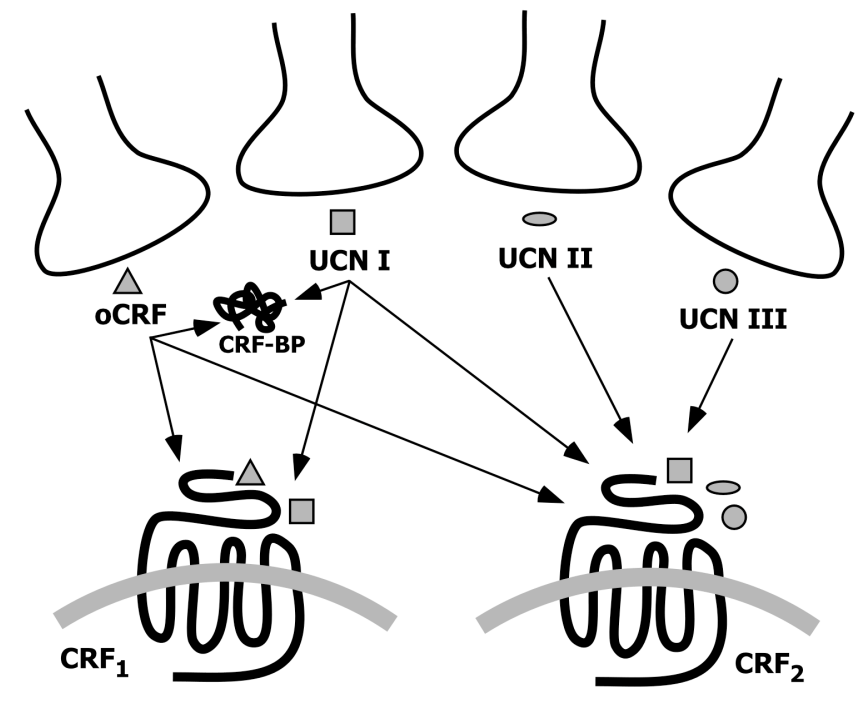


Owens \& Nemeroff, 1991). Das CRF-System ist außerdem an Psychopathologien wie Depression und Angststörungen beteiligt (reviewed von Kasckow et al., 2001). Bei Säugetieren sind vier native peptidische Liganden von CRF-Rezeptoren bekannt: CRF, Urokortin I (UCNI), UCNII und UCNIII (Abb. 1.2). Diese aktivieren zwei G-Protein gekoppelte CRFRezeptor-Subtypen, $\mathrm{CRF}_{1}$ und $\mathrm{CRF}_{2}$ (Chang et al., 1993) und binden teilweise zusätzlich an das CRF-Bindeprotein (reviewed von Jahn et al., 2005). Von $\mathrm{CRF}_{2}$ sind zwei SplicingVarianten, $\mathrm{CRF}_{2 \alpha}$ und $\mathrm{CRF}_{2 \beta}$ bekannt (De Souza \& Grigoriadis, 2000). Bei Nagetieren ist $\mathrm{CRF}_{1}$ im ZNS weit verbreitet (Primus et al., 1997). $\mathrm{CRF}_{2 \alpha}$ mRNA ist im ZNS nachgewiesen worden, während $\mathrm{CRF}_{2 \beta}$ vor allem in peripheren Geweben inklusive des Herzens zu finden ist (Chalmers et al., 1995; Lovenberg et al., 1995; Parkes et al., 2001). Die meisten Studien zu kardiovaskulären CRF-Effekten erfolgten mit Hilfe peripherer und zentraler Injektion von CRF-Rezeptor-Liganden in Ratten. Periphere Injektion von CRF führt zu Hypotension und Tachykardie infolge von Vasodilatation (reviewed von Owens \& Nemeroff, 1991). Die durch zentral (intrazerebroventrikulär) appliziertes CRF induzierte Tachykardie bei Ratten wurde als Analogon zur Stress induzierten neuroautonomen Aktivierung interpretiert (reviewed von Parkes et al., 2001). Auf Basis dieser Untersuchungen wurde CRF als Mediator Stress induzierter kardiovaskulärer Anpassungsprozesse angesehen (Fisher, 1989). Diese frühen Untersuchungen fanden jedoch mit weitgehend unselektiven CRF-Rezeptor Agonisten statt. Die Identifizierung weiterer endogener CRF-Rezeptor Liganden (UCNII, UCNIII) (Hsu \& Hsueh, 2001; Reyes et al., 2001) mit unterschiedlichen Affinitäten für $\mathrm{CRF}_{1}$ und $\mathrm{CRF}_{2}$ verdeutlichten die Komplexität des CRF-Systems und der zugrunde liegenden Mechanismen. Durch die Entwicklung selektiver peptidischer Liganden werden Untersuchungen spezifischer CRF-Rezeptor-Effekte möglich (Tezval et al., 2004). Nur wenige Studien umfassten jedoch kombinierte Messungen von kardiovaskulären und Verhaltens-Parametern unter Berücksichtigung der neuesten Kenntnisse (Nijsen et al., 1998; Stiedl \& Meyer, 2003; Stiedl et al., 2003).

Die Verfügbarkeit genetischer Modelle mit selektiven Veränderungen des CRF-Systems führte $\mathrm{zu}$ weiteren Erkenntnissen hinsichtlich der Funktion des CRF-Systems. $\mathrm{CRF}_{1}$ -

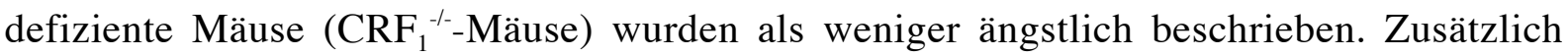
wurde eine fehlende "Stressreaktion" in diesen Mäusen berichtet (Contarino et al., 1999; Smith et al., 1998; Timpl et al., 1998). Vermehrte Furcht und Angst auf Basis von Verhaltensmessungen wurde hingegen bei $\mathrm{CRF}_{2}$-defizienten Mäuse beschrieben (Bale \& Vale, 2004). Zudem wurden erhöhte Stressreaktionen und gestörte kardiovaskuläre Regulation dieser Mäuse berichtet (Coste et al., 2000). Im Gegensatz dazu wurde in neueren Studien mit Hilfe 
nicht-linearer Analysen keine Beeinträchtigung der Herzratendynamik durch $\mathrm{CRF}_{2}$-Defizienz ermittelt (Stiedl \& Meyer, 2002, 2003). Die Lebenserwartung dieser Mäuse war zudem unbeeinträchtigt (Stiedl et al., 2003). Transgene Mäuse, die systemisch CRF überproduzieren (CRF overexpressing mice: CRFOE), leiden unter Symptomen des Hyperkortisolismus (Cushing's Syndrom) mit einhergehender deformierter Physiognomie (reduzierte Extremitätenlänge), Fellverlust, Fettakkumulation und Muskelatrophie. Sie wurden als überempfindlich gegenüber Stress beschrieben (Stenzel-Poore et al., 1994) und zeigten kognitive Defizite in verschiedenen Lerntests (Heinrichs et al., 1996).

Zum gegenwärtigen Stand der Forschung bleibt die physiologische Rolle des CRFSystems bei kardiovaskulärer Regulation unklar. In der vorliegenden Arbeit sollte mit Hilfe pharmakologischer Interventionen mit selektiven CRF-Rezeptor Agonisten und genetischen Modellen diese Rolle näher beleuchtet werden.

\subsection{Furchtkonditionierung - Modell für emotionalen Stress?}

Als charakteristisches Merkmal einer Stressreaktion gilt die vermehrte Ausschüttung von Glukokortikoiden in den Blutkreislauf (Wuttke, 2000). Ein weit verbreitetes Modell für experimentell erzeugten Stress bei Mäusen ist die Immobilisierung (restraint stress). Dabei wird die Bewegungsfreiheit der Versuchstiere für einen definierten Zeitraum durch Fixierung der Gliedmaßen oder durch Platzierung in einem engen Zylinder stark eingeschränkt (Kishimoto et al., 2000; Smith et al., 1998). Diese Prozedur repräsentiert einen massiven systemischen Stressor (Armario et al., 2004) und führt zur Aktivierung der HHN-Achse mit erhöhten Kortikosteronkonzentrationen im Blutplasma. Die maximale Aktivierung der Nebennierenrinde erfordert etwa 15 min, und es kann je nach Art des Stressors einige Stunden bis zur vollständigen Rückregulierung dauern (Korte, 2001). In CRF ${ }^{-/}$-Mäusen wurden abgeschwächte ACTH- und Kortikosteronantworten nach Immobilisationsstress gefunden (Smith et al., 1998).

Es stellte sich die Frage, ob an den deutlichen Furchtantworten von Mäusen auf Verhaltens- und kardiovaskulärer Ebene auch endokrine Anpassungsmechanismen beteiligt sind. Es ist bekannt, dass auch psychologischer Stress zu gesteigerter Freisetzung von Kortikosteron führen kann (Rasmusson \& Charney, 1997). Bei Ratten konnte ein Beitrag der Amygdala zur Kortikosteronantwort auf einen konditionierten Stressor nachgewiesen werden (Goldstein et al., 1996). Auf Basis dieses Wissens wurden Experimente zur HHN-Achsen 
Aktivierung bei auditorischer Furchtkonditionierung mit folgenden Erwartungen durchgeführt: 1. Die Retention konditionierter Furcht während des Gedächtnistest verursachet eine Stressreaktion mit höheren Plasma-Kortikosteronkonzentrationen auch bei Mäusen. 2 . Diese Antwort fehlt bei $\mathrm{CRF}^{-/-}$-Mäusen. Die gewonnenen Ergebnisse sollten die neuroautonomen Ergebnisse komplementieren und zu einem erweiterten Verständnis der umfassenden Furchtreaktion bei Mäusen beitragen.

\subsection{Neuronale Netzwerke der kardiovaskulären Regulation}

Die autorhythmische Herztätigkeit wird von den intrinsischen Schrittmacherzentren im Herzen (Sinusknoten, AV-Knoten, etc.) bestimmt, unterliegt jedoch der Kontrolle des autonomen Nervensystems. Während emotionaler Situationen bedingt dies unmittelbare Änderungen in Herzrate, Kontraktionskraft, AV-Verzögerung und koronalem Blutfluss. Parasympathische Aktivität verlangsamt die Herzrate und Reizübertragung im Herzmuskel und vermindert die Kontraktionskraft. Sympathische Aktivität führt zu einem Herzratenanstieg, schnellerer Reizleitung und gesteigerter Kontraktionskraft. Die Feineinstellung der autonomen Aktivität erfolgt über neuronale Regelkreise in Hirnstamm und Rückenmark. Hier werden die Rückkopplungen von Barorezeptorreflex, Respiration und die Eingänge höherer zentralnervöser Strukturen integriert (Busse, 2000). Allerdings sind die Hirnareale, in denen die tonische Parasympathikusaktivität generiert wird, bisher nicht charakterisiert worden.

\subsubsection{Limbisches System}

Das Konzept des limbischen Systems als übergeordneter Begriff für Emotionen verarbeitende Hirnbereiche wird noch immer diskutiert (LeDoux, 2002; Ter Horst, 2000). Unzweifelhaft ist jedoch die wichtige Rolle der Amygdala und des ventralen Hippokampus bei der Verarbeitung von Emotionen. Der Hypothalamus, erhält Eingänge von diesen Vorderhirnbereichen, die auch für kognitive Verarbeitung wichtig sind und ist die Schnittstelle zu den Basalfunktionen des Hirnstamms, die u.a. auch die Aktivität des autonomen Systems kontrollieren (Abb. 1.3). Hormone des Hypothalamus kontrollieren die Aktivität der Hypophyse, welche die endokrine Stressantwort vermittelt. Das an der Expression von Furcht 
beteiligte neuronale Netzwerk überlappt teilweise mit dem neuroautonomen Netzwerk, welches die Herzaktivität kontrolliert (Loewy, 1990; Ter Horst, 2000). Experimente mit Hirnareal spezifischen Läsionen oder Stimulationen und Furchtkonditionierung an Ratten haben die Funktion des zentralen Kerns der Amygdala in Furcht- und Angstverhalten (LeDoux, 1996) und in kardiovaskulärer Regulation nachgewiesen (Kapp et al., 1982; Roozendaal et al., 1991). Eine modulatorische Funktion des Hippokampus bei kardiovaskulären Anpassungsprozessen in emotionalen Situationen wird diskutiert (LeDoux, 1996, 2002; Ter Horst, 2000). Diese sollte in der vorliegenden Arbeit untersucht werden.

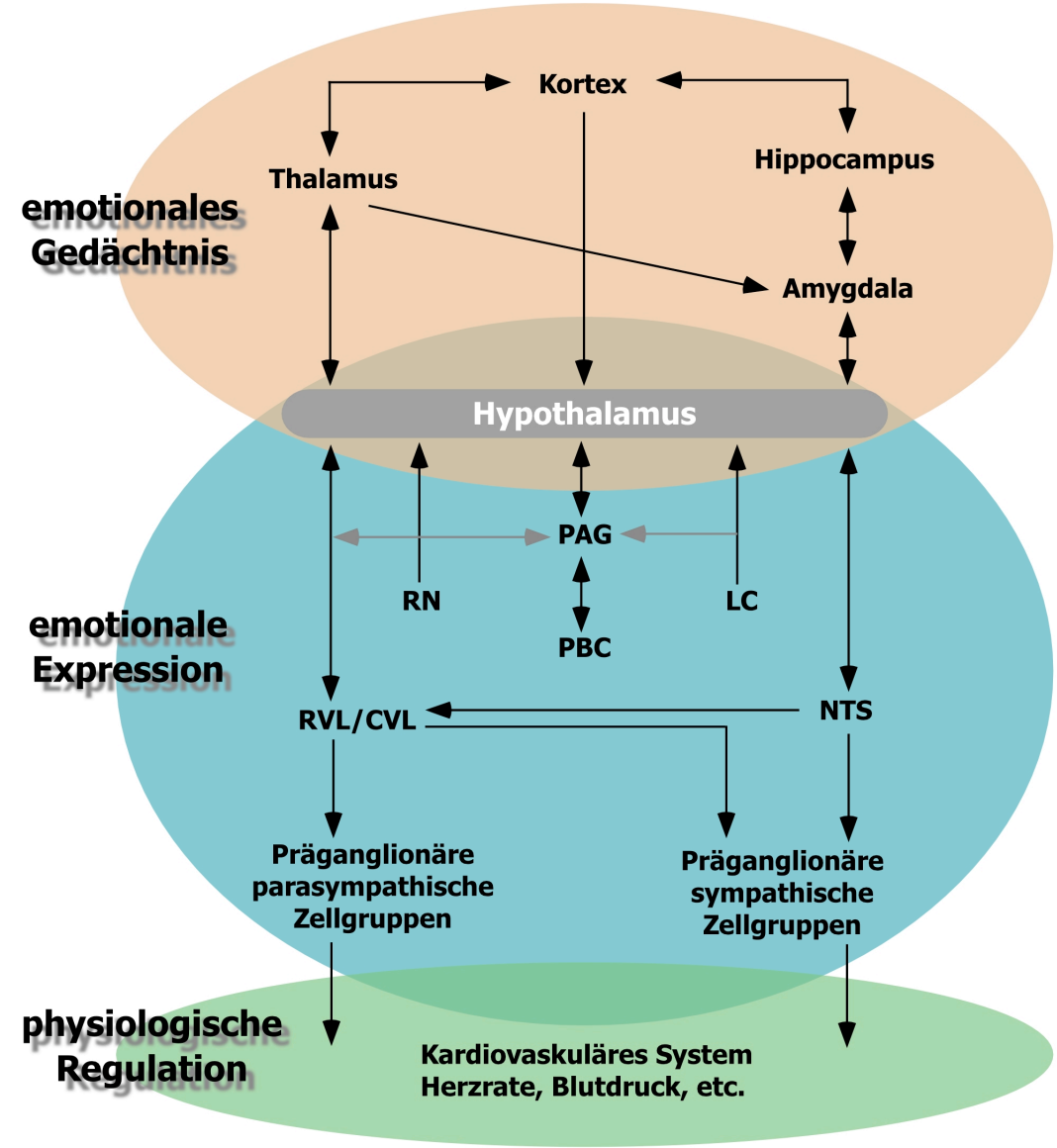

Abb. 1.3: Schematisches Modell des neuralen Netzwerks für Emotionen und kardiovaskuläre Regulation mit möglichen $\mathrm{Ge}$ bieten der Interaktion. Der Unterteilung in emotionales $\mathrm{Ge}$ dächtnis und emotionale Expression liegen Hypothesen von J.E. LeDoux (1996) zugrunde. $P A G=$ Periaquäduktale graue Substanz; $P B C=$ Parabrachialer Komplex; LC=Locus Coeruleus, $\mathrm{RN}=$ Raphe Nucleus; NTS= Nucle. us Tractus Solitarius, RVL/CVL= Rostrale und caudale ventrolaterale retikuläre Formation.

\subsubsection{Hippokampus und Furchtkonditionierung}

Der dorsale Hippokampus spielt eine wichtige Rolle bei Furchtreaktionen auf konditionierte kontextuelle Reize, nicht jedoch bei Antworten auf diskrete Reize wie den Ton-CS bei der Delay-Furchtkonditionierung. Bei Delay-Furchtkonditionierung folgen CS und US im Training direkt aufeinander, im Gegensatz zu Trace-Furchtkonditionierung, bei 
der CS und US durch ein zeitliches Intervall getrennt sind. Die Inaktivierung von N-methylD-aspartat (NMDA)-Rezeptoren, einem Subtyp ionotroper Glutamatrezeptoren im Hippokampus stört räumliches Lernen (Morris et al., 1986) und assoziatives Lernen in der Delay-Furchtkonditionierung (Sanders et al., 2003; Stiedl et al., 2000). Die Mehrzahl der Studien mit Delay-Furchtkonditionierung und NMDA-Rezeptor Inhibierung durch Antagonisten wie MK-801 oder DL-2-amino-5-Phosphonovaleronsäure (DL-2-amino-5phosphonovaleric acid: APV) beschreiben verminderte kontextuelle Furcht bei unbeeinflusster Ton abhängiger Furcht (Bast et al., 2003; Fanselow et al., 1994; Kim et al., 1991; Stiedl et al., 2000). Bei Trace-Furchtkonditionierung wurde nach hippokampalen Läsionen abgeschwächte kontextuelle wie auch auditorische Furcht nachgewiesen (McEchron et al., 1998; Quinn et al., 2002). Dabei wurden Trace-Intervalle unterschiedlicher Länge von $1 \mathrm{~s}$ bis zu 30 s und multiple (10) CS-US Wiederholungen im Training verwendet (Huerta et al., 2000; McEchron et al., 1998; Shors et al., 2002). Der Beitrag dorsaler hippokampaler NMDARezeptoren bei Trace-Furchtkonditionierung wurde bei Mäusen noch nicht untersucht.

Aufgrund der variierenden Erkenntnisse zur Länge des Trace-Intervalls wurde in der vorliegenden Arbeit zunächst systematisch der Beitrag von NMDA-Rezeptoren im dorsalen Hippokampus zur Trace-Furchtkonditionierung in Abhängigkeit des Trace-Intervalls untersucht. Da für statistisch relevante Ergebnisse hohe Zahlen an Versuchstieren benötigt werden, für kardiovaskuläre Messungen jedoch ein großer operativer und zeitlicher Aufwand für jedes Individuum getroffen werden muss, erfolgten diese Untersuchungen zunächst auf Verhaltensebene. Damit wurde ein Zeitfenster des maximalen hippokampalen Beitrags zu Verhaltensantworten in der Trace-Furchtkonditionierung bestimmt, mit dessen Hilfe dann der Beitrag des Hippokampus zu neuroautonomer Regulation untersucht wurde. Die Experimente wurden mit singulärer CS-US Präsentation im Training durchgeführt, um einen Wechsel von multisensorischer zu unisensorischer Assoziation des US mit dem CS zu vermeiden, der bei multiplen CS-US Präsentationen bei gleichzeitiger Inhibierung des Hippokampus erfolgen kann. Diskriminative Tests legen nahe, dass dieser Wechsel der Lernstrategie die Bildung kontextuellen Gedächtnisses unabhängig vom Hippokampus auf der Basis einzelner kontextspezifischer Stimuli verursacht, so dass Läsionen des Hippokampus vor dem Training unwirksam erscheinen (Frankland et al., 1998). 


\section{Material und Methoden}

\subsection{Versuchstiere}

Es wurden Mäuse der Inzuchtlinien C57BL/6N sowie C57BL/6J (Charles River, Sulzfeld) verwendet. Die Tiere wurden im Alter von 8 Wochen mit einem Durchschnittsgewicht von $22 \mathrm{~g}$ geliefert. $\mathrm{CRF}_{1}$-defiziente Mäuse enstammten aus Verpaarungen heterozygoter C57BL/6-Mäuse. Diese wurden mittels eines Zielvektors generiert, in dem der Abschnitt des $\mathrm{CRF}_{1}$-Gens, welcher für die letzten zwölf Aminosäuren der ersten extrazellulären Domäne kodiert, durch eine Neomycin-resistente Genkassette ersetzt wurde (Smith et al., 1998). $\mathrm{CRF}_{2}$-defiziente Mäuse entstammten einer Kreuzung der C57BL/6J und 129SvJ-Mausstämme. Das für die dritte extrazelluläre Schleife des $\mathrm{CRF}_{2}$ kodierende Exon wurde durch eine Neomycin-resistente Genkassette ersetzt (Kishimoto et al., 2000). Die Genotypisierung erfolgte anhand von Gewebeproben im Alter von 5-7 Wochen. Die Experimente begannen frühestens im Alter von 9 Wochen und fanden in den darauf folgenden vier Wochen statt.

Die Mäuse wurden unter standardisierten Bedingungen in Makrolonkäfigen (Typ 2: $22 \mathrm{~cm}$ x $16 \mathrm{~cm}$ x $13 \mathrm{~cm}$, Länge x Breite x Höhe) mit freiem Zugang zu Nagetierfutter-Pellets (Ssniff, Soest) und Trinkwasser gehalten. Die Käfige befanden sich in schallgeschützten, ventilierten Haltungscontainern (Scantainer, Scanbur, Køge, Dänemark) bei einer Temperatur von $21-22^{\circ} \mathrm{C}$. Die Haltungscontainer hatten einen gefilterten Zulufteinlass und einen Abluftauslass, der direkt an den Abluftschacht gekoppelt war, um eine sehr geringe Geruchsbelastung und Allergieentwicklung zu erreichen. Die Container befanden sich in lichtdichten Kammern mit einem 12/12-h Licht-Dunkel-Zyklus (Licht an: 7 Uhr morgens). Alle Experimente wurden während der Lichtphase durchgeführt. Alle in der vorliegenden Arbeit beschriebenen tierexperimentellen Eingriffe wurden mit Genehmigung der Bezirksregierung Braunschweig (Aktenzeichen 509.42502/02-01.00) durchgeführt.

\subsection{Genotypisierung}

Die genetisch modifizierten Mäuse wurden vor den Experimenten auf die erfolgreiche Inaktivierung des entsprechenden Gens hin überprüft. Diese Charakterisierung erfolgte 
aufgrund der Zuchtbedingungen, bei denen heterozygote Männchen und Weibchen verpaart wurden.

\subsubsection{DNS-Isolierung}

Zur Isolierung von DNS wurde das QIAamp ${ }^{\circledR}$ DNA Mini Kit (Qiagen, Hilden) verwendet. Gewebeproben der Mausschwanzspitzen wurden mit $180 \mu 1$ ATL Puffer und $20 \mu 1$ Proteinase $\mathrm{K}$ in je einem $1.5 \mathrm{ml}$ Eppendorfcup bei $55^{\circ} \mathrm{C}$ über Nacht geschüttelt. Das Lysat wurde gevortext und $5 \mathrm{~min}$ bei $13000 \mathrm{U} / \mathrm{min}$ zentrifugiert. Vom Überstand wurden ca. $200 \mu 1$ in ein $1.5 \mu \mathrm{l}$ Eppendorfcup abpipettiert, mit $200 \mu \mathrm{l}$ AL Puffer vermischt und 10 min bei $70^{\circ} \mathrm{C}$ inkubiert. Danach wurden $200 \mu 1$ Ethanol (96\%ig, p.a.) zugegeben, gevortext und kurz abzentrifugiert. Nun wurden etwa $600 \mu 1$ auf eine den Proben entsprechende Anzahl von Zentrifugenröhrchen (Qiagen, Hilden) aufgetragen und diese dann 1 min bei 8000 upm zentrifugiert. Die Säulen wurden anschließend mit $500 \mu$ l Waschpuffer AW 1 für 1 min bei 8000 upm und danach mit $500 \mu \mathrm{l}$ Waschpuffer AW 2 für 3 min bei $13000 \mathrm{U} / \mathrm{min}$ zentrifugiert. Nun wurden die Säulen mit $200 \mu$ l Elutionspuffer 7 min bei Raumtemperatur inkubiert und dann 1 min bei 8000 upm zentrifugiert. Das Eluat wurde in 2 ml Eppendorfcups bei $-20^{\circ} \mathrm{C}$ gelagert.

\subsubsection{Polymerase-Kettenreaktion}

Die $\mathrm{CRF}_{1}$-Allele bindenden Primer (Metabion, Martinsried) bestanden aus den Nukleotidsequenzen 5'-ACT GCT AGT GTG ATG TCC TGC-3' bzw. 5'-TCT CAG GAT TGC TAA GTT CAG-3', der die Neokassette bindende Primer aus 5'-GGG AAC TTC CTG ACT AGG GG-3'. Die $\mathrm{CRF}_{2}$-Allele bindenden Primer hatten die Sequenzen 5'-ACG TCC GAG ACA ATC CAA TAC AGG TA-3' bzw. 5'-CGT TTT GGT GCT CAT ATA ACC CAT C-3'. Die für die Neomycinresistenz kodierende Region wurde von Primern mit den Seqenzen 5'-AGA GGC TAT TCG GCT ATG ACT GGG CA-3' bzw. 5'-CCA CAC CCA GCC GGC CAC AGT CGA TGA-3' erkannt. Der sogenannte Mastermix bestand je Probe aus $16.5 \mu 1$ demineralisiertem Wasser, $0.5 \mu 1$ DNTP-Mix (Sigma, Steinheim), $2.5 \mu 1$ 10x REDTaq $^{\mathrm{TM}}$-Puffer und jeweils $1 \mu 1$ der entsprechenden Primer-Lösungen. 
Drei $\mu 1$ (entspr. 200 ng DNA je Probe) des DNA-Eluats wurden nach dem Auftauen zunächst in $200 \mu 1$ PCR-Tubes (Biozym Scientific, Hessisch Oldendorf) mit $21.5 \mu 1$ Mastermix versetzt, bevor ca. 2 Tropfen Mineralöl (Sigma, Steinheim) aufgetragen wurden, um ein Verdampfen der Reaktionslösung zu verhindern. Danach wurden $0.5 \mu 1$ REDTaq $^{\text {TM }}$-DNA Polymerase (Sigma, Steinheim) hinzupipettiert und die enthaltende DNA mittels automatisierter PCR (Whatman/ Biometra, Göttingen) in 34 $\left(\mathrm{CRF}_{1}\right)$ bzw. $35\left(\mathrm{CRF}_{2}\right)$ Zyklen amplifiziert. Über ein mit $10 \mu \mathrm{g} / \mu 1$ Ethidiumbromid versetztes $1.5 \%$-iges Agarosegel wurden $15 \mu 1$ des PCR-Reaktionsgemisches elektrophoretisch aufgetrennt. Mit Hilfe eines DNA-Markers (Smartladder; Eurogentec, Seraing, Belgien) wurde die Größe der aufgetrennten Banden der enthaltenen PCR-Fragmente bestimmt (Abb. 2.1).
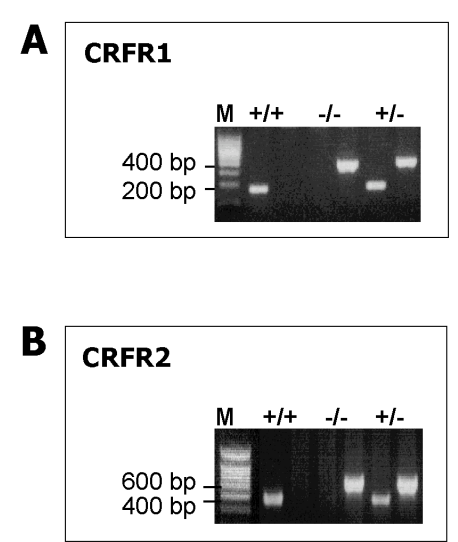

Abb. 2.1: PCR-amplifizierte Fragmente genomischer DNA von $\mathrm{CRF}_{1^{-}}(\mathbf{A}), \mathrm{CRF}_{2^{-}}$ defizienter (B) und CRF-überproduzierender Mäuse (C). $M=$ Markerbande mit Angabe der amplifizierten PCR-Fragmentgröße (in bp).

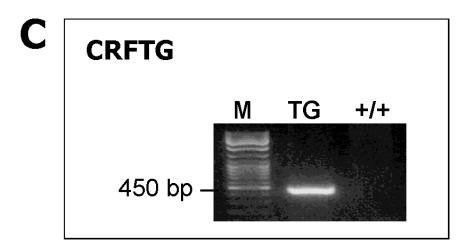

\subsection{Pharmaka und Lösungen}

\subsubsection{Peptide}

Peptide, die intrazerebroventrikulär injiziert werden sollten, wurden am Tag der Injektion in entsprechender Konzentration in künstlicher Hirnflüssigkeit (artificial cerebrospinal fluid: aCSF) gelöst (Tab. 1). Die aCSF-Lösung (Matthies et al., 2000) enthielt: $124 \mathrm{mM} \mathrm{NaCl}, 25.6 \mathrm{mM} \mathrm{NaHCO}, 10 \mathrm{mM} \mathrm{D}(+)$-Glucose, $1.3 \mathrm{mM} \mathrm{MgSO} \cdot 7 \mathrm{H}_{2} \mathrm{O}, 4.9 \mathrm{mM}$ $\mathrm{KCl}, 1.2 \mathrm{mM} \mathrm{K \textrm {KH } _ { 2 }} \mathrm{PO}_{4}, 2.5 \mathrm{mM} \mathrm{CaCl}{ }_{2} \cdot 2 \mathrm{H}_{2} \mathrm{O}$. Der $\mathrm{pH}$-Wert betrug 7.4, die Osmolalität etwa $300 \mathrm{mOsm}$. Intraperitoneal zu injizierende Peptide wurden in Phosphatpuffer (PBS; Gibco/Invitrogen, Karlsruhe) gelöst. Dieser enthielt $150 \mathrm{mM} \mathrm{NaCl}, 5.9 \mathrm{mM} \mathrm{Na} 2 \mathrm{HPO}_{4} \cdot 7 \mathrm{H}_{2} \mathrm{O}$, $1.5 \mathrm{mM} \mathrm{KH}_{2} \mathrm{PO}_{4}$ : Der pH-Wert betrug 7.2, die Osmolalität etwa 300 mOsm. 
Tab.1: Injizierte Peptide

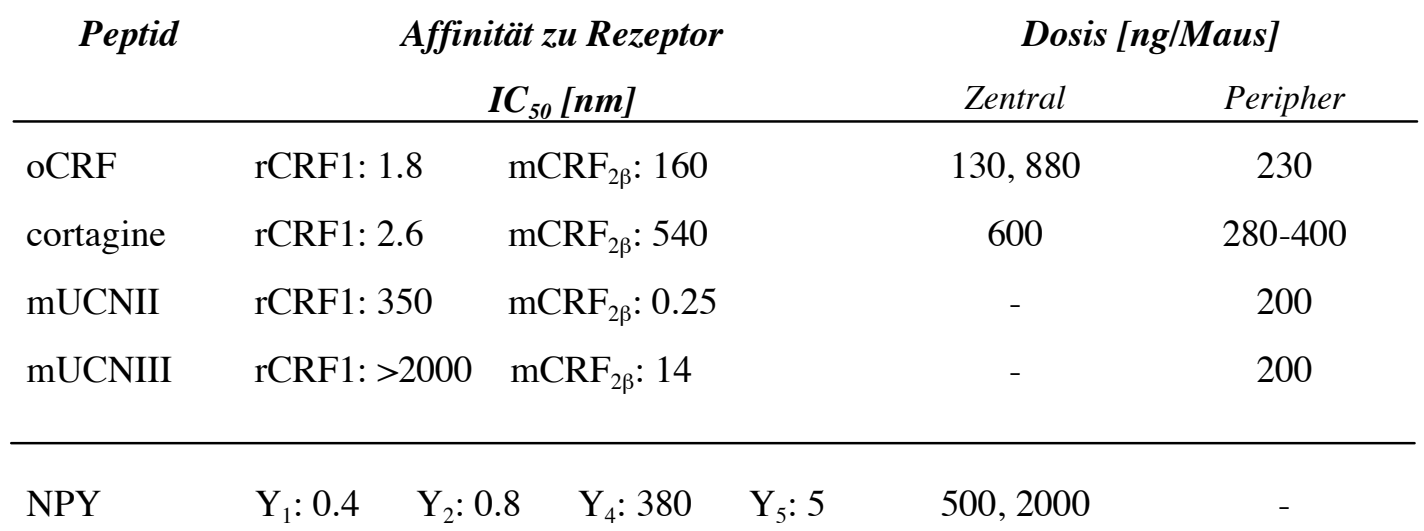

Die Konzentration der für die Experimente hergestellten Peptid-Lösungen wurde mittels Aminosäureanalyse bestimmt (Aminosäuranalyse-System 6300: Beckman Coulter, München). Dazu wurden direkt nach Beendigung der Experimente definierte Volumina der zuvor injizierten Substanzen mit dem Injektionssystem in Hydrolyse-Röhrchen (Corning Glas, New York, USA) abgefüllt. Der zu analysierenden Probe wurde $1 \mathrm{nmol}$ der künstlichen Aminosäure Norvalin als interner Standard zugesetzt. Die Totalhydrolyse der Peptide wurde mit $6 \mathrm{M} \mathrm{HCl}$ für $24 \mathrm{~h}$ bei $110^{\circ} \mathrm{C}$ durchgeführt. Die Analyse des Aminosäuregemisches erfolgte durch Ionenaustausch-Chromatografie und Derivatisierung der eluierenden Aminosäuren mit Ninhydrin. Die derivatisierten Aminosäuren wurden spektroskopisch detektiert und die erhaltenen Chromatogramme mit dem Datensystem GOLD (Beckman Coulter, München) ausgewertet. Die Aminosäureanalyse der gereinigten Peptide lieferte Zusammensetzungen, die maximal $12 \%$ unterhalb der zu erwarteten theoretischen Werte lagen.

\subsubsection{Rezeptor-Antagonisten}

Zur Inhibierung von NMDA-Rezeptoren im dorsalen Hippokampus wurde der selektive Antagonist DL-2-amino-5-phosphonovaleric acid (APV; Sigma, Deisenhofen) verwendet. Auf der Basis früherer Studien (Stiedl et al., 2000) wurde eine Dosis von $3.2 \mu \mathrm{g}$ APV je Maus in einem Volumen von $0.5 \mu 1$ verwendet. 


\subsection{Herzraten-Messungen}

\subsubsection{EKG-Transmitter}

Alle EKG-Messungen wurden mit EKG-Transmittern für kleine Labor-Nagetiere (TA10EA-F20, Data Sciences, St. Paul, Minnessota, USA) durchgeführt. Der Transmitterkörper (Länge: $2.1 \mathrm{~cm}$, Gewicht: $3.4 \mathrm{~g}$, Volumen: $1.9 \mathrm{~cm}^{3}$ ) enthält die für die Detektion, Transformation und Übermittlung des EKG-Signals notwendige Elektronik, einen magnetisch aktivierbaren Schalter und eine Batterie. Die Sendefrequenz liegt bei $550 \mathrm{kHz}$. Auf einer Seite des Transmitterkörpers befinden sich drei Plastikösen, mit denen dieser im Peritoneum fixiert wird. Aus der Oberseite des Transmitters führen zwei mit Silikonschlauch isolierte spiralisierte Edelstahlelektroden heraus, mit denen die Biopotential-Fluktuationen registriert wurden.

\subsubsection{EKG-Transmitter Implantation}

Die Transmitterelektroden wurden vor der Sterilisation auf die richtige Länge zugeschnitten. Die zum rechten Vorderbein führende Elektrode hatte eine Länge von $3 \mathrm{~cm}$, die zum linken Hinterbein ziehende $5 \mathrm{~cm}$. Beide Elektrodenenden wurden auf $7 \mathrm{~mm}$ abisoliert und das Schlauchende mit chirurgischem Faden durch einen Knoten verschlossen, um das Eintreten von Flüssigkeit in den Isolationsbereich zu verhindern. Silikonschutzkappen wurden an den Drahtenden der beiden Elektroden mit nicht resorbierbarem chirurgischem Faden befestigt. Die Transmitter wurden daraufhin über Nacht in 2\%-igem Glutaraldehyd (Helipur Hplus, Braun, Melsungen) sterilisiert. Direkt vor der Operation wurden sie dreimal für 15 min in steriler 0.9\%-iger Kochsalzlösung gewaschen.

Die Anästhesie der Mäuse für die Operation erfolgte mittels eines InhalationsnarkoseSystems (tabletop research unit, SurgiVet/Anesco, Waukesha, Wisconsin, USA) mit einem Isofluran-Verdampfer, Durchflussregler und Aktivkohlefilter. Das System erlaubte eine genaue prozentuale Beimischung von Isofluran zum Trägergas Sauerstoff. Die Einleitung der Narkose erfolgte bei etwa 3\% Isofluran zunächst in einer abgeschlossenen Plexiglasbox $(14 \mathrm{~cm}, 10 \mathrm{~cm}, 10 \mathrm{~cm}$; L x B x H). Dann wurde die narkotisierte Maus an den Beinen auf einer frei beweglichen, zuvor mit $70 \%$-igem Alkohol gereinigten und auf $37^{\circ} \mathrm{C}$ temperierten Wärmeplatte fixiert. Hier wurde die Narkose über die kontinuierliche Zufuhr von $1.5 \%$ 
Isofluran bei einer Durchflussrate von 0.5 1/min über eine Atemmaske, in der sich die Schnauze der Maus befand, gewährleistet.

Mit Enthaarungscreme (Pilca, Schwarzkopf, Hamburg) wurde der mediane Abdominalbereich vom Fell befreit und mit Hautsterilisationslösung (Cutasept F, Bode, Hamburg) gereinigt. Die Bauchhaut wurde nun vorsichtig mit einer kleinen Präparierschere etwa $3 \mathrm{~cm}$ longitudinal und median unterhalb des Processus xiphoideus eingeschnitten, ohne das darunter liegende Muskelgewebe zu verletzen. Von diesem Zeitpunkt an wurde das Operationsgebiet mit steriler 0.9\%-iger Kochsalzlösung feucht gehalten. Subkutane Trakte zum rechten Vorderbein und zum linken Hinterbein für die Platzierung der Transmitterelektroden wurden mit Sonde und Schere präpariert, um eine EKG-Ableitung vom Typ II zu ermöglichen. Das abdominale Muskelgewebe wurde nun ebenfalls in der Mitte in Richtung der Körperlängsachse durch einen $2 \mathrm{~cm}$ langen Schnitt entlang der Linea alba eröffnet. Durch diesen Schnitt wurde der EKG-Transmitter mit nach cranial gerichteten Elektroden in die Bauchhöhle eingeschoben (Abb. 2.2). Mit einer spitzen Pinzette wurde die Bauchmuskulatur cranial und lateral des Einschnitts durchstochen, um die Elektroden aus der Bauchhöhle herauszuführen. Nun wurde der Transmitter-

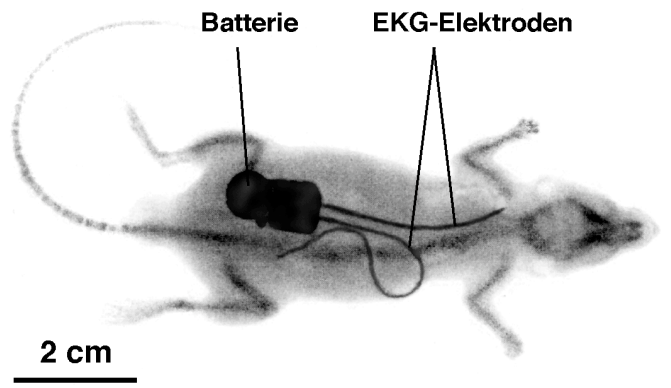

Abb. 2.2: Röntgenaufnahme einer Maus mit implantiertem EKG-Iransmitter (modifiziert nach Kramer et al., 1993) körper durch die ventral liegenden Plastikösen mit nicht-resorbierbarem chirurgischen Faden am Muskelgewebe vernäht. Ein Wegrutschen des Transmitterkörpers in die Bauchhöhle und die damit verbundene Gefahr eines Darmverschlusses wurde dadurch verhindert. Gleichzeitig wurde so auch der Schnitt in der Bauchmuskulatur teilweise geschlossen. Die noch verbliebenen offenen Stellen des Schnitts wurden zusätzlich mit resorbierbarem Faden zugenäht. Die Elektroden wurden in den vorbereiteten subkutanen Trakten platziert, wobei jeglicher Druck der Elektroden auf die Haut vermieden wurde. Der Transmitter wurde eingeschaltet, die korrekte Ableitung des EKGSignals und seine Qualität sofort überprüft und bei Bedarf die Lage der Elektroden korrigiert. Danach wurde der Transmitter abgeschaltet, um unnötige Batterieentladung während der Regenerationsphase zu vermeiden. Abschließend wurde der Hautschnitt durch sterile WundKlammern (Autoclip $9 \mathrm{~mm}$; Becton Dickinson, Sparks, Maryland, USA) mit Hilfe anatomischer Pinzetten geschlossen. Die Käfige der operierten Tiere wurden mit 70\%-igem Alkohol gereinigt, mit sauberem Zellstoff als Nestmaterial ausgelegt und auf eine 
Wärmeplatte $\left(37^{\circ} \mathrm{C}\right)$ gestellt, um eine Hypothermie der aus der Narkose aufwachenden Tiere $\mathrm{zu}$ vermeiden.

Der Gesundheitszustand (Lokomotion, Defäkation) und die Gewichtsentwicklung der Tiere wurden im Anschluss an die Implantation täglich kontrolliert. Die in seltenen Fällen auftretenden lokalen Entzündungen der Operationswunde wurden mit antibiotischer Salbe (Aureomycin, Lederle, Wolfratshausen) behandelt. Bei ausbleibender Gewichtszunahme infolge möglicher Infektion wurde im Trinkwasser 0.33\% eines Antiinfektikums (Baytril 5\%, Bayer, Leverkusen) über einen Zeitraum von fünf Tagen verabreicht. In wenigen Fällen von massivem Gewichtverlust und schlechtem Allgemeinzustand der Tierer wurden zusätzlich einmalig $0.5 \mathrm{ml}$ Nährlösung pro Maus (Amynin, Rhone Merieux, Laupheim) subkutan appliziert. Die Herzratenexperimente wurden nach einer Erholungsphase von etwa 2-3 Wochen durchgeführt. Nach diesem Zeitraum hatten die Mäuse ihr Prä-Operationsgewicht meist überschritten. Diese Tiere zeigen wieder ihre normale circadiane Rhythmik und eine normale Lokomotionsaktivität (Kramer \& Kinter, 2003).

\subsubsection{EKG-Aufzeichnung}

Das EKG wurde im Heimkäfig der jeweiligen Maus aufgezeichnet. Dies erfolgte bei basalen Messungen im Haltungscontainer oder -bei Gedächtnistests- in einem vom Haltungsbereich abgetrennten Raum. Dazu wurde das Tier unter einen Lautsprecher gestellt. In pharmakologischen Experimenten wurde 15 min nach der letzten Injektion die Messung der Herzrate gestartet. Diese wurde kontinuierlich während des gesamten Versuchs aufgezeichnet. Dazu wurden die EKG-Signale vom EKG-Transmitter bei einer Sendefrequenz von $550 \mathrm{kHz}$ abgegeben, von einem Empfänger (RLA 1020, Data Sciences, St. Paul, Minnesota, USA) aufgenommen und digitalisiert. Über einen an den Empfänger angeschlossenen Analog-EKG-Adapter (Option RO8, Data Sciences, St. Paul, Minnesota, USA) wurden die Signale wieder in Analogsignale konvertiert und an einen Analog-DigitalWandler (MacLab 4s, ADInstruments, Spechbach) weitergeleitet. Dieser digitalisierte die Signale mit einer Abtastrate von $4 \mathrm{kHz}$. Zusätzlich wurden die EKG-Signale auf einem Oszilloskop kontrolliert. Mittels entsprechender Software (MacLab Chart Vers. 3.6/s- 5.0, ADInstruments, Spechbach) wurden die EKG-Signale aufgenommen, abgespeichert und später bearbeitet bzw. ausgewertet. 


\subsubsection{EKG-Auswertung}

Die Bestimmung der Herzschlagfrequenz (Herzrate) erfolgte mit der Software (MacLab Chart 3.6/s-5.0, Software-Erweiterung HRV, ADInstruments, Spechbach). Aus den Intervallen zwischen den R-Wellen des aufgezeichneten EKG-Signals wurde die instantane Herzrate (HR) als Schläge pro Minute (beats per minute: bpm) errechnet (Abb. 2.3). Die RRIntervalle des EKGs konnten nahezu immer ermittelt werden, obwohl die Amplitude der EKGSignale aufgrund unterschied-

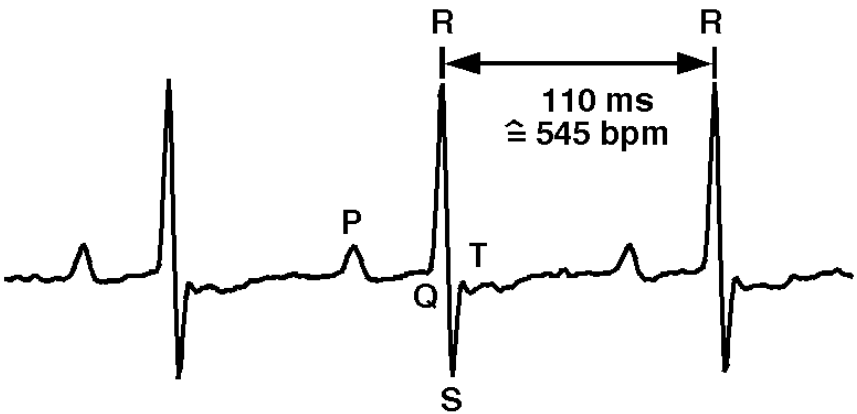

licher Elektrodenlage varriierte. Artefakte in den EKG-Signalen wurden manuell editiert, um die exakten Herzraten und ihre Varia-
Abb. 2.3: EKG-Signal und Ermittlung der Herzrate auf Basis des RRIntervalls. Die instantane Herzrate wurde auf Basis der Zeitabstände aufeinander folgender R-Wellen des EKG-Komplexes (mit den Wellen P-T) berechnet.

bilität zu berechnen. Für die statistische Analyse der Daten wurden die kontinuierlichen Messungen in kürzere Intervalle aufgeteilt, über die dann die Herzrate gemittelt wurde. Beim Tontest wurden $30 \mathrm{~s}$ Messintervalle gebildet, bei $10 \mathrm{~s}$ dauernder Tonpräsentation betrug die Intervalllänge $10 \mathrm{~s}$, bei Messungen über $1.5 \mathrm{~h}$ wurde über $10 \mathrm{~min}$ Abschnitte gemittelt. Als Maß für Herzratenvariabilität (HRV) diente die mittlere Quadratwurzel der Summen aufeinander folgender RR-Intervalle, der sogenannte RMSSD (root mean squared of the sum of successive differences)-Wert.

\section{$2.5 \quad$ Blutdruckmessungen}

\subsubsection{Blutdruck-Transmitter}

Alle Blutdruckmessungen wurden mit Transmittern für kleine Labor-Nagetiere (TA11PA-C20, Data Sciences, St. Paul, Minnessota, USA) durchgeführt (Abb. 2.4). Der Transmitterkörper (Länge: $2.1 \mathrm{~cm}$, Gewicht: $3.3 \mathrm{~g}$, Volumen: $1.9 \mathrm{~cm}^{3}$ ) enthält die für die Detektion, Transformation und Übermittlung des Blutdrucksignals notwendige Elektronik, 
einen magnetisch aktivierbaren Schalter und eine Batterie. Auf einer Seite des Transmitterkörpers befinden sich drei Plastikösen, mit denen dieser im Peritoneum fixiert wird. An der Seite des Transmitters führt ein $40 \mathrm{~mm}$ langer, flüssigkeitsgefüllter Katheter von $0.3 \mathrm{~mm}$ Spitzendurchmesser heraus.

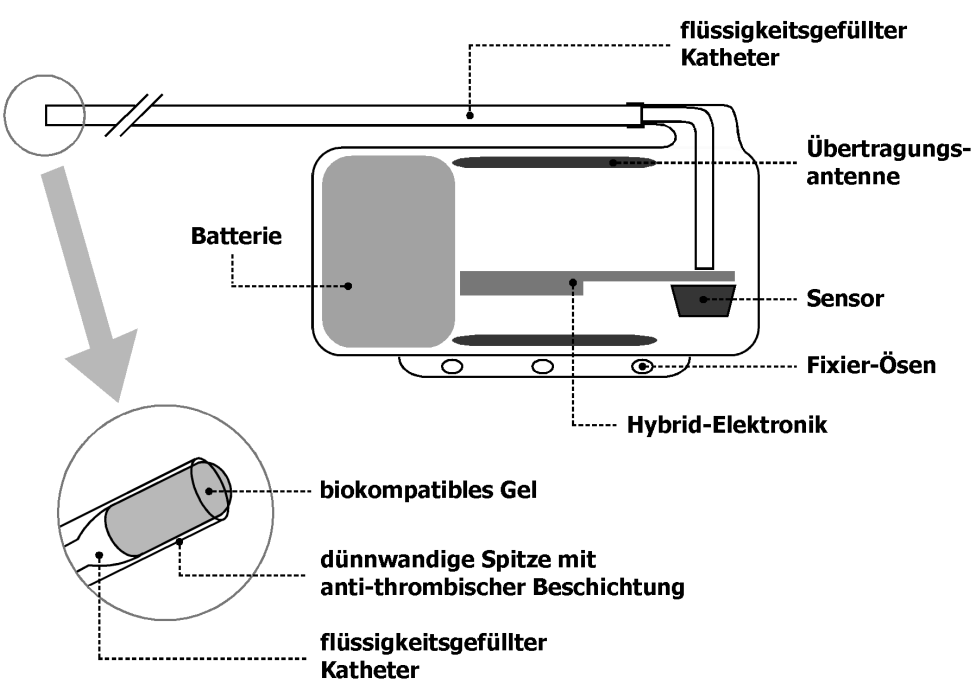

Dessen offene Spitze ist mit anti-thrombischem, biokompa-

Abb. 2.4: Schematische Darstellung des Blutdruck-Transmitters.

tiblem Gel gefüllt und die Außenwand ist mit einem anti-thrombischen Film beschichtet. Über das blasenfreie Gel, die daran anschließende Flüssigkeit und einen Hebel im Innern des Transmitters werden Druckänderungen auf einen semi-konduktiven Sensor übertragen. Das amplitudenmodulierte Signal wird über drei Messpunkte kalibriert. Dabei wurde der Nullpunkt mit $750 \mathrm{mmHg}$ angenommen (Normaldruck $=1013 \mathrm{hPa}=760 \mathrm{mmHg}$ ). Um den physiologisch relevanten Messbereich von bis zu $200 \mathrm{mmHg}$ über Normaldruck abzudecken, werden weitere Kalibrationspunkte bei 850 und $950 \mathrm{mmHg}$ bestimmt. Die Kalibrations- bzw. Messdaten wurden vom PC-basierten Messsystem mit einem den Umgebungsdruck messenden Barometer abgeglichen.

\subsubsection{Kalibrierung und Implantation des Blutdrucktransmitters}

Vor der Implantation wurden im Falle von unbenutzten oder neu überarbeiteten Transmittern die jeweiligen mitgelieferten Drei-Punkt-Kalibrationsdaten in das Messprogramm eingegeben. Bei zuvor bereits implantierten Sendern wurde eine Rekalibrierung durchgeführt. Um eine konstante Körpertemperatur von $37^{\circ} \mathrm{C}$ zu gewährleisten, erfolgte die Kalibrierung des Transmitters in einer doppelwandigen, wasserumspülten selbstentwickelten Druckkammer (Abb. 2.5). Das Ausgangssignal des Senders wurde bei Umgebungsdruck und mittels eines medizinischen Differenzdruckgebers (KAL 84, Halstrup-Walcher, Kirchzarten) zusätzlich angelegten $100 \mathrm{mmHg}$ und $200 \mathrm{mmHg}$ gemessen. Auftretende Druckdifferenzen wurden dann über entsprechend modifizierte 


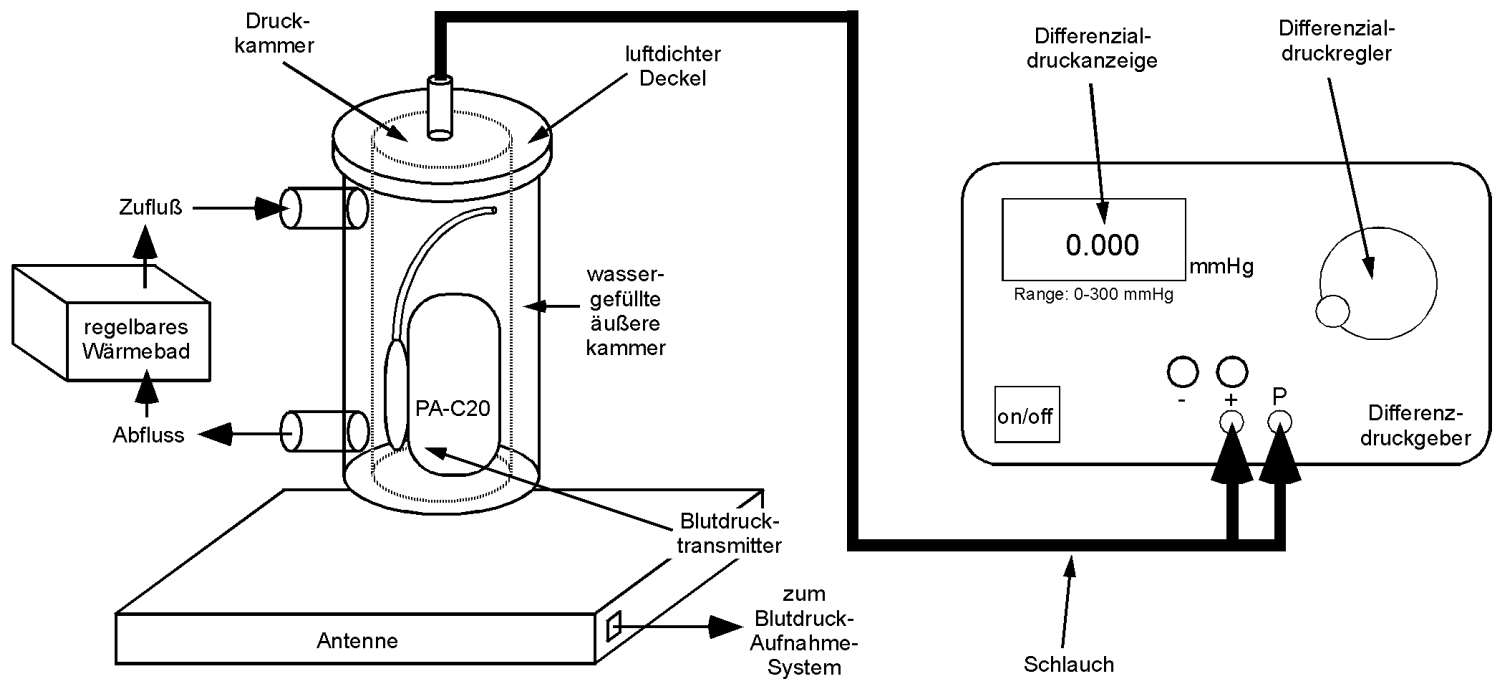

Abb. 2.5: Versuchsaufbau für die Kalibrierung des Blutdrucktransmitters

Kalibrierdaten in der Software angeglichen. Dabei wurde eine Abweichung des Messdrucks vom Solldruck von $\pm 1 \mathrm{mmHg}$ toleriert.

Nach Sterilisation des Transmitters in 2\%-igem Glutaraldehyd wurde er vor der Implantation noch dreimal in steriler 0.9\%-iger Kochsalzlösung gewaschen. Analog zur EKGTransmitter-Implantation wurde nach Narkotisierung der Maus sowie der Enthaarung und Desinfizierung der Abdominalgegend zunächst die Oberhaut caudal des Brustbeins median und longitudinal etwa $3 \mathrm{~cm}$ eingeschnitten. Die Bauchhaut wurde vom darunter liegenden Muskelgewebe getrennt und der Bauchraum entlang der Linea alba eröffnet. Mit sterilisierten feuchten Wattestäbchen wurden Leber, und Milz nach frontal, Nieren und Darm vorsichtig in die seitliche Bauchhöhle geschoben und mit Hilfe von abgerundeten, $1 \mathrm{~cm}$ breiten, flachen Operationshaken am Zurückgleiten gehindert, um den Zugang zur dorsal liegenden Aorta descendens freizupräparieren. Mit zwei spitzen, gebogenen

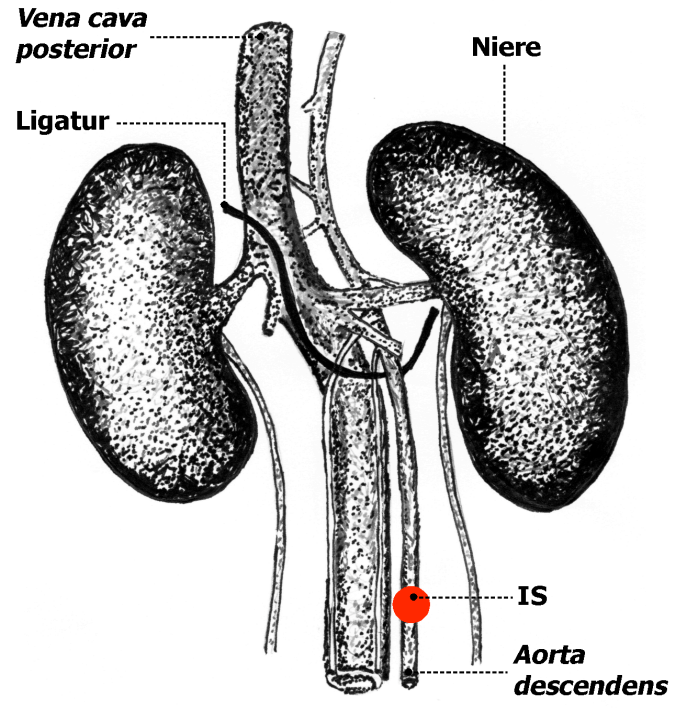

Abb. 2.6: Lage von Ligatur und Insertionsstelle (IS) für den Katheter des Blutdrucktransmitters unterhalb der abzweigenden Nierenäste freipräpariert, indem vorsichtig das darüberliegende Fett- und Bindegewebe abgezupft wurde. Dorsal wurde chirurgischer Faden (Supramid, Braun-Dexon, Spangenberg) unter der Aorta und über der Vena cava posterior hindurch gezogen (Abb. 2.6). Um das Gefäß zu relaxieren 
und so Verletzungen vorzubeugen, wurden 1-2 Tropfen von 2\%-igem Lidocain (Xyclocain, Astra, Wedel) direkt auf die Punktionsstelle der Aorta aufgetragen. Der Blutstrom wurde nun durch Anspannen der Ligationsnaht mittels eines Fadenhalters kurzfristig stark gedrosselt. Mit der Spitze einer zuvor vorbereiteten gebogenen Kanüle von 26 gauge $(0.46 \mathrm{~mm})$ Durchmesser wurde die Aorta punktiert und sofort der Katheter des Blutdrucktransmitters etwa $6 \mathrm{~mm}$ nach frontal in das Gefäß eingeschoben. Der Katheter wurde mit einigen Tropfen Gewebekleber (Vetbond ${ }^{\mathrm{TM}}$, 3M, Berlin), der mit einer feinen Kanüle appliziert wurde an der Punktionsstelle der Aorta fixiert. Um die weitere Stabilisierung des Katheters in der Aorta durch Bindegewebswachstum zu fördern, wurde ein Cellulose-patch über der Punktionsstelle fixiert. Die Ligation der Aorta wurde vorsichtig gelöst und der Ligationsfaden entfernt, der Transmitter eingeschaltet und die Signalqualität überprüft. Anschließend wurden die Operationshaken aus der Bauchhöhle entfernt und der Darm wieder in die ursprüngliche Position massiert. Der Transmitter wurde nun über die Ösen an der Muskelschicht vernäht und die Hautnaht zugeklammert. Der ganze Eingriff dauerte maximal $30 \mathrm{~min}$. Anschließend wurde die Narkose beendet und das Lokomotionsverhalten des Tieres nach dem Aufwachen beobachtet (Abb. 2.7A). Die post-operative Nachsorge erfolgte wie nach EKG-TransmitterImplantation (Abb. 2.7B).

A
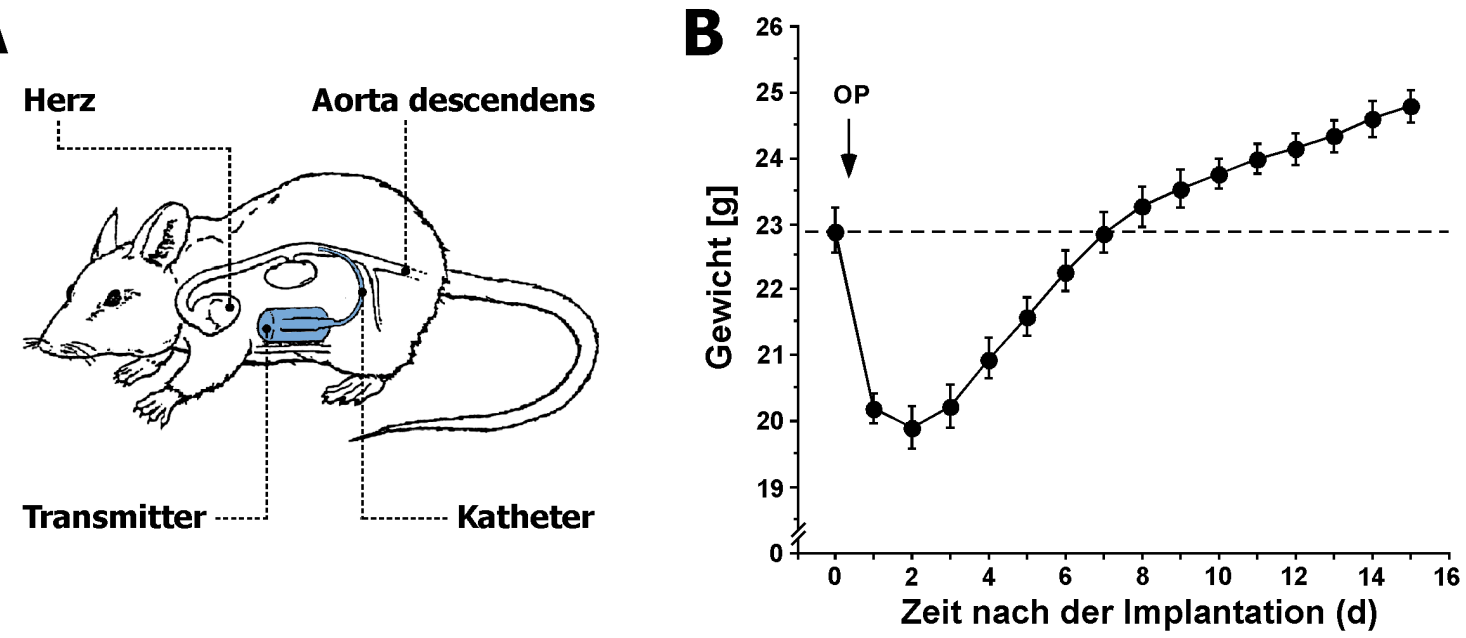

Abb. 2.7: Schematische Zeichnung einer Maus mit implantiertem Blutdrucktransmitter (A) und Gewichtsentwicklung der Mäuse nach erfolgter Implantation (B) unter Berücksichtigung des Transmittergewichts. Das Prä-Operationsgewicht ist am Tag 0 vor der Implantation angegeben. 


\subsubsection{Blutdruckaufzeichnung}

Das vom Empfänger (RLA 1020, Data Sciences, St. Paul, Minnesota, USA) aufgenommene und digitalisierte Blutdrucksignal wurde von einer Datenaustauschmatrix (Data Exchange Matrix, Data Sciences, St. Paul, Minnesota, USA) über die auch das Signal eines Umgebungsdruckmessers integriert wurde, in ein PC-basiertes Aufnahmesystem mit entsprechender Software (A.R.T. Acquisition GOLD, Data Sciences, St. Paul, Minnesota, USA) eingespeist (Abb. 2.8). Das digitalisierte und kalibrierte Blutdrucksignal wurde zu einem Analogsignal konvertiert (A.R.T. Analog Output Matrix, Data Sciences, St. Paul, Minnesota, USA) und bei 4 kHz Abtastrate von einem Macintosh-basierten Computersystem

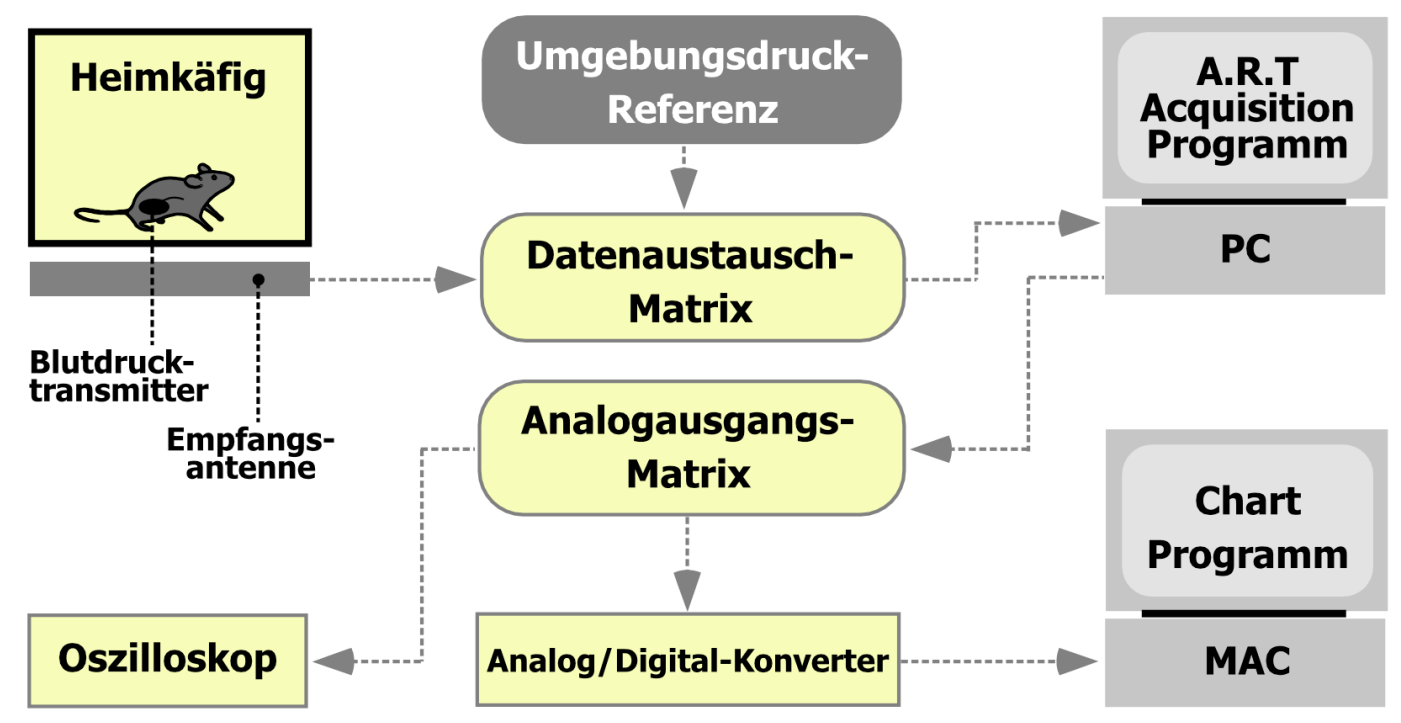

Abb. 2.8: Versuchsaufbau für die Blutdruckmessungen im Heimkäfig.

(MacLab 4 s, ADInstruments, Spechbach) digital aufgenommen. Diese Mehrfachkonvertierung war notwendig, um die Aufnahme des Signals und seine kontinuierliche Messung mit Verhaltensexperimenten koppeln (triggern) zu können. Die Analyse der Daten erfolgte später mit entsprechender Software (Chart 5.0, HRV Erweiterung, ADInstruments, Spechbach).

Der mittlere arterielle Blutdruck (mean arterial pressure: MAP) wurde als Summe der Blutdruckwerte geteilt durch ihre Anzahl pro Herzfunktions-Periode, d.h. von Diastole zu Diastole ermittelt. Der diastolische Minimalwert wurde aufgrund seiner im Vergleich zum systolischen Maximalwert höheren Genauigkeit als Periodenanfangs- bzw. Endpunkt für die Berechnung der Herzrate herangezogen (Abb. 2.9). Die kontinuierlichen Messungen wurden 
abhängig von der zu betrachtenden Gesamtlänge in kürzere Intervalle untergliedert, in denen dann der mittlere Blutdruck als arithmetisches Mittel der periodischen MAP-Werte bestimmt wurde. Gelegentlich auftretende Störungen des Blutdrucksignals durch Signalverlust wurden von der Analyse ausgeschlossen. Zusätzlich wurden unphysiologisch hohe Druckschwankungen (aufgrund Verbiegens oder Torsion des Katheters) bei der Berechnung der mittleren Blutdruckwerte für

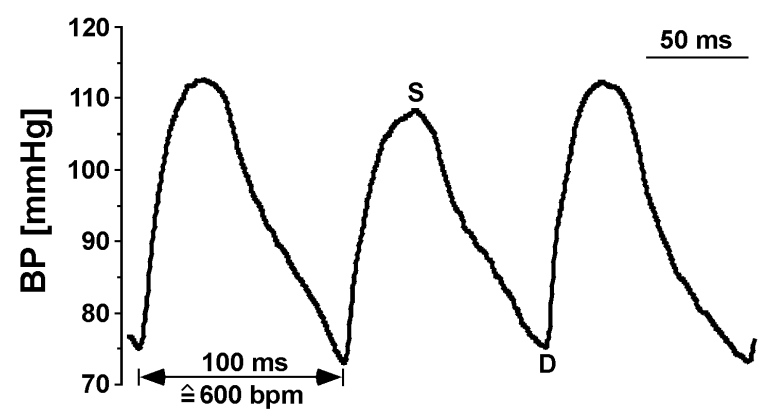
ein bestimmtes Zeitintervall ausgeschlossen.

Abb. 2.9: Blutdrucksignal mit Systole (S) und Diastole (D) und Berechnng der Herzrate auf Basis des Diastolen-Intervalls.

\subsection{Intraperitoneale Injektion}

Um die peripher vermittelten kardiovaskulären Effekte der zu untersuchenden Substanzen zu testen, wurden intraperitoneale Injektionen vorgenommen. Dazu wurden die Mäuse für die Dauer der Injektion (30 s) narkotisiert. Die Narkose erfolgte mit jeweils $0.2 \mathrm{ml}$ Isofluran, das in einem Becherglas von 11 Volumen verdampft worden war und in das die Mäuse für etwa 30 s gesetzt wurden. Mit einer $100 \mu 1$ Hamilton-Spritze (Gastight ${ }^{\circledR}$, Bonaduz, Schweiz) wurde ein Volumen von $100 \mu 1$ der Substanzlösung mit entsprechender Konzentration intraperitoneal (IP) injiziert. Nach Gebrauch wurden die Spritzen sofort mit 70\%-igem Ethanol und steriler Saline gespült. Die kardiovaskulären Messungen begannen entweder sofort nach dem Zurücksetzen des Tieres in den Heimkäfig oder 15 min später.

\subsection{Intrazerebrale Injektion}

Um die zentrale Wirkung von Substanzen zu untersuchen, welche die Blut-HirnSchranke nicht passieren, erfolgte die operative Implantation von Hirnkanülen, durch die gelöste Substanzen zentral appliziert werden konnten. 


\subsubsection{Operationsnarkose}

Die Mäuse wurden etwa 5 Minuten vor der Implantation der Hirnkanülen durch intraperitoneale Injektion einer Avertin-Lösung narkotisiert. Diese bestand aus $1 \mathrm{~g}$ Tribromethanol (Sigma-Aldrich, Steinheim) und $0.81 \mathrm{~g}$ (1 ml) Amylalkohol in wässriger Lösung. Zur Herstellung wurden sukzessiv $71.49 \mathrm{ml}$ Wasser mit einer Temperatur von maximal $42^{\circ} \mathrm{C}$ zur Alkoholmischung pipettiert. Dabei wurde die Lösung immer wieder gevortext, bis sich sämtlicher Alkohol gelöst hatte. Schließlich wurde die Lösung auf Raumtemperatur abgekühlt, sterilgefiltert und maximal für einen Tag als Injektionsnarkotikum verwendet. Für eine ausreichende Narkose von 20-30 Minuten wurde ein Volumen von $25 \mathrm{ml} / \mathrm{kg}$, d.h. $0.6 \mathrm{ml}$ für eine Maus mit $25 \mathrm{~g}$ Körpergewicht injiziert. Das Fehlen jeglicher Schmerzperzeption der narkotisierten Mäuse wurde kurz vor der Operation mit einem Reflextest durch leichten Druck auf die Pfote der Maus überprüft.

\subsubsection{Hirnkanülenimplantation}

Unter weitgehend sterilen Bedingungen wurden zuvor in 70\%-igem Alkohol desinfizierte Doppel-Führungskanülen (C235, Plastics One, Roanoke, Virginia, USA; Abb. 2.10A) mit einem Außendurchmesser von 26 gauge $(0.46 \mathrm{~mm})$ zur Applikation von Lösungen in definierte Zielgebiete intrazerebral implantiert (Abb. 2.10B).

Das narkotisierte Tier wurde in einem stereotaktischen System (Cartesian Research, Sandy, Oregon, USA) mit einer verstellbaren Schnauzen-Klemme fixiert. Mit einer Pinzette wurde die Kopfhaut zwischen den Ohren angehoben und mit einer Schere eine kleine Öffnung ( $\varnothing$ ca. $1 \mathrm{~cm})$ geschnitten. Auf dem Schädel verbleibendes Gewebe wurde vorsichtig entfernt, die Knochenoberfläche mit einer sterilen Rasierklinge aufgeraut und mit 70 \%-igem Alkohol gereinigt. Zur exakten Positionierung der Kanüle wurden individuelle anatomische Differenzen der Mäuse mit Hilfe von Verstellschrauben ausgeglichen. So wurde der frontocaudale Neigungswinkel des gewölbten Schädels an der Kanülenposition senkrecht eingestellt. Bei intrazerebroventrikulären (ICV) Injektionen betrug dieser ca. $10^{\circ}$, bei intrahippokampalen (IH) Injektionen ca. $14^{\circ}$. Um das Schädeldach an der Kanülenposition in lateraler Richtung waagerecht auszurichten, wurde der Kopf in Längsachse rotiert. Anhand der Kopfform und der longitudinalen Schädelplatten-Verwachsungsnähte wurde der Schädel durch Drehung des Halters parallel zur Längsachse des Systems ausgerichtet. 


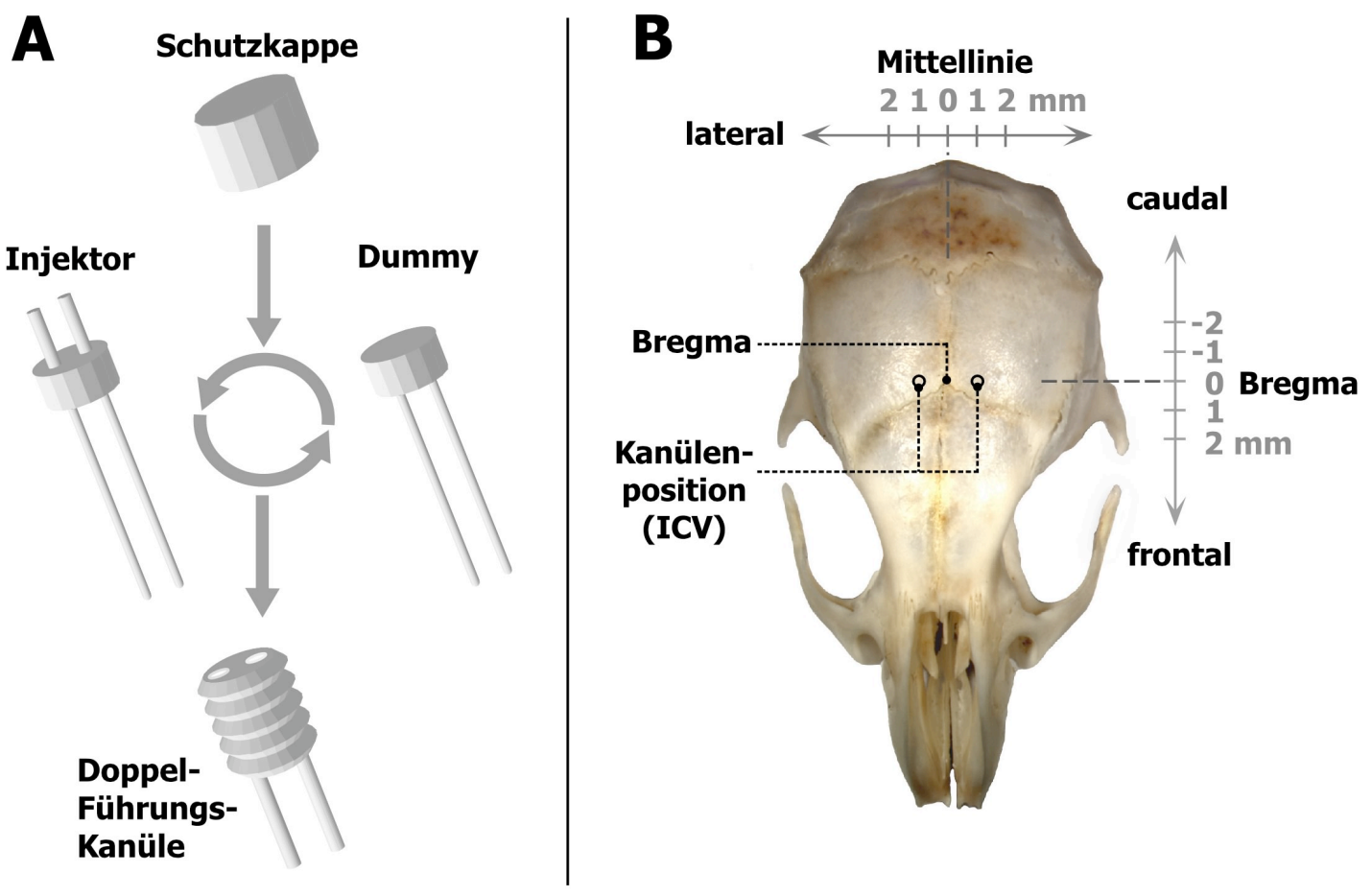

Abb. 2.10: Aufbau der Hirnkanüle für bilaterale Injektionen (A) und Ermittlung der Injektionsposition anhand der Schädelsuturen (B).

Die Spitze eines Zentrierbohrers $(\varnothing=0.5 \mathrm{~mm})$ wurde genau über die zuvor mittels optischer Vergrößerung und der digitalen Wegaufnehmer ermittelten Bregma-Position gebracht. Die Operationskoordinaten wurden entsprechend des Maushirn-Atlas (Franklin und Paxinos, 1997) ausgewählt. Die Bohrungen für die intrazerebroventrikulären (ICV) Injektionen erfolgten $1.0 \mathrm{~mm}$ lateral zur Verwachsungsstelle der beiden vorderen und der hinteren Schädelplatten (Bregma; Abb. 2.10B). Die eingesetzte Doppelführungskanüle endete $2.0 \mathrm{~mm}$ unter der Schädeloberfläche. Die Injektionsstelle des Injektors lag $1.0 \mathrm{~mm}$ unter dem Ende der Kanüle, d.h. 3 mm unter der Schädeloberfläche. Bei intrahippokampalen (IH) Injektionen erfolgten Bohrungen $1.0 \mathrm{~mm}$ lateral und $1.6 \mathrm{~mm}$ caudal von der Bregma-Position. Die Injektionstiefe, welche durch Unterlegscheiben variiert wurde, lag bei $2.2 \mathrm{~mm}$ unter der Schädeloberfläche. Auf beiden Seiten wurde vorsichtig ein Loch gebohrt, ohne den unter dem Schädeldach liegenden Kortex zu verletzen. Die Schädeloberfläche wurde mit alkoholgetränkten Wattestäbchen sofort gereinigt und getrocknet.

Die Kanüle wurde nun senkrecht eingeführt und zunächst mit einem Kanülen-Halter stabilisiert. Mittels frisch angerührtem Dentalzement mit einem Zementpulver/FluidVerhältnis von 1:1 (Durelon Carboxylatzement, Espe, Seefeld) wurde schließlich die Kanüle auf dem Schädel fixiert und gleichzeitig die Hautwunde verschlossen. Bis der Zement getrocknet war, wurde das Tier noch in der Halterung belassen. Danach wurde der 
Kanülenhalter entfernt, das Tier aus dem stereotaktischen Halter genommen und zurück in den Heimkäfig gelegt. Dieser befand sich auf einer auf $37^{\circ} \mathrm{C}$ aufgeheizten Wärmeplatte. Der Käfig wurde mit einem modifizierten Aluminiumdeckel versehen, um ein Verhaken der Kanüle zwischen den Gitterstäben der Standarddeckel zu verhindern. Der neue Deckel besaß kleinere runde Luftlöcher und eine große Öffnung für die Trinkflasche. Die Nahrungspellets wurden auf den Boden des Käfigs gelegt. Alle Experimente wurden nach einer Regenerationspause von drei bis vier Tagen nach der Operation innerhalb von fünf Tagen durchgeführt.

Nach beendeten Experimenten wurden die Hirnkanülen zunächst explantiert und manuell von anhaftenden Zementresten befreit. Die Einzelteile wurden über Nacht in enzymatischer Reinigungslösung gelegt, dann für $40 \mathrm{~min}$ bei $50^{\circ} \mathrm{C}$ im Ultraschallbad behandelt und anschließend in 70\%-igem Alkohol desinfiziert. Nach Abtrocknen des Alkohols wurden die Kanülen erneut implantiert.

\subsubsection{Injektionsprozedur}

Die zentralen Injektionen der zu untersuchenden Pharmaka erfolgten zu definierten Zeitpunkten relativ zu Training, Gedächtnistests und EKG-Messungen. Die bilaterale Applikation erfolgte über zwei $25 \mu 1$ Spritzen $\left(\right.$ Gastight $^{\circledR}, \# 1702$, Hamilton, Bonaduz, Schweiz) und einen Mikroinjektor (CMA/100, CMA/Microdialysis, Solna, Schweden). Die Spritzen wurden über medizinischen Polyethylenschlauch (V/3A, Scientific Commodities, Lake Havasu City, Arizona, USA) luftdicht mit dem Doppelinjektor verbunden. Die Tiere wurden mit jeweils $0.2 \mathrm{ml}$ Isofluran, das zuvor in einem Becherglas von 11 Volumen verdampft worden war, narkotisiert. Während der Injektion wurde die Narkose bei Bedarf durch Isofluran in einem Eppendorfcup mit Watte verlängert. Die beobachtete Atemtiefe und Atemfrequenz dienten dabei als Index für Tiefe der Narkose. Die Injektion erfolgte bilateral in einem Volumen von $0.25 \mu 1 /$ Hirnhemisphäre bei einer Injektionsrate von $0.33 \mu 1 / \mathrm{min}$.

\subsubsection{Kontrolle der Injektionsposition}

Nach Beendigung von Versuchen mit zentralen Injektionen wurden bei jedem Tier die genauen Injektionspositionen kontrolliert (Abb. 2.11A). Dazu wurden die Tiere mit Isofluran 
zunächst tief narkotisiert. Dann wurde ihnen $0.25 \mu 1$ sterilgefilterte gesättigte Methylenblaulösung je Hemisphäre intrazerebral injiziert, wie bereits in Kapitel 2.7.4 beschrieben. Daraufhin wurden die Tiere im narkotisierten Zustand durch Dekapitation getötet, die Gehirne sofort entnommen und über flüssigem Stickstoff gefroren. Bis zur histologischen Analyse wurden die Gehirne bei $-20^{\circ} \mathrm{C}$ gelagert.

Zur histologischen Verifikation der Applikationsorte wurden die gefrorenen Gehirne auf einem Gewebeblockhalter mit Einbettmedium (Tissue Tek, Sakura Finetek, Torrance, Kalifornien, USA) fixiert. Mit einem Gefriermikrotom (CM 3050, Leica, Nussloch) wurden bei Objekt- und Kammertemperaturen von $-15^{\circ} \mathrm{C}$ bzw. $-20^{\circ} \mathrm{C}$ Koronarschnitte (Dicke: $50 \mu \mathrm{m}$ ) der Injektionsbereiche der Gehirne angefertigt, die sofort auf Objektträger aufgebracht wurden. Bilder repräsentativer Schnitte (Abb. 2.11) wurden mit einem computergestützten Bildanalysesystem digitalisiert, gespeichert und mit entsprechender Software (Photoshop 5.0, Adobe Systems, San Jose, Kalifornien, USA) ausgewertet. Das Aufnahmesystem bestand aus

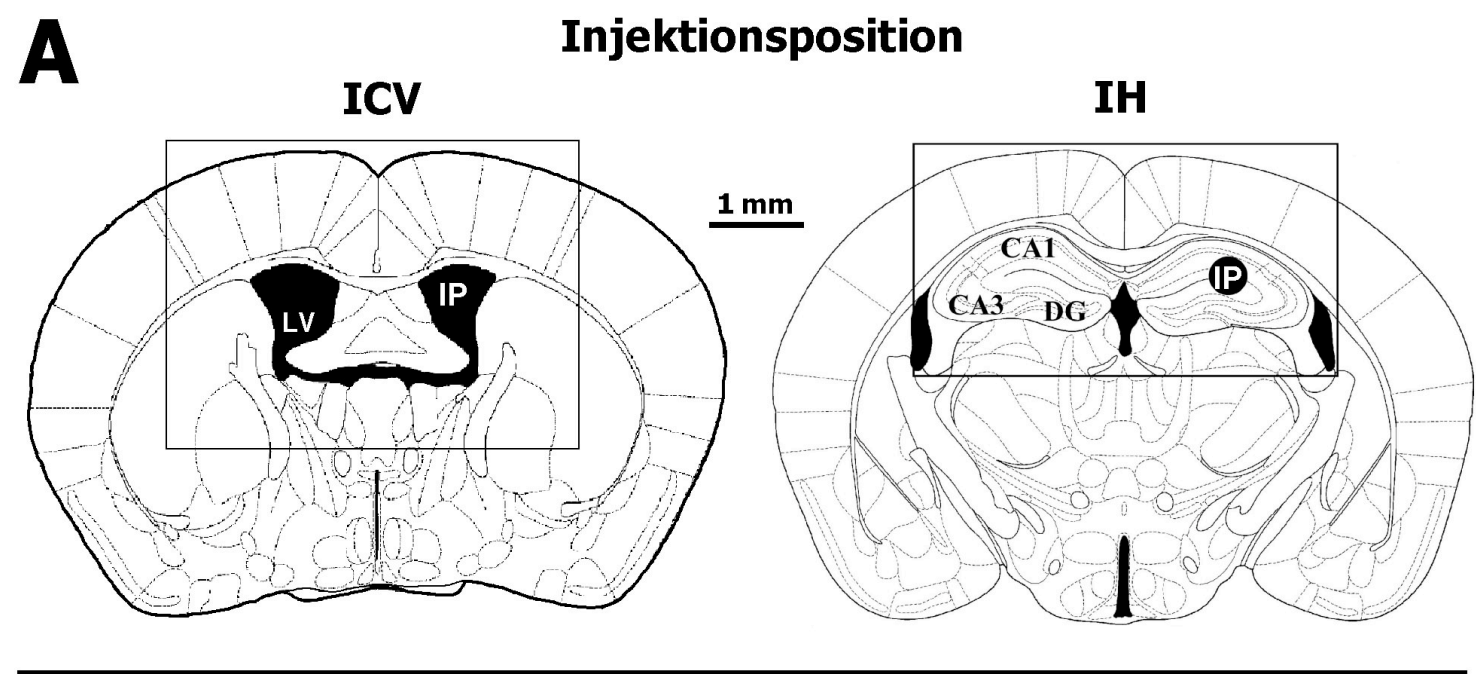

B Methylenblau-Injektion

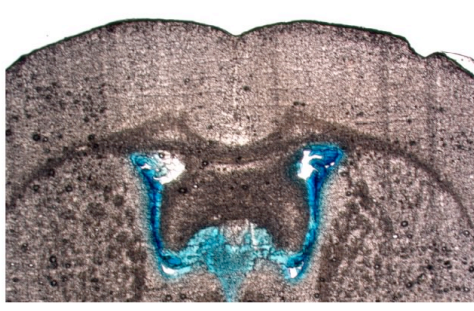

Bregma

$-0,34 \mathrm{~mm}$

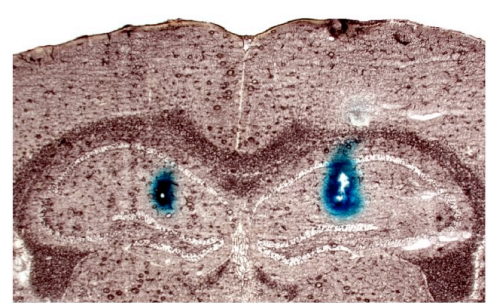

Bregma

$-1.7 \mathrm{~mm}$

Abb. 2.11: Schematische Zeichnungen der Injektionspositionen (nach Franklin \& Paxinos, 1997; A) und Kontrolle der Injektionspositionen in Methylenblau-injizierten Koronarschnitten (B). 
einer digitalen Kamera (Visitron Systems, Puchheim), die an das Mikroskop (Axiophot, Zeiss, Oberkochen) gekoppelt war.

Die Injektionsorte aller getesteten Tiere wurden histologisch analysiert. Nur die Daten der Tiere, bei denen die Farbinjektionen im gewünschten Zielgebiet sichtbar waren und keine massiven Läsionen aufwiesen (Abb. 2.11B), wurden in die statistische Auswertung der Versuchsergebnisse einbezogen.

\section{$2.8 \quad$ Verhaltenstests}

In verschiedenen Verhaltenstests wurden die Auswirkungen aversiver emotionaler Zustände auf die neuroautonome Regulation bei Mäusen untersucht. Mit Hilfe des Furchtkonditionierungsparadigmas konnte gleichzeitig auch das emotionale Gedächtnis überprüft werden.

\subsubsection{Handling}

Bei der Handling-Prozedur wurde die Versuchsmaus zunächst in ihrem Heimkäfig vom Haltungscontainer in den Versuchsraum transportiert. Dann wurde sie am Schwanz angehoben, kurzzeitig in eine neue Umgebung und dann wieder zurück in den Käfig gesetzt. Dieser wurde anschließend zurück in den Haltungscontainer gestellt und die telemetrische Messung gestartet. Dieser Vorgang dauerte etwa 60 s und simuliert annähernd den Beginn eines jeden Verhaltenstests, welcher nicht im Heimkäfig ausgeführt wird. Somit sollten die kardiovaskulären Effekte eines manuellen Interferierens mit den Versuchsmäusen untersucht werden.

\subsubsection{Novelty}

Für den Novelty-Test wurden die Mäuse aus ihrem gewohnten Heimkäfig in einen sauberen Käfig gleicher Größe mit neuem Einstreu, neuem Futter und neuem Deckel, allerdings ohne Nestmaterial aus Zellstofftuch gesetzt. Bei einer zweiten experimentellen Gruppe wurde das Nestmaterial erneuert, während bei einer zweiten Gruppe von Mäusen das alte Nestmaterial mit umgesetzt wurde. Anschließend wurden die Mäuse in ihrem jeweiligen 
Käfig wieder zurück in den Haltungscontainer gestellt und die telemetrischen Messungen gestartet.

\subsubsection{Furchtkonditionierung}

Die Furchtkonditionierungs-Experimente fanden in einem schallgeschützten, von dem Haltungsbereich der Mäuse abgetrennten Raum statt. Die Furchtkonditionierung erfolgte mit Hilfe eines computergesteuerten Furchtkonditionierungssystems (303410, TSE, Bad Homburg). Eine Kontrolleinheit steuerte die Intensitäten von Licht, Ton und Elektroschock im Konditionierungsexperiment (Abb. 2.12). Vor jedem Experiment wurde die Furchtkonditionierungskammer mit $70 \%$-igem Alkohol gereinigt. Ein akustisches Breitbandsignal diente als Hintergrundrauschen und wurde in der Kammer über einen Hochfrequenzlautsprecher (Conrad, KT-25-DT, Hirschau) bei einer Intensität von 68 dB SPL (SPL; sound pressure level $=$ Schalldruckpegel) abgegeben. Die Kammer wurde außerdem permanent ventiliert, wobei der Ventilator aufgrund der niedrigen Frequenzen $(<400 \mathrm{~Hz})$ und der geringen Intensität kein für die Mäuse hörbares Hintergrundgeräusch produzierte (Shnerson \& Pujol, 1982).

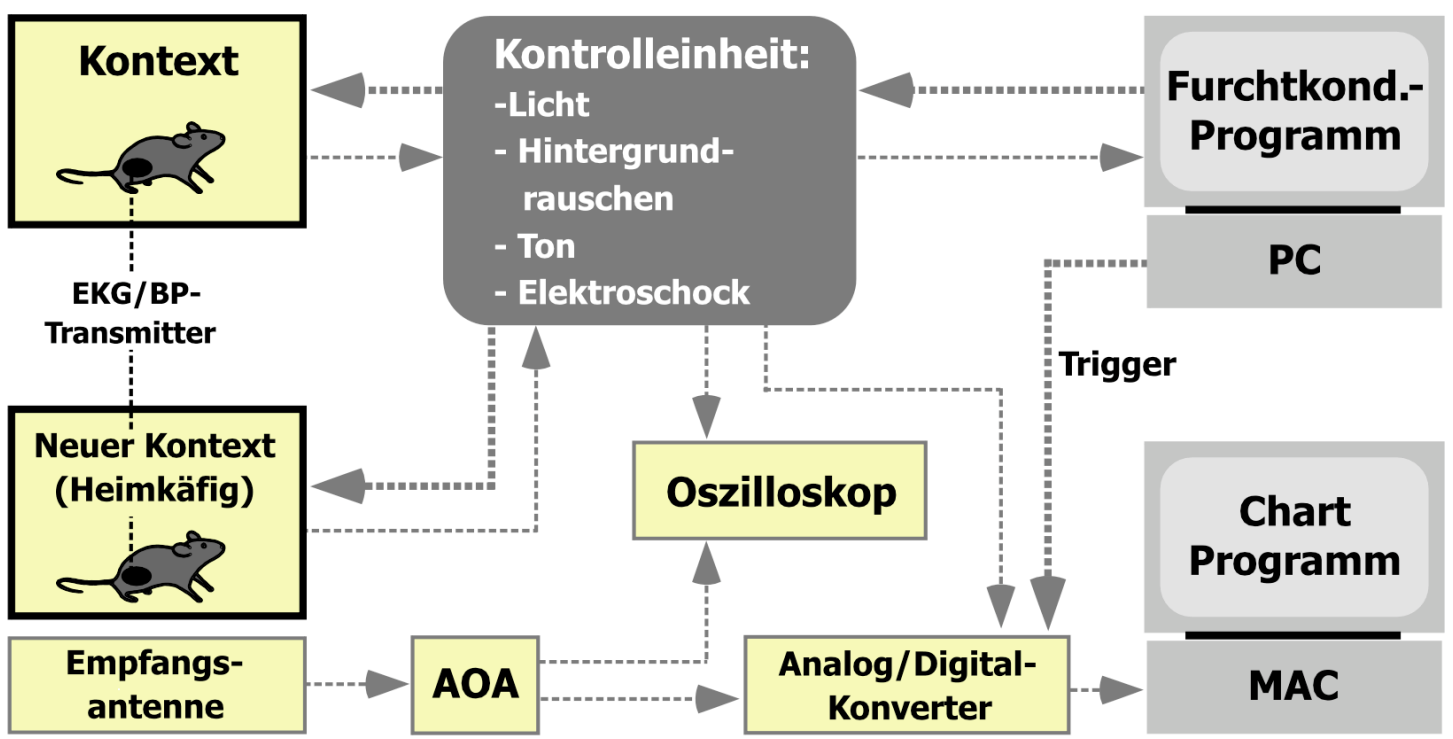

Abb. 2.12: Aufbau des Furchtkonditionierungs-Systems und des EKG-Messsystems. Die Kontrolleinheit erlaubte die Einstellung aller Reizintensitäten sowie der Tonfrequenz. AOA=Analog-0utput-Adapter 
Als zu konditionierender Reiz diente der Konditionierungskontext, bestehend aus der Gesamtheit der unterschiedlichen sensorischen Stimuli der Konditionierungsumgebung. Visuelle Reize waren der Plexiglaskäfig (36 cm x $21 \mathrm{~cm}$ x $20 \mathrm{~cm}$, Länge x Breite x Höhe) und die umgebende beleuchtete (12 V/10 W Halogenlampe, 100-500 lx) Furchtkonditionierungsbox aus grauem PVC. Taktile Reize waren die Wände des Käfigs und ein EdelstahlBodengitter, über das ein milder Elektroschock $(0.7 \mathrm{~mA}, 2 \mathrm{~s}$ Dauer, Gleichstrom) als unkonditionierte Stimuli (US) verabreicht wurde. Die runden Gitterstäbe lagen $0.9 \mathrm{~cm}$ auseinander und besaßen einen Durchmesser von $4 \mathrm{~mm}$. Olfaktorische Reize wurden im wesentlichen vom Reinigungsalkohol bestimmt, und auditorischer Reiz war das Hintergrundrauschen. In manchen Experimenten wurde zusätzlich als definierter auditorischer Reiz ein phasischer Sinuston zur Konditionierung verwendet. Dieser konditionierende Stimulus (10 kHz, $75 \mathrm{~dB}$ SPL, gepulst $5 \mathrm{~Hz}$ ) wird im folgenden als Ton-CS bezeichnet. Die Kalibrierung des akustischen Systems wurde mit einem 1/2" Mikrophon (Typ 4165, Brüel und Kjær, Darmstadt) und Messverstärker (Typ 2608, Brüel und Kjær, Darmstadt) bei Messung der Spitzenintensitäten durchgeführt. Die Fast Fourier Analyse des CS (ADInstruments, MacLab Chart 3.6/s, Spechbach) bestätigte die Ausgabe eines reinen Tons einer Frequenz von $10 \mathrm{kHz}$. Bei einer Intensität von 75 dB SPL liegt diese Frequenz im Bereich der maximalen auditorischen Empfindlichkeit von C57BL/6 Mäusen (Shnerson \& Pujol, 1982).

\subsubsection{Kontextuelle Furchtkonditionierung: Training und Gedächnistests}

Vor der Konditionierungs- bzw. Akquisitionsphase, dem Training, wurde die Maus zunächst an drei aufeinander folgenden Tagen für jeweils $32 \mathrm{~min}$ in drei verschiedene Umgebungen (Kontexte 1-3) gesetzt (Abb. 2.13). Dies diente der Habituierung der Maus an Handling und Novelty. Kontext 1 an Tag Eins war ein mit 70\%-igem Ethanol gereinigter, rechteckiger Standard-Makrolonkäfig (Typ II) mit Abdeckgitter in einer hellerleuchteten, weißen Umgebung (350-500 1x). Kontext 2 an Tag Zwei bestand aus einer rechteckigen, innen diagonal geteilten Plexiglasbox (36 cm x $21 \mathrm{~cm}$ x $20 \mathrm{~cm}$, Länge x Breite x Höhe) mit grauer PVC-Bodenplatte in einer weniger hellen Umgebung (100 lx). Diese Box wurde zuvor mit 1\%-iger Essigsäure gereinigt. Kontext 3 an Tag Drei war ein außen mit blauem Tonpapier umwickelter, runder Zylinder $(\varnothing=20 \mathrm{~cm})$ aus Plexiglas in einer hell beleuchteten Umgebung. Dieser wurde mit 70\%-igem Ethanol gereinigt. 
Am vierten Tag fand das Training in der Furchtkonditionierungsbox (Kontext 4) statt (Abb. 2.13). Es wurden drei Versuchsgruppen untersucht, die jeweils einer unterschiedlichen Trainingssequenz ausgesetzt wurden. Der ersten Gruppe $\left(\mathrm{US}_{l}\right.$; late) wurde nach $180 \mathrm{~s}$ Explorationszeit in der neuen Umgebung ein Ton-CS (s.o.) für $30 \mathrm{~s}$ präsentiert. Das akustische Signal endete gleichzeitig mit der Gabe des elektrischen Fußschocks. Nach weiteren $30 \mathrm{~s}$ wurden die Mäuse wieder in den Heimkäfig zurückgesetzt. Die zweite Gruppe (kein $\mathrm{US}_{n}$; no) wurde der gleichen Trainingssequenz, jedoch ohne Gabe des Fußschocks ausgesetzt. Die dritte Gruppe (sofortiger $\mathrm{US}_{i}$; immediate) erhielt unmittelbar nach Einsetzen in die Plexiglasbox einen Fußschock, auf den $180 \mathrm{~s}$ Explorationszeit, $30 \mathrm{~s}$ Ton-CS und $30 \mathrm{~s}$ ohne zusätzliche Stimulation folgten. Während dieser Akquisitionsphase wurden Verhaltensmessungen durchgeführt, um Explorationsverhalten, lokomotorische Aktivität und US-Sensitivität

Tag 1: Habituierung

Tag 2: Habituierung

Tag 3: Habituierung

Tag 4: Training für drei Gruppen abhängiger Gedächtnis-

Tag 5: Kontext test

\section{$32 \mathrm{~min}$ in Kontext 1}

$32 \mathrm{~min}$ in Kontext 2

\section{$32 \mathrm{~min}$ in Kontext 3}

\section{Kontext 4}

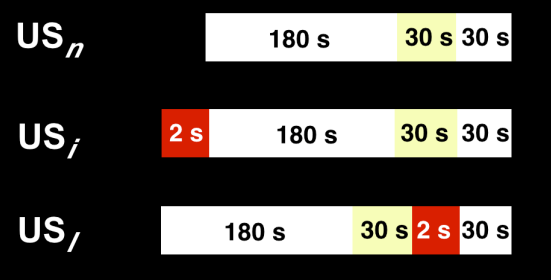

32 min Re-Exposition in Kontext 4

EKG und Aktivitätsmessungen

Abb. 2.13: Ablauf der Kontext abhängigen Furchtkonditionierungsexperimente mit Habituierung an den Tagen 1-3, Training an Tag 4 und Kontext abhängigem Gedächtnistest an Tag 5. zu untersuchen.

Der Gedächtnistest (Retention) erfolgte an Tag Fünf durch erneutes Einsetzen der Mäuse in den aversiv konditionierten Kontext 4 für 32 min. Kontinuierliche EKG-Messungen wurden vom Furchtkonditionierungssystem mit automatisierten Aktivitätsmessungen synchronisiert. Die Infrarotsensoren des Messsystems hatten einen Abstand von $13 \mathrm{~mm}$ in horizontaler und $25 \mathrm{~mm}$ in vertikaler Richtung und erfassten die Bewegungen der Maus, d.h. lokomotorische Aktivität und lokale Körperbewegungen mit einer Abtastrate von $10 \mathrm{~Hz}$. Aus den so gewonnenen Aktivitätsdaten wurden Aktivitätsplots erstellt und die gemittelte prozentuale Aktivität in 162 min-Intervallen des Gedächtnistests ermittelt. Inaktivität wurde als der prozentuale Zeitanteil definiert, in dem die Aktivität unter $1 \mathrm{~cm} / \mathrm{s}$ lag. Des Weiteren wurde die prozentuale Explorationsfläche je 2 min-Intervall ermittelt. 


\subsubsection{Auditorische Delay-Furchtkonditionierung: Training und Gedächtnis- tests}

Im Training wurde eine Maus in den Konditionierungskontext gesetzt, in dem sie zunächst für $180 \mathrm{~s}$ ohne phasische Stimulation verblieb, bevor der zu konditionierende auditorische Stimulus für 30 s präsentiert wurde, auf den unmittelbar der US folgte (delay mode). In einigen Experimenten erfolgte $30 \mathrm{~s}$ nach Ende des Fußschocks eine erneute Tonpräsentation mit abschließendem Fußschock. Diese Sequenz von Ton (30 s), Schock (2 s) und Pause (30 s) wurde maximal vier Mal wiederholt. Danach wurde das Tier aus der Furchtkonditionierungsbox wieder zurück in seinen Heimkäfig gesetzt.

Die computergestützte Analyse der Aktivität der Versuchstiere während der Konditionierung erlaubte eine Kontrolle der US induzierten Stressantwort. Diese äußerte sich in Vokalisation und reflexartigem Umherspringen der Mäuse bei Gabe des Fußschocks, und sog. Freezing-Verhalten in den Pausen und während der Tonpräsentation, das nach Ende der USPräsentation sofort aufhörte.

Die Ton abhängigen Gedächtnistests wurden im Heimkäfig durchgeführt. Beim Tontest folgte auf die $180 \mathrm{~s}$ anhaltende prä-CS Phase eine $180 \mathrm{~s}$ dauernde Ton-CS Präsentation (CS Phase) gefolgt von einer abschließenden Messung (post-CS Phase) von $30 \mathrm{~s}$ (Abb. 2.14). In einem weiteren Versuch betrug die CS-Phase nur $10 \mathrm{~s}$, die post-CS Phase jedoch $180 \mathrm{~s}$. Zusätzlich wurden Messungen ohne jegliche externe Stimulation im Heimkäfig durchgeführt, der sich im Haltungscontainer der Mäuse befand.
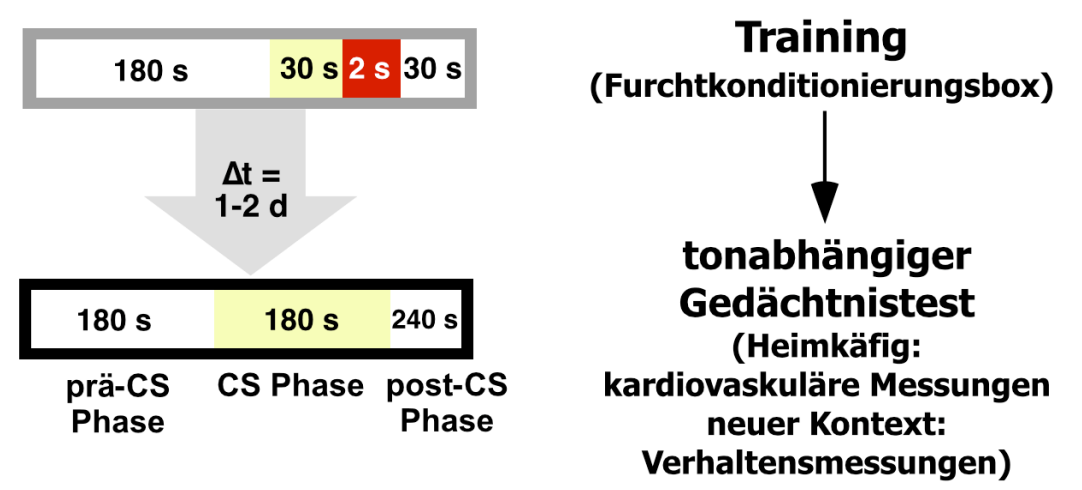

Stimuli:

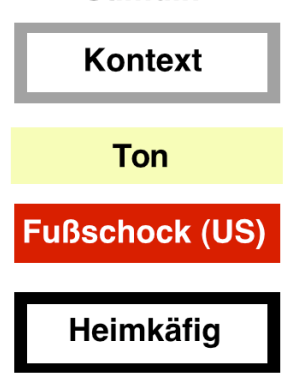

Abb. 2.14: Ablauf der Ton abhängigen Furchtkonditionierungsexperimente und die verwendeten Reize. $\Delta t$ gibt den zeitlichen Abstand der aufeinander folgenden Tests an. 


\subsubsection{Trace-Furchtkonditionierung}

Um den spezifischen Beitrag des Hippokampus zu konditionierter Furcht und den beteiligten kardiovaskulären Mechanismen zu untersuchen, wurde eine abgewandelte Form der Furchtkonditionierung verwendet (Abb. 2.15). Dabei wurden im Training Ton-CS und Fußschock-US durch ein Trace-Intervall voneinander getrennt präsentiert. Das TraceIntervall wurde in verschiedenen experimentellen Gruppen systematisch variiert, um die zeitliche Dynamik der hippokampalen Involvierung für assoziatives Lernen komplexerer zeitlicher Beziehungen zu untersuchen. Die Intervalllängen betrugen 1, 3, 5, 10, 15, 30 und $45 \mathrm{~s}$. Dafür wurde der NMDA-Rezeptor Antagonist APV (3.2 $\mu \mathrm{g} / \mathrm{Maus})$ über bilateral implantierte Hirnkanülen 15 min vor dem Training in den dorsalen Hippokampus injiziert. Als Kontrollgruppe dienten aCSF-injizierte Mäuse. Mäuse, die keinen Fußschock erfahren hatten (kein US) dienten als zusätzliche Kontrolle zur Validierung der Freezing-InaktivitätsKorrelationsanalyse.

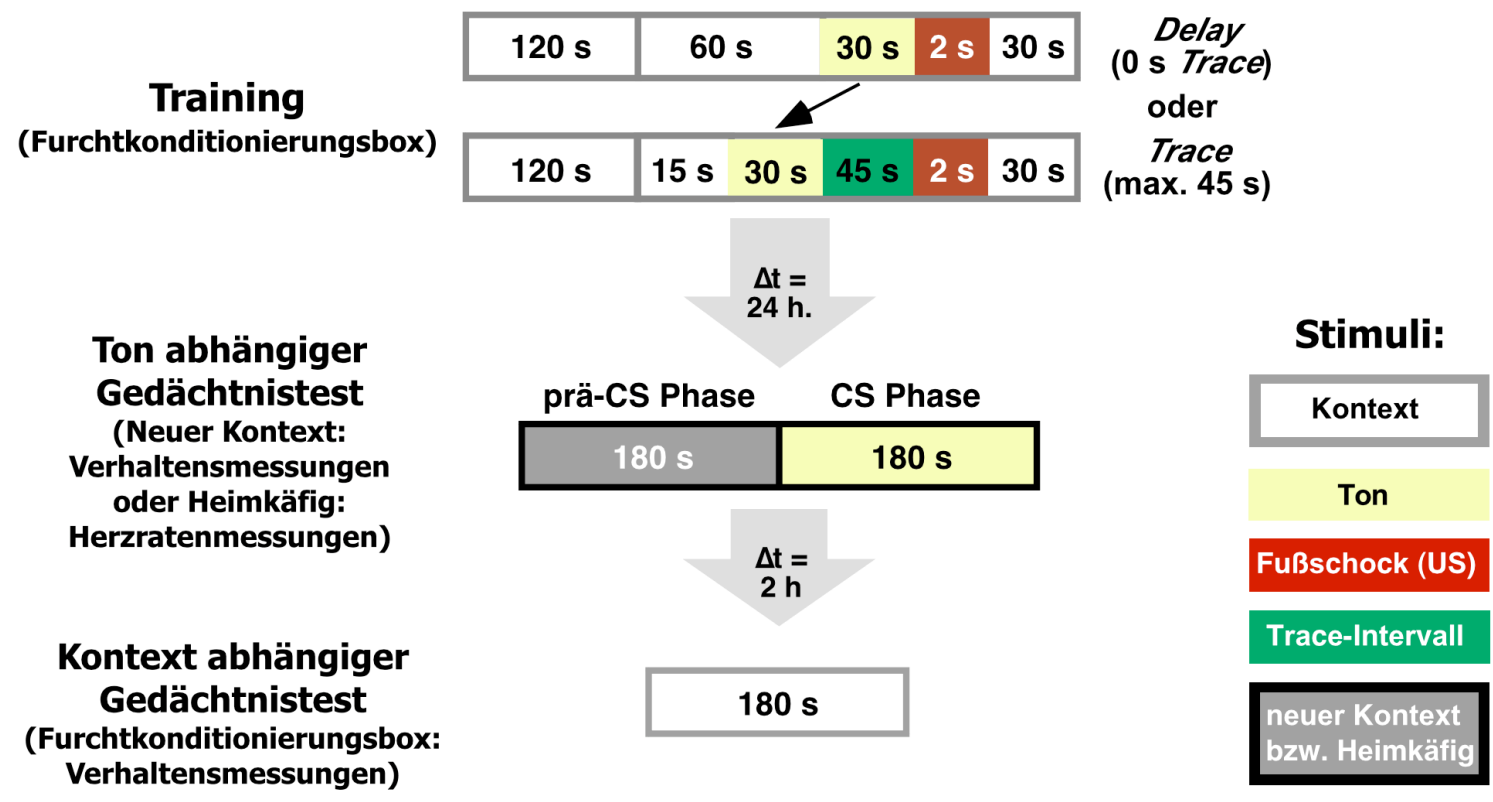

Abb. 2.15: Ablauf der Ton abhängigen Furchtkonditionierungsexperimente und die verwendeten Reize. $\Delta t$ gibt den zeitlichen Abstand der aufeinander folgenden Tests an. 


\subsubsection{Startle-Test}

Mit Hilfe des Startle-Tests sollten die Auswirkungen eines unkonditionierten akustischen Stimulus auf Herzraten- und Blutdruckdynamik untersucht werden. Die Experimente fanden innerhalb einer schalldichten Box (Abb. 2.16) statt, in der die Versuchsmäuse zunächst für 24 Stunden in ihrem Heimkäfig habituiert wurden. Am Boden des Käfigs, der auf einer Schaumstoffunterlage stand, wurde mit Bienenwachs ein

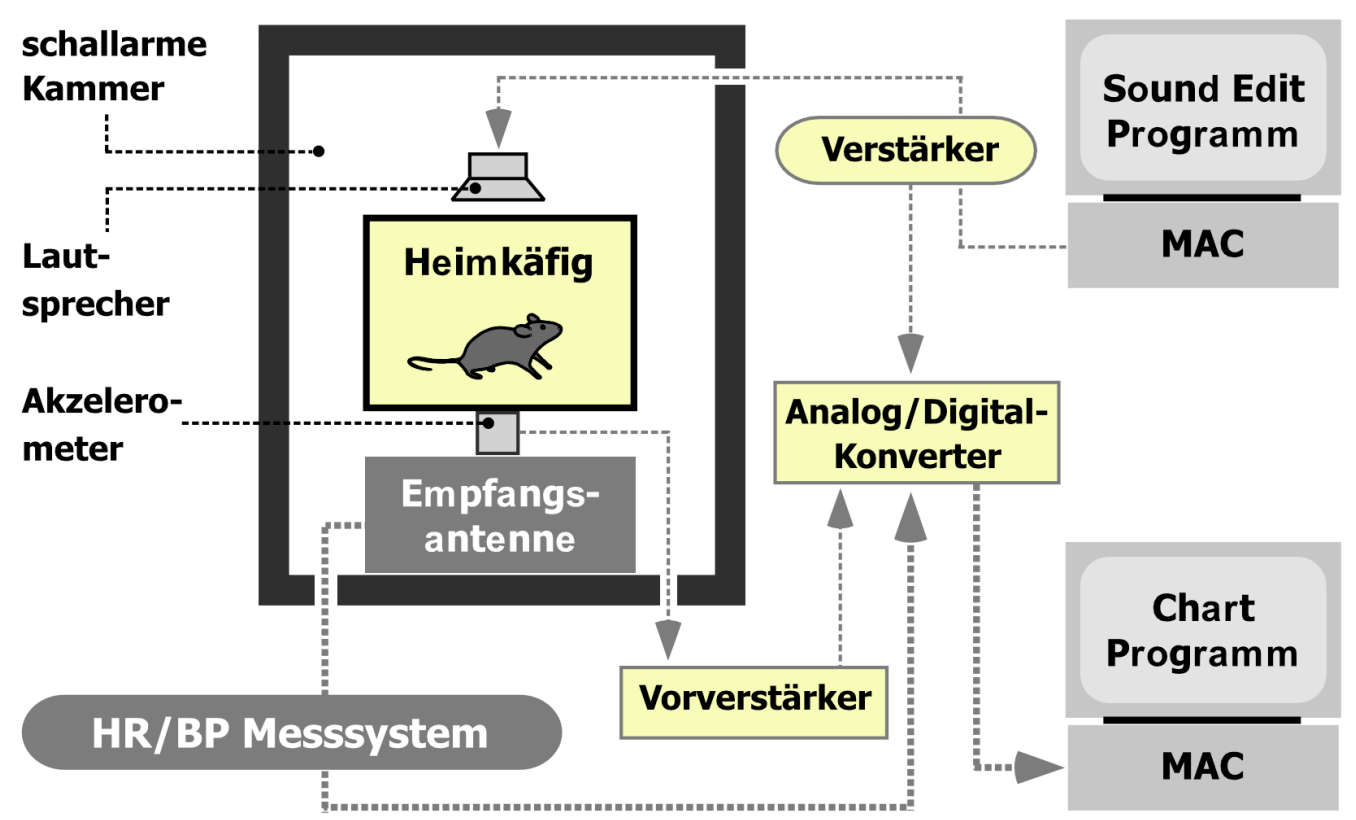

Abb. 2.16: Aufbau der StartleApparatur. Startle-Signale waren weißes Rauschen von 110 dB SPL Intensität, 20 ms Dauer und mit $1 \mathrm{~ms}$ an- und absteigenden Flanken.

Akkzelerometer (Type 8307, Brüel \& Kjær, Bremen) angebracht, das an einen Differenzverstärker (Type 2635, Brüel \& Kjær, Bremen) angeschlossen wurde. Über einen in der Box installierten Lautsprecher (Tonsil GTC 12-19/100, Conrad, Hirschau) wurden dann die computergenerierten (SoundEdit ${ }^{\mathrm{TM}} 16$ V. 2G, MacroMedia, San Francisco, USA) und verstärkten (HiFi-Verstärker, Pioneer, Willich) definierten akustischen Reize (weißes Rauschen, 110 dB, 20 ms Dauer, 2 ms Flanke) abgespielt (Abb. 2.17), während der Blutdruck telemetrisch gemessen wurde (s. Kap. 2.5.3). Das Hintergrundrauschen lag im Bereich der Hörschwelle der Mäuse, die bei einer Frequenz von 10-14 kHz etwa 35 dB SPL beträgt (Shnerson \& Pujol, 1982). Signale des Beschleunigungsaufnehmers, des Schallgenerators und des Blutdrucksenders wurden von einem Macintosh-basierten Computersystem (MacLab $4 \mathrm{~s}$, 
ADInstruments, Spechbach) aufgenommen und später mit entsprechender Software (Chart 5.0, HRV Erweiterung, ADInstruments, Spechbach) analysiert. Im Startle-Test wurden jeweils fünf Startle-Signale im Abstand von 1 min präsentiert. Die Messungen begannen eine Minute vor Beginn des ersten Stimulus und endeten 5 min nach dem letzten Startle-Stimulus.

Abb. 2.17: Power-Spektrum des Startle-Signals (blau) und des Hintergrundrauschens (rot).

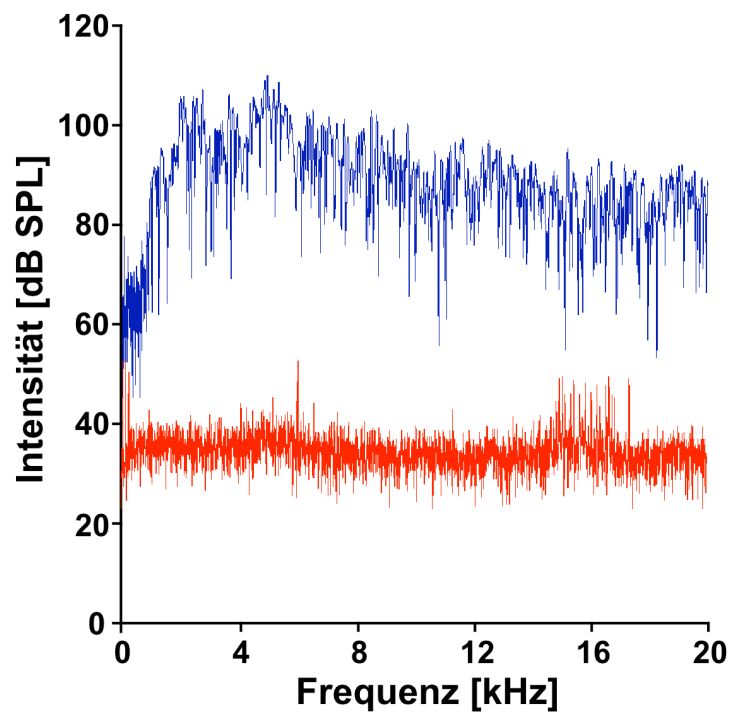

\subsection{Geruchsexperimente}

Um die Effekte unkonditionierter olfaktorischer Stimuli auf die Herzratendynamik zu ermitteln, wurden den Versuchsmäusen verschiedene Gerüche präsentiert. Als Geruchsstoff mit potentiell aversiven Eigenschaften diente 2,5-Dihydro-2,4,5-trimethyl-Thiazolidin (TMT, Pherotech, Delta, Kanada), ein synthetisch hergestellter Stoff, der ursprünglich aus den Analdrüsensekret des Fuchses gewonnen wurde. TMT wird in der Forstwirtschaft zur Reduktion von Baumschäden durch Wild genutzt. Als ebenfalls intensiv riechende Kontrollsubstanz wurde Butansäure (Buttersäure) verwendet.

\subsubsection{Aufbau und Kalibrierung des Systems}

Erneut fanden die EKG-Messungen im Heimkäfig der Mäuse statt. Dieser wurde in einem vom Haltungsbereich abgetrennten Raum auf einem Tisch von einer Plexiglaskammer (52 cm x $32 \mathrm{~cm}$ x $32 \mathrm{~cm}$, Länge x Breite x Höhe) mit Gummidichtlippe umschlossen, an die im unteren Bereich der Stirnseite ein Zuluftschlauch $(\varnothing=50 \mathrm{~mm})$ sowie im gegenüberliegenden Bereich der Dachseite ein Abluftschlauch $(\varnothing=60 \mathrm{~mm})$ angeschlossen wurde (Abb. 2.18). In dem angrenzenden Raum befand sich die Geruchsproduktionskammer, von der aus über den Zuluftschlauch die olfaktorischen Stimuli kontrolliert wurden. Die 
flüssigen Duftstoffe wurden mit einer Pipette auf ein Filterpapierstück in der Geruchskammer getropft. Mittels eines eingebauten Ventilators wurde dann ein kontinuierlicher Luftstrom über den Zuluftschlauch zur Plexiglaskammer erzeugt. Um den Versuchsmäusen eine etwa gleiche Anzahl von Molekülen der zu vergleichenden Duftsubstanzen zu präsentieren, war es notwendig, die Versuchsapparatur zu kalibrieren. Dazu wurden zunächst etwa $10 \mathrm{~g}$ pulverisierte Aktivkohle in einer Petrischale genau abgewogen. Nach luftdichtem Transfer bis zu den Versuchsräumen wurde diese dann in einem Mauskäfig inkl. Einstreu, jedoch ohne Maus innerhalb der Plexiglasumkammerung platziert. Nun wurden definierte Volumina der zu testenden Substanzen (Reinstoffe) in die Geruchskammer eingetropft. Nach 15 min wurde die Aktivkohle entnommen und erneut genau abgewogen. Über die Gewichtsdifferenz und die bekannte Molmasse der Duftstoffe (TMT: $129.2 \mathrm{~g} / \mathrm{mol}$; Buttersäure: $80.1 \mathrm{~g} / \mathrm{mol}$ ) konnte dann die Anzahl der von der Kohle absorbierten Moleküle errechnet werden. Dabei ergab sich, dass ein im Vergleich zu TMT etwa dreifaches Volumen der Kontrollsubstanz Butansäure eingesetzt werden musste, um äquivalente Mengen an absorbierten Molekülen zu erreichen.

\section{Geruchskammer (im "Geruchsproduktionsraum")}

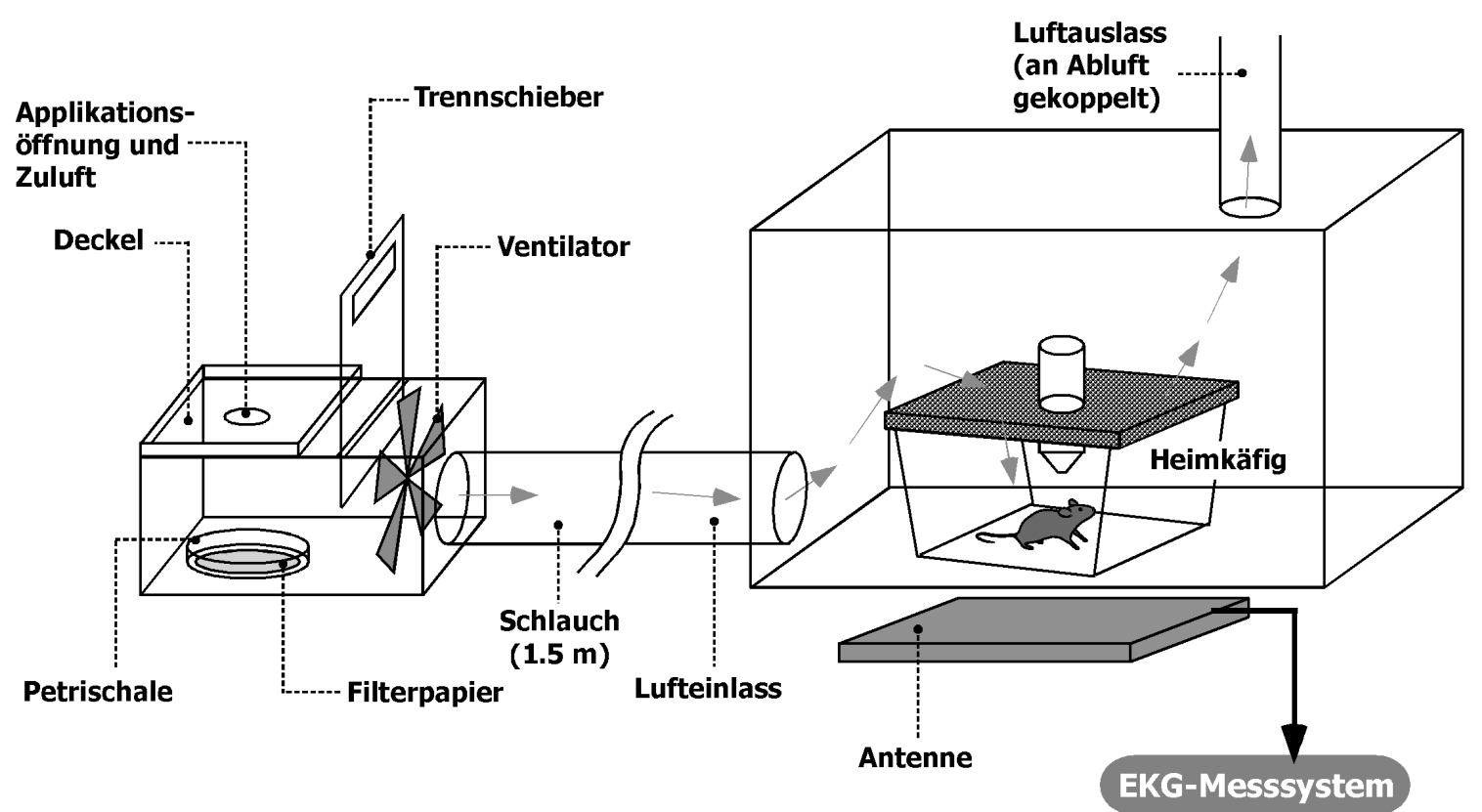

Abb. 2.18: Aufbau der Versuchsapparatur für olfaktorische Stimulation und EKG-Messung. Die Produktion der intensiv riechenden Duftstoffe und die Herzraten-Messungen fanden in getrennten Räumen statt.
Testbox

(im EKG-Messraum)

EKG-Messsystem 


\subsubsection{Herzratenmessungen während olfaktorischer Stimulation}

Zur Habituierung an die Testumgebung wurde das Versuchstier mit eingeschaltetem EKG-Transmitter einen Tag vor Versuchsbeginn in seinem Heimkäfig in die Plexiglasumkammerung gestellt und die Ventilation eingeschaltet (Abb. 2.18). Der Geruchstest begann mit einer dreiminütigen Messung der basalen Herzrate, bevor dann die Testsubstanz eingetropft wurde. Nach zwei Minuten wurde die Petrischale mit Filterpapier entfernt. Danach wurden die EKG-Signale noch weitere 15 min lang aufgezeichnet. Nach einer Unterbrechung der Versuche bei gleichzeitiger Ventilation des Systems ohne Duftstoff von etwa 2 h wurde ein zweiter Geruchstest durchgeführt.

\subsection{Hormonbestimmungen}

Um den Effekt der Furchtkonditionierung auf die Aktivierung der HypothalamusHypophysen-Nebennieren (HHN)- Achse zu ermitteln, wurde die Konzentration von Kortikosteron im Blutplasma furchtkonditionierter C57BL/6N-Mäuse und CRFR1-defizienter Mäuse gemessen.

\subsubsection{Blutplasmaisolation}

In der Standard-Trainingsprozedur wurden den Mäusen eine Sequenz von direkt aufeinander folgendem Ton (CS) und Fußschock (US) präsentiert, die zur aversiven Assoziation von CS mit US führte (CS+US). Alternativ wurde nur der Ton ohne Elektroschock präsentiert, was keine aversive Assoziation zur Folge hatte (kein US). Am Tag darauf wurde den Mäusen im Ton abhängigen Gedächtnistest der CS für 180 s präsentiert, bevor jeweils nach 5, 15 bzw. 90 min die Tiere innerhalb von $30 \mathrm{~s}$ mit Isofluran narkotisiert, dekapitiert und das aus dem Rumpf austretende Blut gesammelt wurde. Als Kontrollgruppen für basale und CSinduzierte Werte dienten zum einen naive Mäuse sowie Mäuse, die keinen US im Training erfahren hatten. Eine weitere Kontrollgruppe für den Vergleich der durch das aversive Ereignis (Fußschock im Training) bzw. die Erinnerung an das Ereignis verursachten Veränderungen des Kortikosteronspiegels bildeten Mäuse, denen Blut 15 min nach dem Training entnommen wurde. Zusätzlich wurden die Kortikosteronkonzentrationen $\mathrm{CRF}_{1^{-}}$ 
defizienter Mäuse und ihrer Wildtyp-Wurfgeschwister im naiven Zustand und 15 min nach dem Gedächtnistest ermittelt.

Das gesammelte Blut wurde in auf Eis gelagerte $1.5 \mathrm{ml}$ Eppendorfcups getropft, die $5 \mu \mathrm{l}$ 0.5 M Na-EDTA-Lösung enthielten, und mit einem Plastikplümper gemischt. Auf diese Weise wurden etwa 300 bis $600 \mu 1$ Blut pro Versuchstier gewonnen. Nach Beendigung der Blutprobengewinnung wurden die Proben mit $3000 \mathrm{U} / \mathrm{m}$ für $15 \mathrm{~min}$ bei $4^{\circ} \mathrm{C}$ zentrifugiert (Allegra $^{\mathrm{TM}}$ 6R, Beckmann, München). Aus dem Überstand wurden dann erst $50 \mu 1$ Blutplasma, dann $150 \mu \mathrm{l}$ abpipettiert und in Eppendorfcups bei $-80^{\circ} \mathrm{C}$ gelagert.

\subsubsection{Kortikosteronbestimmung}

Mit Hilfe eines kompetetiven Radioimmunoassays (ICN, Costa Mesa, USA) erfolgte die Analyse der Kortikosteron-Konzentrationen im Blutplasma. Dabei konkurrierte mit ${ }^{125} \mathrm{I}$ radioaktiv markiertes Kortikosteron mit dem in der Blutplasma-Probe befindlichen Kortikosteron um die Bindung an einen selektiven Antikörper. Der sich dabei bildende Komplex wurde ausgefällt und die Radioaktivität in einem Radioaktivitäts-Messgerät für $\gamma$ Strahlung (Wallac 1470 Wizard $^{\mathrm{TM}}$, Turku, Finnland) gemessen. Über die sich aus den mitgelieferten Eichstandards ergebende Kalibrierkurve konnten die Probenwerte mit einer Punkt-für-Punkt Approximation berechnet werden.

\subsection{Statistik}

Die statistische Analyse erfolgte mit entsprechender Software (StatView 5.0, SAS Institute, Cary, North Carolina, USA) und bei Herzratenverläufen immer mit ANOVA für repetitive Messungen, sonst mit ANOVA. Die post hoc Analyse wurde immer mit Fisher's Protected Least Significant Difference (PLSD) durchgeführt. Der Vergleich der Regressionskoeffizienten von berechneten Regressionsgeraden erfolgte nach Sachs (1974). Berechnungen von Halbwertszeiten der HR- und MAP-Anstiege und der Kalibrierkurven bei Hormonanalysen erfolgten mit Hilfe von GraphPad Prism 3.0cx (GraphPad Inc., San Diego, USA). 


\subsection{Zeitliche Abfolge der operativen Eingriffe und Experimente}

Die Abfolge der Operationen und Experimente unterlag einem standardisierten Zeitplan (Abb. 2.2). Nach erfolgter EKG-Transmitter- bzw. Hirnkanülen-Implantation hatten die Versuchstiere entsprechende Regenerationszeiten zur Wundheilung. EKG-Messungen von Mäusen im Heimkäfig wurden sowohl unter stressfreien Bedingungen als auch im Rahmen des tonabhängigen Gedächtnistests nach vorheriger Furchtkonditionierung durchgeführt. Die EKG-Transmitter wurden nach beendeten Experimenten explantiert, überarbeitet, sterilisiert und dann erneut implantiert. 


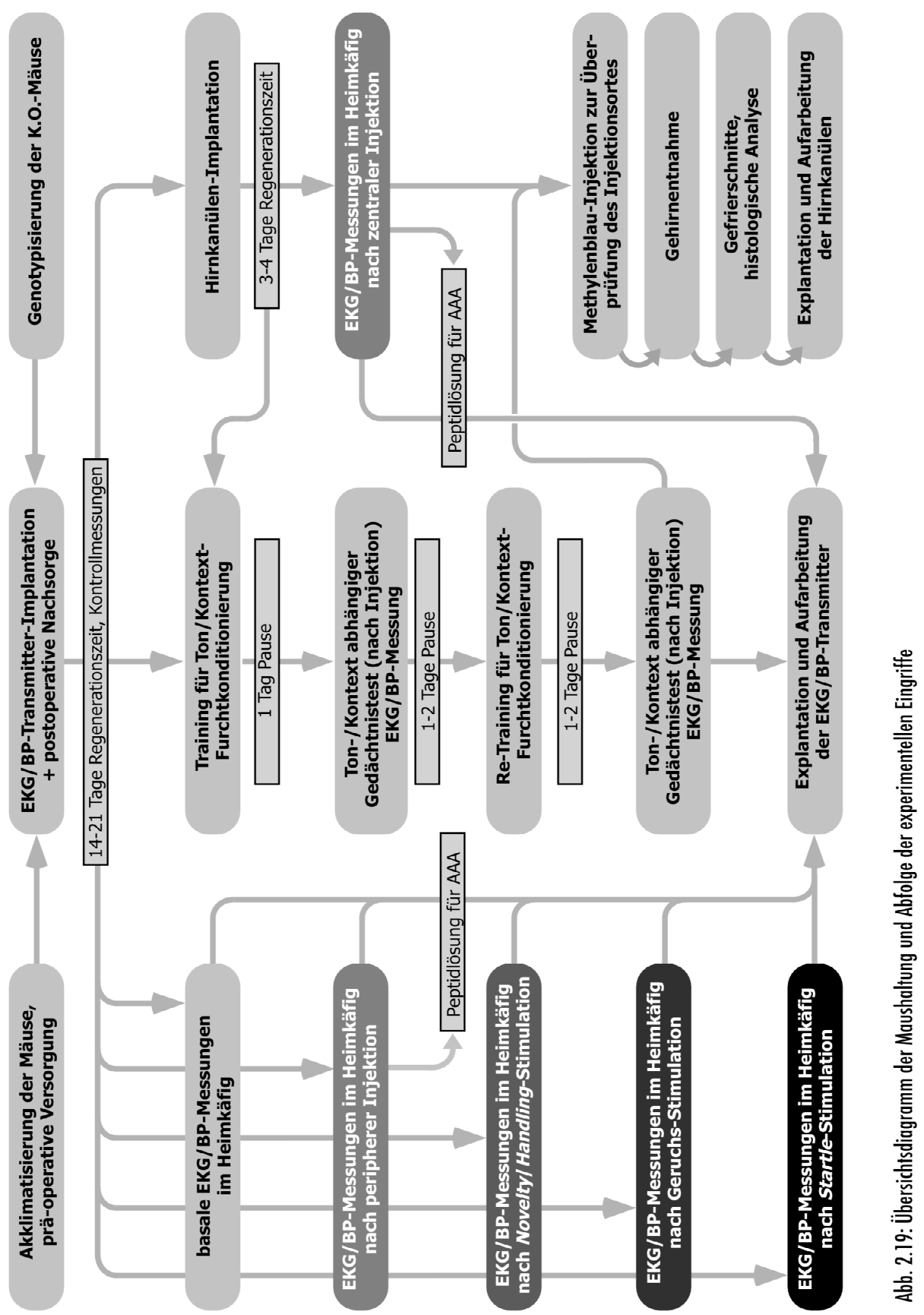




\section{Ergebnisse}

\subsection{Allgemeiner Vergleich der Herzraten- und Blutdruckdaten}

Grundlage der kardiovaskulären Analysen bildeten die telemetrisch kontinuierlich mit $4 \mathrm{kHz}$ Abtastrate aufgezeichneten Rohdaten: die subkutan abgeleiteten, durch den Erregungszyklus des Herzens verursachten bioelektrischen Fluktuationen des Elektrokardiogramms (EKG) und die Fluktuationen des Blutdrucks innerhalb der abdominalen Aorta. Störungen des EKGSignals durch Bewegung des Tieres oder Signalverlust waren als solche klar zu erkennen und konnten bei der Analyse editiert werden. Bei den Blutdruckrohdaten konnten neben den sehr schnellen, periodisch durch die Herzkontraktionsabfolge bedingten Blutdruckschwankungen von Diastole zu Systole auch nichtperiodische Schwankungen im Millisekunden- oder auch im Sekundenbereich beobachtet werden (Abb. 3.1). Die hochfrequenten Schwankungen konnten die korrekte Ermittlung des Blutdrucks und somit auch der Herzrate erheblich beeinträchtigen, da neben Diastole und Systole zusätzliche Minima bzw. Maxima auftraten (Abb. 3.1B). Solche Bereiche gestörter Signale wurden von der Blutdruckanalyse ausgeschlossen, bzw. für die

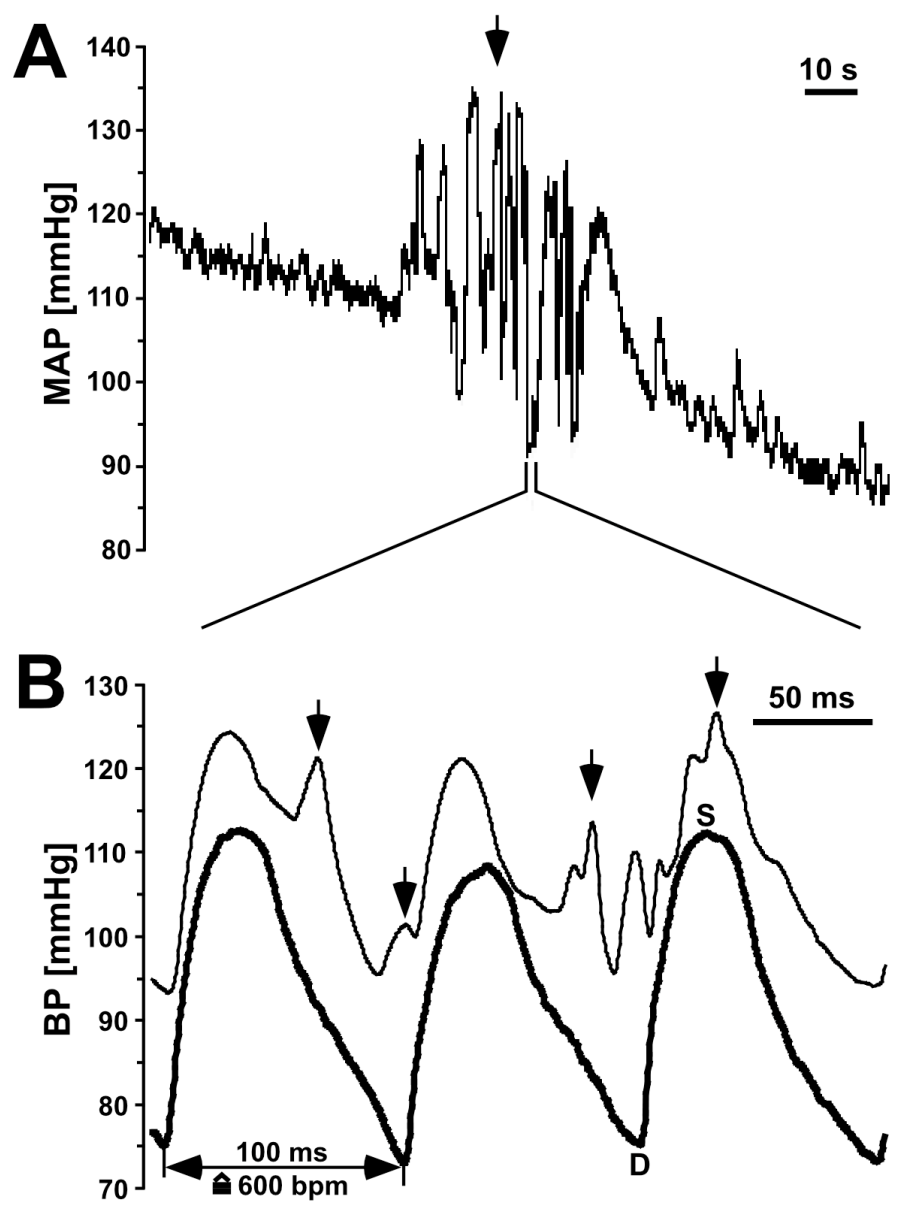

Abb. 3.1: Störungen/Messartefakte (Pfeile) des Blutdrucksignals im Sekunden- (A) und Millisekundenbereich (B). Im instantanen MAP-Verlauf (A) sind Bereiche mit großen Amplitudenschwankungen sichtbar (Pfeil), die bei höherer zeitlicher Auflösung als bewegungsinduzierte Messstörungen erkennbar sind (Pfeile). Zum Vergleich ist ein normales Signal (B, dicke Linie) dargestellt, bei dem die Berechnung der Herzrate (HR)

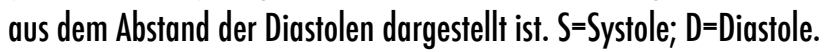

Herzratenanalyse editiert. Die niederfrequenteren Fluktuationen blieben im mittleren arteriellen Blutdruck (MAP), der Grundlage der Blutdruckanalysen war, sichtbar. Diese 
konnten im mittleren Blutdruck Differenzen von über $10 \mathrm{mmHg}$ aufweisen. Meist korrelierten diese Störungen des Blutdrucksignals mit lokomotorischer Aktivität des freibeweglichen Tieres. Im narkotisierten Tier waren solche schnellen Änderungen nicht zu beobachten. Durch Körperrotationen (Lateralbewegungen) verursachte mechanische Kräfte, die direkt auf das notwendigerweise flexible Material des Katheters einwirkten und von dem empfindlichen Drucksensor erfasst wurden, können demnach das Blutdrucksignal beeinflussen. Allerdings wird der Blutdruck auch durch Lokomotion mit einhergehender sympathischer Aktivierung und gesteigerter Herzleistung verändert. Eine eindeutige Identifizierung der schnellen Schwankungen des mittleren arteriellen Blutdrucks als Bewegungsartefakte war dennoch meist möglich. Durch die Mittelwertbildung über längere Intervalle und größere Gruppen wurden schnelle Schwankungen, die zuvor nicht ausgeschlossen werden konnten, ausnivelliert.

\subsection{Zirkadiane Fluktuation von Herzrate und Blutdruck in freibeweglichen Mäusen}

Zur Validierung der Methode der telemetrischen intra-aortalen Blutdruck- und Herzratenmessung und zur Ermittlung des basalen Dynamikbereich der kardiovaskulären Parameter, wurden HR und MAP bei ungestörten, freibeweglichen C57BL/6N Mäusen im zirkadianen Verlauf gemessen.

In Abb. 3.2A sind die Fluktuationen von HR und MAP im Tagesverlauf dargestellt. In der Lichtphase von 7 bis 19 Uhr, der Schlaf-

Abb. 3.2: Zirkadiane Fluktuationen von Herzrate (HR) und mittlerem arteriellem Blutdruck (MAP) bei freibeweglichen (57BL/6N-Mäusen (A). Mittelwerte während der Licht- (L) und Dunkel- (D) Phase (B).

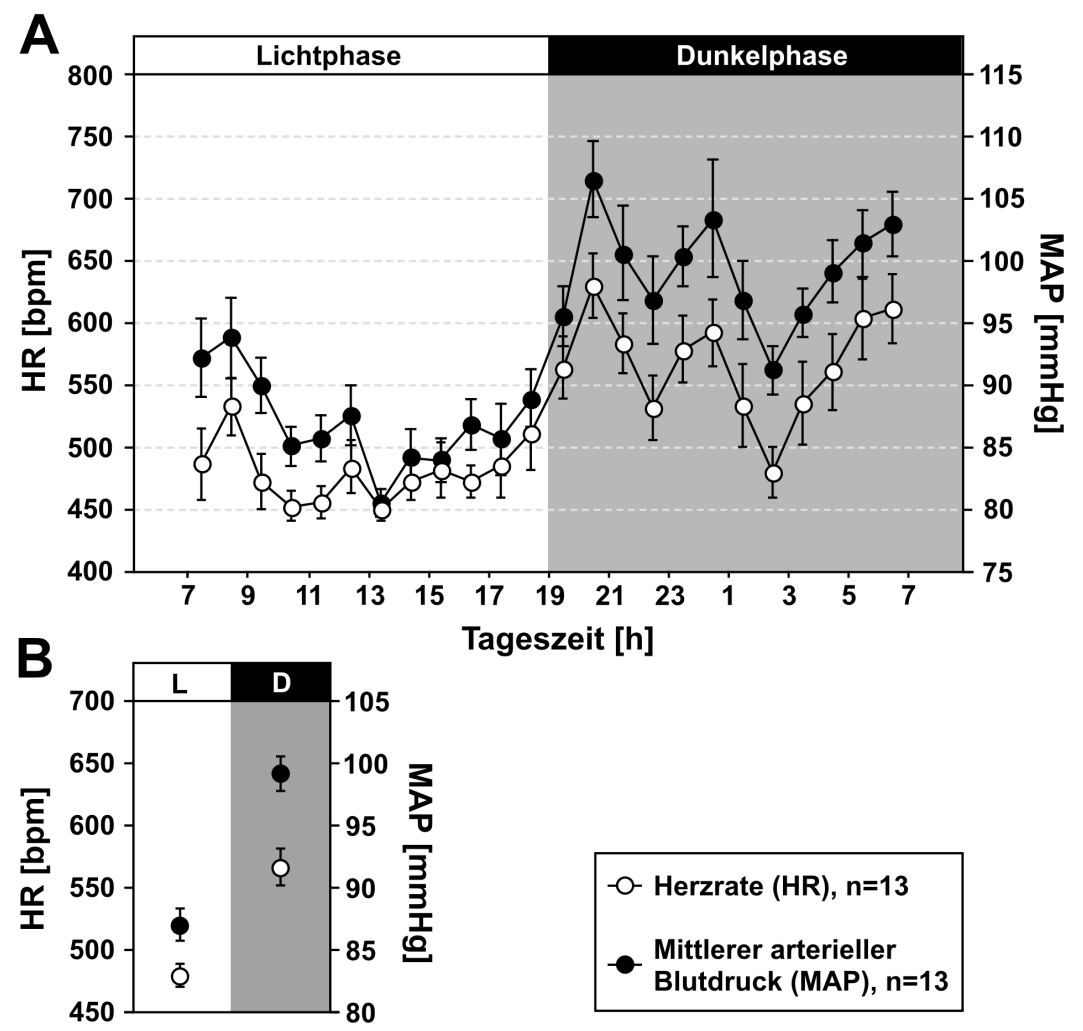


phase der nachtaktiven Mäuse, lagen HR und MAP im unteren Bereich physiologischer Werte. In der Dunkelphase von 19 bis 7 Uhr, der Wachphase der Mäuse, waren HR $(567 \pm 15 \mathrm{bpm})$ und MAP $(99 \pm 1.5 \mathrm{mmHg})$ gegenüber den Werten der Lichtphase (HR: $F_{1,24}=23.20, \mathrm{p}<0.001$; MAP: $\left.F_{1,24}=43.46, \mathrm{p}<0.001\right)$ signifikant erhöht.

\subsection{Kardiovaskuläre Expression von Emotionalität in verschiedenen Ver- haltenstests}

In verschiedenen Experimenten wurden die Effekte unkonditionierter bzw. konditionierter Stimuli auf die Dynamik von Herzraten- und Blutdruckänderungen sowie die lokomotorische Aktivität untersucht.

\subsubsection{Herzrateneffekte infolge Handling}

Viele Verhaltenstests finden aufgrund der speziellen experimentellen Bedingungen außerhalb des Heimkäfigs der Versuchstiere statt. Diese Tests verlangen somit manuelles Interferieren (sog. Handling) mit dem Versuchstier. Typischerweise wird dabei zunächst der Käfig in den Versuchsraum transferiert, geöffnet, das Versuchstier entnommen und in das Testsystem eingesetzt. Dabei kann es je nach beobachtetem Parameter zu erheblichen Beeinträchtigungen der basalen Werte und dem normalerweise stressfreien Zustand kommen, die das Testergebnis nachhaltig beeinflussen können.

Um die Auswirkung manueller Intervention auf die Herzrate zu untersuchen, wurden die Mäuse einer Handling-Prozedur unterzogen, die in einem kurzen Anheben am Schwanz und dem darauf folgenden Absetzen in den Heimkäfig bestand. Abb. 3.3 zeigt die Entwicklung der HR nach Beendigung des Handlings in einem Zeitfenster von $32 \mathrm{~min}$. Zum Vergleich ist der Herzratenverlauf ungestörter Mäuse ebenfalls dargestellt. Die beiden HRVerläufe unterschieden sich signifikant voneinander $\left(F_{1,14}=26.27, \mathrm{p}<0.001\right)$. Eine initiale Tachykardie von $\sim 730$ bpm wurde in der Handling-Gruppe festgestellt, die sich über die analysierten 32 min hinweg nahezu linear abschwächte. Die Halbwertszeit der Rückkehr zu basalen HR-Werten $\left(\mathrm{T}_{1 / 2}\right)$ lag bei $~ 15$ min. Die HR der ungestörten Mäuse blieb dagegen relativ stabil bei $\sim 520 \mathrm{bpm}$. 


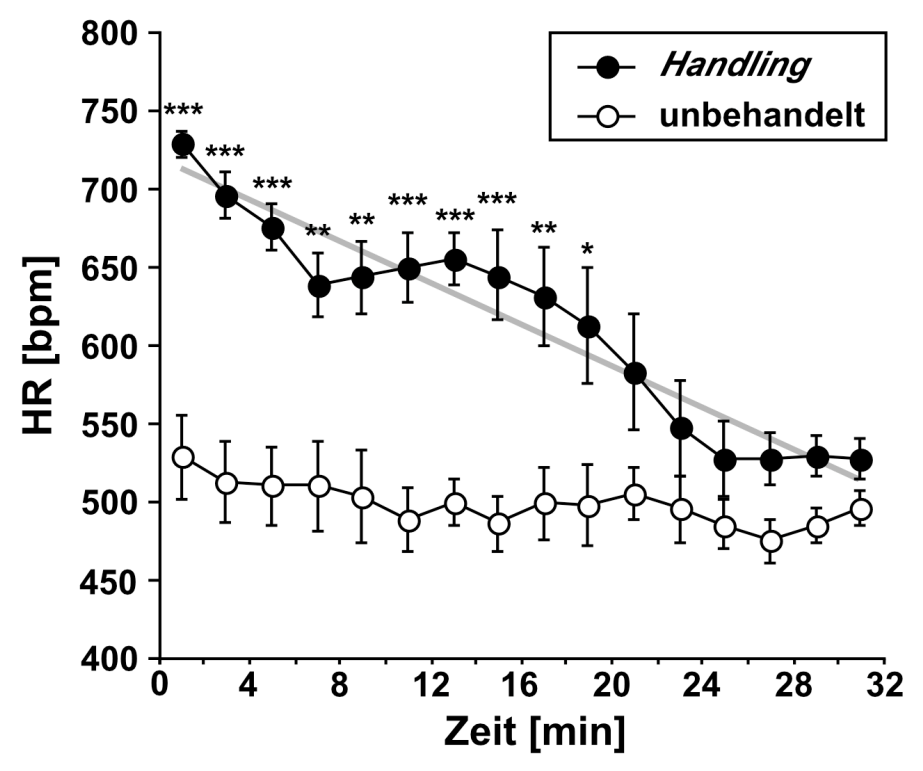

Abb. 3.3: Herzraten-Verläufe unbehandelter C57BL/6N-Mäuse und nach kurzer manueller Intervention (Handling) für 32 min im Heimkäfig. Signifikant unterschiedliche Werte ergaben sich von 0-20 min. Die grave Linie verdeutlicht den nahezu linearen Abfall $(r=0.92)$ der Herzrate bis auf basale Werte. ${ }^{\star} p<0.05,{ }^{* \star} p<0.01$, ${ }^{\star \star \star} p<0.001 ; n=9 /$ Gruppe.

\subsubsection{Herzrate im Novelty-Test}

Auch eine im Verhaltenstest präsentierte neue Umgebung (Novelty) kann sich auf die autonome Funktion auswirken. Daher wurden die Effekte von Novelty-Exponierung auf die kardiovaskulären Parameter untersucht. Dazu wurden die Mäuse aus ihrem Heimkäfig in einen neuen identischen Käfig mit neuem Einstreu gesetzt. Zusätzlich wurde entweder ein Teil des alten, aus zerissenem Zellstofftuch bestehenden Nestmaterials (bedding) oder neues Zellstofftuch mit hinzugegeben. In einem weiteren Experiment wurde dem Tier kein Zellstoff angeboten. So wurden in dem ersten Fall partielle, im zweiten und dritten Fall komplette Novelty-Bedingungen geschaffen. Bei allen Mäusen wurde intensives Explorationsverhalten (= erhöhte lokomotorische Aktivität) beobachtet. Abb. 3.4 zeigt basale HR-Werte und deren Verlauf von zwei Stunden in der neuen Umgebung. Ein massiver Anstieg der HR bis in den Bereich physiologisch maximaler Werte ( 780 bpm) wurde sowohl bei Mäusen mit altem als auch bei Mäusen mit neuem oder keinem Nestmaterial direkt nach Einsetzen in die neue Umgebung festgestellt. Unabhängig von der Art des Nestmaterials verblieb die HR relativ lange Zeit (ca. $60 \mathrm{~min}$ ) auf hohem Niveau und fiel dann langsam wieder ab. Bei Mäusen denen das vertraute Nestmaterial mitgegeben worden war, konnte ab etwa 60 min nach Einsetzen in die neue Umgebung eine signifikant schnellere Rückkehr der HR zu basalen Werten festgestellt werden, als bei Mäusen, die neues $\left(F_{1,7}=14.12, \mathrm{p}<0.01\right)$ bzw. kein Nestmaterial $\left(F_{1,9}=11.40, \mathrm{p}<0.01\right)$ zur Verfügung hatten. 


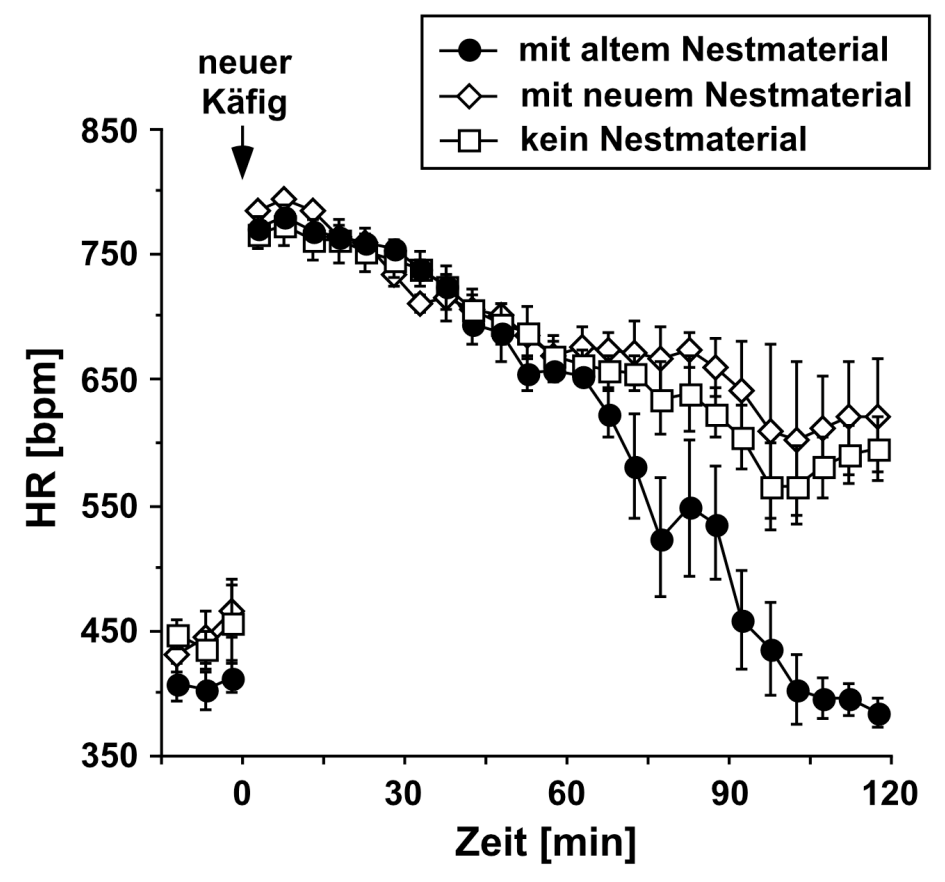

Abb. 3.4: Herzratenverläufe von C57BL/6NMäusen vor und während Novelty mit unterschiedlichem Nestmaterial. Bin-Weite 5 min bei kontinuierlichen Messungen. Mittelwerte \pm SF, $\mathrm{n}=4-6$ pro Gruppe.

\subsubsection{Effekte olfaktorischer Reize auf die Herzrate}

Die Auswirkungen der Präsentation synthetischer Geruchsstoffe auf die Herzrate ansonsten ungestörter Mäuse wurden im Heimkäfig untersucht. Es wurde erwartet, dass die den Fuchsgeruch imitierende Substanz TMT einen aktivierenden kardiovaskulären Effekt auslösen würde, der in einer Herzratenzunahme sichtbar würde. Als Kontrollgeruch diente Butansäure (Hotsenpiller \& Williams, 1997), der hingegen keine Auswirkungen auf die mittlere Herzrate haben sollte.

Nach Applikation von $100 \mu 1$ wurden keine signifikanten Auswirkungen auf den Verlauf der HR, die bei basalen Werten von $\sim 500 \mathrm{bpm}$ lag ermittelt (Abb. 3.5A). Eine minimale Beschleunigung der basalen HR um 25 bpm im Zeitraum von 1.5-2.5 min nach Eintropfen der Substanz wurde ermittelt (Abb. 3.5B). Eine Menge von $100 \mu 1$ 99\%-igem Ethanol verursachte einen ebenfalls geringen Anstieg der Herzrate um 40 bpm im Zeitraum von 1.5-2.5 min nach dem Eintropfen. Die Herzratenanstiege $(\Delta H R)$ wie auch die Herzratenverläufe von Mäusen, denen Butansäure- oder Ethanolgeruch präsentiert wurde, unterschieden sich nicht signifikant $\left(\Delta \mathrm{HR}: F_{1,16}=0.62, \mathrm{p}=0.44\right.$; HR-Verlauf: $F_{1,16}<0.01$, $\mathrm{p}=0.99)$. Im Unterschied zur Applikation von Butansäure resultierte die Applikation von $35 \mu 1$ TMT, einer Menge, die eine etwa gleiche Anzahl von Molekülen in der Gasphase der Apparatur erzeugte (s. Kap. 2.9.1), in einem signifikant höherem Anstieg der HR von 
$\sim 164 \mathrm{bpm}\left(F_{1,16}=10.22, \mathrm{p}<0.01\right)$ auf $\sim 650 \mathrm{bpm}$ und einem unterschiedlichen HR-Verlauf $\left(F_{1,16}=8.93, \mathrm{p}<0.01\right)$. Die Herzratenbeschleunigung begann zudem bereits 1 min nach der Applikation von TMT und somit schneller als bei Butansäure oder Ethanol. Erst etwa 45 min nach Ende der Applikation von TMT wurden wieder basale HR-Werte gemessen.

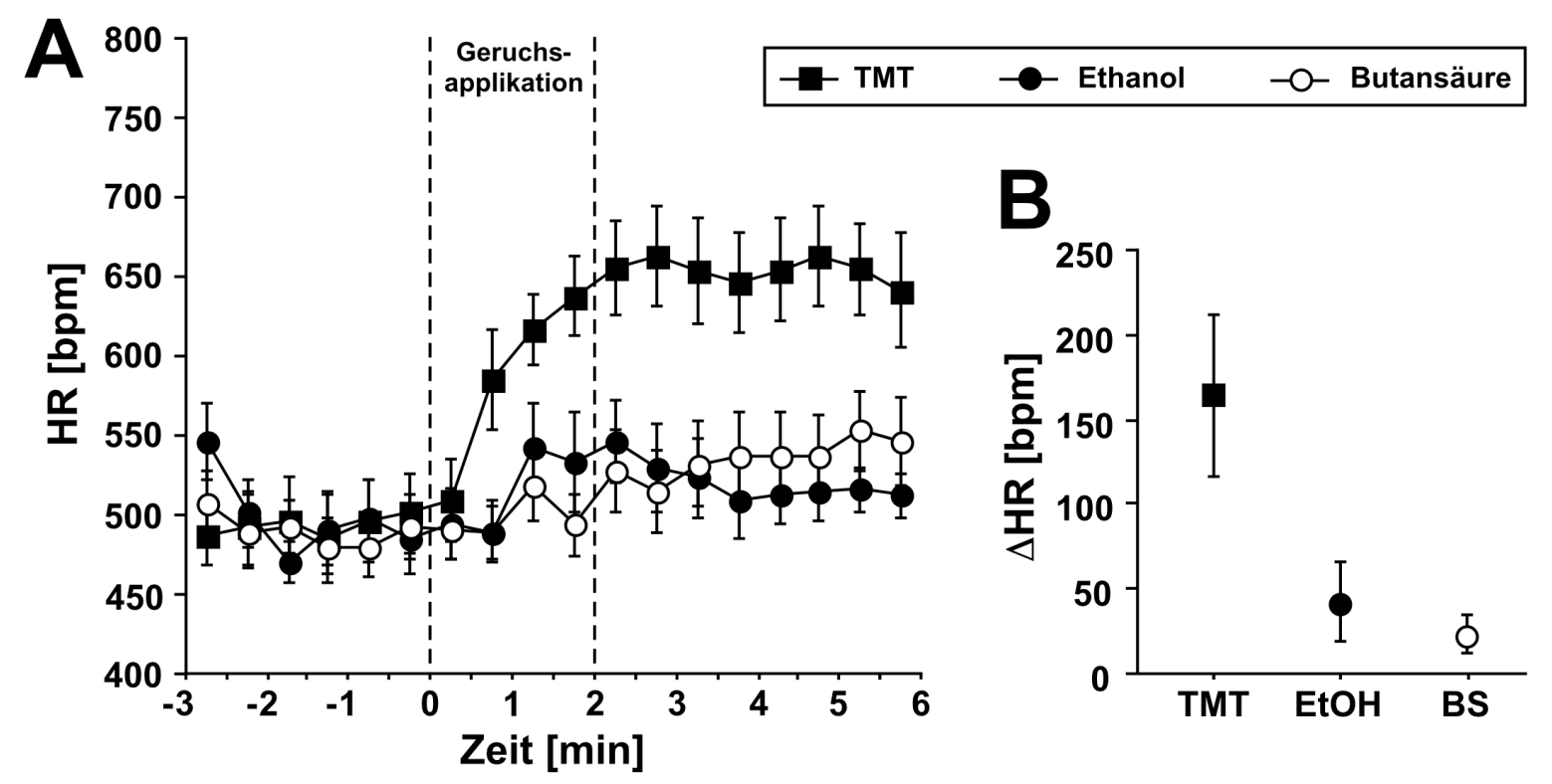

Abb. 3.5: Herzratenverläufe von C57BL/6N-Mäusen vor, während und nach der olfaktorischen Stimulation mit synthetischem

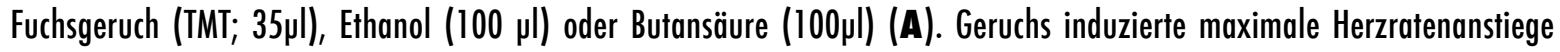
$(\triangle H R, B)$ Mittelwerte \pm SF; $\mathrm{n}=8-10$ pro Gruppe.

\subsubsection{Herzratendynamik und Verhaltensreaktionen in Kontext abhängigen Gedächtnistests}

Die Dynamik der Verhaltenseffekte sowie der Herzrate wurden im Gedächtnistest untersucht, nachdem die Versuchsmäuse zuvor einem aversiv konditionierten Kontext ausgesetzt worden waren. Drei experimentelle Gruppen wurden dabei unterschiedlichen Trainingssequenzen ausgesetzt (s. Kap. 2.8.3.1).

\section{Verhalten während Habituation und Training}

In den drei Exponierungsphasen in verschiedenen Kontexten, die dem eigentlichen Training vorausgingen und der Habitation an Handling und an unterschiedliche neutrale, unbekannte Umgebungen (Kontext 1-3) dienten, zeigten die Mäuse durchgängig arttypisches 
Explorationsverhalten mit typischen Schnüffel-, Such- und Ortungsbewegungen des Kopfes und der Ohren, Stretch-Attend-Bewegungen und Aufstellen auf den Hinterpfoten. Seltener wurden Furcht anzeigende Verhaltensmuster wie Freezing beobachtet.

Die Lokomotionsaktivität der Mäuse während des Trainings in Kontext 4 ist in Abb. 3.6A dargestellt. Während die mittlere Aktivität von Mäusen mit später US-Präsentation $\mathrm{US}_{l}$ ) und in der Kontrollgruppe, die keinen US erhalten hatte $\left(\mathrm{US}_{n}\right)$, bei $\sim 6 \mathrm{~cm} / \mathrm{s} \mathrm{lag}$, wurden bei Mäusen, die im Training einen sofortigen Schock erhalten hatten $\left(\mathrm{US}_{i}\right)$, mit $\sim 4 \mathrm{~cm} / \mathrm{s}$ signifikant niedrigere Aktivitätswerte ermittelt $(\mathrm{p}<0.05)$. Die durch den Fußschock ausgelöste erhöhte Aktivität $(\sim 24 \mathrm{~cm} / \mathrm{s})$ war zwischen der $\mathrm{US}_{l^{-}}$und $\mathrm{US}_{i}$-Gruppe ähnlich. Somit war die durch den US ausgelöste unmittelbare lokomotorische Reaktion unabhängig vom Zeitpunkt der Präsentation (Abb. 3.6B).

Abb. 3.6: Basale Lokomotionsaktivität (A) und US-Aktivität (B) im Konditionierungs-Kontext in den drei experimentellen Gruppen von C57BL/6J-Mäusen während des Trainings. Mittelwerte \pm SF aus 2-min Intervallen, $\mathrm{n}=9$ pro Gruppe.

${ }^{*} p<0.05$ US $_{i}$ Vs. US, und US ${ }_{n i}{ }^{* * *} p<0.001$ US $_{n}$ vs. US, und US $S_{i}$ US $S_{n}=$ Gruppe, die keinen US im Training erhielt. US $S_{i}=$ Gruppe, die den US im Training sofort erhielt. US = Gruppe, die den US im Training verzögert erhielt.

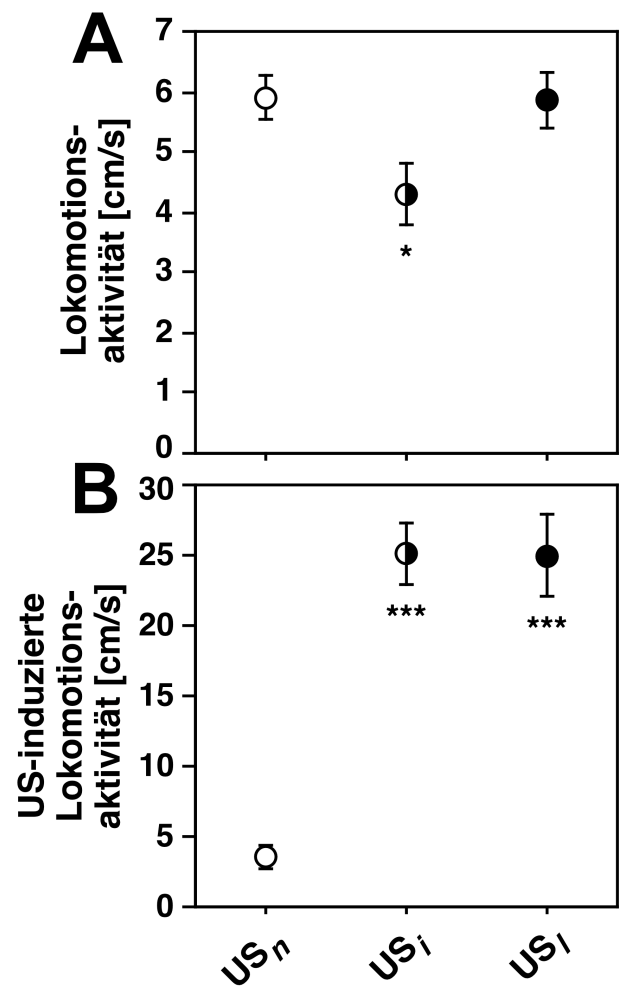

\section{Verhalten und Herzrate während des Kontext abhängigen Gedächtnistests}

Die relative Inaktivität während des kontextuellen Gedächtnistestes (Abb. 3.7A) in Kontext 4 war in der US $_{l}$-Gruppe im Vergleich zu den beiden anderen Kontrollgruppen $\left(\mathrm{US}_{i}\right.$, $\mathrm{US}_{n}$ ) signifikant erhöht $\left(\mathrm{US}_{n}: \mathrm{p}<0.02 ; \mathrm{US}_{i}: \mathrm{p}<0.01\right)$. Die Inaktivitätswerte in den Kontrollgruppen unterschieden sich nicht signifikant voneinander $(\mathrm{p}>0.27)$. Es wurde ersichtlich, dass die Assoziation des aversiven Stimulus, angezeigt durch höhere Inaktivität, nur dann erfolgte, wenn er zu einem späteren Zeitpunkt nach der Exposition im Kontext appliziert wurde. Die Ergebnisse hinsichtlich der Explorationsfläche von Mäusen im Kontext abhängigen Gedächtnistest spiegeln die Inaktivitäts-Ergebnisse wider. Hier war die von Mäusen der US,-Gruppe explorierte Fläche im Vergleich zu den anderen Gruppen signifikant geringer (Abb. 3.7B). 


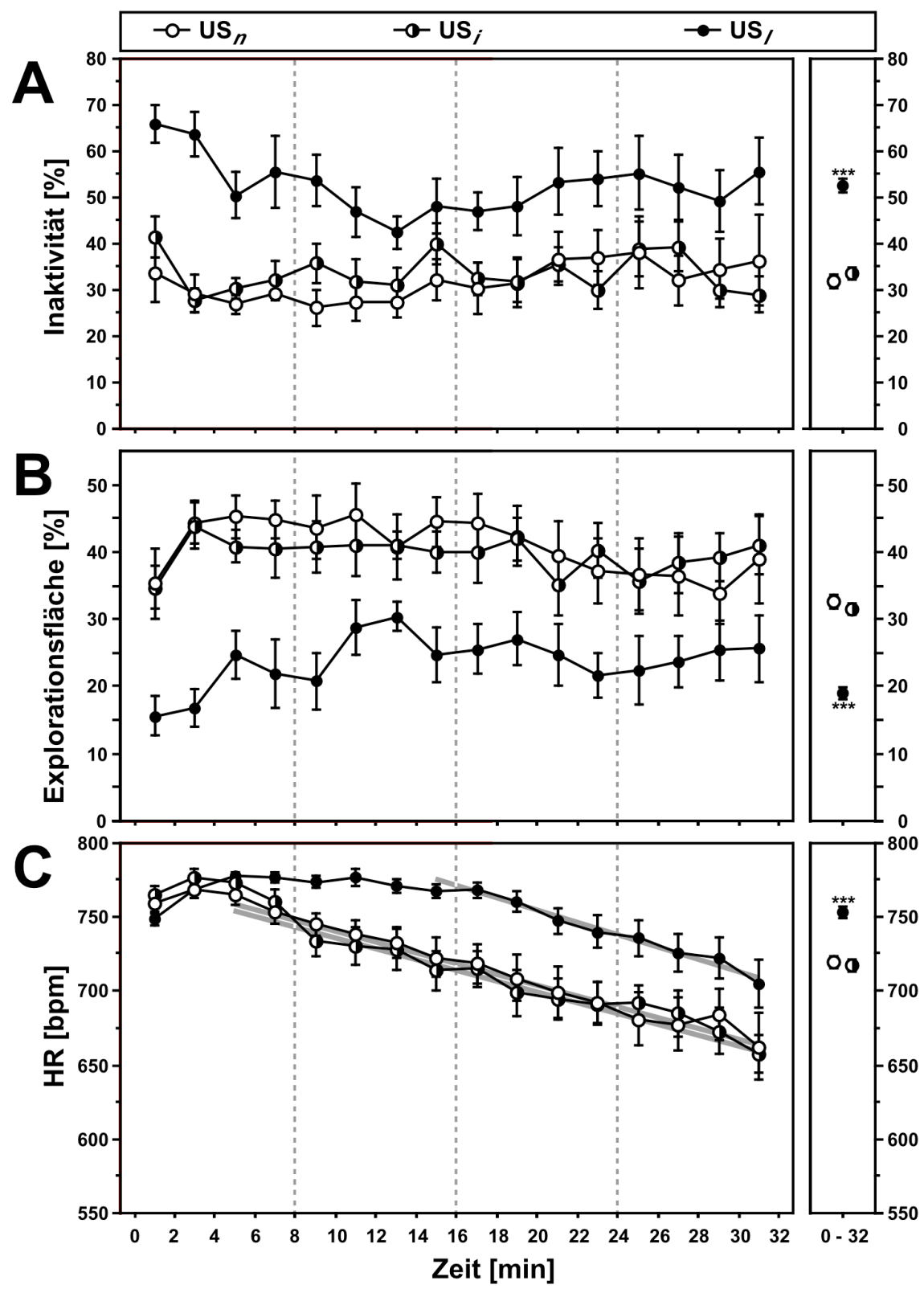

Abb. 3.7: Inaktivität (A), Explorationsfläche (B) und Herzrate (C) der drei experimentellen Gruppen von C57BL/6J-Mäusen während des Kontext abhängigen Gedächtnistestes. Mittelwerte \pm SF aus 2 min Intervallen $\mathrm{n}=9$ pro Gruppe. Die grauen Linien verdeutlichen den nahezu linearen Abfall der Herzraten bis auf basale Werte $\left(r \cup S_{n}=0.98, r U S_{i}=0.95, r U S_{n}=0.97\right)$.

${ }^{* \star *} p<0.01$ US F Gruppe vs. US $S_{n}$ und US, Gruppe. US ${ }_{n}=$ Gruppe, die keinen US im Training erhielt. US $=$ Gruppe, die den US im Training sofort erhielt. US F Gruppe, die den US im Training verzögert erhielt.

In allen drei Gruppen war zu Beginn des Tests im Konditionierungs-Kontext eine uniforme Beschleunigung der Herzrate bis hin zu physiologischen Maxima ( 770 bpm) ersichtlich (Abb. 3.7C). Während die Herzraten von Mäusen der beiden Kontrollgruppen $\left(\mathrm{US}_{i}, \mathrm{US}_{n}\right)$ jedoch bereits nach $\sim 5$ min wieder abzufallen begannen, blieben die Herzraten von Mäusen der US,-Gruppe etwa 15 min auf hohem Niveau und fielen danach langsam wieder auf basale Werte ab. Die Halbwertszeit der Rückkehr zu basalen HR-Werten war in den Kontrollgruppen mit $\sim 50$ min geringer als in der $\mathrm{US}_{l}$-Gruppe mit $\sim 60 \mathrm{~min}$ (Abb. 3.7C). Dieser 
unterschiedliche Herzratenverlauf in der $\mathrm{US}_{l}$-Gruppe bestätigt, dass die Mäuse den im Training erfahrenen aversiven Stimulus mit dem Kontext assoziierten.

\subsubsection{Herzrate und Blutdruck in Ton abhängigen Gedächtnistests}

Der charakteristische Verlauf der HR und des MAP einer Furcht konditionierten Maus im Ton abhängigen Gedächtnistest ist in Abb. 3.9 dargestellt. Dieser wurden zuvor im Training Ton-CS und Schock-US einmalig präsentiert. Auf Einsetzen des Tons (im Gedächtnistest) reagierte die Maus mit augenblicklicher Beschleunigung der Herzrate (Abb. 3.9A) und verzögerter, langsam ansteigender Blutdruckerhöhung (Abb. 3.9B).

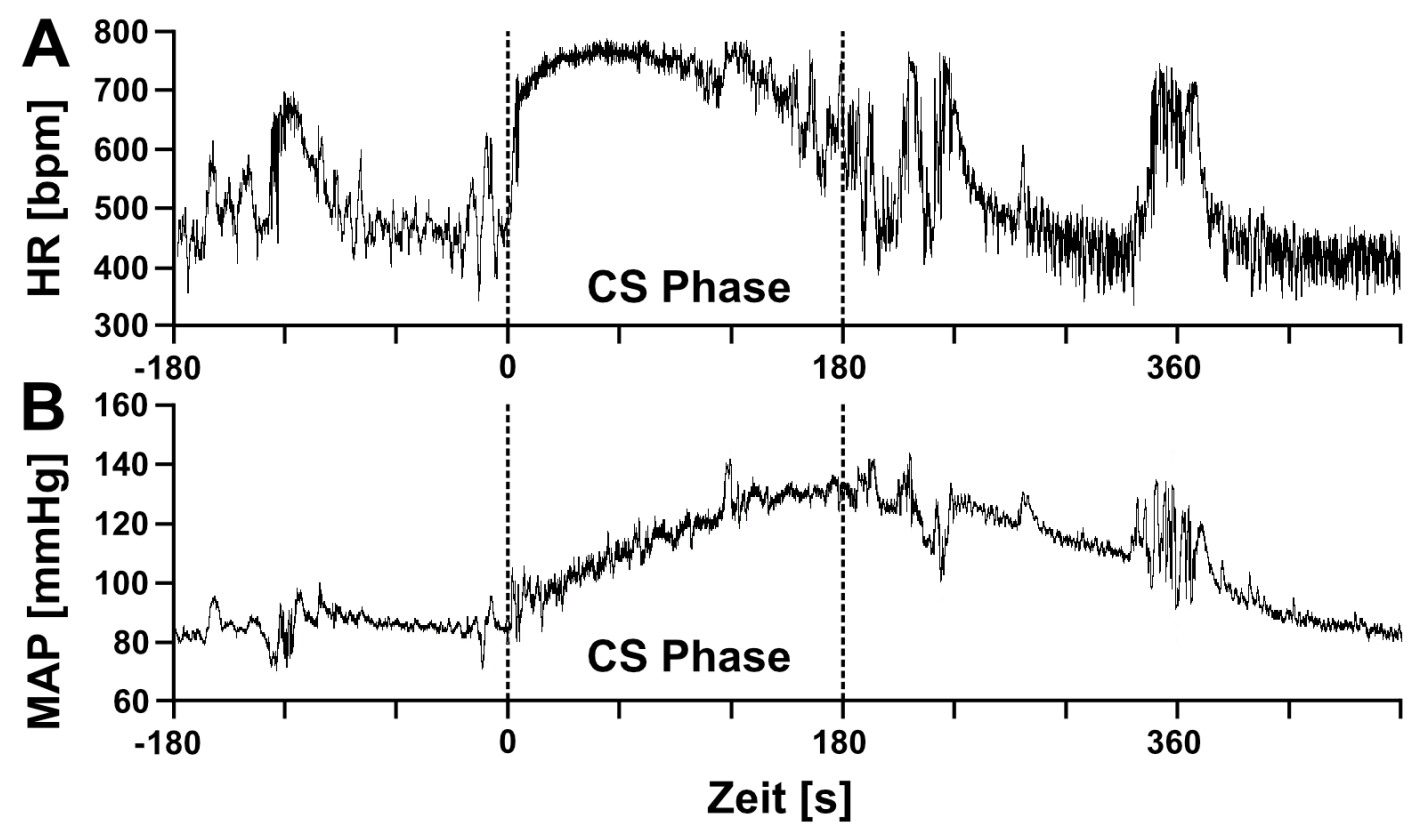

Abb. 3.9: Typischer Herzratenverlauf (A) und gleichzeitiger Verlauf des mittleren Blutdrucks (B) einer C57BL/6N-Maus im Ton (CS) abhängigen Gedächtnistest. Tonpräsentation erfolgte während der CS Phase.

Abbildung 3.10 zeigt mittlere HR- und MAP-Werte von drei verschiedenen experimentellen Gruppen. Mäuse, die im Training der direkten Abfolge von CS und US (CS+US) ausgesetzt wurden und denen im Gedächtnistest ein $180 \mathrm{~s}$ dauernder Ton-CS präsentiert wurde, erreichten maximale HR-Werte 30-60 s nach Einsetzen des Tons, während maximale MAP-Werte erst ab 120-150 s nach Tonbeginn gemessen wurden (Abb. 3.10). Am Ende der CS-Phase begannen HR und MAP wieder abzufallen, wobei der MAP erheblich langsamer zu den Basalwerten zurückkehrte. Nach Beendigung der Tonpräsentation erreichten die HR-Werte nach 60-90 s wieder prä-CS Niveau $\left(F_{1,32}=3.32, \mathrm{p}>0.08\right)$, während 
die MAP-Werte erst nach 150-180 s wieder auf Basalwerte abgesunken waren $\left(F_{1,32}=4.09\right.$, $\mathrm{p}>0.05)$.

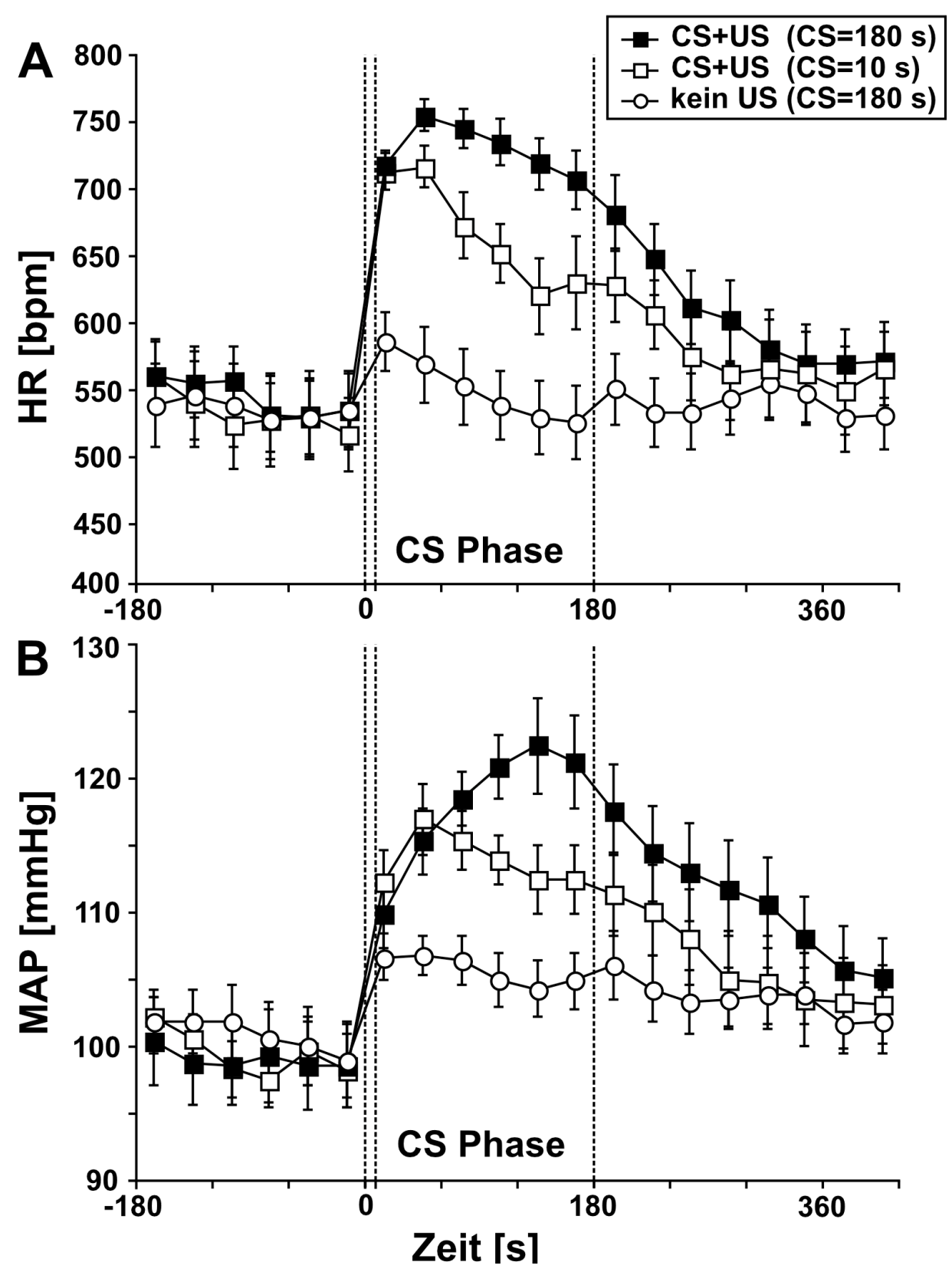

Abb. 3.10: Mittlere Herzrate (A) und einhergehender mittlerer arterieller Blutdruck (B) von C57BL/6N-Mäusen in 30-s Intervallen des Ton abhängigen Gedächtnistestes. Mäuse wurden entweder mit direkt aufeinander folgendem CS und US (CS+US) oder nur mit CS (kein US) trainiert. Zusä̈zlich sind Antworten von Mäusen die mit CS+US trainiert wurden, dargestellt, denen der Ton im Gedächtnistest nur $10 \mathrm{~s}$ präsentiert wurde ( $C S=10 \mathrm{~s})$. Gestrichelte Linien bei 0 und 10 bzw. $180 \mathrm{~s}$ zeigen Beginn und Ende der Tonpräsentation (CS Phase). Mittelwerte \pm SF, $\mathrm{n}=16-17$ pro Gruppe.

Um den Einfluss der CS-Dauer auf die Antwortdynamik zu untersuchen, wurden Mäuse, die wiederum im Training der direkten Abfolge von CS und US ausgesetzt wurden, im Gedächtnistest für nur $10 \mathrm{~s}$ mit dem Ton-CS stimuliert. Der $180 \mathrm{~s}$ wie auch der $10 \mathrm{~s}$ dauernde Ton induzierte einen ähnlichen Anstieg der HR (Abb. 3.10A), die in der $10 \mathrm{~s}$ CS- 
Gruppe jedoch schneller wieder abfiel. Ein Anstieg im MAP war in beiden CS+US-Gruppen zu beobachten, wobei die hypertonische Antwort bei nur 10s CS-Präsentation in ihrer Höhe und Dauer niedriger ausfiel als bei $180 \mathrm{~s}$ auditorischer Stimulation (Abb. 3.10B). Mäuse, die im Training zwar CS-Präsentation aber keine US-Stimulation erfahren hatten und somit den Ton nicht aversiv assoziierten, dienten als Kontrollgruppe (kein US). Diese Mäuse reagierten auf den CS mit einem kurzen und milden Anstieg der HR ( $\triangle \mathrm{HR} \sim 50 \mathrm{bpm})$ in den ersten $30 \mathrm{~s}$ der CS-Phase (Abb. 3.10A), der nicht signifikant von Basalwerten zu unterscheiden war $\left(F_{1,30}=1.91, \mathrm{p}>0.17\right)$. Der MAP dieser Mäuse war in der CS-Phase leicht erhöht ( $\triangle \mathrm{MAP}$ $\sim 6 \mathrm{mmHg}$ ), jedoch waren auch hier die Spitzenwerte, die im 30-60 s Intervall der CS-Phase auftraten, nicht signifikant unterschiedlich von den Basalwerten $\left(F_{1,30}=3.90, \mathrm{p}>0.05\right.$; Abb. $3.10 \mathrm{~B})$.

Ein Vergleich der Ton induzierten Anstiege von HR $(\Delta \mathrm{HR})$ und MAP $(\Delta \mathrm{MAP})$ in den drei experimentellen Gruppen ist in Abb. 3.11 dargestellt. In der 180 s-Gruppe betrug der $\Delta$ HR 213 bpm (Abb. 3.11A) und der $\Delta$ MAP etwa 24 mmHg (Abb. 3.11B). Die $\Delta$-Werte in der $180 \mathrm{~s}-$ und der $10 \mathrm{~s}-$

Gruppe waren nicht signifikant unterschiedlich (HR: $F_{1,24}=0.59$, $\mathrm{p}>0.45$, Abb. 3.11A, MAP: $F_{1,24}=1.40, \mathrm{p}>$ 0.25 , Abb. 3.11B). Um die zeitliche Dynamik der Aktivierung der Antworten quantifizieren und miteinander vergleichen zu können, wurden die Beschleunigungsraten von HR und MAP

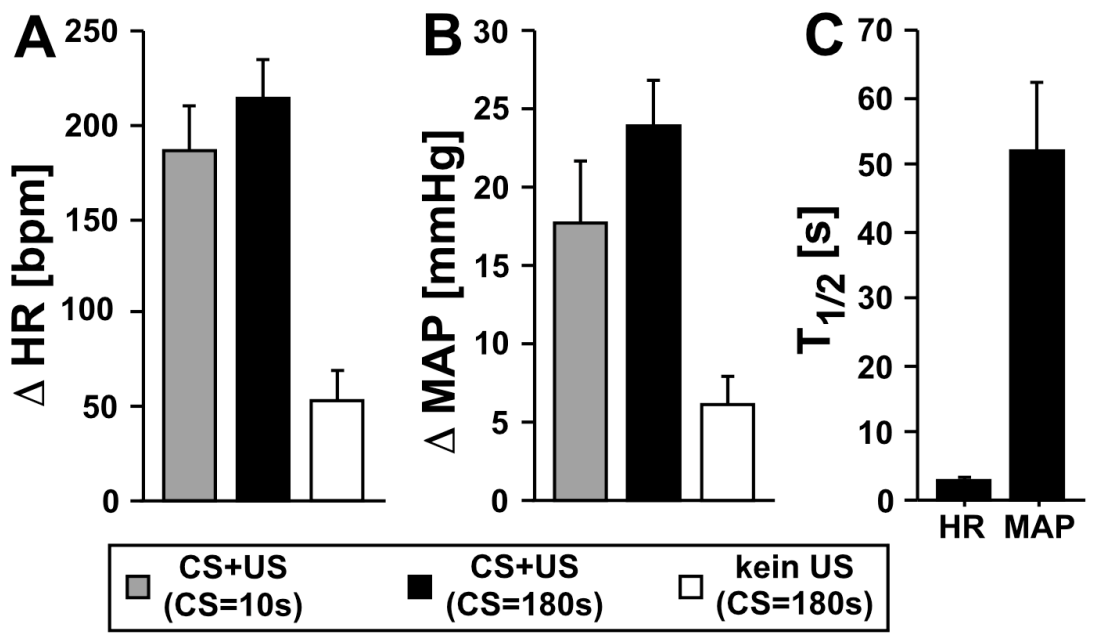

Abb. 3.11: Mittlere Herzrate- (A) und einhergehende mittlere arterielle BlutdruckAnstiege (B) nach Einsetzen des Ton-CS in den drei experimentellen Gruppen (s. Abb. 3.10). Zeit zum Erreichen halbmaximaler HR- bzw. MAP-Werte $\left(\mathrm{T}_{1 / 2}\right)$ in der 180-s CSGruppe nach Training mit aufeinander folgendem $C S$ und US (C). Mittelwerte $\pm S F$, $n=$ 16-17 pro Gruppe.

berechnet. Dazu wurden die Zeiten bis zum Erreichen des halbmaximalen Anstiegs von HR und MAP (Halbwertszeit $\mathrm{T}_{1 / 2}$ ) in der $180 \mathrm{~s}$-Gruppe ermittelt. Auf Grundlage dieser Analyse wurde eine signifikant

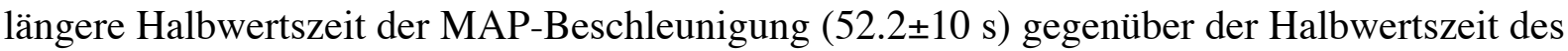
HR-Anstiegs $(3.1 \pm 0.2)$ festgestellt $\left(F_{1,20}=13.52, \mathrm{p}<0.02\right.$; Abb. 3.11C). Insgesamt wurde eine wesentlich schnellere Anpassung der HR gegenüber dem MAP an konditionierte Furcht 
festgestellt, was auf die direkte neuroautonome Regulation der Herzfrequenz, im Gegensatz zur eher indirekt und humoral vermittelten Regulation des Blutdrucks, zurückzuführen ist.

Neben dem CS induzierten, lang anhaltenden hypertensiven Effekt bei furchtkonditionierten Mäusen, wurde in den hochaufgelösten Originalaufzeichnungen der Gedächtnistests jedoch auch ein schneller und transienter MAP-Anstieg direkt nach dem Einsetzen des Tons festgestellt. Deshalb wurden HR und MAP auch in einem Zeitfenster $10 \mathrm{~s}$ vor bis $20 \mathrm{~s}$ nach Einsetzen des CS in $1 \mathrm{~s}$ Intervallen analysiert (Abb. 3.12). Die unmittelbare MAP-Antwort auf den CS bestand aus einem transienten, schnellen Anstieg mit einer Latenz von $1.45 \pm 0.11 \mathrm{~s}$ in der $180 \mathrm{~s}-$

Gruppe mit direkter Abfolge von CS und US im Training. Jedoch wurde auch bei Mäusen der Kontrollgruppe (kein US) eine solche schnelle MAPAntwort auf den CS mit nicht signifikant unterschiedlicher Latenz $\left(F_{1,21}=0.37, \mathrm{p}>0.55\right)$ ermittelt (Abb. 3.12B). In beiden Gruppen waren die Spitzenwerte des $\triangle \mathrm{MAP}$ in den 2-3 s Intervallen nach Einsetzen des Tons nicht signifikant unterschiedlich $\left(F_{1,31}=\right.$ 2.34, $\mathrm{p}>0.14)$. Diese Werte fielen etwa $40 \%$ geringer $(\sim 14 \mathrm{mmHg})$ aus als der maximale $\triangle$ MAP $(\sim 24 \mathrm{mmHg})$ in der $180 \mathrm{~s}$-Gruppe 120-150 s nach Einsetzen des Tons. Im

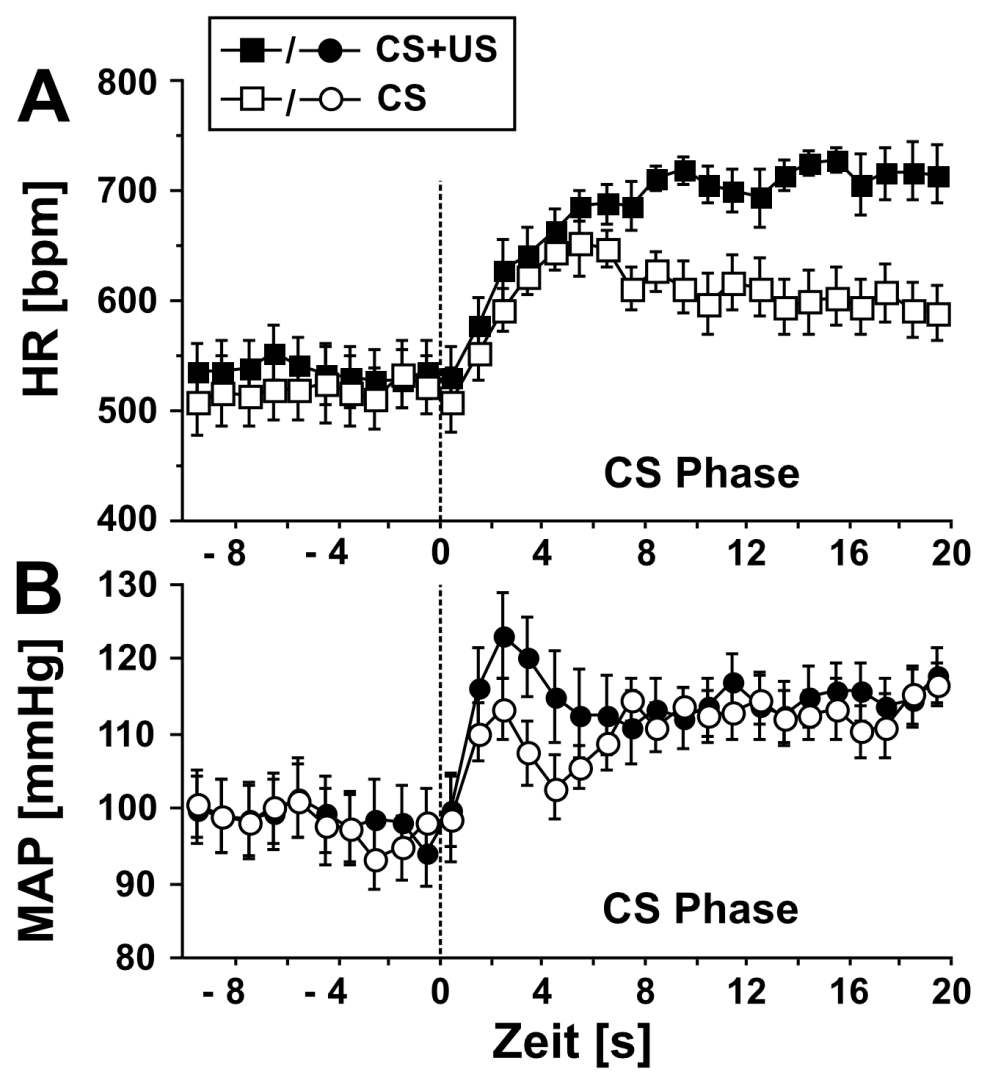

Abb. 3.12: Mittlere Herzrate (A) und einhergehender mittlerer arterieller Blutdruck (B) von C57BL/6N-Mäusen in $1 \mathrm{~s}$ Intervallen des Ton abhängigen Gedächtnistests, $10 \mathrm{~s}$ vor bis $20 \mathrm{~s}$ nach Einsetzen des $180 \mathrm{~s}$ Ton-CS. Mäuse wurden entweder mit direkt aufeinander folgenden CS und US (CS+US) oder nur mit CS (kein US) trainiert. Gestrichelte Linien bei 0 s zeigen den Beginn der Tonpräsentation (CS Phase). Mittelwerte $\pm S F, n=16$-17 pro Gruppe.

Gegensatz hierzu unterschied sich die HR-Beschleunigung von Mäusen, die im Training, der direkten CS und US Abfolge ausgesetzt waren signifikant $\left(F_{1,31}=4.46, \mathrm{p}<0.05\right)$ von der Kontrollgruppe (kein US) in diesen ersten $20 \mathrm{~s}$ des Gedächtnistests (Abb. 3.12A). Diese Ergebnisse legten nahe, dass diese 
sehr schnelle Blutdruckantwort als eine Attentions-bzw. Erregungsanwort und nicht als konditionierte Furchtantwort zu interpretieren ist.

\subsubsection{Herzrate und mittlerer arterieller Blutdruck in akustischen Startle- Experimenten}

Um die Hypothese der schnellen kardiovaskulären Attentions-bzw. Erregungsanwort zu überprüfen, wurden weitere Experimente durchgeführt bei denen kardiovaskuläre Parameter nach akustischer Startle-Stimulation bei Mäusen im Heimkäfig gemessen wurden. Es wurden schnelle, durch den unkonditionierten akustischen Startle-Reiz induzierte HR- und MAPReaktionen erwartet.

Die Startle-Signale bewirkten klare motorische Startle-Reaktionen im charakteristischen Zeitfenster von 20-50 ms nach dem Einsetzen des Stimulus (Davis et al., 1997; Koch, 1999), die mit dem Akzelerometer detektiert wurden (nicht gezeigt). Bei 19 Mäusen, denen jeweils fünf Startle-Stimuli präsentiert wurden, konnten nur 19 von insgesamt 85 (22.4\%) Stimuli eindeutige, wenn auch milde Anstiege von HR und MAP (Abb. 3.13) bei gleichzeitig immer erkennbarer lokomotorischer Startle-Antwort gemessen werden. Bei diesen 19 Mäusen fielen HR- und MAP-Antworten ähnlich aus. Im Test mit fünf, im Abstand von einer Minute präsentierten Startle-Stimuli wurde kein Anstieg der basalen HR oder des basalen MAP beobachtet (Abb. 3.13).

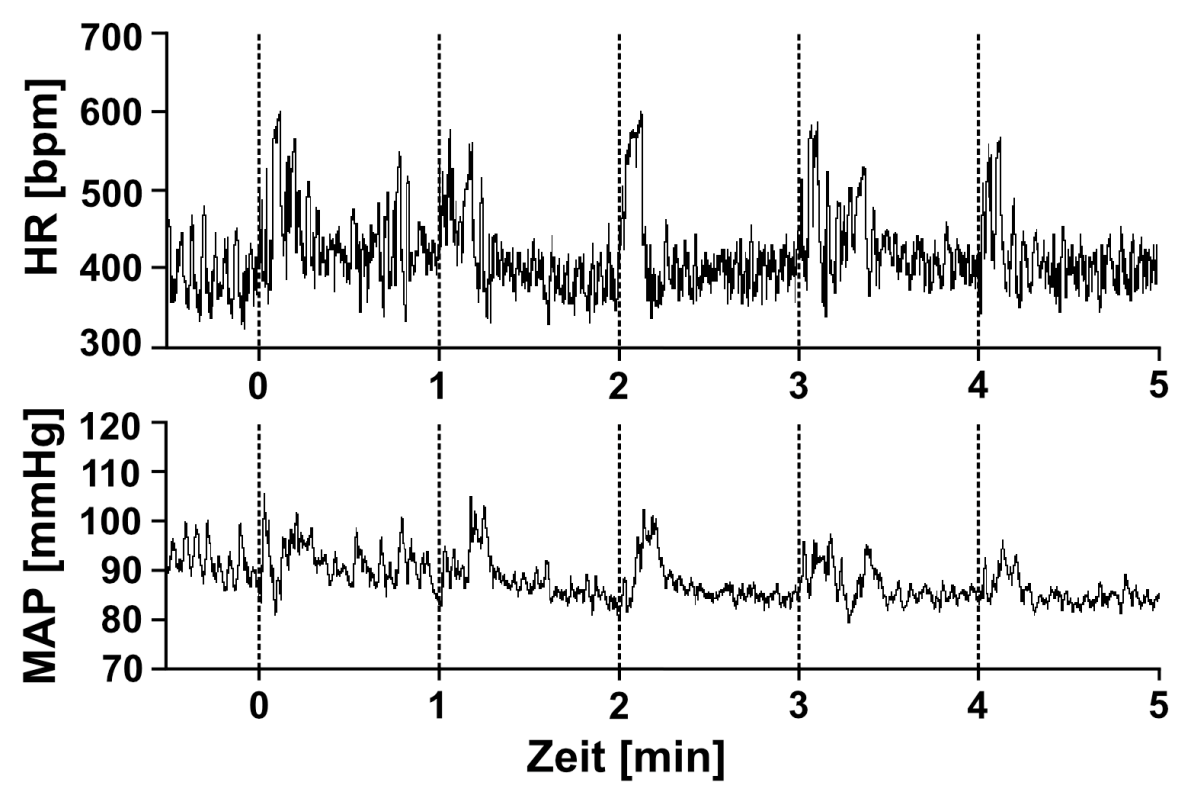

Abb. 3.13: Typische Dynamik von Herzrate (A) und einhergehenden mittleren arteriellen Blutdruck (B) einer $\quad 57 \mathrm{BL} / 6 \mathrm{~N}$-Maus während der Präsentation von 5 StartleSignalen (gestrichelte Linien) im Abstand von jeweils 1 min. Deutlich erkennbar ist das Fehlen des Anstiegs der Basalwerte von HR und MAP im Verlauf der Präsentation der 5 Reize. 
Verglichen mit den profunden und relativ lang anhaltenden Effekten des Ton-CS auf HR und BP bei furchtkonditionierten Mäusen (s. Abb. 3.9, 3.10) bewirkten die Startle-Stimuli eine geringfügige und kurzfristige kardiovaskuläre Aktivierung. Die Latenzen des HR-bzw. MAP-Anstiegs nach Startle-Stimulation, die anhand klar erkennbarer Antworten ermittelt wurden, betrugen $\sim 1$ s. In Abb. 3.14(A, B) sind gemittelte HR und MAP Werte im Zeitfenster von $10 \mathrm{~s}$ vor bis $20 \mathrm{~s}$ nach Präsentation des Startle-Stimulus in 1s Intervallen dargestellt. Um diese Antworten mit den schnellen kardiovaskulären Änderungen furchtkonditionierter Mäuse, die dem $180 \mathrm{~s}$ dauernden Ton-CS ausgesetzt wurden, zu vergleichen, sind deren Antwortmuster im gleichen Zeitfenster dargestellt. Die von den Startle-Stimuli verursachten mittleren HR-und MAP-Anstiege hatten relativ geringe Amplituden (Abb. 3.14C, D), die signifikant niedriger als die Amplituden der kardiovaskulären Antworten der furchtkonditionierten Mäuse im Gedächtnistest ausfielen (HR: $F_{1,34}=14.97$, p < 0.001; MAP: $F_{1,34}=13.98$, p < 0.001). Die HR war $10 \mathrm{~s}$ und der MAP $15 \mathrm{~s}$ nach Startle-Stimulation wieder auf die vor der Stimulation gemessenen Werte abgefallen, die sich nicht signifikant von prä-Stimulus Werten unterschieden (HR: $F_{1,36}=1.57, \mathrm{p}>0.05$; MAP: $F_{1,36}=2.64, \mathrm{p}>0.05$ ).
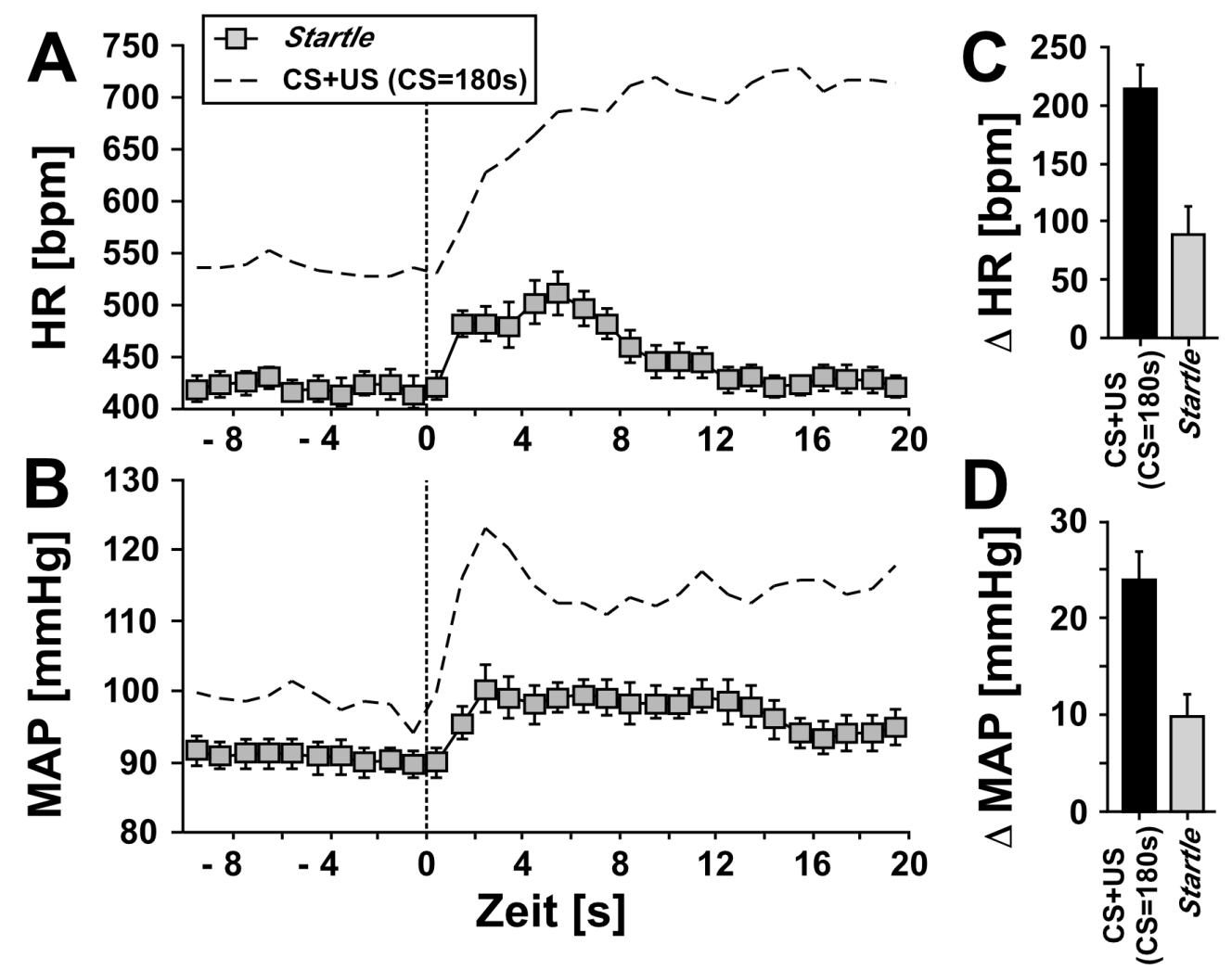

Abb. 3.14: Mittlere Herzrate (HR; A) und einhergehender mittlerer arterieller Blutdruck (MAP; B) von C57BL/6N-Mäusen in 1-s Intervallen des Ton abhängigen Gedächtnistests von $10 \mathrm{~s}$ bis 20 s nach Präsentation des StartleSignals. Zum Vergleich sind HRund MAP-Antworten von Furcht konditionierten Mäusen (CS+US/ $C S=180 \mathrm{~s}$ ) mit gestrichelten Kurven dargestellt. Gestrichelte vertikale Linien zeigen den Beginn der Tonprösentation (CS Phase) bei 0 s. Mittelwerte $\pm S F, n=16-19$ pro Gruppe. 


\subsection{Untersuchungen zum Beitrag des CRF- und des NPY-Systems zur kardiovaskulären und ethologischen Expression von Emotionalität}

Neben den Untersuchungen zur zeitlichen Ausprägung der kardiovaskulären Furchtantwort, sollten auch die daran beteiligten neurochemischen Signale näher beleuchtet werden. Sowohl für das CRF- als auch das NPY-System wird eine Rolle bei der basalen Regulation und der Stress abhängigen Modulation der kardiovaskulären Funktion diskutiert (s. Einleitung). Daher wurden pharmakologische Interventionen mit selektiven Rezeptorsubtyp-Liganden auf zentraler und peripherer Ebene durchgeführt sowie mit Hilfe genetisch modifizierter Mausmodelle die Beiträge des CRF- und des NPY-Systems zu Herzraten- und Blutdruckdynamik und zu stressabhängigem Verhalten untersucht.

\subsubsection{Zentral vermittelte Modulation von Herzratendynamik und Blutdruck durch CRF-Rezeptorsubtyp $1\left(\mathrm{CRF}_{1}\right)$}

Mit Hilfe neu entwickelter peptidischer Liganden wurden die kardiovaskulären Effekte der Aktivierung zentraler CRF-Rezeptoren untersucht. Die Liganden wurden in künstlicher Hirnflüssigkeit (aCSF) gelöst und bilateral in die lateralen Ventrikel (intrazerebroventrikulär: ICV) appliziert bevor 15 min später HR und MAP für 18 min gemessen wurden.

Der CRF-Rezeptor-Agonist oCRF (ovine CRF) wurde in zwei unterschiedlichen Dosierungen ICV appliziert (Abb. 3.15). Eine Dosis von $130 \mathrm{ng}$ oCRF je Maus führte im Vergleich zur aCSF-Injektion, mit einer durchschnittlichen HR von $\sim 650 \mathrm{bpm}$, zu einer signifikant niedrigeren $\mathrm{HR}$ von $500-550 \mathrm{bpm}\left(F_{1,14}=43.04, \mathrm{p}<0.0001\right.$; Abb. 3.15A), während keine unterschiedlichen Blutdruckwerte gemessen wurden $\left(F_{1,14}=0.26, \mathrm{p}>0.05\right.$, Abb. 3.15B). Eine höhere Dosis oCRF von $880 \mathrm{ng}$ je Maus verursachte im Vergleich zu aCSF-Kontrollen ebenfalls signifikant niedrigere $\mathrm{HR}$ von $\sim 550 \mathrm{bpm}\left(F_{1,14}=17.88, \mathrm{p}<0.001\right)$ und einen gleichzeitigen signifikanten Abfall des MAP $\left(F_{1,14}=7.80, \mathrm{p}<0.05\right)$, der 20 min nach der Injektion deutlich erkennbar war. Die Injektion des selektiven $\mathrm{CRF}_{1}$-Agonisten Cortagine in einer Dosis von 600 ng und 300 ng je Maus resultierte in signifikant niedrigeren HR (600 ng: $F_{1,12}=78.38, \mathrm{p}<0.001 ; 300 \mathrm{ng}: F_{1,12}=42.72$, p <0.001) von 400-500 bpm im Vergleich zu aCSF-injizierten Mäusen (Abb. 3.15C). Im MAP zeigten sich bei beiden Dosierungen Tendenzen hin zu niedrigeren Werten, ANOVA für repetetive Messungen ergab 
jedoch keine signifikant unterschiedlichen Verläufe im Vergleich zu aCSF-Kontrollen (600 ng: $F_{1,12}=3.94, \mathrm{p}=0.07 ; 300 \mathrm{ng}: F_{1,12}=3.77, \mathrm{p}=0.08 ;$ Abb. 3.15D).

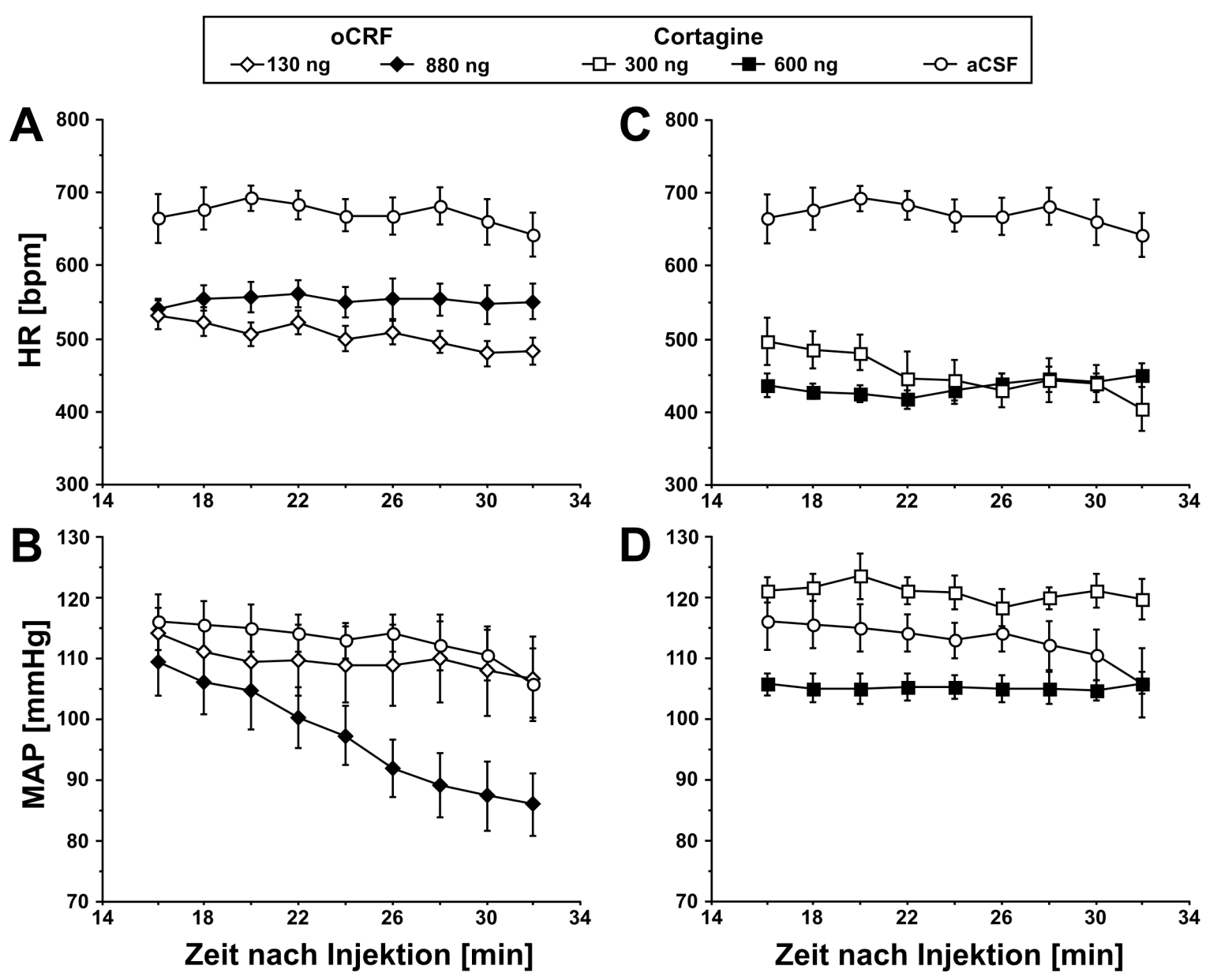

Abb. 3.15: Mittlere Herzrate (A, C) und einhergehender mittlerer arterieller Blutdruck (B, D) von C57BL/6N-Mäusen in 2 min Intervallen nach intrazerebroventrikulärer Injektion der CRF-Agonisten Cortagine und des endogenen, präferentiell an CRF $_{1}$ bindenden Agonisten ovine (RF (OCRF) in unterschiedlichen Dosierungen pro Maus. aCSF=artificial cerebrospinal fluid (Kontrolllösung). Mittelwerte \pm SF, $n=6-8$ pro Gruppe.

\subsubsection{Zentral vermittelte NPY-Effekte auf Herzratendynamik}

In Ergänzung vorhergehender Untersuchungen der zentralen Wirkung von NPY (Tovote, 2001) wurde der Zusammenhang von Herzrate und Herzratenvariabilität nach pharmakologischer Intervention durch NPY untersucht. Als Kontrolle dienten aCSF-injizierte Mäuse. In Abbildung 3.16 sind RR-Intervall bzw. HR halblogarithmisch gegen RMSSD (als Maß für HRV) aufgetragen. Es wird deutlich, dass zwischen HR und HRV eine negative Korrelation besteht. Die näherungsweise exponentielle Funktion weist auf minimale HRV- 
Werte bei maximaler HR hin. Dies zeigte sich bei den aCSF-injizierten wie auch bei den NPY-injizierten Mäusen. Die Injektion von 500 ng NPY führte zu einer Verschiebung der Funktion hin zu niedrigeren Herzraten bei gleich bleibender HRV. Das allgemeine, negativ exponentielle Verhältnis von HR zu HRV (erkennbar an den Steigungen der Funktionen) änderte sich nach Injektion von 500 ng NPY im Vergleich zur aCSF-Injektion nicht. Eine niedrigere Steigung des HRRMSSD Verhältnisses zeigte eine Reduktion der HRV bei gleichen HR-Werten durch Injektion von $2 \mu \mathrm{g}$ NPY an.

Abb. 3.16: Herzratenvariabilität (HRV) als Funktion der Herzrate auf der Basis des RR-Intervalls von C57BL/6N-Mäusen nach intracerebroventrikulärer Injektion von artificial Cerebrospinal fluid (aCSF), 500 ng Neuropeptid Y (NPY) und 2pg NPY. HRV wurde anhand der RMSSD-Werte von 30 s-Intervallen im Ton abhängigen Gedächtnistest ermittelt. $r=$ Regression, $S=$ Steigung der Funktion.

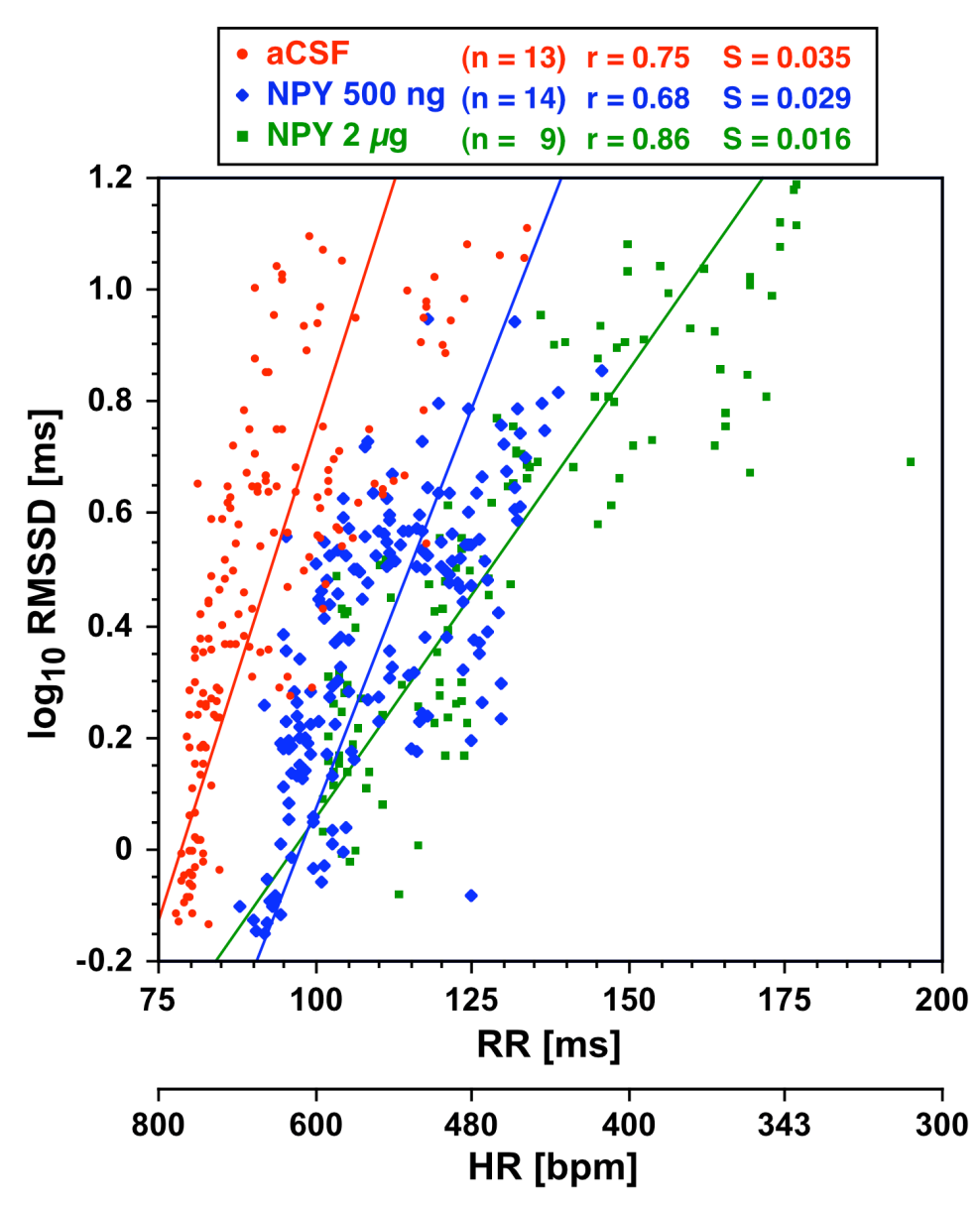

\subsubsection{Vergleich von CRF- bzw. NPY- vermittelten Effekten auf Herzratendy- namik}

Der Vergleich der HR- und HRV-Effekte von zentral appliziertem oCRF bzw. NPY sollte Aufschluss über die zugrunde liegenden Mechanismen geben. In Abbildung 3.17 sind die Herzratenverläufe von oCRF- und NPY-injizierten Mäusen während des Ton abhängigen Gedächtnistests dargestellt. ICV-Injektion von $210 \mathrm{ng}$ oCRF resultierte in relativ niedrigen basalen Herzraten in der prä-CS Phase. Die Ton abhängige Tachykardie wurde signifikant abgeschwächt. Nach ICV-Injektion von 500 ng NPY wurden ebenfalls niedrige basale Herzratenwerte und ein geringerer CS induzierter Herzratenanstieg ermittelt. Die mittleren 
Herzratenwerte von oCRF- und NPY-injizierten Mäusen im Gedächtnistest unterschieden sich nicht signifikant voneinander $(\mathrm{p}>0.48$; Abb. 3.17B). Signifikante Unterschiede bestanden jedoch in der HRV zwischen oCRF- und NPY-injizierten Mäusen ( $<<0.0001)$. So zeigten Mäuse nach oCRFInjektion stark erhöhte HRV, während NPY-injizierte Mäuse niedrige HRV hatten. Diese Differenzen deuten auf unterschiedliche zugrunde liegende, CRF- bzw. NPY- vermittelte Aktivierungszustände des neuroautonomen Systems hin.

Abb. 3.17: Typische Herzratenverläufe im Ton abhängigen Gedächtnistest nach intracerebroventrikulärer-Injektion von $210 \mathrm{ng}$ oCRF oder $500 \mathrm{ng}$ NPY (A). Der Vergleich von Herzraten und Herzratenvariabilität (RMSSD) ergab ähnliche Herzraten oCRF- bzw. NPY-injizierter Mäuse ( $p>0.48)$ bei substantiell unterschiedlicher Herzratenvariabilität $(\mathrm{p}<0.0001)$ (B). Mittelwerte $\pm \mathrm{SF}$, $\mathrm{n}=13-19$.
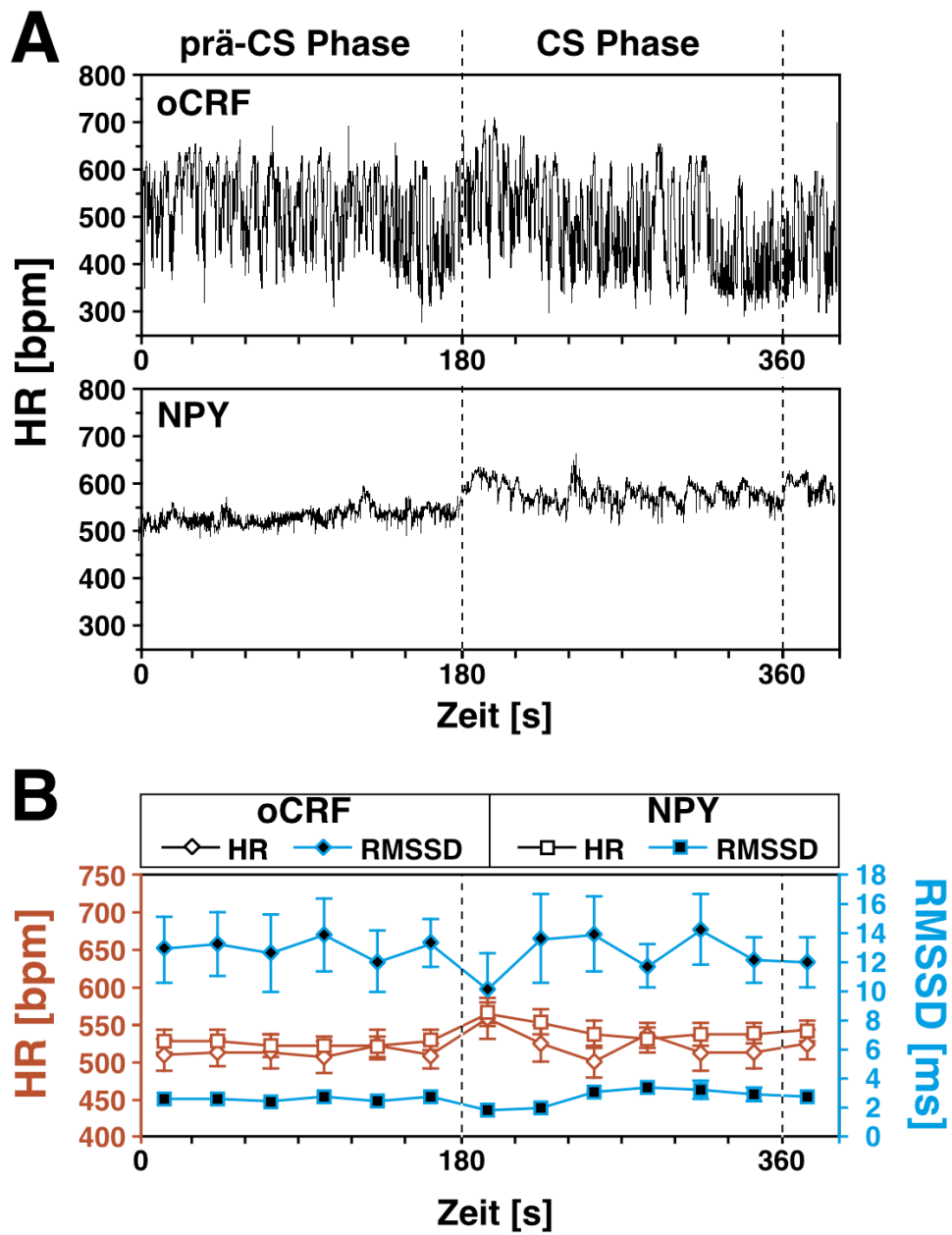

\subsubsection{Peripher vermittelte CRF-Effekte auf Herzratendynamik und Blutdruck}

Die Effekte peripherer Aktivierung von CRF-Rezeptoren wurden mit peptidischen CRF-Rezeptor-Liganden untersucht, die in Phoshatpuffer (PBS)-Lösung intraperitoneal (IP) appliziert wurden. Die 18 min dauernden Blutdruckmessungen, aus denen MAP und HR berechnet wurden, begannen 15 min nach der Injektion (Abb. 3.18).

Die Injektion von $230 \mathrm{ng}$ des $\mathrm{CRF}_{1}$-Liganden oCRF resultierte im Vergleich zu PBSKontrollen in erhöhter HR $\left(F_{1,19}=20.80, \mathrm{p}<0.001\right.$; Abb. 3.18A), jedoch nicht signifikant unterschiedlichem MAP $\left(F_{1,19}=0.03, \mathrm{p}>0.05\right.$; Abb. 3.18B). Nach der Injektion von $300 \mathrm{ng}$ des selektiven $\mathrm{CRF}_{1}$-Agonisten Cortagine wurde im Vergleich zu PBS-Kontrollen eine tendenziell höhere $\mathrm{HR}\left(F_{1,23}=4.0, \mathrm{p}=0.06\right)$ bei nicht signifikant unterschiedlichem MAP $\left(F_{1,23}=0.04, \mathrm{p}>0.85\right)$ gemessen. Die Injektion von $200 \mathrm{ng}$ des selektiven $\mathrm{CRF}_{2}$-Liganden 
mUCNII führte zu einer signifikanten Zunahme der HR gegenüber den Werten der aCSFKontrollen $\left(F_{1,17}=22.41, \mathrm{p}<0.001\right.$; Abb. 3.18C) mit einhergehendem deutlichem Abfall des $\operatorname{MAP}\left(F_{1,17}=19.24, \mathrm{p}<0.001 ;\right.$ Abb. 3.18D). Wurden $200 \mathrm{ng}$ des selektiven $\mathrm{CRF}_{2}$-Liganden mUCNIII injiziert, führte dies ebenfalls zu signifikanter HR-Zunahme $\left(F_{1,17}=16.05\right.$, $\mathrm{p}<0.001$; Abb. 3.18B) und gleichzeitigem Abfall des MAP $\left(F_{1,17}=14.34, \mathrm{p}<0.01 ;\right.$ Abb. 3.18D).
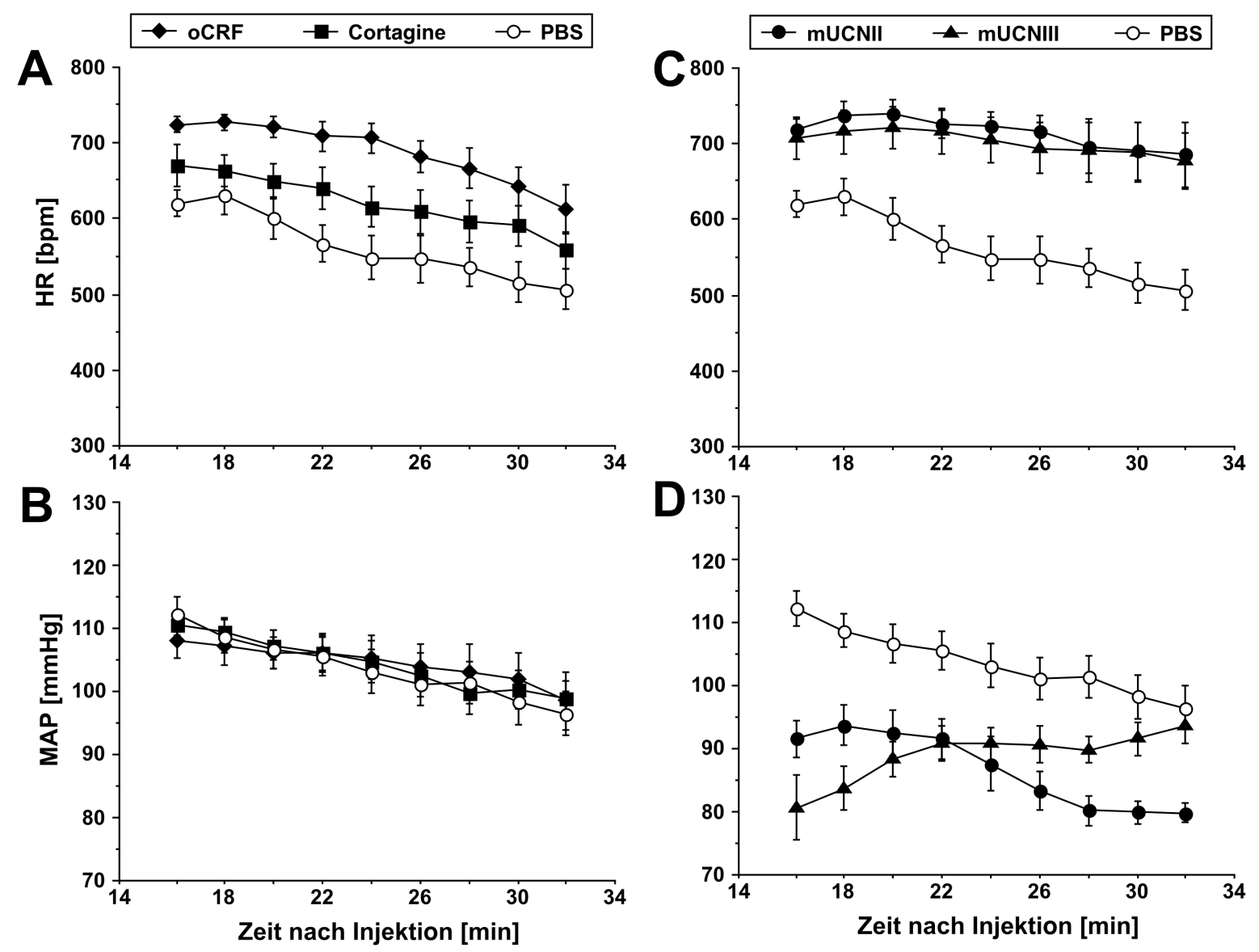

Abb. 3.18: Mittlere Herzrate (HR; A,C) und einhergehender mittlerer arterieller Blutdruck (MAP; B,D) von C57BL/6N-Mäusen in 2 min-Intervallen nach intraperitonealer Injektion des (RF ${ }_{1}$-Agonisten Cortagine (300 $\mathrm{ng} /$ Maus), nach ovine CRF (oCRF) Injektion (230ng/Maus) und nach Injektion der (RF 2 -Agonisten mUCNII (200ng/Maus) bzw. mUCNIII (200ng/Maus). Phosphatpufferlösung (PBS) diente als Kontrolllösung. Mittelwerte $\pm S F, n=7-13$ pro Gruppe.

\subsubsection{Herzratendynamik und Verhalten $\mathrm{CRF}_{1-}, \mathrm{CRF}_{2}$-defizienter und CRF- transgener Mäuse bei Novelty und Furchtkonditionierung}

Zur Ergänzung der Ergebnisse aus den pharmakologischen Experimenten mit CRFRezeptorliganden bei C57BL/6N-Mäusen wurden Versuche mit genetisch modifizierten 
Mäusen durchgeführt. Dazu wurden Mauslinien mit $\mathrm{CRF}_{1^{-}}, \mathrm{CRF}_{2}$-Defizienz und CRFtransgene Mäuse untersucht, die eine erhöhte CRF-Produktion (CRFOE-Mäuse) haben.

\subsubsection{Lokomotionsaktivität und Herzratendynamik während Novelty}

\section{Lokomotionsaktivität während Novelty}

Um Unterschiede in emotionaler Responsivität und potentiellem Angstverhalten zwischen den Genotypen der verschiedenen Mausmodelle zu untersuchen, wurden Lokomotionsaktivität und Herzrate im Novelty-Test gemessen. Vom Einsetzen in die neue Umgebung an wurden die Parameter für 34 min gemessen. $\mathrm{CRF}_{1}^{-{ }^{-}-}$und $\mathrm{CRF}_{1}^{+/+}-\mathrm{Mäuse}$ unterschieden sich in ihrer Lokomotionsaktivität nicht signifikant voneinander $\left(F_{1,53}=0.01\right.$, p > 0.95; Abb. 3.19A). $\mathrm{CRF}_{2}^{-1-}$-Mäuse unterschieden sich hinsichtlich ihrer Lokomotions-
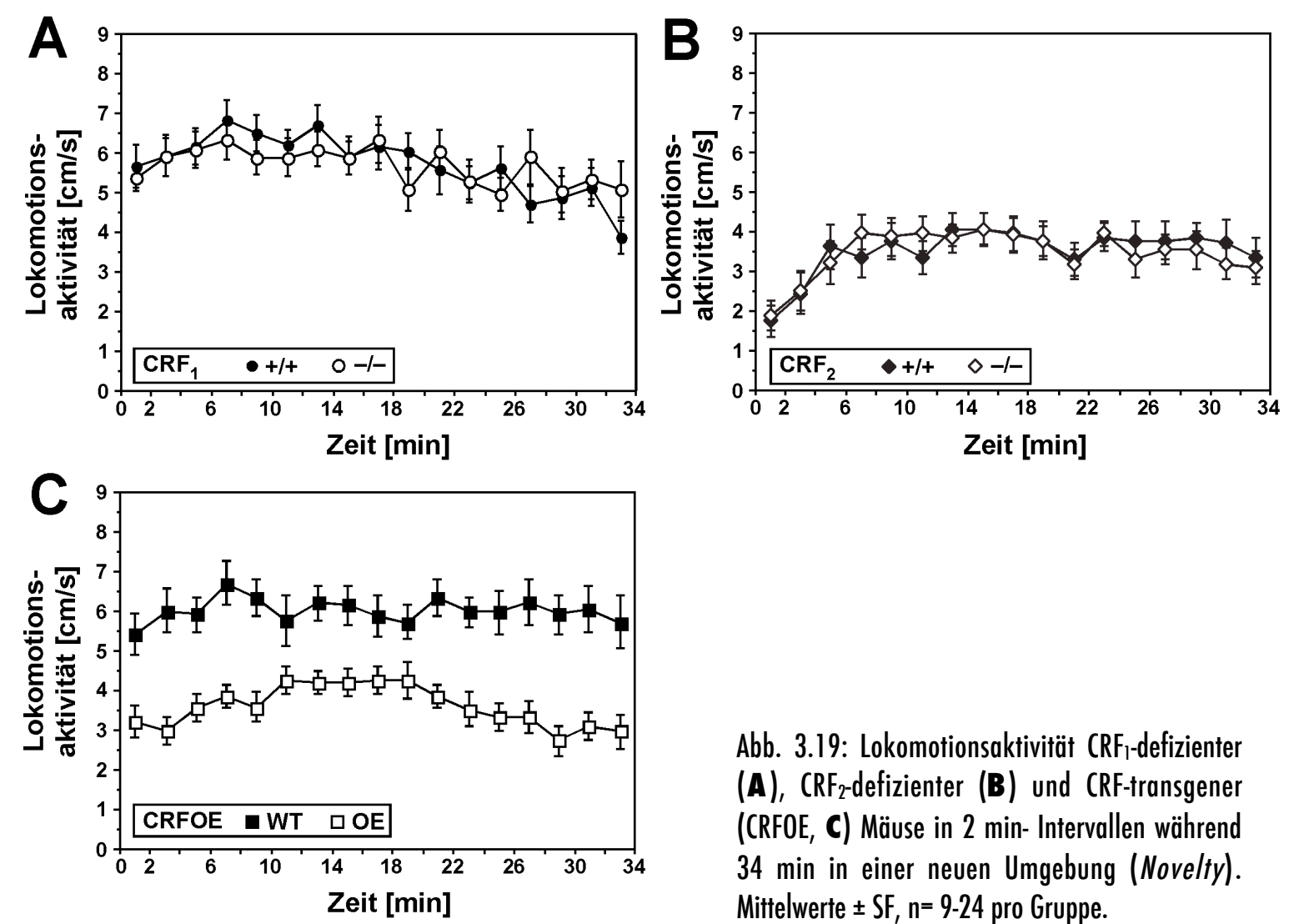

Abb. 3.19: Lokomotionsaktivität (RF-1-defizienter (A), CRF $_{2}$-defizienter (B) und CRF-transgener (CRFOE, C) Mäuse in 2 min- Intervallen während $34 \mathrm{~min}$ in einer neuen Umgebung (Novelty). Mittelwerte $\pm S F, n=9-24$ pro Gruppe. 
aktivität nicht von $\mathrm{CRF}_{2}{ }^{++}$-Mäusen $\left(F_{1,30}=0.01, \mathrm{p}>0.91\right.$; Abb. 3.19B) zeigten aber geringere lokomotorische Aktivitäten als $\mathrm{CRF}_{1}{ }^{-/}$-bzw. $\mathrm{CRF}_{1}{ }^{+/+}$-Mäuse. CRFOE-Mäuse zeigten während des Novelty-Tests eine signifikant niedrigere Aktivität als ihre Wildtyp-Wurfgeschwister $\left(F_{1,15}=21.64, \mathrm{p}<0.0005 ;\right.$ Abb. 3.19C).

\section{Basale und Novelty induzierte Herzratendynamik}

Vor der Präsentation der neuen Umgebung wurden HR und HRV aller Mäuse zunächst unter stressfreien Bedingungen im

Heimkäfig gemessen. Basale HR von $\mathrm{CRF}_{1}^{-/-}$- und $\mathrm{CRF}_{1}^{+/+}$- Mäusen befanden sich im normalen Bereich von 450-550 bpm (Abb. 3.20A). Zwischen $\mathrm{CRF}_{1}^{-{ }^{-}-}$und $\mathrm{CRF}_{1}^{+/+}$ Mäusen bestanden keine signifikanten Unterschiede in basaler HR $\left(F_{1,14}=0.42, \mathrm{p}>0.53\right.$; Abb. $\left.3.20 \mathrm{~A}\right)$ und $\operatorname{HRV}\left(F_{1,14}=0.11, \mathrm{p}>0.75\right.$; Abb. 3.20B). $\mathrm{CRF}_{2}^{-/-}$und $\mathrm{CRF}_{2}^{+/+}$ Mäuse wiesen ebenfalls keine signifikanten Unterschiede in basaler HR und HRV auf. Mittlere basale HR und HRV von CRFOEMäusen und entsprechende Werte der Wildtyp-Kontrollen waren nicht

Abb. 3.20: Mittlere Herzrate (HR, A) und Herzratenvariabilität (HRV, B) auf der Basis der RMSSD-Werte von CRF F, $^{-}$CRF $F_{2}$-defizienten und CRF-transgenen Mäusen im Vergleich zu ihren jeweiligen Wildtyp-Wurfgeschwistern vor (basal) und während $34 \mathrm{~min}$ in einer neuen Umgebung (Novelty) sowie Noveltyinduzierter HR-Anstieg (C). Mittelwerte $\pm S F$, $\mathrm{n}=9-24$ pro Gruppe.
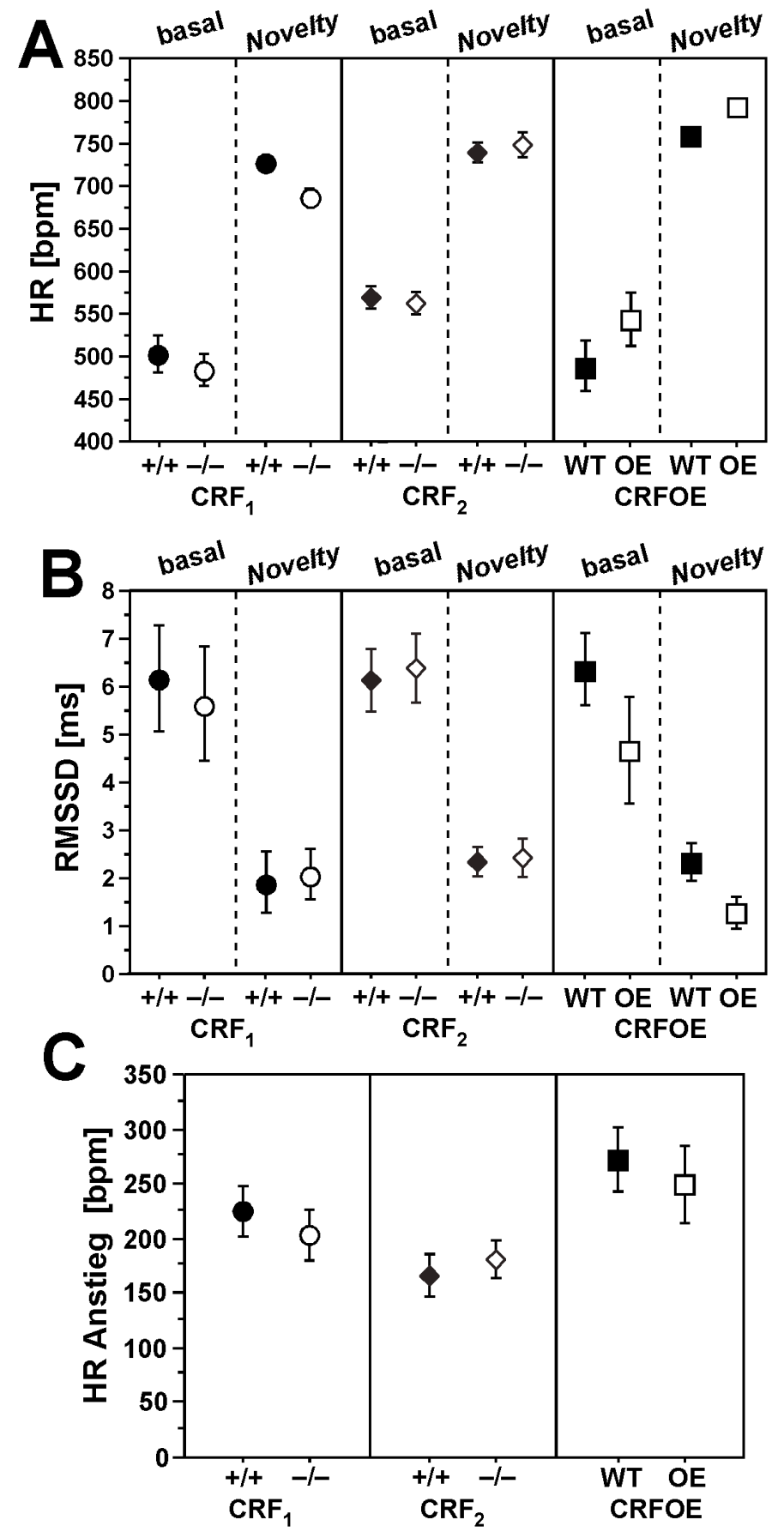
signifikant unterschiedlich (HR: $\left.F_{1,14}=1.60, \mathrm{p}=0.23 ; \mathrm{HRV}: F_{1,14}=0.11, \mathrm{p}=0.75\right)$.

Die Antwort des autonomen Systems auf den Novelty-Stimulus bestand in allen getesteten Mäusen in einer Tachykardie und einhergehender reduzierter HRV. Auf Basis der vorgenommenen Berechnungen waren bei nicht unterschiedlicher HRV $\left(F_{1,14}=0.04\right.$,

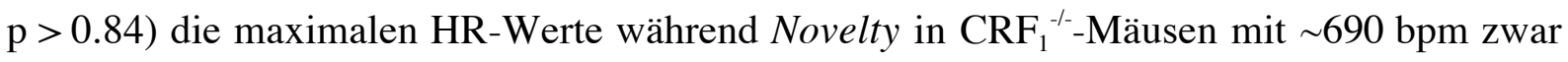
geringer als bei $\mathrm{CRF}_{1}^{+/+}$-Mäusen mit $\sim 730 \mathrm{bpm}\left(F_{1,14}=12.45, \mathrm{p}<0.05\right)$. Im Novelty induzierten HR-Anstieg bestanden jedoch keine Unterschiede zwischen den Genotypen (Abb. 3.20C). Ebenso wurden keine Unterschiede im HR-Verlauf zwischen $\mathrm{CRF}_{2}^{-{ }^{--}}$- und $\mathrm{CRF}_{2}{ }^{+/+}-$ Mäusen ermittelt $\left(F_{1,33}=1.74, \mathrm{p}>0.19\right)$. Während des Novelty-Tests erreichten die HR-Werte von CRFOE-Mäusen und den entsprechenden Wildtyp-Kontrollen nahezu maximale physiologische Werte von $~ 760-790$ bpm, wobei die HR von CRFOE-Mäusen signifikant höher ausfiel $\left(F_{1,14}=14.53, \mathrm{p}<0.05\right)$. Wiederum fiel der spezifische HR-Anstieg durch den Novelty-Test ähnlich aus $\left(F_{1,14}=0.24, \mathrm{p}=0.63\right)$. Auf Basis von HRV war während des Novelty-Tests eine Tendenz hin zu niedrigeren RMSSD-Werten in CRFOE-Mäusen verglichen mit Wildtyp-Kontrollen zu erkennen $\left(F_{1,14}=4.22, \mathrm{p}=0.06\right)$.

\subsubsection{Herzratendynamik von $\mathrm{CRF}_{1-}, \mathrm{CRF}_{2}$-defizienten und $\mathrm{CRF}$-transgenen Mäusen im Ton abhängigen Gedächtnistest}

Die Herzratenantworten der genetisch modifizierten Mäuse auf einen konditionierten emotionalen Stressor wurden mittels auditorischer Furchtkonditionierung untersucht. Mittlere basale HR und HRV in der prä-CS Phase des Ton abhängigen Gedächtnistests unterschieden

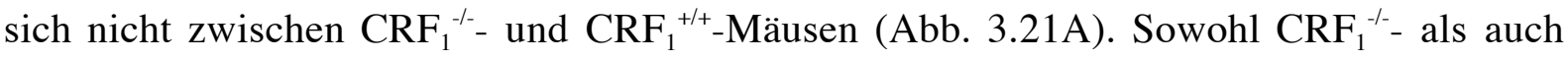
$\mathrm{CRF}_{1}{ }^{+/+}$-Mäuse zeigten eine Ton induzierte Tachykardie, die charakteristisch für die konditionierte Furchtantwort von Mäusen ist. Der Ton-CS induzierte eine sehr schnelle Beschleunigung der Herzrate bis hin zu maximalen physiologischen Werten und eine darauf folgende, langsame Rückkehr zu den Ausgangswerten. ANOVA für repetetive Messungen ergab keinen signifikanten Unterschied im HR-Verlauf zwischen den Genotypen $\left(F_{1,20}<0.01\right.$, p >0.99). Die spezifischen Ton induzierten HR-Anstiege unterschieden sich ebenfalls nicht $\left(F_{1,20}=0.01, \mathrm{p}=0.95 ;\right.$ Abb. 3.21D). Die HR-Antworten $\mathrm{CRF}_{2}$-defizienter Mäuse und ihrer Wildtyp-Wurfgeschwister während des Gedächtnistests unterschieden sich ebenfalls nicht und zeigten den normalen Verlauf von basaler HR und Ton-induzierter Tachykardie (Abb. 3.21B, D). Die basalen HR in der prä-CS Phase von CRFOE-Mäusen und Wildtyp-Kontrollen 

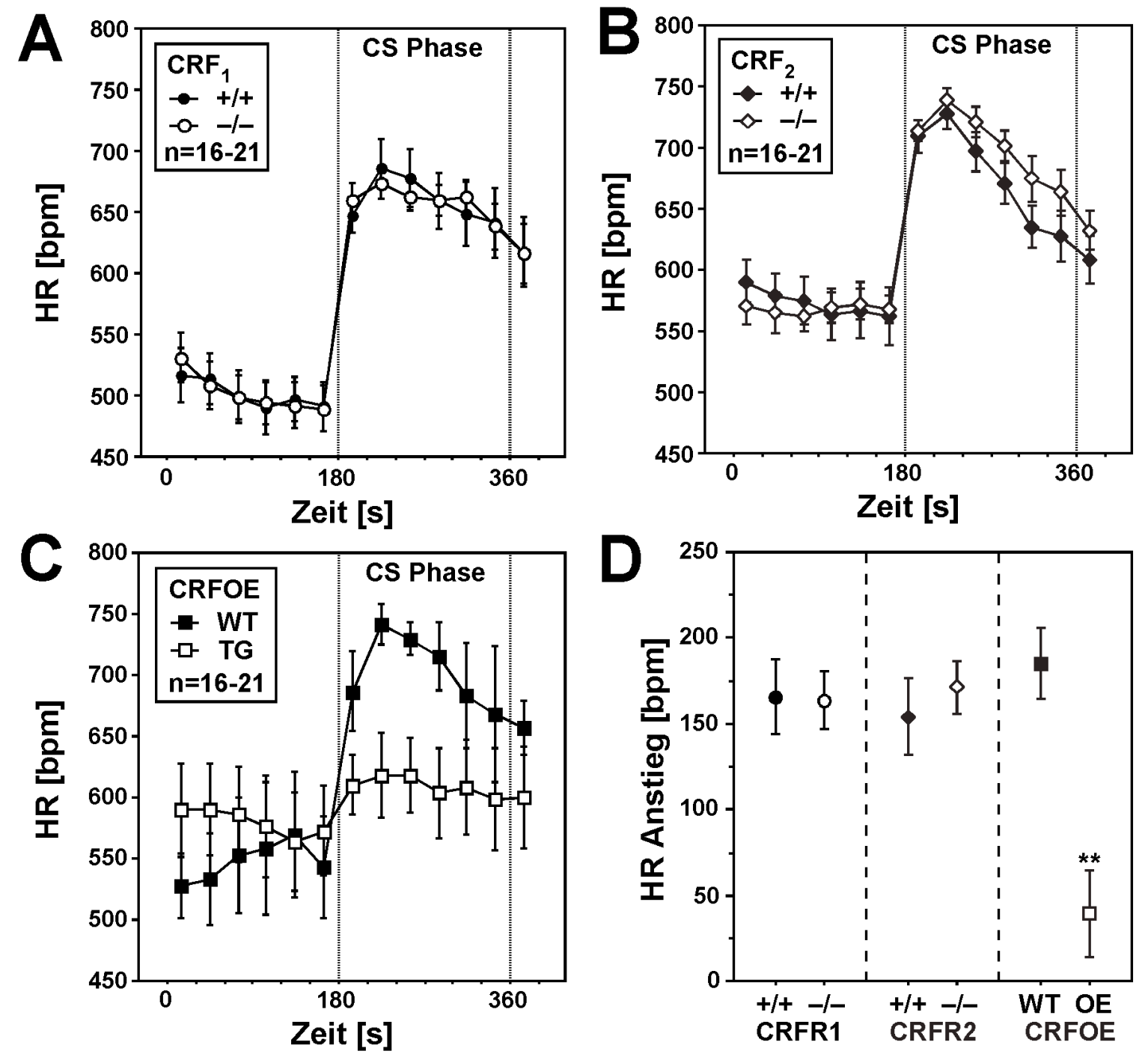

Abb. 3.21: Herzraten (HR)-Verläufe von CRF $_{1-}^{-}$(A), CRF $_{2}$-defizienten (B) und CRF-transgenen (C) Mäusen sowie Ton-induzierte Herzraten-Anstiege (HR, D) im Vergleich zu ihren jeweiligen Wildtyp-Wurfgeschwistern im Ton abhängigen Gedächtnistest. Gestrichelte Linien in A-C zeigen Beginn und Ende der Tonpräsentaion an. Mittelwerte \pm SF, $n=7-11$ pro Gruppe.

unterschieden sich nicht signifikant voneinander $\left(F_{1,12}=0.48, \mathrm{p}>0.50\right.$; Abb. 3.21C). Allerdings blieb die Ton induzierte Tachykardie als konditionierte Furchtantwort in CRFOEMäusen aus, während Wildtyp-Kontrollen mit normaler Tachykardie antworteten. Somit unterschieden sich die Verläufe der HR-Antworten wie auch die Ton induzierten HRAnstiege signifikant zwischen den Genotypen (HR-Verlauf: $F_{1,12}=7.24, \mathrm{p}<0.02 ; \Delta \mathrm{HR}$ : $\left.F_{1,14}=20.50, \mathrm{p}<0.001\right)$.

Zusätzlich wurde das Verhältnis zwischen HR (RR-Intervall) und HRV (RMSSD) während der Gedächtnistests analysiert, um einen weiten Bereich kardiodynamischer Anpassungen zu untersuchen. Die in Abb. 3.22 halblogarithmisch dargestellten Verhältnisse von HR gegen RMSSD verdeutlichten, dass zwischen HRV und HR eine inverse, nichtlineare Beziehung besteht (vgl. Abb. 3.16). Das näherungsweise exponentielle Verhältnis von 
minimaler HRV bei maximaler HR $\left(\sim 800 \mathrm{bpm}\right.$; RR Intervall $(\sim 75 \mathrm{~ms})$ wurde bei $\mathrm{CRF}_{1}^{-{ }^{-}-}$ bzw. $\mathrm{CRF}_{1}^{+/+}-$Mäusen, bei $\mathrm{CRF}_{2}^{-/-}$bzw. $\mathrm{CRF}_{2}{ }^{+++}-$Mäusen und bei CRFOE sowie deren Wildtyp-Kontrollen, durch nahezu identische Geraden beschrieben (Abb. 3.22). Als Ursache für den Unterschied der Steigung der Geraden zwischen $\mathrm{CRF}_{1^{-}}, \mathrm{CRF}_{2}$ - und $\mathrm{CRFOE-Mäusen}$ wird der nicht ganz identische genetische Hintergrund der drei Mausmodelle angesehen.
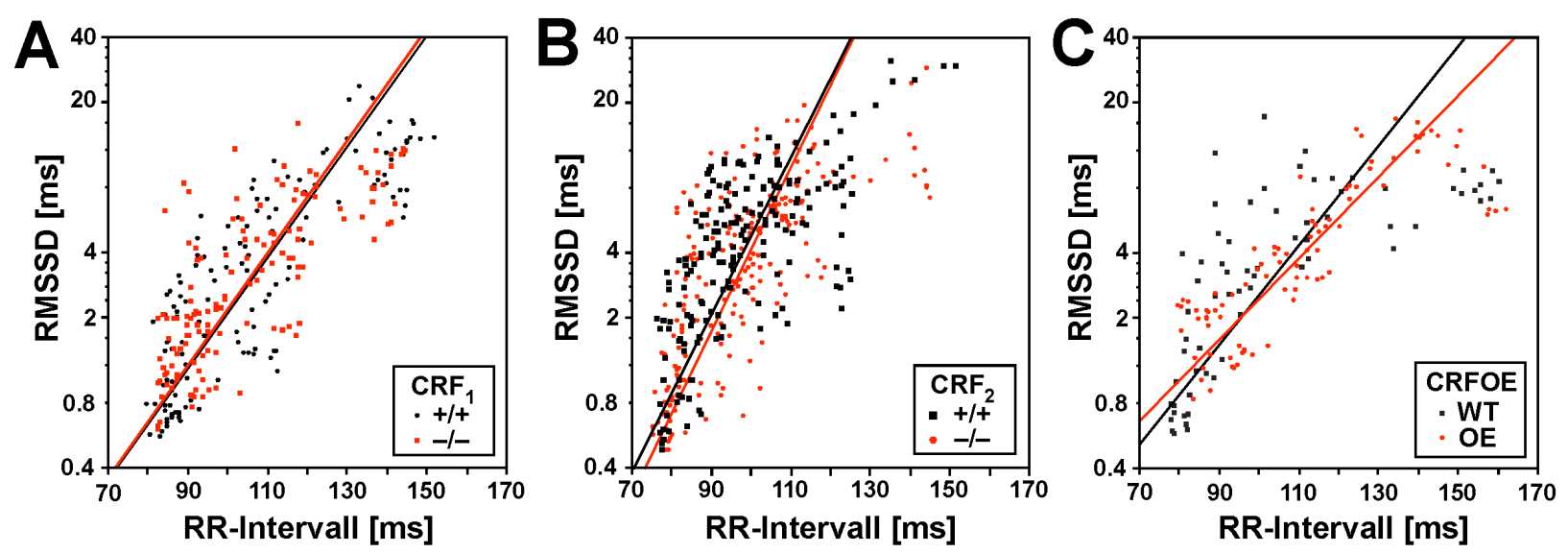

Abb. 3.22: Herzratenvariabilität (HRV) auf Basis von RMSSD als Funktion des RR-Intervalls von CRF- (A), CRF-defizienten (B) und CRF-transgenen (C) Mäusen im Vergleich zu ihren jeweiligen Wildtyp-Wurfgeschwistern. RR- und RMSSD-Werte wurden anhand von 30 s-Intervallen im Ton abhängigen Gedächtnistest ermittelt. Die farbigen Linien repräsentieren die Regressionsfunktionen für die beiden Genotypen der jeweiligen Mausmutanten. Mittelwerte \pm SF, $n=7-11$ pro Gruppe.

\subsubsection{Verhalten $\mathrm{CRF}_{1}$-defizienter Mäuse während auditorischer Furchtkon- ditionierung}

Da $\mathrm{CRF}_{1}^{-{ }^{-}}$-Mäuse im Vergleich zu ihren Wildtyp-Kontrollen keine unterschiedlichen HR-Antworten während des Novelty-Tests und der Retention konditionierter Furcht auf der Basis von HR aufwiesen, wurden Furchtkonditionierungs-Experimente ausschließlich auf der Basis von Verhaltensparametern durchgeführt. Aufgrund von Untersuchungen, die reduziertes Angstverhalten und abgeschwächte Stress-Antworten in $\mathrm{CRF}_{1}^{-1-}$-Mäusen berichteten (Smith et al., 1998; Timpl et al., 1998), sollte das Fehlen jeglicher Effekte in den Experimenten mit autonomen Messungen mit Ergebnissen aus Verhaltensexperimenten verglichen bzw. überprüft werden.

Freezing, Inaktivität, Lokomotionsaktivität und Explorationsfläche wurden sowohl in Kontext abhängigen als auch in Ton abhängigen Gedächtnistests sowie während des zuvor durchgeführten Trainings gemessen (Tabelle 3.1). Bei der Analyse dieser Verhaltens- 
Parameter mittels ANOVA wurden keine signifikanten Unterschiede als Funktion des Genotyps ermittelt. Stattdessen wurden normale Furchtantworten in allen getesteten Mäusen unabhängig vom Genotyp beobachtet.

Tabelle 3.1: Verhalten (RF 1 -defizienter Mäuse (-/-) und ihrer Wildtyp-Wurfgeschwister $(+/+)$ in Ton- bzw. Kontext abhängiger Furchtkonditionierung.

\begin{tabular}{cccccc} 
& Genotyp & Training & Retention & kein Ton & Ton \\
\hline $\begin{array}{c}\text { Freezing } \\
\text { [\%] }\end{array}$ & $+/+$ & $0 \pm 0$ & $36.0 \pm 5.4$ & $6.7 \pm 2.4$ & $43.9 \pm 4.4$ \\
\hline Inaktivität & $-/-$ & $0 \pm 0$ & $30.0 \pm 5.9$ & $3.9 \pm 1.6$ & $43.6 \pm 3.6$ \\
[\%] & $+/+$ & $10.8 \pm 1.2$ & $53.8 \pm 4.7$ & $29.1 \pm 3.6$ & $62.9 \pm 3.2$ \\
\hline Aktivität & $-/-$ & $11.0 \pm 1.0$ & $53.5 \pm 5.2$ & $27.0 \pm 3.8$ & $60.2 \pm 3.1$ \\
[cm/s] & $+/+$ & $7.3 \pm 0.2$ & $2.6 \pm 0.3$ & $5.2 \pm 0.5$ & $2.3 \pm 0.3$ \\
\hline Explorations- & $-/-$ & $7.0 \pm 0.2$ & $2.5 \pm 0.3$ & $6.1 \pm 0.5$ & $2.6 \pm 0.3$ \\
fläche [\%] & $+/+$ & $55.8 \pm 2.1$ & $22.9 \pm 3.4$ & $46.9 \pm 3.8^{*}$ & $25.2 \pm 3.1$ \\
\hline
\end{tabular}

*gößte Differenz zwischen allen ermittelten Parametern: $F_{1,37}=2.23, \mathrm{p}=0.14$.

Mittelwerte \pm SF, $n=19-20$ pro Gruppe.

\subsubsection{Untersuchungen der Furchtreaktion auf Basis der Blutplasma-Konzen- tration von Kortikosteron}

In vorhergehenden Experimenten wurde eine starke Aktivierung des kardiovaskulären Systems während der Retention der konditionierten Furcht nachgewiesen. Ein Bestandteil einer umfassenden Furchtreaktion ist auch die Aktivierung der Hypothalamus-HypophysenNebennierenrinden-Achse (HHN), deren Aktivierung durch CRF-Freisetzung im Hypothalamus gesteuert wird. Dies sollte mit Hilfe von Bestimmungen der Kortikosteronkonzentration im Blutplasma von C57BL/6N untersucht werden (Abb. 3.23A).

Basale Kortikosteronwerte naiver Mäuse lagen bei $11 \pm 3 \mathrm{ng} / \mathrm{ml}$. Im Blutplasma, das 15 min nach dem Training gesammelt wurde, ergaben sich sowohl bei der Kontrollgruppe von 


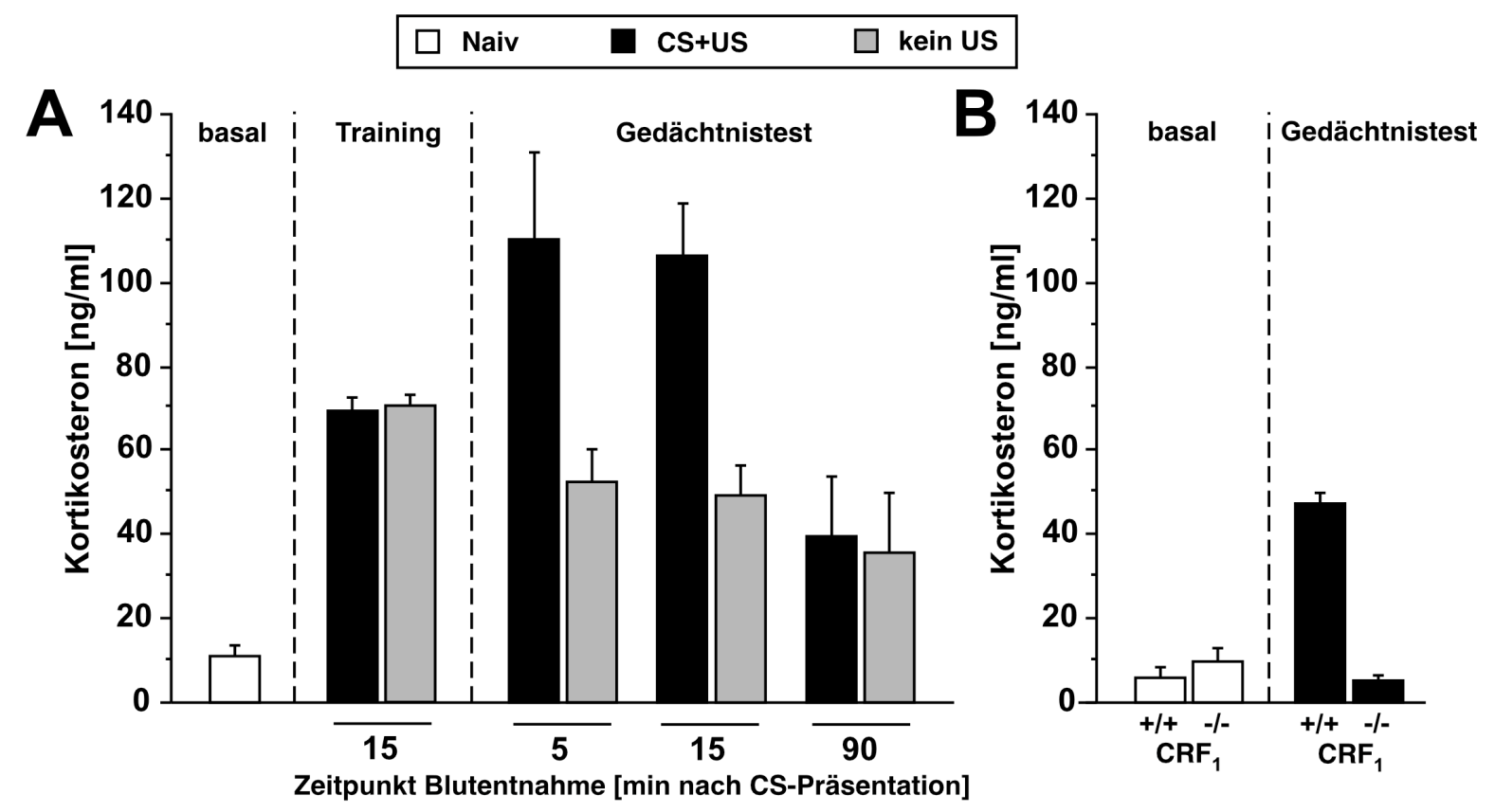

Abb. 3.23: Plasma-Kortikosteronkonzentrationen ungestresster C57BL/6N-Mäuse (Naiv) sowie Kortikosteronwerte von C57BL/6N- Mäusen, die entweder mit direkt aufeinander folgendem CS und US (CS+US) oder ohne (kein US) Präsentation des Fußschocks trainiert wurden, zu unterschiedlichen Zeitpunkten nach CS-Präsentation im Ton abhängigen Gedächtnistest (A). Plasma-Kortikosteronkonzentrationen naiver CRF 1 -defizienter Mäuse sowie CRF 1 -defizienter Mäusen, denen CS und US (CS+US) im Training direkt aufeinander folgend präsentiert wurden, 15 min nach Tonpräsentation im Gedächtnistest im Vergleich zu ihren Wildtyp-Kontrollen (B). Mittelwerte \pm SF, n= 6-10 pro Gruppe.

Mäusen, denen nur der Ton präsentiert worden war (kein US) als auch bei Mäusen, die zusätzlich einen an den Ton gekoppelten Fußschock erhalten hatten (CS+US) signifikant höhere Kortikosteronwerte $(\mathrm{p}<0.001 / 0.001)$. Fünf min nach Tonpräsentation im Gedächtnistest wurden sowohl in der CS+US- ( $p<0.0001)$, als auch in der kein US-Gruppe ( $\mathrm{p}<0.05)$ im Vergleich zu den Basalwerten signifikant höhere Kortikosteronkonzentrationen ermittelt. Dabei wiesen die im Training dem CS+US ausgesetzten Mäuse mit $110 \pm 21 \mathrm{ng} / \mathrm{ml}$ signifikant höhere Kortikosteronwerte auf als die nur dem CS ausgesetzten Kontrollmäuse mit $53 \pm 8 \mathrm{ng} / \mathrm{ml}(\mathrm{p}<0.01)$. Ebenfalls hohe Kortikosteronkonzentrationen wurden in Blutproben, die 15 min nach der Tonpräsentation gesammelt wurden, ermittelt. In diesen waren die Werte der im Training CS+US ausgesetzten Mäuse mit $106 \pm 12$ ng/ml signifikant höher als die der nur dem CS ausgesetzten Mäuse mit $49 \pm 7 \mathrm{ng} / \mathrm{ml}(\mathrm{p}<0.01)$. Zum Zeitpunkt der Blutentnahme von 90 min nach Ton-Präsentation wurden erneut niedrigere, nicht-signifikant unterschiedliche Kortikosteronkonzentrationen in beiden Gruppen ermittelt ( $p>0.05)$, die sich nicht signifikant von Kortikosteronwerten naiver Mäuse unterschieden ( $p>0.05)$.

Zusätzlich wurden die Kortikosteronkonzentrationen CRF-Rezeptor 1-defizienter Mäuse im ungestressten Zustand wie auch nach dem Gedächtnistest untersucht (Abb. 3.23B). 
Basale Kortikosteronwerte von naiven $\mathrm{CRF}_{1}^{-/-}$- und $\mathrm{CRF}_{1}^{+/+}$-Mäusen lagen im Bereich von 6$10 \mathrm{ng} / \mathrm{ml}$ und unterschieden sich nicht signifikant von Kortikosteronwerten naiver C57BL/6N-Mäuse ( $\mathrm{p}>0.05)$. Hingegen konnte bei $\mathrm{CRF}_{1}^{-{ }^{-/}}$-Mäusen, die im Training CS+US ausgesetzt wurden, 15 min nach Ton-Präsentation keine erhöhte Kortikosteronkonzentration im Vergleich zu basalen Werten festgestellt werden $(p>0.05)$. Damit unterschieden sich diese von ihren Wildtyp-Wurfschwistern $\left(\mathrm{CRF}_{1}^{+/+} ; \mathrm{CS}+\mathrm{US}\right)$, die signifikant erhöhte Kortikosteronwerte von $47 \pm 3 \mathrm{ng} / \mathrm{ml}$ als Folge der Präsentation des CS aufwiesen $(\mathrm{p}<0.0001)$.

\subsection{Beitrag des dorsalen Hippokampus zur Gedächtnisbildung und neuro- autonomer Regulation bei Trace-Furchtkonditionierung}

Zusätzlich zu der Untersuchung der kardiovaskulären Furchtreaktion auf neuroautonomer und neurochemischer Ebene sollte die Untersuchung der neuroanatomischen Grundlagen $\mathrm{zu}$ einem umfassenden Bild beitragen. Zur Ermittlung eines passenden Zeitfensters für eine vom Hippokampus vermittelte Furcht abhängige Herzratenantwort wurde zunächst in einer breit angelegten Studie der Beitrag des Hippokampus zur TraceFurchtkonditionierung auf Verhaltensebene untersucht. Dies erfolgte zunächst auf der Basis von Verhaltens-Indikatoren wie Freezing und Inaktivität. Mit dem selektiven NMDARezeptor-Antagonisten APV wurde der dorsale Teil des Hippokampus während des Trainings inaktiviert, um so den Beitrag dieses Hirnareals für die Akquisition Kontext- und Ton abhängiger Gedächtnisinhalte zu untersuchen und diese dann auf neuroautonomer Ebene zu testen.

\subsubsection{Ergebnisse auf Verhaltensebene}

\section{Training}

Intrahippokampale (IH) Injektion von APV (3.2 $\mu \mathrm{g} / \mathrm{Maus}) 15$ min vor dem Training bewirkte einen signifikanten Anstieg der mittleren lokomotorischen Aktivität $\left(F_{1,174}=52.93\right.$, $\mathrm{p}<0.001)$ und eine Reduktion der Inaktivität $\left(F_{1,174}=52.93, \mathrm{p}<0.001\right)$ in den ersten $120 \mathrm{~s}$ der kontextuellen Explorationsphase gegenüber aCSF-injizierten Mäusen. Unabhängig von 
der injizierten Substanz zeigten die Mäuse während des Trainings keinerlei Freezing (Tabelle 3.2). Höhere Aktivitätswerte wurden bei APV-injizierten Mäusen im Vergleich zu aCSFinjizierten Mäusen gemessen. Bei allen Mäusen wurde eine klare Aufmerksamkeitsreaktion auf das Einsetzen des $30 \mathrm{~s}$ andauernden Tons beobachtet, die durch ein kurzes Aussetzen lokomotorischer Aktivität, Anheben des Kopfes und Bewegungen des Außenohrs gekennzeichnet war. APV-Injektion resultierte in einem Anstieg der US induzierten Aktivität $\left(F_{1,174}=4.21, \mathrm{p}<0.05\right.$, Tabelle 3.2).

Tabelle 3.2: Effekte intrahippokampaler APV- bzw. aCSF-Injektionen auf das Verhalten im Training.

\begin{tabular}{llllll}
$\begin{array}{l}\text { injizierte } \\
\text { Substanz }\end{array}$ & $\mathbf{n} /$ Gruppe & $\begin{array}{l}\text { basale } \\
\text { Aktivität }{ }^{\S}[\mathbf{c m} / \mathbf{s}]\end{array}$ & $\begin{array}{l}\text { basale } \\
\text { Inaktivität }[\%]\end{array}$ & $\begin{array}{l}\text { basales } \\
\text { Freezing [\%] }\end{array}$ & $\begin{array}{l}\text { US Aktivität } \\
{[\mathbf{c m} / \mathbf{s}]^{\S}}\end{array}$ \\
\hline aCSF & $93 / 85^{\#}$ & $7.29 \pm 0.13$ & $10.12 \pm 0.84$ & $0.26 \pm 0.13$ & $35.43 \pm 1.16$ \\
APV & $102 / 91^{\#}$ & $8.82 \pm 0.16^{* * *}$ & $5.47 \pm 0.42^{* * *}$ & $0.00 \pm 0.00$ & $38.93 \pm 1.24 *$ \\
\hline
\end{tabular}

Mittelwerte \pm SF. $* p<0.05, * * * p<0.001 .{ }^{\S}$ Berechnungsgrundlage: $120 \mathrm{~s}$ Explorationsphase im Konditionierungs-Kontext. "Geringere Gruppengröße für die Bestimmung der US Aktivität aufgrund des fehlenden Fußschocks (US) in der zusätzlichen Kontrollgruppe (no US).

\section{Auditorische Trace-Furchtkonditionierung}

In der CS-Phase des Ton abhängigen Gedächtnistests (Abb. 3.24) wurde ein signifikanter Effekt für die beiden Faktoren Injektion und Trace-Intervalllänge auf Inaktivität (Injektion: $F_{7,160}=24.47, \mathrm{p}<0.0001 ;$ Trace: $F_{7,160}=9.1, \mathrm{p}<0.0001$ ) und auf Freezing (Injektion: $F_{7,160}=21.88, \mathrm{p}<0.0001 ;$ Trace $: F_{7,160}=9.08, \mathrm{p}<0.0001$ ) festgestellt. Eine signifikante Interaktion von Injektion X Trace wurde bei keiner Messmethode festgestellt (Inaktivität: $F_{7,160}=1.96, \mathrm{p}>0.064$; Freezing: $F_{7,160}=1.78, \mathrm{p}>0.096$ ). Keine signifikanten Unterschiede auf Basis von einseitigem ANOVA bestanden zwischen aCSF-Kontrollgruppen und APV-behandelten Gruppen bei Delay-Konditionierung (0 s) oder kurzen TraceIntervallen (1 oder $3 \mathrm{~s}$ ). Bei mittleren Trace-Intervallen (5 and $10 \mathrm{~s}$ ) war Inaktivität reduziert ( $\mathrm{p}<0.05)$, nicht jedoch Freezing $(\mathrm{p}>0.05)$. Sowohl Inaktivität als auch Freezing waren bei APV-behandelten Mäusen, die mit längeren Trace-Intervallen (15 und 30 s) trainiert worden waren, signifikant erniedrigt. Ein im Training auf $45 \mathrm{~s}$ verlängertes Trace-Intervall verhinderte die Assoziation von CS und US im Training und damit die Furchtkonditionierung im Ton abhängigen Gedächtnistest in APV-injizierten und aCSF-injizierten Mäusen (Abb. 
3.24). Die Ergebnisse der Inaktivität- und des Freezing in Abhängigkeit vom Trace-Intervall folgten demselben Trend, abgesehen davon dass die Inaktivität durchgängig höher war als das Freezing (s. Diskussion). In zusätzlichen Kontrollguppen, die im Training jedoch keinen Schock erhalten hatten (kein US) lag die Inaktivität bei 20\%, während Freezing mit $\sim 0 \%$ nicht beobachtet wurde (Abb. 3.24).
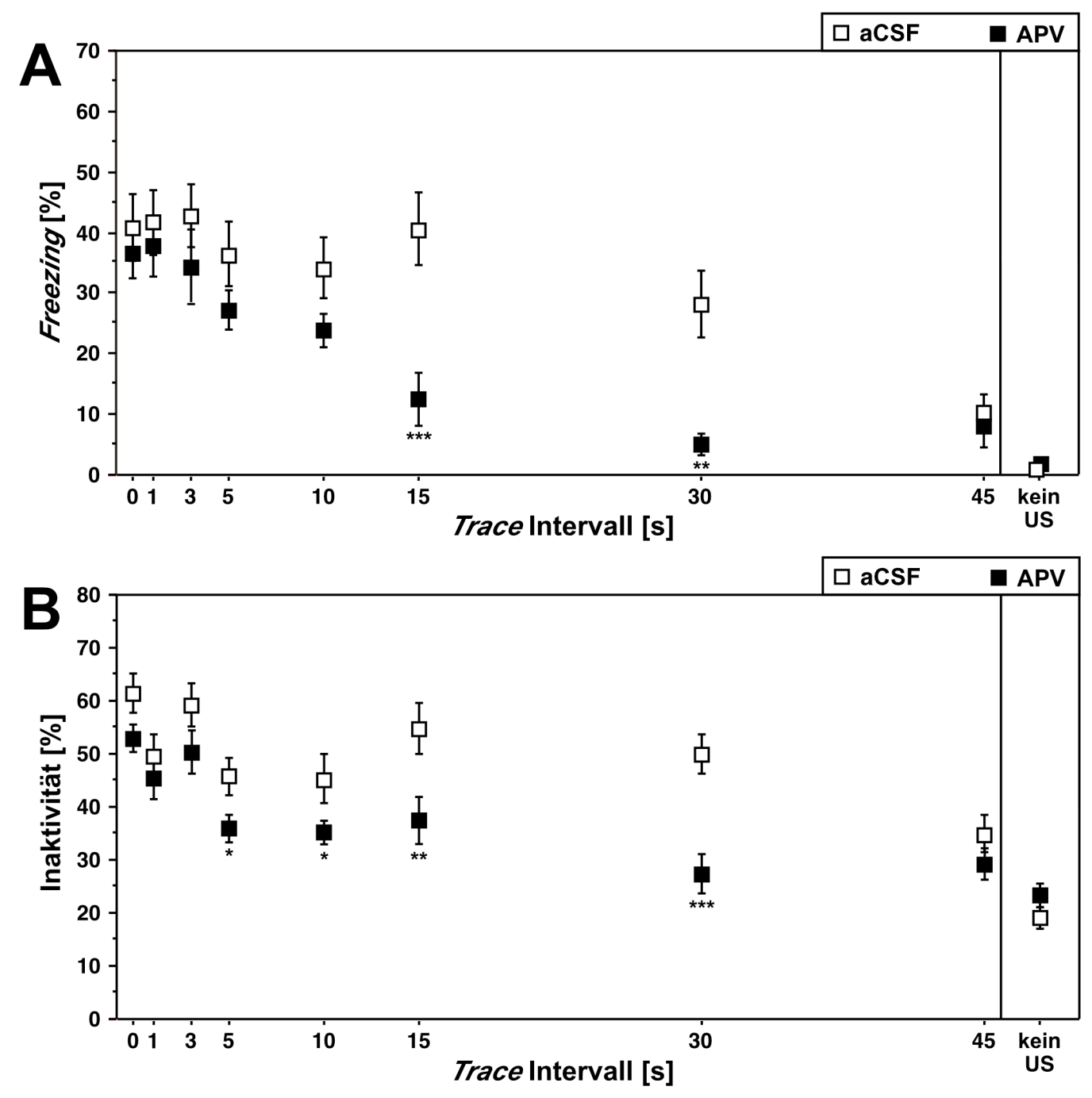

Abb. 3.24: Freezing (A) und Inaktivität (B) von C57BL/6J-Mäusen im Ton abhängigen Gedächtnistest als Funktion des TraceIntervalls im Training und der intrahippokampalen Injektion von entweder künstlicher Hirnflüssigkeit (aCSF) oder des NMDAAntagonisten APV. Mäuse, die im Training keinen Fußschock erhalten hatten (kein US), dienten als zusätzliche Kontrollen. $\mathrm{n}=9$ 22 pro Gruppe.

\section{Kontextuelle Furchtkonditionierung}

Im Kontext abhängigen Gedächtnistest (Abb. 3.25) wurde ein signifikanter Effekt der pharmakologischen Intervention, nicht jedoch des Trace-Intervalls auf Inaktivität (Injektion: 
$F_{7,160}=147.95, \mathrm{p}<0.0001 ;$ Trace $\left.: F_{7,160}=0.95, \mathrm{p}>0.46\right)$ sowie auf Freezing (Injektion: $F_{7,160}=264.18, \mathrm{p}<0.0001$; Trace: $\left.F_{7,160}=1.23, \mathrm{p}>0.29\right)$ ermittelt. APV-Injektion vor dem Training verursachte deutlich niedrigere Inaktivitäts- und Freezing-Werte im Gedächtnistest unabhängig von der CS-US Intervalllänge. Eine signifikante Interaktion von Injektion X Trace wurde für keine der beiden Messmethoden ermittelt (Inaktivität: $F_{7,160}=0.83, \mathrm{p}>0.56$; Freezing: $\left.F_{7,160}=0.68, \mathrm{p}>0.69\right)$. Trotz leichter Variabilität in den Inaktivitäts- und FreezingWerten wurden keine signifikanten Unterschiede zwischen den Gruppen mit unterschiedlichen Trace-Intervalllängen innerhalb der beiden unterschiedlich behandelten Gruppen ,,aCSF“ (Inaktivität: $F_{7,77}=0.68, \mathrm{p}>0.69$; Freezing: $F_{7,77}=1.30, \mathrm{p}>0.26$ ) und
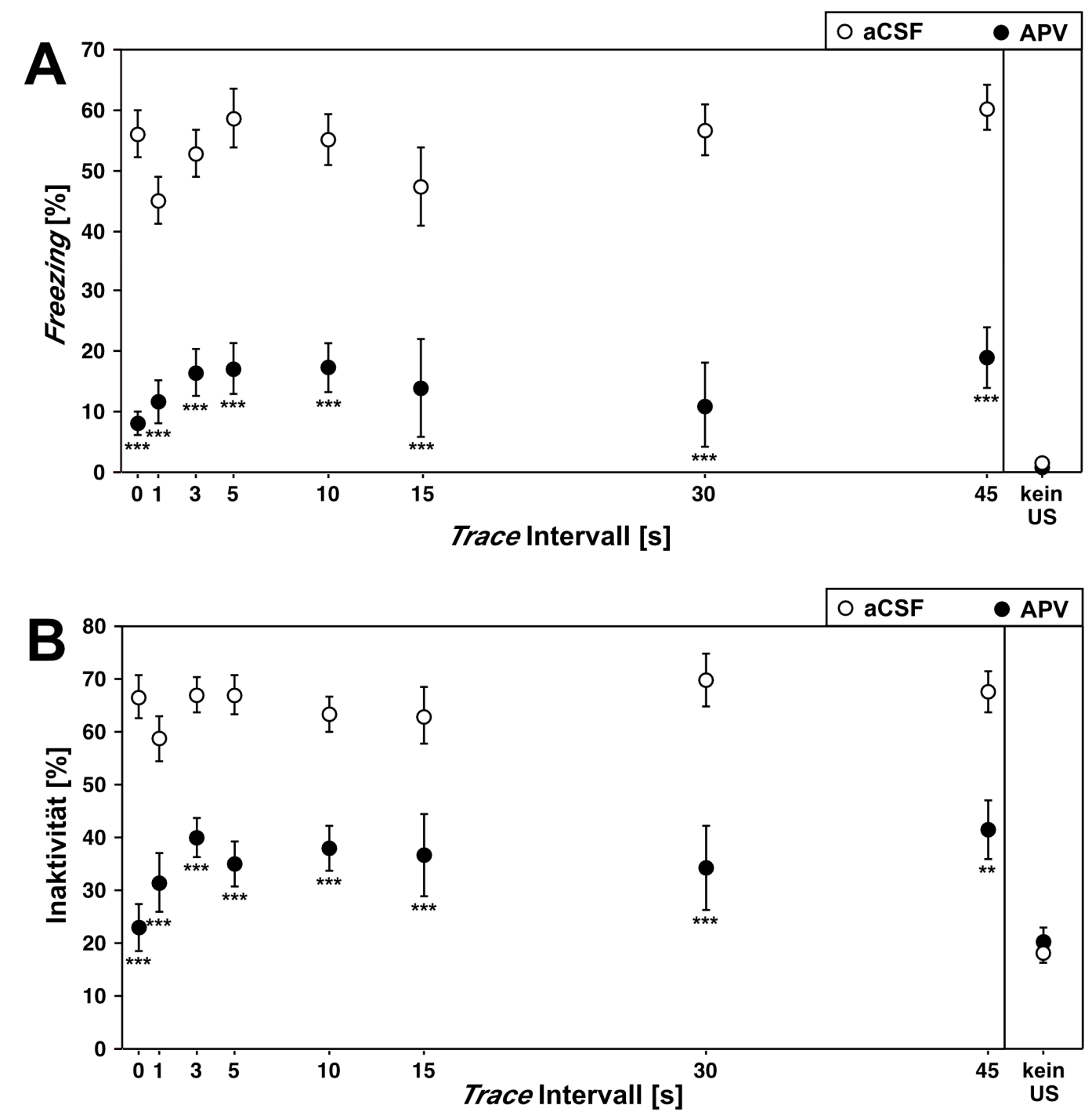

Abb. 3.25: Freezing (A) und Inaktivität (B) von C57BL/6J-Mäusen im Kontext abhängigen Gedächtnistest als Funktion des TraceIntervalls im Training und der intrahippokampalen Injektion von entweder künstlicher Hirnflüssigkeit (aCSF) oder des NMDA-Antagonisten APV. Mäuse, die im Training keinen Fußschock erhalten hatten (kein US), dienten als zusätzliche Kontrollen. $\mathrm{n}=8-22$ pro Gruppe. 
„APV“ (Inaktivität: $F_{7,83}=1.00, \mathrm{p}>0.43$; Freezing: $F_{7,83}=0.68, \mathrm{p}>0.68$ ) ermittelt. Die Intensität der Antworten von aCSF- und APV-injizierten Mäusen war unabhängig von der Trace-Intervalllänge. Wie schon im Ton abhängigen Gedächtnistest zeigten Inaktivität und Freezing ähnliche zeitliche Profile, wobei die Inaktivität systematisch das Freezing überstieg. Das Verhalten der Kontrollgruppen (kein US) im Kontext abhängigen Gedächtnistest war mit 20\% Inaktivität und $~ 0 \%$ Freezing ähnlich.

\subsubsection{Vergleich der Messmethoden für Freezing und Inaktivität}

In den Gedächtnistests wurde das charakteristische Freezing-Verhalten vom Experimentator in $10 \mathrm{~s}$-Abständen bewertet, während die Inaktivität mit Hilfe eines Computersystems bei $\sim 10 \mathrm{~Hz}$ ermittelt wurde. Mit Hilfe einer ANOVA Regressionsanalyse wurde eine enge lineare Korrelation zwischen beiden Messmethoden sowohl im Ton abhängigen $\left(F_{1,193}=603.85, \mathrm{p}<\right.$ 0.001) als auch im Kontext abhängigen $\left(F_{1,193}=1217.92, \mathrm{p}<\right.$ 0.001) Gedächtnistest festgestellt (Abb. 3.26). Die Steigung beider Regressionsgeraden lag bei $\sim 0.94$. Für 0\% Freezing zeigte sich ein Offset von $18 \%$ Inaktivität. Abbildung 3.26 kann als eine auf die Messdaten bezogene „Kalibrierkurve“ herangezogen werden, die verdeutlicht, dass die Sensitivitäten der beiden

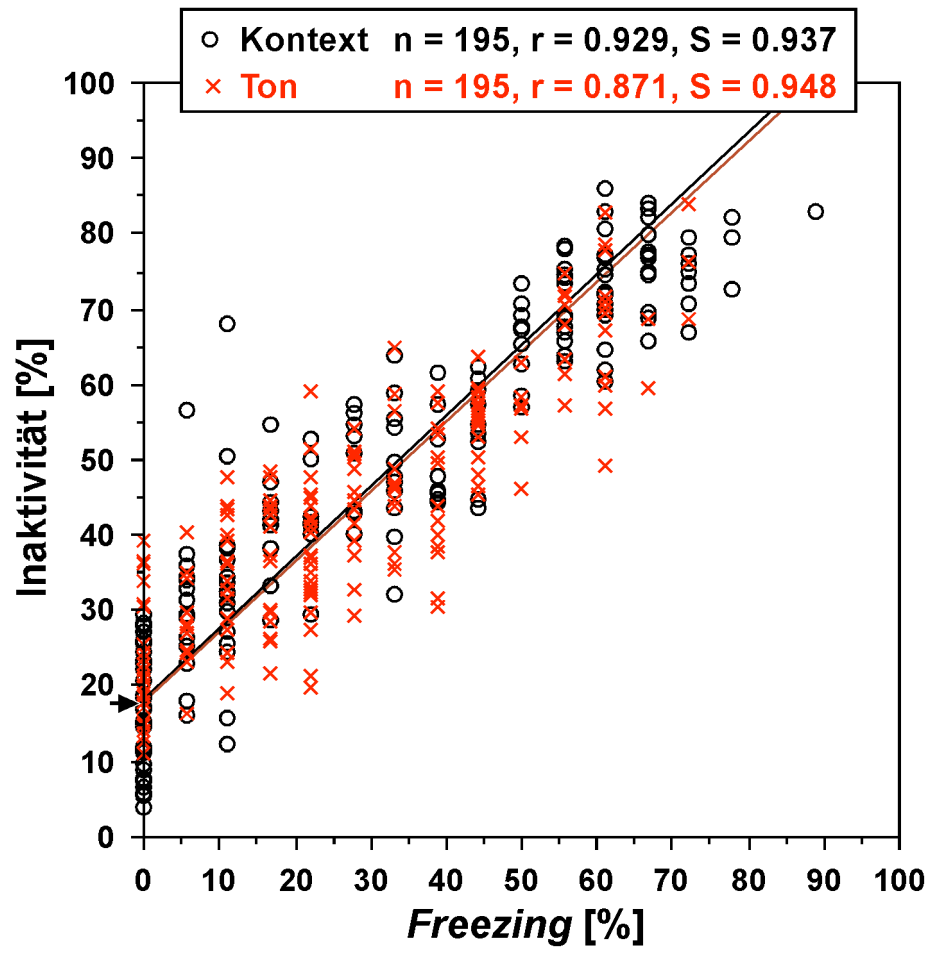

Abb. 3.26: Lineare Regression von Freezing und Inaktivität im Kontext und Ton abhängigen Gedächtnistest. $r=$ Regression, $S=$ Steigung der Funktion. Messmethoden zur Detektierung von Freezing äquivalent sind. Inaktivität $\leq 18 \%$ kann somit als unspezifische Inaktivität interpretiert werden, die nicht im Zusammenhang mit Furcht induziertem Freezing steht. Nach Korrektur des Inaktivitäts-Offsets fallen die Regressionsgeraden mit der Trennungslinie, 
die das Diagramm in zwei gleiche Sektoren teilt, zusammen. Infolge dessen kann die Inaktivität direkt als Freezing abgelesen werden.

\subsubsection{Ergebnisse auf Basis der autonomen Funktion bei der Trace-Konditio- nierung}

Die Ergebnisse auf Verhaltensebene demonstrierten eine Beteiligung des Hippokampus an der Gedächtnisbildung bei Trace-Intervallen von 15 s und 30 s. Aufgrund der deutlichen Effekte von NMDA-Rezeptor-Inhibierung im dorsalen Hippokampus bei TraceFurchtkonditionierung auf Verhaltensebene von Mäusen, wurden Effekte auch auf eine konditionierte Tachykardie bei

Trace-Furchtkonditionierung erwartet. Diese Hypothese wurde mit Hilfe von Herzratenmessungen in Ton abhängigen Gedächtnistests bei Trace-Intervalllängen von $15 \mathrm{~s}$ und $30 \mathrm{~s}$ untersucht. Entgegen den Erwartungen reagierten auch APV-injizierte Mäuse mit starker Beschleunigung der HR auf den Ton-CS (Abb. 3.27). Mittels ANOVA für repetitive Messungen konnten keine signifikanten Unterschiede

Abb. 3.27: Herzraten -Verläufe in C57BL/6N-Mäusen im Ton abhängigen Gedächtnistest. 15 min vor dem Training mit entweder $15 \mathrm{~s}$ Trace-Intervall und einmaliger Ton-Schock-Abfolge (CS+US) im Training (A) oder 30 s TraceIntervall und dreimaliger Ton-Schock-Abfolge (CS+US) im Training (B) wurde der NMDA-Antagonist APV in den dorsalen Hippokampus appliziert. Intrahippokampale Injektion künstlicher Hirnflüssigkeit (aCSF) diente jeweils als Kontrolle. Mittelwerte \pm SF, $n=$ 5-7 pro Gruppe.
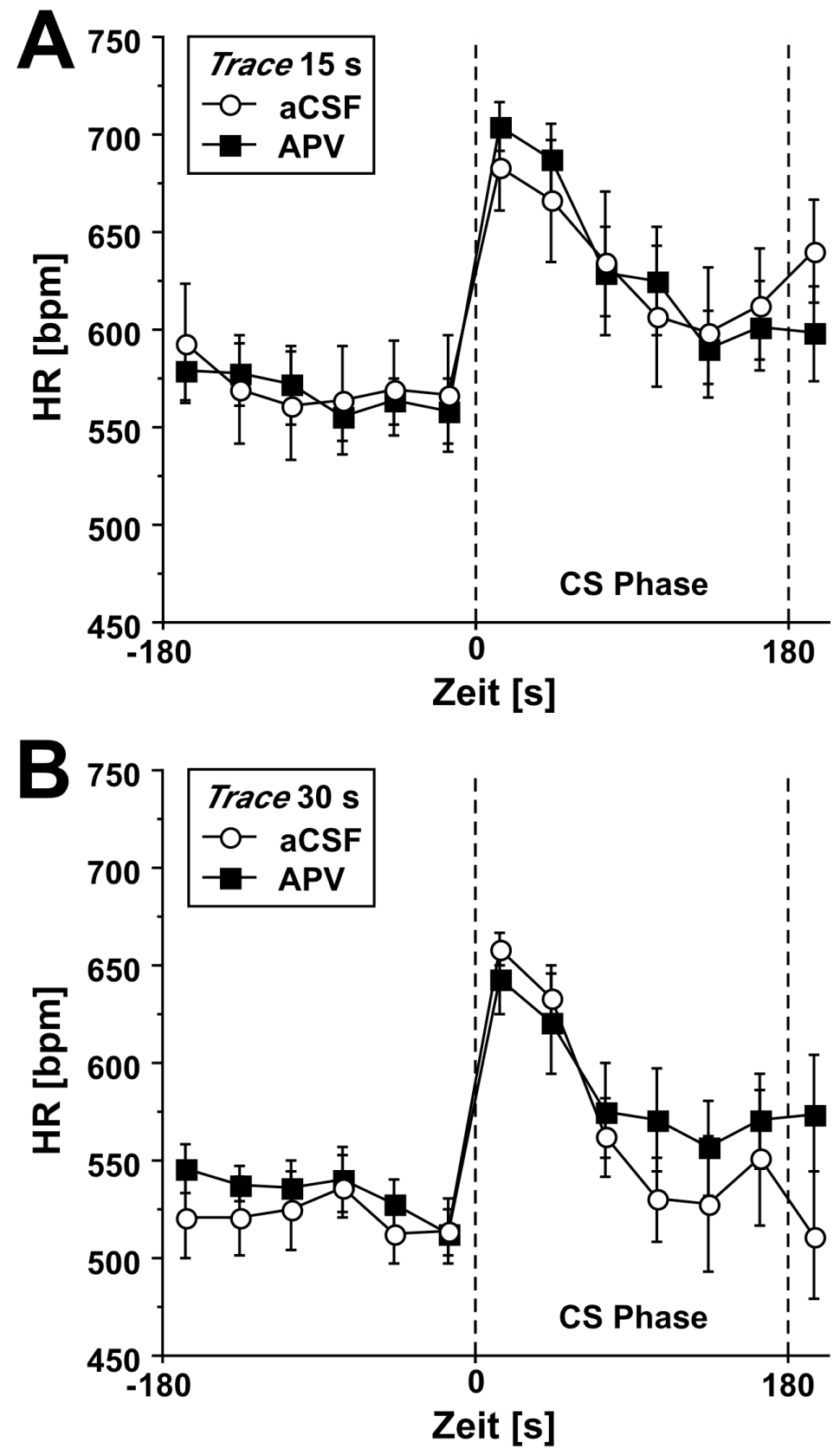
zwischen Herzratenverläufen aCSF- bzw. APV-injizierter Mäuse, denen im Training eine einfache Ton-Schock Sequenz mit 15-sekündigem Trace-Intervall präsentiert worden war, festgestellt werden $\left(F_{1,11}=0.01, \mathrm{p}=0.94\right.$; Abb. 3.27A). Auch bei aCSF- bzw. APV-injizierten Mäusen, die im Training der dreimaligen Ton-Schock Abfolge mit einem Trace-Intervall von $30 \mathrm{~s}$ trainiert wurden, ergaben sich keine unterschiedlichen Herzratenantworten $\left(F_{1,11}=0.56\right.$, $\mathrm{p}=0.47 ;$ Abb. 3.27B). 


\section{Diskussion}

In der vorliegenden Arbeit wurden neuroautonome Regulationsmechanismen und deren Modulation mittels externer Stimuli unterschiedlichen emotionalen bzw. kognitiven Bedeutungsgehalts oder durch pharmakologische Interventionen im Zentralnervensysten bzw. in der Peripherie untersucht. Der Schwerpunkt lag dabei auf den neuroautonomen bzw. kardiovaskulären Antworten von Mäusen auf aversiv konditionierte Stimuli und dem Beitrag des CRF-Systems zu den zugrunde liegenden Mechanismen. Die Interpretation der Aktivierungszustände des autonomen Nervensystems mit seinen beiden Ästen, dem Sympathikus und Parasympathikus, wurde indirekt über die Bewertung der Wechselbeziehungen von Herzrate, Herzratenvariabilität und Blutdruck möglich.

Ein wesentliches Ergebnis der vorliegenden Arbeit stellt die zeitliche Charakterisierung der kardiovaskulären Anpassungsprozesse während der Retention konditionierter Furcht dar, die mit Hilfe der kontinuierlichen telemetrischen Aufnahmetechnik ermöglicht wurde. Eine zeitliche Dissoziation von schnellen Herzraten- und langsameren Blutdruckänderungen wurde festgestellt. Dabei konnten schnelle Blutdruckantworten von Mäusen - im Gegensatz zu früheren Ergebnissen von Experimenten mit Ratten- als unkonditionierte Antworten nachgewiesen werden. Zur umfassenden Analyse der konditionierten Furchtantwort wurde zusätzlich auch die Aktivität der Hypothalamus-Hypophysen-Nebennieren (HHN)-Achse untersucht. Der Nachweis gesteigerter Kortikosteronwerte im Blutplasma von Mäusen, die eine aversive Assoziation von Ton mit Fußschock ausgebildet hatten, qualifizierte die auditorische Furchtkonditionierung als Modell für akute emotionale Belastung.

Des Weiteren konnte die Involvierung des CRF-Systems zur neuroautonomen Regulation auf pharmakologischer Basis bestätigt und näher beschrieben werden. Dennoch bleibt der physiologische Beitrag endogenen CRFs zu kardiovaskulären Regulationsmechanismen unklar. Im Gegensatz zu früheren Hypothesen und Befunden bei Ratten konnte eine wichtige Rolle für CRF bei akuten neuroautonomen Anpassungsprozessen in emotionalen Situationen nicht bestätigt werden.

Mit Hilfe von Trace-Furchtkonditionierung und Verhaltensmessungen konnte ermittelt werden, dass hippokampale NMDA-Rezeptoren an der Verarbeitung zeitlich getrennter Zusammenhänge während assoziativen Lernens beteiligt sind. Gleichzeitig konnten mit Hilfe neuroautonomer Messungen parallele Hippokampus unabhängige Gedächtnisfunktionen 
untersucht werden. Diese neuen Ergebnisse tragen zu einem Grund legenden Verständnis der emotionalen Modulation neuroautonomer bzw. kardiovaskulärer Regulation bei.

\subsection{Kardiovaskuläre Untersuchungen mit Hilfe von Radiotelemetrie}

Eine wichtige Vorraussetzung für die Untersuchung experimentell erzeugten Stresses sind stressfreie, basale Ausgangsbedingungen. Viele experimentelle Modelle oder Tests erfüllen dieses Kriterium jedoch nicht, da durch manuelle Interventionen mit den Versuchstieren oder Änderungen der Umgebung hinsichtlich Haltungs- und Versuchsbedingungen exogene Stimulation mit potentiell Stress auslösenden Effekten einhergeht. In der vorliegenden Arbeit wurden mit Hilfe chronisch implantierter Radiotransmitter die kardiovaskulären Parameter Herzfrequenz und Blutdruck gemessen. Die Methode der telemetrischen Übertragung dieser physiologischen Messgrößen ermöglichte ihre Aufzeichnung unter basalen, stressfreien Bedingungen. Die Untersuchungen zu den Effekten externer Stimuli auf Herzrate und Blutdruck machten deutlich, dass die Versuchsmäuse eine empfindliche kardiovaskuläre Responsivität hinsichtlich äußerer Störungen besitzen, d.h. auf exogene Reize sensibel mit Herzratenbeschleunigung und Blutdruckerhöhung reagieren. Ergebnisse und Schlussfolgerungen zur physiologischen Relevanz in Studien, welche kardiovaskuläre Messungen mit hohen Basalwerten beinhalten, jedoch keine Kontrolle über den Beitrag der äußeren Versuchsbedingungen erlauben (Bale et al., 2004; Shekhar et al., 2003), sollten aufgrund der Ergebnisse der vorliegenden Arbeit kritisch bewertet werden.

\section{Herzraten vs. Blutdruckmessungen}

Die Validität telemetrischer Messungen der Herzrate sowohl aus methodologischer Sicht als auch hinsichtlich ihrer Aussagekraft als Messgröße basaler und emotional modulierter Zustände von Mäusen ist in vielen Publikationen belegt (Carrive, 2000; Stiedl et al., 2003; Stiedl \& Spiess, 1997). In der vorliegenden Arbeit wurde zum ersten Mal die telemetrische Blutdruckmessung bei freibeweglichen Mäusen während der Retention konditionierter Furcht untersucht. Im Gegensatz zu konventionellen Studien, in denen automatisierte Messsysteme MAP-Werte über z.B. nur $3 \mathrm{~s}$ Intervalle pro $20 \mathrm{~s}$ bei $90 \mathrm{~min}$ Versuchsdauer generieren (Dielenberg et al., 2001), liegen den gemittelten Ergebnissen der 
vorliegenden Arbeit kontinuierlich aufgezeichnete Rohdaten zugrunde. Erst dadurch können schnelle Fluktuationen erkannt werden. Dies war die Vorraussetzung für die Differenzierung der schnellen und der langsamen Komponente der Furcht induzierten Blutdruckantwort. Im Vergleich zur Analyse der Herzraten zeigten sich jedoch methodische Schwächen der Blutdruckmessungen. So wurden unterschiedliche Amplituden des Blutdrucksignals beobachtet. Neben physiologischen Schwankungen oder individuellen Unterschieden zwischen den Versuchsmäusen (Strömungsverhältnisse in der Aorta) könnte u.U. auch die leicht unterschiedliche Lage der Insertionsstelle des Katheters in der Aorta verantwortlich sein. Die Ergebnisse der vorliegenden Arbeit wurden daher immer auf Basis des mittleren Blutdrucks ermittelt, mit dem diese Amplitudenschwankungen vernachlässigt werden konnten. Während das Herzschlagintervall auf Basis der klar detektierbaren R-WellenMaxima des EKG sehr genau bestimmbar war, bot die Blutdruckkurve kein so exakt definiertes Zeitfenster (vergl. Abb. 2.4/2.10). Eine erste Kalkulation der Herzrate basierend auf dem Systolen-Intervall wurde zugunsten des Diastolen-Intervalls verworfen, da das spitze diastolische Minimum einen genaueren Punkt der Herzperiode lieferte. Somit waren zuverlässige Herzratenberechnungen mit hinreichender Genauigkeit möglich. Jedoch wurde auf die Berechnung der Herzratenvariabilität auf Grundlage der Blutdruckdaten verzichtet, da hierfür keine ausreichende Genauigkeit in der Bestimmung des Herzschlagintervalls erzielt werden konnte.

\subsection{Kardiovaskuläre Antworten auf konditionierte und unkonditionierte Stimuli}

Die Ergebnisse der kardiovaskulären Messungen in den Ton und Kontext abhängigen Gedächtnistests bestätigten die Messgröße Herzrate als zuverlässigen Indikator für konditionierte Furcht. Gleichzeitig konnte mit dem Auftreten einer Tachykardie während der Retention konditionierter Furcht die Assoziation von konditioniertem und unkonditioniertem Stimulus nachgewiesen und frühere Untersuchungen an Mäusen bestätigt werden (Stiedl \& Spiess, 1997). Zusätzlich wurde erstmals an Mäusen der mittlere Blutdruck als Messparameter zur Untersuchung konditionierter Furchtreaktionen eingeführt. Es konnte nachgewiesen werden, dass auch dieser Indikator für konditionierte auditorische Furcht ist, wenn auch mit gegenüber der Herzrate etwas verzögerter zeitlicher Dynamik. Obwohl kardiovaskuläre Parameter zur Bewertung konditionierter Furchtantworten herangezogen 
werden (Shekhar et al., 2003), liegen bislang wenige oder ungenaue Untersuchungen zu ihrer zeitlichen Dynamik vor (Carrive, 2000; Dielenberg et al., 2004).

\section{Kardiovaskuläre Antworten auf auditorische Stimuli}

Basale Herzraten und Herzratenantworten auf den emotionalen Stimulus des aversiv konditionierten Tons (CS) bestätigten die Ergebnisse früherer Studien (Stiedl et al., 2003; Stiedl et al., 1999a; Stiedl et al., 1999b). Die CS induzierte Herzratenantwort war die sofort eintretende Beschleunigung zu maximalen physiologischen Werten bei einer Latenz von etwa $1 \mathrm{~s}$ und einer Halbwertszeit der Beschleunigung von etwa $3 \mathrm{~s}$. Frühere Experimente mit periphererer $\beta$-adrenerger Blockade verdeutlichten, dass diese schnelle Reaktion auf die Aktivierung des Sympathikus bei gleichzeitiger Zurücknahme des parasympathischen Tonus (Nijsen et al., 1998; Stiedl \& Spiess, 1997; Tovote, 2001) zurückzuführen ist. Verglichen mit der Präsentation eines $180 \mathrm{~s}$ Ton-CS resultierte ein nur $10 \mathrm{~s}$ Ton-CS in einem ähnlichen Herzratenanstieg. Daher konnte eine unkonditionierte, durch die Dauer des CS verursachte Herzratenantwort ausgeschlossen werden. Ein nur sehr milder Herzratenanstieg in unkonditionierten Mäusen wurde als Attentions- bzw. Erregungsantwort interpretiert. Aufgrund dieser Ergebnisse konnte eine generalisierte Furchtantwort auf den verwendeten konditionierten Stimulus ausgeschlossen werden (Radulovic et al., 1998; Stiedl et al., 1999b).

In zirkadianen Untersuchungen wurde ein normaler Dynamikbereich des mittleren Blutdrucks ermittelt (Butz \& Davisson, 2001; Van Vliet et al., 2003). Im Vergleich zur Herzratenantwort ergab sich eine unterschiedliche zeitliche Dynamik der Blutdruckantwort in Ton abhängigen Gedächtnistests. Diese bestand aus einer schnellen Komponente - einer transienten hypertonischen Reaktion im Sekundenbereich nach Stimulation und einem langsam einsetzenden, lang andauernden Blutdruckanstieg im Minutenbereich während der Retention konditionierter Furcht. Dieser verzögerte, jedoch massive Blutdruckanstieg, dessen Maxima basale MAP-Werte der prä-CS Phase (welche im oberen Bereich zirkadianer Werte in der aktiven Phase der Mäuse lagen) um etwa $25 \%$ überstiegen, wurde nur bei konditionierten, d.h. aversiv assoziierenden Mäusen, nicht jedoch bei unkonditionierten Mäusen ermittelt. Daher wird dieser als spezifische konditionierte Furchtantwort interpretiert. Im Wesentlichen sind dabei humorale Prozesse, die über systemisch zirkulierende Katecholamine vermittelt werden und über eine längere Latenzzeit verfügen, involviert (Guyton et al., 1972). Die Messung der Katecholaminkonzentrationen im Blut vor und nach 
der Furchtkonditionierung und dem Gedächtnistest in zukünftigen Experimenten wird das Verständnis der kardiovaskulären Furchtreaktion vertiefen. Ein permissiver Beitrag erhöhter Kortikosteronwerte (Wuttke, 2000) infolge gesteigerter HHN-Achsen-Aktivität zu den Spitzenwerten der konditionierten Blutdruckantwort ist nicht auszuschließen, wurde bislang jedoch nicht beschrieben (s.u.).

Im Gegensatz zu Untersuchungen bei Ratten, die einen schnellen initialen Blutdruckanstieg als konditionierte Furchtantwort interpretierten (Iwata \& LeDoux, 1988; LeDoux et al., 1988), deuten die vorliegenden Ergebnisse bei Mäusen darauf hin, dass es sich bei der schnellen Komponente der Blutdruckreaktion um eine sympathisch-neuronal vermittelte unkonditionierte Attentions- bzw. Erregungsantwort handelt (Baudrie et al., 1997). Dies wurde anhand der gleichartigen, schnellen Antworten unkonditionierter Kontrolltiere deutlich. Diese Befunde wurden durch Ergebnisse aus Startle-Experimenten verstärkt. Durch den unkonditionierten Reiz wurden ebenfalls schnelle und transiente, jedoch milde hypertonische Antworten ausgelöst. Auf Basis der Herzrate konnten bei Mäusen leichte Akzelerationsreaktionen nach Startle-Stimulation nachgewiesen werden. Die kardiovaskulären Antworten erfolgten in einem Zeitfenster von 1-15 s nach Präsentation des StartleReizes und damit im Vergleich zu den motorischen Startle-Reaktionen $(\sim 20 \mathrm{~ms})$ deutlich verzögert. Somit scheiden die Muskelkontraktionen als direkte Ursache für den Blutdruckanstieg aus. Vielmehr wird sympathisch vermittelte Vasokonstriktion als zugrunde liegender Mechanismus vorgeschlagen. Da sowohl Herzraten- als auch Blutdruckantworten nur milde und transiente Anstiege mit darauffolgender schneller Rückregulierung zeigten, werden Furcht- oder Angstprozesse als Ursachen dieser Reaktionen verworfen, und stattdessen Attentions- bzw. Erregungsprozesse als zugrunde liegende Mechanismen hypothetisiert. In ihrem zeitlichen Verlauf ähnelten diese den HR-Antworten von Ratten nach Stimulation mit Startle-Reizen. Abbildung 4.1 präsentiert einen Vergleich von Herzratenantworten von Mäusen mit Ergebnissen bei Ratten, der in Kooperation mit Peter Pilz (Tübingen) angestellt wurde (Tovote et al., 2005). Unterschiedliche Flanken der Startle-Signale verursachten in diesen Experimenten gleichartige HR-Antworten, während motorische StartleAntworten nur von Signalen Ratten: Mäuse: $=$

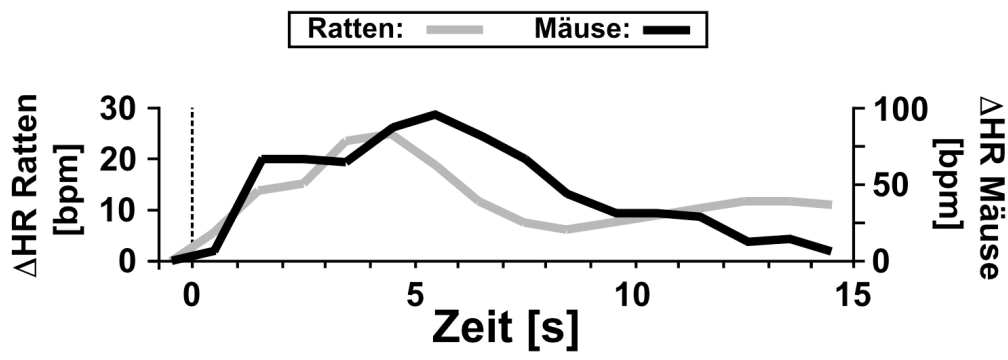

Abb. 4.1: Vergleich von Startleinduzierten Herzratenanstiegen ( $\Delta H R$ ) von Ratten und Mäusen. Die gestrichelte Linie zeigt die Präsentation des StartleSignals an. 
mit steiler Flanke verursacht wurden (Fleshler, 1965; Pilz \& Leaton, 1999). Damit wurde erneut ausgeschlossen, dass die motorische Startle-Antwort, die durch die reflexartige Kontraktion bestimmter Muskeln (s. Kap. 1.2.2) generiert wird (Koch, 1999; Plappert \& Pilz, 2001), für die beobachtete autonome Reaktion verantwortlich ist. Nahe liegende Schlussfolgerung ist, dass die schnelle HR-Antwort auf Startle-Stimulation sowohl bei Mäusen als auch bei Ratten reflexiven Mechanismen ohne emotionalen oder kognitiven Beitrag zuzuschreiben und somit als unkonditionierte Antworten zu interpretieren ist. In Anbetracht der engen Verknüpfung von Herzfrequenz- und Blutdruckregulation wird die Interpretation der schnellen Blutdruckantwort als unkonditionierte Attentions-bzw. Erregungsantwort gestärkt. Es wird somit vermutet, dass sowohl der schnellen Blutdruckantwort auf den CS im Ton abhängigen Gedächtnistes als auch der milden hypertonischen Antwort auf unkonditionierte Startle-Stimuli keine zentralnervösen Mechanismen (z.B. Aktivierung der Amygdala) für die Verarbeitung und Expression emotionalen Gedächtnisses zugrunde liegen (Hamann, 2001).

\section{Kardiovaskuläre Antworten auf kontextuelle Stimuli}

In Kontext abhängigen Gedächtnistests wurden konditionierte neuroautonome Furchtantworten in der $\mathrm{US}_{l}$-Gruppe aversiv assoziierender Mäuse im Vergleich zu unkonditionierten neuroautonomen Anpassungsreaktionen nicht-assoziierender Mäuse (US ${ }_{i}$, $\mathrm{US}_{n}$ ) ermittelt. Die $\mathrm{US}_{i}$-Gruppe (sofortige Applikation des unkonditionierten Stimulus im Training) gilt dabei als Kontrollgruppe, um eventuell auftretende Effekte des US ohne die Ausbildung einer aversiven Assoziation auf das Verhalten zu untersuchen (Fanselow, 1990; Milanovic et al., 1998). Die konditionierte Furchtantwort der $\mathrm{US}_{l}$-Gruppe wurde in einer massiven Tachykardie ausgedrückt, die im Vergleich zu der ebenfalls erhöhten initialen Herzrate nicht-assoziierender Mäuse $\left(\mathrm{US}_{i}, \mathrm{US}_{n}\right)$ länger andauerte. Die dadurch reflektierte neuroautonome Aktivierung in allen Gruppen, bestehend aus sympathischer Aktivierung mit einhergehender parasympathischer Inhibition (Nijsen et al., 1998; Stiedl \& Spiess, 1997; Tovote, 2001), liefert als Teil einer „Alarmreaktion“ die physiologischen Vorraussetzungen

für die „Flight or Fight“ (s. Kap. 1.1.1) Verhaltensentscheidung. Die „Alarmreaktion“ wird auch bei emotionalen Belastungen, wie sie die Präsentation einer neuen Umgebung (Novelty) darstellt, typischerweise ausgelöst (Denenberg, 1969; Ramos \& Mormede, 1998). Dabei wird die Möglichkeit einer Bedrohung durch Fressfeinde in der unbekannten Umgebung antizipiert 
und kann erst durch Erkundung derselben und Erlangen eines allmählichen „Sicherheitsgefühls“ ausgeschlossen werden (van den Buuse et al., 2001). Daher löst die Präsentation einer neuen Umgebung bei Nagetieren zunächst typischerweise intensives Explorationsverhalten aus, das durch gesteigerte Lokomotionsaktivität mit Such- bzw. Ortungsbewegungen des Kopfes und Schnuppern charakterisiert ist (Dulawa et al., 2004). Die gesteigerte Lokomotionsaktivität bedarf erhöhter Muskelaktivität, die wiederum gesteigerten Blutfluss erforderlich macht. Dies wird mittels sympathisch vermittelter Erhöhung des Herzinnenvolumens u.a. durch Herzratenzunahme und Blutdrucksteigerung sowie gesteigerter Kontraktionskraft erreicht (Busse, 2000). Die kardiovaskuläre Aktivierung während des Kontext abhängigen Gedächtnistests ist somit auf das Zusammenwirken von emotionaler Stimulation und physischer Aktivität sowohl in aversiv assoziierenden als auch in unkonditionierten Mäusen zurückzuführen. Jedoch ging bei unkonditionierten Mäusen die durch den Novelty-Stimulus ausgelöste kardiovaskuläre Aktivierung mit gesteigerter lokomotorischer Aktivität einher, während aversiv konditionierte Mäuse die Unterdrückung der lokomotorischen Aktivität bzw. Freezing bei voller kardiovaskulärer Aktivierung aufwiesen. Aufgrund des fehlenden physischen Ausgleichs ist in diesem Fall von einer starken Belastung des kardiovaskulären Systems auszugehen. Dabei spielen die Versuchsbedingungen eine entscheidende Rolle: So ist Freezing die dominante Verhaltensreaktion auf eine Bedrohung, wenn keine Fluchtmöglichkeiten bestehen. Sind diese vorhanden, wird bei Nagetieren überwiegend Fluchtverhalten beobachtet (Blanchard et al., 1993).

Die neuroautonomen Antworten der Kontrollgruppen in Kontext abhängigen Gedächtnistests verdeutlichten den nachhaltigen Einfluss einer neuen Umgebung als unkonditioniertem Stimulus auf die kardiovaskuläre Regulation. Die Ergebnisse der NoveltyTests auf Basis von Herzrate bestätigten diese Ergebnisse. Die lange Dauer (60-90 min) dieses für den Organismus energetisch aufwendigen Zustands verdeutlicht seine Bedeutung als Folge der wahrgenommenen Bedrohungen. Die schnellere Rejustierung der Herzrate in Mäusen, denen vertrautes Nestmaterial als „Sicherheitssignal“ mitgegeben wurde, ist zum einen tatsächlich auf ein schnelleres Abfallen der emotionalen Aktivierung zu den Ausgangswerten zurückzuführen. Jedoch ist nicht auszuschließen, dass Mäuse mit unbekanntem Nestmaterial auch deshalb länger höhere Herzraten aufwiesen, da sie mit dem Bau eines neuen Nestes beschäftigt waren. Darauf deuten die Herzraten dieser Mäuse hin, die mit $~ 650 \mathrm{bpm}$ im Vergleich zu Herzraten aktiver, ungestresster Mäuse im Heimkäfig (während der Dunkel-, d.h.Wachphase der Tiere) nur leicht erhöht waren. 
Die vorliegenden Studien belegen, dass die initiale kardiovaskuläre Aktivierung aufgrund erhöhtem sympathischem Tonus während der Konfrontation mit einer relativ neuen Umgebung, wie während des kontextuellen Gedächtnistests unabhängig von dem emotionalen Gehalt des Kontextes (z.B. aversiv konditioniert) ausgelöst wird. Auch unter gänzlichen Novelty-Bedingungen, welche einen umfassenden unkonditionierten Stimulus repräsentieren erfolgt die zunächst maximale kardiovaskuläre Aktivierung. Durch „Sicherheitsignale“ wird die Rückregulierung der physisch belastenden kardiovaskulären Aktivierung beschleunigt. Eine gleichartige Aktivierung, jedoch von geringerer Dauer wird durch manuelles Interferieren (Handling) mit den Mäusen verursacht. Diese Ergebnisse sind im Einklang mit Ergebnissen bei Ratten, die während Novelty Tachykardie und Hypertension zeigten, die durch Blockade von $\beta_{1}$-Rezeptoren bzw. ganglionäre Blockade verhindert werden konnten (van den Buuse et al., 2001). Dementsprechend wurden sympathische Aktivierung bzw. parasympathische Hemmung als zugrunde liegende Mechanismen identifiziert.

\section{Kardiovaskuläre Antworten auf olfaktorische Stimuli}

Gerüche von Raubtieren lösen bei Nagetieren die angeborenen Reaktionsmuster von Vermeidungs- bzw. Verteidigungsverhalten und kardiovaskulärer Aktivierung aus (Dielenberg \& McGregor, 2001). Ihre Untersuchung kann zu Erkenntnissen über die neurobiologischen Aspekte von Emotionen und Stress beitragen. Synthetischer Fuchsgeruch als Reinstoff (TMT) kann standardisiert verwendet werden und hat den Vorteil der Kontrollierbarkeit (s. Kap. 2.9.1) im Gegensatz zu inhärenten, aus vielen verschiedenen Duftstoffen kombinierten nativen Predatorengerüche. Diese werden beispielsweise in Form von getragenen Halsbändern, Fellteilen oder Exkrementen von Katzen eingesetzt (Dielenberg \& McGregor, 1999; File et al., 1993; Zangrossi \& File, 1994). In der vorliegenden Arbeit verursachte die Präsentation des synthetischen Fuchsgeruchs als unkonditionierter, olfaktorischer Stimulus eine deutliche Zunahme der Herzrate von Mäusen über einen längeren Zeitraum ( 30 min). Die Dynamik dieses Herzratenanstiegs unterschied sich jedoch stark von den Herzratenantworten während des Novelty-Tests oder der Furchtkonditionierung. So wurden nach olfaktorischer Stimulation keine maximalen Herzraten wie während des NoveltyTests erreicht. Auch stieg die Herzrate verzögert und langsam an, während sie bei der Retention konditionierter Furcht augenblicklich auf maximale Werte anstieg. Daraus lässt sich folgern, dass der olfaktorische Stimulus unter den verwendeten Versuchsbedingungen 
keine unmittelbare Furcht-auslösende Wirkung auf die Mäuse hatte. Ursache hierfür kann das relativ langsame Aufkommen des Stimulus durch die Verteilung des Geruches in der Versuchsapparatur sein. Aufgrund der lang anhaltenden Wirkung des Geruchs liegt jedoch die Interpretation einer emotionalen Aktivierung der Mäuse mit einhergehender Aktivierung des Sympathikus nahe. Weitere Versuche mit modifizierten experimentellen Bedingungen (schnellere Luftzirkulation bei kleinerer Versuchskammer) und bei gleichzeitiger Messung von Verhaltensantworten sind notwendig, um die Effekte olfaktorischer Stimuli auf neuroautonome Regulation und Furchtreaktionen bei Mäusen aufklären zu können.

\subsection{Endokrine Regulation bei auditorischer Furchtkonditionierung}

Im Rahmen der Untersuchungen der durch die Retention konditionierter auditorischer Furcht in Mäusen ausgelösten Veränderungen im Verhalten und der kardiovaskulären Funktion stellte sich die Frage, ob auch hormonale Veränderungen als Teil der umfassenden systemischen Gesamtreaktion nachweisbar sind. Übereinstimmend zentrales Merkmal einer Stressreaktion ist die Aktivierung der HHN-Achse, die bei Mäusen zu einer Erhöhung des Kortikosteronspiegels im Blut führt (reviewed von Korte, 2001; Owens \& Nemeroff, 1991; Roozendaal et al., 1992). Es wird somit erwartet, dass die Retention konditionierter Furcht auch eine Aktivierung der HHN-Achse auslöst und somit eine akute Stressreaktion hervorruft. Diese Erwartung bestätigte sich mit der Ermittlung erhöhter Kortikosteronkonzentrationen im Blut aversiv assoziierender Mäuse im Vergleich zu nicht-aversiv assozierenden Mäuse nach Beendigung des Gedächtnistestes. Dies konnte schon 5 min nach Beginn der Tonpräsentation im Gedächtnistest demonstriert werden. Abbildung 4.2 zeigt den zeitlichen Verlauf der kardiovaskulären und endokrinen Antworten während der Retention konditionierter Furcht. Die vermehrte Freisetzung von Kortikosteron kann somit durch die permissive Wirkung auf Katecholamin-vermittelte Vasokonstriktion (Wuttke, 2000) mitverantwortlich für den massiven Blutdruckanstieg sein. Ein Beitrag zur Ton induzierten Tachykardie kann aufgrund der langsamen Dynamik der HHN-Achse jedoch ausgeschlossen werden. Interessanterweise wurden im gleichen Zeitfenster höhere Kortikosteronwerte nach dem Gedächtnistest als nach dem Training ermittelt. Somit konnte mit Hilfe der Furchtkonditionierung beispielhaft gezeigt werden, dass die Erinnerung an Stress auslösende Ereignisse zu Stressreaktionen führen kann, die die eigentliche (unkonditionierte) Reaktion sogar noch übertreffen können. Dies ist im Hinblick auf humane psychologische Störungen wie Depression, Angstpsychosen und die 
Post-traumatische Belastungsstörung (post traumatic stress disorder: PTSD) bedeutungsvoll (reviewed von Claes, 2004), bei denen erhöhte Kortisolspiegel im Blut und in der Zerebrospinalflüssigkeit gefunden werden .

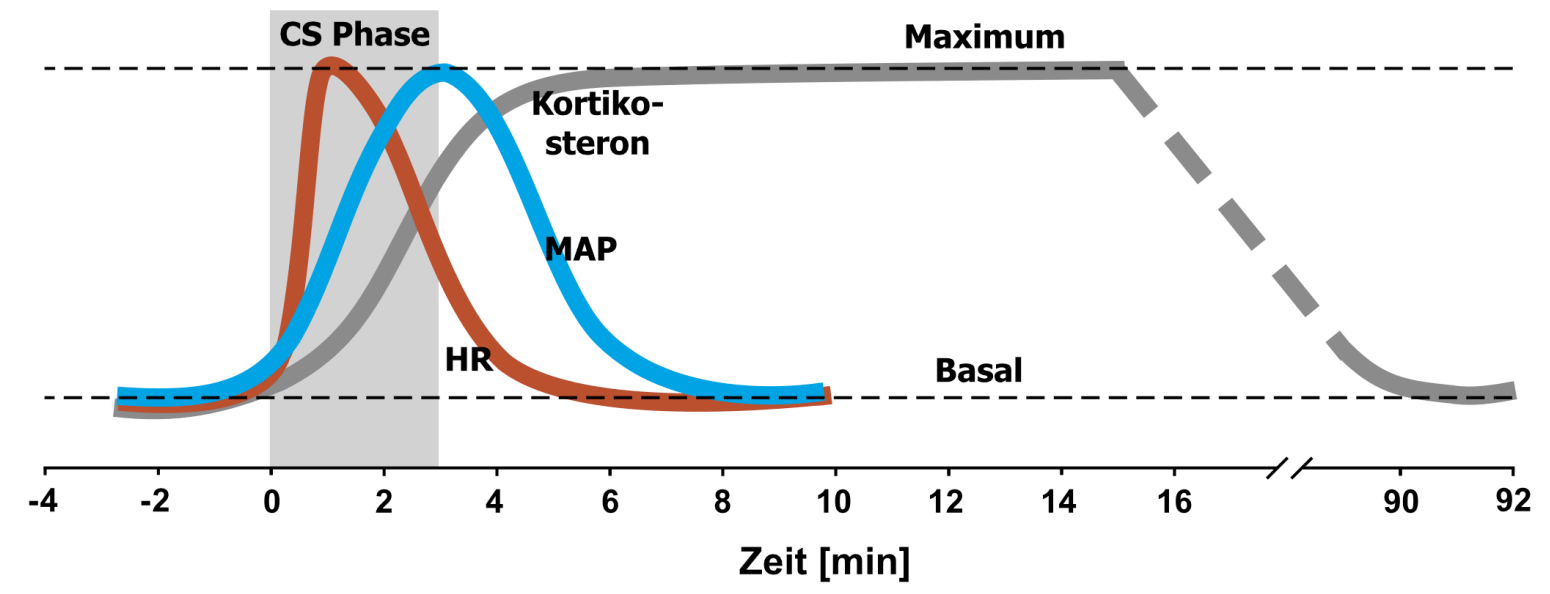

Abb. 4.2: Schematische Darstellung des zeitlichen Verlaufs der HR-, MAP- und Kortikosteron-Antworten in Mäusen vor-, während und nach Retention konditionierter Furcht im Ton abhängigen Gedächtnistest. Gestrichelte horizontale Linien verdeutlichen basale bzw. maximale Werte. Das graue Feld zeigt Beginn und Ende der Ton-CS Phase an. CS=Konditionierter Stimulus (Ton).

Gleichzeitig konnte nachgewiesen werden, dass auch die Präsentation eines nichtaversiv konditionierten Tons eine milde Aktivierung der HHN-Achse verursacht. Außerdem führt die Trainingsprozedur selbst bei unterlassener Elektroschock-Gabe zu massiver Kortikosteron-Aktivierung ohne Unterschied zwischen CS und US und CS+US-Präsentation. Aufgrund der insgesamt geringen Kortikosteronkonzentrationen nicht aversiv assoziierender Mäuse und in Anbetracht ausbleibender Verhaltensänderungen und kardiovaskulärer FurchtAntworten dieser Mäuse ist anzunehmen, dass die alleinige Präsentation des nicht aversiv assozierenden CS im Gedächtnistest keine belastende Stimulation darstellt.

$\mathrm{CRF}_{1}$-defiziente Mäuse wiesen, im Gegensatz zu ihren Wildtyp-Kontrollen, nach dem Gedächtnistest keine erhöhten Kortikosteronkonzentrationen im Blut auf. Dieses Ergebnis bestätigt das in anderen Studien berichtete Fehlen der HHN-Achsen-Aktivierung bei diesen Mäusen (Smith et al., 1998; Timpl et al., 1998), die mit mangelnder ACTH-Ausschüttung aufgrund fehlender $\mathrm{CRF}$-Vermittlung über hypophysäre $\mathrm{CRF}_{1}$-Rezeptoren erklärt wird. Gleichzeitig wurde deutlich, dass die neuroautonome Expression konditionierter Furcht unabhängig von der Aktivierung der HHN-Achse erfolgen kann. Zusammenfassend lässt sich sagen, dass auditorische Furchtkonditionierung nicht nur als Paradigma für Lernen und Gedächtnis, sondern auch als Modell für emotionale Belastung bzw. Stress dienen kann. 


\subsection{Beitrag des CRF-Systems zu neuroautonomer Regulation}

Eine Rolle für CRF sowohl in der Regulation basaler kardiovaskulärer Funktionen als auch in der Modulation neuroautonomer Stress-Antwort wird seit langem diskutiert (Bale \& Vale, 2004; Heinrichs et al., 1995; Owens \& Nemeroff, 1991; Parkes et al., 2001). Jedoch konnten Experimente an $\mathrm{CRF}_{2}$-defizienten Mäusen keinen Beitrag dieses Rezeptors zur basalen und Furcht induzierten neuroautonomen Regulation der Herzrate nachweisen (Stiedl \& Meyer, 2002). Pharmakologische Studien konnten ebenfalls keinen Beitrag zentraler $\mathrm{CRF}_{1^{-}}$ Rezeptoren zur Furcht induzierten Tachykardie nachweisen (Stiedl et al., 2005). In der vorliegenden Arbeit wurden zusätzliche Erkenntnisse über den Beitrag des CRF-Systems zu basaler kardiovaskulärer Regulation und zu neuroautonomen Furcht- und Stressreaktionen, unter der Berücksichtigung von Blutdruckeffekten, gewonnen.

\section{Basale Regulation}

Mit peripheren Injektionen selektiver peptidischer Agonisten konnte ein Beitrag von $\mathrm{CRF}_{1}$ und $\mathrm{CRF}_{2}$ zur basalen Herzrate und Blutdruckregulation demonstriert werden. Der Blutdruckabfall nach IP-Injektion der $\mathrm{CRF}_{2}$-Agonisten mUCNII und mUCNIII bestätigte eine seit langem bekannte CRF-vermittelte Hypotension, vermutlich durch $\beta$-Endorphin-abhängige Vasodilation (Fisher et al., 1983; Overton \& Fisher, 1991; Richter \& Mulvany, 1995). Die einhergende Herzratenzunahme ist über den Baroreflex-Feedback-Mechanismus erklärbar. In derselben Weise lässt sich jedoch die durch intraperitoneale Injektion der $\mathrm{CRF}_{1}$-Agonisten oCRF und Cortagine ausgelöste Tachykardie nicht interpretieren, da keine gleichzeitige Hypotension erfolgte. Ein direkter Effekt der injizierten Liganden durch Aktivierung von $\mathrm{CRF}_{1}$-Rezeptoren im Herzen (Hillhouse \& Karteris, 2002; Kimura et al., 2002) ist nicht auszuschließen. Hier sind weitergehende Experimente, z.B. mittels intravenöser Injektionen nötig, welche auf dem Weg des Blutkreislaufs direkten Zugang zum Herzen bieten, um die den differentiellen kardiovaskulären Effekten der peripheren $\mathrm{CRF}_{1}$-und $\mathrm{CRF}_{2}$-Aktivierung zugrunde liegenden Mechanismen aufzuklären.

Die zentralnervösen Mechanismen der basalen kardiovaskulären Regulation durch $\mathrm{CRF}_{1}$-Aktivierung konnten im Rahmen dieser Arbeit noch nicht vollständig aufgeklärt werden. Der Vergleich von basalen Herzraten und Herzratenvariabilität sowie ihrer Korrelation über den physiologischen Dynamikbereich zwischen $\mathrm{CRF}_{1}$-defizienten Mäusen 
und Wildtyp-Kontrollen ergab keine Unterschiede. In Übereinstimmung mit neuesten Ergebnissen (Stiedl et al., 2005) konnte eine pharmakologisch vermittelte basale Bradykardie über $\mathrm{CRF}_{1}$-Aktivierung ermittelt werden. Aufgrund einer gleichzeitig erhöhten Herzratenvariabilität (Abb.4.3) wird diese auf eine gesteigerte parasympathische Aktivität bei gleichzeitiger sympathischer Aktivierung zurückgeführt, die als sympatho-vagaler Antagonismus bezeichnet wird (Stiedl et al., 2005). Jedoch überraschte der gleichzeitige Abfall von Herzrate und Blutdruck nach Applikation hoher Dosen von oCRF. Dies kann mit verringerter Auswurfleistung des Herzens infolge erniedrigter Herzraten erklärt werden. Jedoch ist dann die Postulierung einer zentralen Hemmung des Barorezeptor-Reflexes in entsprechenden Hirnstammregionen (Nucleus Tractus Solitarius) notwendig, um die ausbleibende Gegenregulierung des Blutdrucks zu erklären. In zusätzlichen Experimenten mittels peripherer adrenerger Blockade bzw. Aktivierung können diese Hypothesen überprüft werden (Ishii et al., 2001; Just et al., 2000; Peotta et al., 2001). Der im Vergleich zu der massiven oCRF induzierten Tachykardie abgeschwächte Effekt nach ICV-Injektion von Cortagine könnte jedoch auf einen $\mathrm{CRF}_{2}$-vermittelten Mechanismus des Blutdruckabfalls hinweisen, da Cortagine eine höhere $\mathrm{CRF}_{1}$-Selektivität bzw. geringere Affinität zum $\mathrm{CRF}_{2}$ als oCRF besitzt (Tezval et al., 2004).

Bei CRF-transgenen Mäusen mit CRF-Überproduktion wurden leicht erhöhte basale Herzratenwerte und erniedrigte Herzratenvariabilität ermittelt. Diese Effekte können jedoch auf das geringere Körpergewicht dieser Mäuse infolge des, das Cushing's Syndrom auslösenden chronischen Hyperkortisolismus (Stenzel-Poore et al., 1992) zurückgeführt werden. Eine umgekehrt proportionale Beziehung zwischen Körpergewicht und Herzrate ist bekannt $\left(241 *\right.$ Körpergewicht ${ }^{-0.25}$; (Clark, 1927)). Die aufgrund der Gewichtsunterschiede theoretisch um 11\% erhöhte Herzrate in CRFOE-Mäusen im Vergleich zu Wildtypkontrollen stimmt mit dem tatsächlich gemessenem Wert von $11 \%$ genau überein. Ein deutlicher Effekt von CRF-Überproduktion auf basale neuroautonome Regulation konnte mit den durchgeführten Analysen somit nicht belegt werden.

\section{Emotionale Modulation}

Überraschenderweise konnte in Experimenten mit $\mathrm{CRF}_{1}$ - und $\mathrm{CRF}_{2}$-defizienten Mäusen kein Beitrag dieser Rezeptoren zur emotionalen Modulierung neuroautonomer Funktion ermittelt werden. Die Herzraten-Antworten während der Konfrontation mit dem 
psychologischen Stressor (Crawley \& Goodwin, 1980) einer neuen Umgebung (Novelty) und Furchtkonditionierung, wie auch die Herzratenvariabilität und die Korrelation von Herzrate und Herzratenvariabilität, zeigten keine Auffälligkeiten und unterschieden sich zudem nicht zwischen $\mathrm{CRF}_{1}$ - und $\mathrm{CRF}_{2}$-defizienten Mäusen. Die fehlenden Unterschiede zwischen diesen genetisch veränderten Mäusen und ihren Wildtyp-Kontrollen hinsichtlich ihres Verhaltens während des Novelty-Tests und der Furchtkonditionierung bestätigten dies. Diese Ergebnisse stehen im Widerspruch zu Daten und Deutungen anderer Studien. So zeigten Ratten weniger Freezing nach zentraler Applikation von $\mathrm{CRF}_{1}$-Antagonisten (Takahashi, 2001). Eine abgeschwächte endokrine Stressantwort wurde bei $\mathrm{CRF}_{1}$-defizienten Mäusen gefunden (Smith et al., 1998; Timpl et al., 1998). Dies wurde in der vorliegenden Arbeit durch ausbleibende Kortikosteron-Antworten von $\mathrm{CRF}_{1}$-defizienten Mäusen in der Furchtkonditionierung bestätigt. Darüber hinaus war erwartet worden, dass sich unterschiedliches Angstverhalten von $\mathrm{CRF}_{1^{-}}$(abgeschwächte Angst, Smith et al., 1998) und $\mathrm{CRF}_{2}$-defizienten Mäusen (verstärkte Angst, Kishimoto et al., 2000) auch in unterschiedlichen Herzraten-Antworten auf emotionale Stimuli widerspiegeln würde. Das Fehlen dieser Unterschiede stellt die vorgeschlagene wichtige Rolle für CRF in der Modulation der neuroautonomen Antwort als Bestandteil der akuten Belastungsreaktion in Frage und verdeutlicht, dass zwischen CRF abhängigem Angstverhalten und neuroautonomen Furchtantworten keine einfache Beziehung besteht. Diese Interpretation passt zu den Ergebnissen einer unveränderten konditionierten Tachykardie nach zentraler Applikation von CRF-Rezeptor-Antagonisten (Stiedl et al., 2005). Die physiologische Rolle von CRF bei der Regulation der kardiovaskulären Funktion bleibt somit bislang unklar.

CRF-überproduzierende Mäuse zeigten nicht die charakteristische Furcht induzierte Tachykardie im Ton abhängigen Gedächtnistest. Ein neuroautonomer Defekt oder eine Abschwächung der emotionalen Responsivität konnte als Ursache dadurch ausgeschlossen werden, dass dieselben Mäuse im Novelty-Test hohe Herzraten demonstrierten. Daher legen die Ergebnisse einen kognitiven Defekt dieser Mäuse nahe, d.h. ohne korrekte Assoziation von konditioniertem und unkonditioniertem Stimulus im Training wurde die konditionierte Herzratenantwort nicht gezeigt. Diese Interpretation stimmt mit Ergebnissen verminderter konditionierter auditorischer und kontextueller Furcht auf Verhaltensebene bei Mäusen (Groenink et al., 2003) mit ausschließlich zentraler CRF-Überproduktion (Dirks et al., 2002) überein.

Eine mögliche Erklärung für die CRF-unabhängige akute neuroautonome Antwort auf emotionale Stimuli bietet die Betrachtung der zeitlichen Dynamik einer solchen Reaktion. 
Eine plötzliche Konfrontation mit einer (potentiell) gefährlichen Situation erfordert als Vorraussetzung für eine adäquate Reaktion die sofortige Mobilisierung des Vermeidungsbzw. Verteidigungssytems. Bei Tieren mit hohem Feinddruck am unteren Ende der Nahrungskette sollten diese überlebenswichtigen Mechanismen robust ausgebildet sein. Zudem müssen diese äußerst schnell funktionieren, da die lebensentscheidenden Reaktionsoptionen unmittelbar zur Verfügung stehen müssen. Dafür sind schnelle NeurotransmitterSysteme eher geeignet als relativ langsamere G-Protein gekoppelte Signaltransduktionswege, wie die von CRF. Die schnellsten in vitro Effekte von exogen appliziertem CRF werden durch erhöhte Aktionspotential-Raten in pyramidalen Neuronen von Hirnschnitten des Hippokampus beobachtet (Aldenhoff et al., 1983; Blank et al., 2003), 10-20 s nach CRF Applikation. Diese zeitliche Dynamik ist jedoch zu langsam, um augenblickliche Anpassung an gefährliche Situationen zu bewirken. Die konditionierte Tachykardie nach Tonpräsentation im Gedächtnistest (s.o.) erfolgt jedoch nach wesentlich kürzerer Latenz und ist daher auf direkte neurale Regualtionsmechanismen zurückzuführen.

\section{Vergleich von CRF- und NPY-Effekten auf neuroautonome Regulation}

Der Vergleich von zentralen CRF- und NPY-vermittelten kardiovaskulären Effekten verdeutlicht gegensätzliche Auswirkungen auf die neuroautonome Regulation. Während pharmakologische Aktivierung zentraler NPY- oder CRF-Rezeptoren gleichartige absolute Herzraten bewirkte, ergaben sich erhebliche Unterschiede in der Herzratenvariabilität, die unter NPY-Wirkung sehr niedrig, unter CRF-Wirkung jedoch auffallend hoch war. Eine niedrige Herzratenvariabilität reflektiert unter physiologischen Bedingungen einen erhöhten sympathischen bzw. erniedrigten parasympathischen Tonus, während hohe Herzratenvariabilität einen erhöhten parasympathischen, bzw. erniedrigten sympathischen Tonus anzeigt (Stein et al., 1994). Die Korrelationsanalysen von HR (RR Intervall) mit HRV (RMSSD) verdeutlichten, dass hohe Herzraten unter physiologischen Bedingungen mit niedriger Herzratenvariabilität einhergehen und somit durch sympathische Aktivierung und/oder parasympathische Inhibition verursacht werden. Niedrige Herzraten korrelieren mit gesteigerter Herzratenvariabilität und werden von parasympathischer Aktivierung verursacht. Indirekt lassen sich somit verschiedene, den unterschiedlichen NPY- und CRF-Effekten zugrunde liegende Mechanismen erkennen: Die durch NPY verursachte niedrige Herzratenvariabilität bei gleichzeitig niedrigen Herzraten deuten auf eine zentral vermittelte 
Sympathikolyse hin, die sich in reduzierter Herzschlagfrequenz niederschlägt. Gleichzeitig erfolgt keine erhöhte Aktivierung des Parasympathikus (welche höhere Herzratenvariabilität verursachen würde), sondern vielmehr eine leichte Inhibition des parasympathischen Tonus bei höherer NPY-Dosierung (Tovote, 2001). Die von CRF verursachte hohe Herzratenvariabilität bei ebenfalls niedriger Herzrate weist daraufhin, dass hier eine zentrale Aktivierung sowohl des parasympathischen als auch des sympathischen Nervensystems erfolgt. Als Konsequenz der beiden unterschiedlichen Mechanismen ist die Ton induzierte Tachykardie weitgehend unterdrückt, d.h. kann nicht gezeigt werden. Bei Menschen führt die intravenöse Gabe von Noradrenalin zu einer gleichzeitigen Erhöhung des parasympathischen und sympathischen Tonus mit resultierender hoher Herzratenvariabilität (Tulppo et al., 1998). Diese Erhöhung des sympatho-vagalen Antagonismus kann zu pathologisch erhöhter Herzratenvariabilität führen, welche ein potentielle erhöhtes Arrythmie-Risiko darstellt und im Zusammenhang mit plötzlichem Herztod diskutiert wird (Zipes \& Wellens, 1998).

Zusammenfassend lässt sich sagen, dass eine wichtige tonische Rolle endogenen CRFs bei basalen neuroautonomen Regulationsprozessen unwahrscheinlich erscheint. Auch an der Modulation der neuroautonomen Antwort auf emotionale Stimuli scheinen CRF-Rezeptoren nicht beteiligt zu sein. Die eindeutige pharmakologische Wirksamkeit von CRF und CRFRezeptor-Agonisten hinsichtlich basaler neuroautonomer bzw. kardiovaskulärer Regulation deuten auf bestehende CRF-abhängige Mechanismen hin. Unter chronischen StressBedingungen könnten diese zur neuroautonomen Dysregulation beitragen und bei der Entstehung kardiovaskulärer Erkrankungen mitwirken (Stiedl et al., 2005).

\subsection{Furchtantwort und Hippokampus}

\section{Verhaltensantworten bei Trace-Furchtkonditionierung}

Mit Hilfe der Trace-Furchtkonditionierung und intrahippokampalen Injektionen des NMDA-Rezeptor Antagonisten APV konnte ein Zeit abhängiger Beitrag des dorsalen Hippokampus zur Gedächtnisbildung und zur Ausprägung der auditorisch konditionierten Furchtantwort auf Basis der Inaktivität und Freezing nachgewiesen werden. Die unerlässliche Rolle des dorsalen Hippokampus bei der Verarbeitung kontextueller Stimuli wurde bestätigt (Bast et al., 2003; Kim et al., 1991; Stiedl et al., 2000). Zum ersten Mal wurde bei Mäusen gezeigt, dass funktionale NMDA-Rezeptoren im dorsalen Hippokampus nur bei einem 
spezifischen Zeitfenster des Trace-Intervalls von 15-30 s zur Assoziation von Ton-CS und US notwendig sind. Andere Studien mit genetisch modifizierten Mäusen ermittelten hippokampale Beiträge zur auditorischen Trace-Furchtkonditionierung durch abgeschwächtes Furchtverhalten schon bei kürzeren Trace-Intervallen von 1-2.5 s (Crestani et al., 2002; Holmes et al., 2002; Kinney et al., 2002). Da jedoch gleichzeitig kein abgeschwächtes Furchtverhalten bei Kontext-Konditionierung gefunden wurde, könnten hierfür auch andere Ursachen als die Dysfunktion des Hippokampus angenommen werden (Quinn et al., 2002). Gleichartige Freezing und Inaktivitätswerte von Mäusen mit hippokampaler NMDARezeptor-Blockade während des Trainings und Kontrollmäusen demonstrierten, dass bei Trennung von CS und US durch längere Zeitfenster (45 s) diese nicht mehr miteinander assoziiert wurden. Dies bestätigt frühere Ergebnisse in denen Trace-Intervalle von $45 \mathrm{~s}$ bzw. 60 s verwendet wurden (Paylor et al., 1994; Stiedl \& Spiess, 1997).

\section{Neuroautonome Antworten bei Trace-Furchtkonditionierung}

Die Ton induzierte neuroautonome Furchtantwort bei Trace-Intervallen von 15 bzw. $30 \mathrm{~s}$ in Form der konditionierten Tachykardie wurde im Retentionstest allerdings trotz Inhibierung des Hippokampus mit APV während des Trainings ausgelöst. Diese Hippokampus-unabhängige Herzratenantwort wurde bereits in früheren Studien im DelayModus der Furchtkonditionierung, bei der CS und US direkt aufeinander folgen ermittelt (Stiedl et al., 2000). Dennoch widersprachen diese Ergebnisse anfänglich der Arbeitshypothese von abgeschwächter bzw. fehlender Tachykardie (entsprechend der abgeschwächten Verhaltensantwort) durch APV-Applikation im Training. Eine mögliche, wenn auch triviale Erklärung für diese zunächst widersprüchlichen Ergebnisse auf Verhaltens- und neuroautonomer Ebene könnte die Tatsache unterschiedlicher verwendeter Mauslinien sein. In den Verhaltensexperimenten wurden C57BL/6J-Mäuse getestet, in den Experimenten mit Herzratenmessungen C57BL/6N-Mäuse. Eine generalisierte Furchtantwort wurde auf Basis von Freezing, nicht jedoch durch Herzratenantworten in C57BL/6N Mäusen ermittelt (Stiedl et al., 1999b). 


\section{Neuronale Systeme emotionalen Gedächtnisses}

Eine andere Erklärung für die differierenden Ergebnisse auf Verhaltens- und neuroautonomer Ebene betrifft die unterschiedlichen Messmethoden: So scheint die neuroautonome Messung hinsichtlich konditionierter Furcht sensitiver als die Verhaltensmessung zu sein. Das würde bedeuten, dass die Mäuse trotz Inhibierung des dorsalen Hippokampus während des Trainings die Assoziation von CS und US in anderen Hirnregionen formten, deren Erinnerung im Gedächtnistest dann Furcht auslöste (Abb. 4.3). Die Intensität der Emotion war stark genug, um eine Beschleunigung der Herzrate zu bewirken, führte jedoch nicht zu einer einhergehenden Verhaltensanpassung. Nur bei intaktem Hippokampus führten aversive Erinnerung und emotionale Aktivierung zu einer charakteristischen Verhaltensantwort. Als zugrunde liegende Mechanismen können parallele, Hirnareal abhängige Prozesse der Gedächtnisbildung bei Trace-Furchtkonditionierung

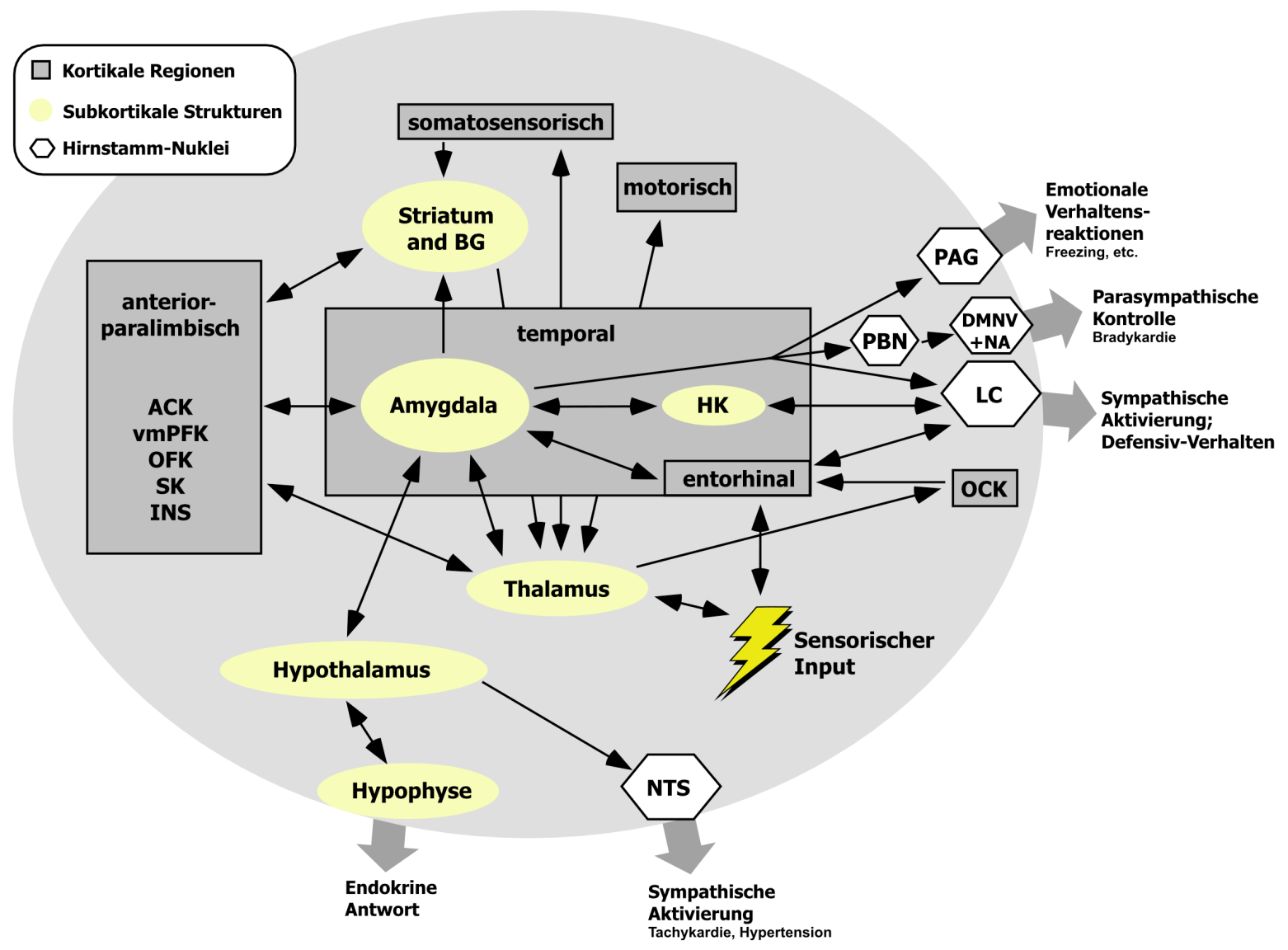

Abb. 4.3: Das neuronale Furcht-Netzwerk (modifiziert nach Cannistraro \& Rausch 2003). ACK=Anterior cingulate Kortex; BG= Basalganglion; HK=Hippokampus; INS=Insulärer Kortex; $\mathrm{LC}=$ Locus Coeruleus, NA=Nukleus Ambiguus; vmPFC=ventraler/medialer präfrontaler Kortex; $0 \mathrm{CK}=0$ ccipitaler Kortex; $0 \mathrm{FC}=0$ rbito-frontaler Kortex; $\mathrm{PAG=Periaquäduktale}$ graue Substanz; PBN= Parabrachialer Nukleus; $S C=$ Subkallosaler Kortex 
postuliert werden. Ein Prozess involviert den dorsalen Hippokampus insofern, als dass dort wichtige Informationsverarbeitung für die Assoziation von Ton-CS und US stattfindet. Dies ist dann notwendige Vorraussetzung für a) das Abrufen der aversiven Erinnerung und b) die Expression der konditionierten Furcht auf Verhaltens-Ebene. Ein parallel ablaufender Prozess erfolgt unabhängig vom dorsalen Hippokampus und involviert andere Hirnareale, die die Assoziation von Ton-CS und US sicherstellen. Somit wird die aversive Erinnerung abgerufen und mit Herzratenanstieg ausgedrückt, schlägt sich jedoch nicht in vermehrtem Freezing nieder. Ein ähnliches Modell wurde auf Basis von Kontext abhängiger Furchtkonditionierung und Hirnareal spezifischen Läsionen bei Ratten postuliert (Antoniadis \& McDonald, 2000).

Abbildung 4.3 zeigt das bei Furcht und Angst beteiligte neuronale Netzwerk. Neuroautonome Aktivierung wird demnach über Amygdala, Hypothalamus und Hirnstammnuklei wie dem Nucleus Tractus Solitarius, dem Parabrachialen Nukleus und dem Locus Coeruleus vermittelt, während Vermeidungsverhalten über Amygdala, Hippokampus und periaquäduktale graue Substanz vermittelt wird. Emotionale Ereignisse werden in der Amygdala als implizite emotionale Erinnerungen prozessiert, während diese im Hippokampus als explizite emotionale Erinnerung verarbeitet werden (Hamann, 2001). Gleichzeitig wird explizitites emotionales Gedächtnis im Hippokampus durch die Aktivität der Amygdala verstärkt (Hamann, 2001; LeDoux, 2002). Es ist bekannt, dass implizite, eher unbewusste traumatische Erinnerungen zur Aktivierung des autonomen Nervensystems führen (LeDoux, 1996). Die vorliegenden Ergebnisse bestätigen diese Erkenntnisse und legen nahe, dass für Vermeidungsverhalten zusätzlich zu impliziten Erinnerungen auch explizites, Hippokampus abhängiges emotionales Gedächtnis notwendig ist (Abb. 4.4).

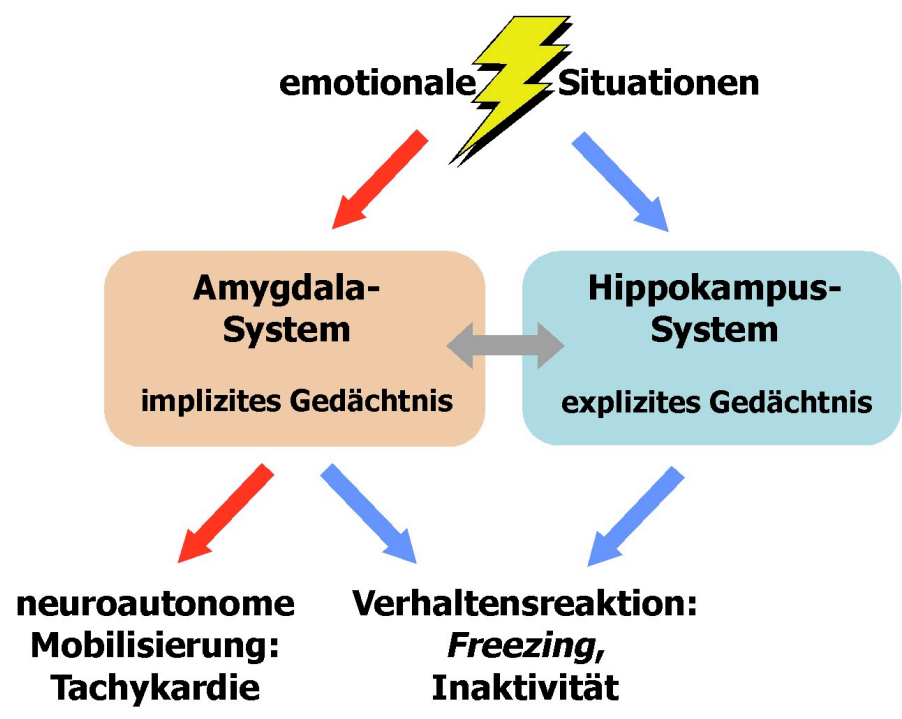

Abb. 4.4: Neuronale Systeme emotionalen Gedächtnisses bei TraceFurchtkonditionierung. In traumatischen Situationen (Training) funktionieren Amygdala- (rote Pfeile) und Hippokampus-System (blaue Pfeile) parallel. Während der Retention konditionierter Furcht (Gedächtnistest) werden beide Systeme reaktiviert. Wird die Verarbeitung des traumatischen Erlebnisses (Fußschock) im Hippokampus gestört, fehlt die explizite Komponente des emotionalen Gedächtnisses, die für Vermeidungsverhalten notwendig ist. Die nur von implizitem Gedächtnis abhängige neuroautonome Antwort ist davon unbeeinflusst. 


\section{Vergleichbarkeit von Freezing und Inaktivität}

Weitere Erkenntnisse dieser Studie wurden über die Vergleichbarkeit von lokomotorischer Aktivität und Freezing gewonnen. So konnte mit Hilfe einer Korrelationsanalyse die grundsätzlich gleiche Aussagekraft der beiden Messmethoden im Bezug auf die Bewertung der Verhaltens-Furchtantwort unter den experimentellen Bedingungen demonstriert werden. Freezing ist als stereotypisches Furcht bzw. Angst anzeigendes Verhaltensmuster gut bekannt (Fendt \& Fanselow, 1999). Jedoch bestehen weiterhin divergierende Auffassungen über die exakte Definition dieses Verhaltens. Hierin und in der Notwendigkeit der subjektiven Bewertung während des Verhaltenstests liegen die Schwächen dieser ethologischen Messgröße. Mit dem Einsatz automatisierter, objektiver Messsysteme können diese potentiellen Quellen von Ungenauigkeit umgangen werden. Jedoch stellen sich andere Probleme: Die objektiv quantifizierbare lokomotorische Aktivität ist nicht notwendigerweise Indikator für die Intensität von Furcht oder Angst. Auch andere exo- oder endogene Faktoren wie z.B. unterschiedliche Verhaltensstrategien in Stresssituationen (Koolhaas et al., 1999) oder pharmakologische Interventionen können Lokomotion nachhaltig beeinflussen. Probleme ergeben sich vor allem bei pharmakologischen Auswirkungen auf das motorische System sowie das kardiovaskuläre System, die sich auf die Lokomotionsaktivität auswirken (z.B. niedriger Blutdruck, dopaminerge Inhibition). Unter diesen systematischen Schwächen leiden auch andere Verhaltenstests wie der Elevated Plus Maze, Morris Water Maze oder Porsolt-Test, deren Grundlage sämtlich die indirekte Messung lokomotorischer Aktivität ist. Zumindest aber unter den experimentellen Bedingungen der in der vorliegenden Arbeit und früheren Studien (Stiedl et al., 2003; Stiedl et al., 1999a; Stiedl et al., 1999b; Stiedl \& Spiess, 1997) erfolgten Furchtkonditionierung konnte die Aktivität als zuverlässige Messgröße für Furcht etabliert werden, unter der Voraussetzung, dass Novelty induziertes Verhalten aktiv unterdrückt werden muss.

\subsection{Bedeutung der Forschungsergebnisse und Ausblick}

Epidemiologische Studien legen nahe, dass mentale bzw. emotionale Belastungen Risikofaktoren für kardiovaskuläre Morbidität und Mortalität darstellen (Rosengren et al., 1991; Ruberman et al., 1984). Die Ko-Morbidität von psychischen Angst- oder Gemütsstörungen und Kardiopathien wird beschrieben (Roose, 2001; Roose \& Spatz, 1999), die 
dieser Assoziation zugrunde liegenden Mechanismen sind jedoch noch unklar (Grippo \& Johnson, 2002). Furcht als emotional belastender Zustand wird auch in Zusammenhang mit Stressreaktionen und psychischen Störungen gestellt (Rosen \& Schulkin, 1998). Akute StressEffekte sind beim Menschen sympathisch vermittelte Vasokonstriktion und Herzratenanstieg (Benschop et al., 1994; Esler et al., 1995). Aufgrund experimenteller Limitationen existieren nur wenige Informationen $\mathrm{zu}$ den zentralnervösen Mechanismen Stress induzierter kardiovaskulärer Antworten in Menschen (Soufer et al., 1998; Wilkinson et al., 1998). Tiermodelle bieten die Möglichkeit, diese Prozesse eingehend zu untersuchen. Dabei sind besonders psychologische, emotionale Stressoren wie Novelty, konditionierte Furcht oder auch soziale Interaktion für die potentielle Übertragung der Ergebnisse auf den Menschen von Bedeutung (van den Buuse et al., 2001). Allerdings sind hier differierende Auffassungen und Definitionen zur Terminologie und den Mechanismen von Furcht und Angst zu beachten. Hier spielen auch Schwierigkeiten bei der deutschen Übersetzung der englischen Begriffe fear und anxiety eine Rolle. In manchen Studien wird keine scharfe Trennlinie zwischen Furcht und Angst gezogen (Fendt \& Fanselow, 1999). Befunde aus anderen Studien zeigen jedoch, dass die Amygdala, die zentrale Struktur bei der Verarbeitung konditionierter Furcht, in verschiedenen Angsttests keine wichtige Rolle bei Angstverhalten spielt (Davis et al., 1997). Die hierbei verwendeten Angsttests (z.B. Elevated Plus Maze) sind jedoch im Wesentlichen aufgrund der Wirksamkeit klinischer, angstlösender Substanzen als Angstparadigmen etabliert. Furcht wird jedoch übereinstimmend als stärker Stimulus-spezifisch charakterisiert, während Angst von einer subjektiven Unsicherheit gegenüber dem negativen Stimulus geprägt ist (Cannistraro \& Rauch, 2003). Dies trifft auch auf die klinische, bzw. auf den Menschen bezogene Definition von Angst(störungen) als überwiegend generalisierte, abstrakte Prozesse zu. Dennoch weisen die Symptome von Furcht in Tiermodellen große Ähnlichkeiten mit Symptomen humaner Angststörungen auf (Davis et al., 1997). In der vorliegenden Arbeit wurden ausschließlich explizite, d.h. akute Stimuli verwendet. Somit wurde im Wesentlichen der Begriff Furcht anstelle von Angst gebraucht.

Mit Hilfe konditionierter und unkonditionierter Stressoren wurden die emotionale Modulation kardiovaskulärer Regulationsmechanismen sowie die Anpassungsreaktionen auf Verhaltens- und hormonaler Ebene untersucht. Dabei wurden relativ stressfreie Ausgangsbedingungen durch den Einsatz telemetrischer Messtechnik ermöglicht. Die grundlegenden Studien zur zeitlichen Ausprägung der verschiedenen Furcht induzierten Regulationsprozesse demonstrierten die zeitliche Dissoziation von Herzraten und Blutdruckantworten während der Retention konditionierter Furcht und verdeutlichten die ausgeprägte Responsivität und 
relative Uniformität neuroautonomer Regulation gegenüber emotional bedeutsamen externen Stimuli. Bei zukünftigen Versuchen mit wiederholter Präsentation eines emotional bedeutsamen, d.h. aversiv konditionierten Kontextes, über längere Zeiträume hinweg, sind verschiedene Entwicklungen denkbar. Zum einen könnten die verhaltensmäßigen und neuroautonomen Furchtantworten im Zuge eines umfassenden Desensibilisierungs- bzw. Gewöhnungsprozesses abgeschwächt werden, zum anderen könnte bei anhaltender mentaler und physischer Belastung ein Zustand chronischen Stresses mit potentiell pathologischen Folgen (Herz-Kreislauferkrankungen, Depression) eintreten. Andere Studien deuten in verschiedene Richtungen: Während sich bei wiederholtem sozialem Stress bei Ratten die Herzratenantworten abschwächen (Tornatzky \& Miczek, 1994), wurden bei Novelty-Stress keine Habituationen der kardiovaskulären Reaktionen ermittelt (Nijsen et al., 1998; van den Buuse et al., 2001).

Es wird vermutet, das CRF eine „neurochemische Schnittstelle“ zwischen Stressinduzierten physiologischen Anpassungsprozessen, kardiovaskulärer Dysregulation und Psychopathologien sein könnte (Claes, 2004; Grippo \& Johnson, 2002). So werden bei depressiven Patienten und Patienten mit Post-traumatischer Belastungsstörung (PTSD) erhöhte CRF-Spiegel in der Zerebrospinalflüssigkeit gefunden (Baker et al., 1999; Kasckow et al., 2001; Nemeroff et al., 1984). Gleichzeitig ist bei diesen Patienten erhöhte kardiale Mortalität belegt. Eine wichtige Rolle für CRF bei der kardiovaskulären Regulation während akuten Stresses bzw. emotionaler Belastung konnte in der vorliegenden Arbeit nicht belegt werden. Dennoch erscheinen aufgrund der pharmakologischen Wirksamkeit exogenen CRFs solche CRF abhängigen kardiovaskulären Regulationsmechanismen zu existieren. Weiterführende Untersuchungen sollten daher den Auswirkungen von chronischem Stress auf CRF-vermittelte Effekte nachgehen. 


\section{$5 \quad$ Zusammenfassung}

Externe Stimuli mit angeborenen oder erlernten aversiven Eigenschaften lösten bei Mäusen charakteristische somatomotorische-, neuroautonome- und endokrine Antwortmuster aus. Unkonditionierte Stimuli wie kurzzeitige Berührung, die Erfahrung einer neuen Umgebung (Novelty) oder die Präsentation synthetischen Fuchsgeruchs führten zu einer durch erhöhten Sympathikotonus vermittelten Beschleunigung der Herzfrequenz (Herzrate) in Folge gesteigerter lokomotorischer Aktivität und emotionaler Aktivierung. Aversiv konditionierte auditorische oder kontextuelle Stimuli resultierten in lokomotorischer Inhibition bzw. Freezing, Herzraten- und Blutdruckanstieg und erhöhter Kortikosteronkonzentrationen im Blutplasma. Während die Verhaltensänderungen und die Anpassung der Herzrate schnelle zeitliche Dynamik zeigten, erfolgten Blutdruck und endokrine Antworten verzögert. Herzrate und Blutdruck konnten somit als Indikatoren für konditionierte Furcht mit zeitlich dissoziierenden Antwortmustern charakterisiert werden. Die Retention konditionierter Furcht resultierte in erhöhten Kortikosteronwerten welche die unkonditionierte Kortikosteronreaktion übertrafen. Daraus wurde geschlussfolgert, dass die auditorische Furchtkonditionierung ein Modell für akute emotionale Belastung bzw. Stress repräsentiert.

Die pharmakologische Aktivierung des Rezeptorsubtyps 1 des Kortikotropinfreisetzenden Hormons $\left(\mathrm{CRF}_{1}\right)$ im Zentralnervensystem (ZNS) führte zu erniedrigten basalen Herzraten, abgeschwächter konditionierter Tachykardie und pathologisch erhöhter Herzratenvariabilität. Als zugrunde liegender Mechanismus wird ein erhöhter sympathovagaler Antagonismus vorgeschlagen, im Gegensatz zu einem abgeschwächten sympathovagalen Antagonismus durch zentrale Aktivierung von Neuropeptid Y-Rezeptoren. Periphere pharmakologische Aktivierung von $\mathrm{CRF}_{1}$ führte zu Herzratenanstieg bei unverändertem Blutdruck, während periphere Aktivierung von $\mathrm{CRF}_{2}$ in Blutdruckabfall und vermutlich Barorezeptorreflex-vermitteltem Herzratenanstieg resultierte. Bei CRF-überproduzierenden Mäusen wurden aufgrund einer fehlenden konditionierten Tachykardie im Ton abhängigen Gedächtnistest, jedoch normalem Herzratenanstieg während des Novelty-Tests kognitive Defizite hypothetisiert. Genetisch modifizierte Mäuse, denen funktionelle $\mathrm{CRF}_{1}$ bzw. $\mathrm{CRF}_{2}{ }^{-}$ Rezoptoren fehlten, zeigten normales Verhalten und normale Herzratenantworten auf emotionale Stimuli im Novelty-Test und in der Furchtkonditionierung. Die physiologische Rolle endogenen CRFs bei der Regulation kardiovaskulärer Funktionen bleibt somit unklar. Ein wichtiger Beitrag von CRF zur akuten emotionalen Modulation neuroautonomer Funktion 
ist unwahrscheinlich, während eine wichtige Rolle endogenen CRFs unter chronischen Stressbedingungen nicht ausgeschlossen werden kann.

Auf Basis von Furcht induziertem Verhalten konnte ein Beitrag des dorsalen Hippokampus zur Trace-Furchtkonditionierung festgestellt werden, wenn die zeitliche Trennung (Trace) von konditioniertem (Ton) und unkonditioniertem (US) Stimulus 15-30 s betrug. Aufgrund der trotz Inhibition hippokampaler NMDA-Rezeptoren unbeeinflussten Herzratenantwort wurde auf parallele Gedächtnisfunktionen auditorisch konditionierter Furcht rückgeschlossen. 


\section{$6 \quad$ Literatur}

Aldenhoff, J. B., Gruol, D. L., Rivier, J., Vale, W., \& Siggins, G. R. (1983). Corticotropin releasing factor decreases postburst hyperpolarizations and excites hippocampal neurons. Science, 221(4613), 875-877.

Antoniadis, E. A., \& McDonald, R. J. (2000). Amygdala, hippocampus and discriminative fear conditioning to context. Behavioral Brain Research, 108(1), 1-19.

Armario, A., Marti, O., Valles, A., Dal-Zotto, S., \& Ons, S. (2004). Long-term effects of a single exposure to immobilization on the hypothalamic-pituitary-adrenal axis: neurobiologic mechanisms. Annals of the New York Academy of Sciences, 1018, 162-172.

Baker, D. G., West, S. A., Nicholson, W. E., Ekhator, N. N., Kasckow, J. W., Hill, K. K., Bruce, A. B., Orth, D. N., \& Geracioti, T. D., Jr. (1999). Serial CSF corticotropin-releasing hormone levels and adrenocortical activity in combat veterans with posttraumatic stress disorder. American Journal of Psychiatry, 156(4), 585-588.

Bale, T. L., Hoshijima, M., Gu, Y., Dalton, N., Anderson, K. R., Lee, K. F., Rivier, J., Chien, K. R., Vale, W. W., \& Peterson, K. L. (2004). The cardiovascular physiologic actions of urocortin II: acute effects in murine heart failure. Proceedings of the National Academy of Sciences of the United States of America, 101(10), 3697-3702.

Bale, T. L., \& Vale, W. W. (2004). CRF and CRF receptors: role in stress responsivity and other behaviors. Annual Review of Pharmacology and Toxicology, 44, 525-557.

Bast, T., Zhang, W. N., \& Feldon, J. (2003). Dorsal hippocampus and classical fear conditioning to tone and context in rats: effects of local NMDA-receptor blockade and stimulation. Hippocampus, 13(6), 657-675.

Baudrie, V., Tulen, J. H., Blanc, J., \& Elghozi, J. L. (1997). Autonomic components of the cardiovascular responses to an acoustic startle stimulus in rats. Journal of Autonomic Pharmacology, 17(5), 303-309. 
Benschop, R. J., Nieuwenhuis, E. E., Tromp, E. A., Godaert, G. L., Ballieux, R. E., \& van Doornen, L. J. (1994). Effects of beta-adrenergic blockade on immunologic and cardiovascular changes induced by mental stress. Circulation, 89(2), 762-769.

Berntson, G. G., Sarter, M., \& Cacioppo, J. T. (1998). Anxiety and cardiovascular reactivity: the basal forebrain cholinergic link. Behavioral Brain Research, 94(2), 225-248.

Blanchard, D. C., Blanchard, R. J., \& Rodgers, R. J. (1991). Risk assessment and animal models of anxiety. In B. Olivier, J. Mos \& J. L. Slangen (Eds.), Animal models in psychopharmacology (pp. 117-134). Basel: Birkhauser.

Blanchard, R. J., Blanchard, D. C., Weiss, S. M., \& Meyer, S. (1990). The effects of ethanol and diazepam on reactions to predatory odors. Pharmacology Biochemistry and Behavior, 35(4), 775-780.

Blanchard, R. J., Yang, M., Li, C. I., Gervacio, A., \& Blanchard, D. C. (2001). Cue and context conditioning of defensive behaviors to cat odor stimuli. Neuroscience and Biobehavioral Reviews, 25(7-8), 587-595.

Blanchard, R. J., Yudko, E. B., Rodgers, R. J., \& Blanchard, D. C. (1993). Defense system psychopharmacology: an ethological approach to the pharmacology of fear and anxiety. Behavioral Brain Research, 58(1-2), 155-165.

Blank, T., Nijholt, I., Grammatopoulos, D. K., Randeva, H. S., Hillhouse, E. W., \& Spiess, J. (2003). Corticotropin-releasing factor receptors couple to multiple G-proteins to activate diverse intracellular signaling pathways in mouse hippocampus: role in neuronal excitability and associative learning. Journal of Neuroscience, 23(2), 700-707.

Bouwknecht, J. A., Hijzen, T. H., van der Gugten, J., Maes, R. A., \& Olivier, B. (2000). Stress-induced hyperthermia in mice: effects of flesinoxan on heart rate and body temperature. European Journal of Pharmacology, 400(1), 59-66.

Brockway, B. P. (1998). Fully implanted radio-telemetry for monitoring laboratory animals. Lab animal, 27, 40-46. 
Busse, R. (2000). Gefäßsystem und Kreislaufregulation. In R. F. Schmidt, G. Thews \& F. Lang (Eds.), Physiologie des Menschen (pp. 535-552). Berlin: Springer.

Butz, G. M., \& Davisson, R. L. (2001). Long-term telemetric measurement of cardiovascular parameters in awake mice: a physiological genomics tool. Physiological Genomics, 5(2), 8997.

Cannistraro, P. A., \& Rauch, S. L. (2003). Neural circuitry of anxiety: evidence from structural and functional neuroimaging studies. Psychopharmacology Bulletin, 37(4), 8-25.

Cannon, W. B. (1929). Bodily changes in pain, hunger, fear and rage. New York: Appleton.

Carrive, P. (2000). Conditioned fear to environmental context: cardiovascular and behavioral components in the rat. Brain Research, 858(2), 440-445.

Chalmers, D. T., Lovenberg, T. W., \& De Souza, E. B. (1995). Localization of novel corticotropin-releasing factor receptor (CRF2) mRNA expression to specific subcortical nuclei in rat brain: comparison with CRF1 receptor mRNA expression. Journal of Neuroscience, 15(10), 6340-6350.

Chang, C. P., Pearse, R. V., 2nd, O'Connell, S., \& Rosenfeld, M. G. (1993). Identification of a seven transmembrane helix receptor for corticotropin-releasing factor and sauvagine in mammalian brain. Neuron, 11(6), 1187-1195.

Claes, S. J. (2004). Corticotropin-releasing hormone (CRH) in psychiatry: from stress to psychopathology. Annals of Medicine, 36(1), 50-61.

Clark, A. J. (1927). Comparative physiology of the heart. New York: MacMillan.

Contarino, A., Dellu, F., Koob, G. F., Smith, G. W., Lee, K. F., Vale, W., \& Gold, L. H. (1999). Reduced anxiety-like and cognitive performance in mice lacking the corticotropinreleasing factor receptor 1. Brain Research, 835(1), 1-9.

Coste, S. C., Kesterson, R. A., Heldwein, K. A., Stevens, S. L., Heard, A. D., Hollis, J. H., Murray, S. E., Hill, J. K., Pantely, G. A., Hohimer, A. R., Hatton, D. C., Phillips, T. J., Finn, D. A., Low, M. J., Rittenberg, M. B., Stenzel, P., \& Stenzel-Poore, M. P. (2000). Abnormal 
adaptations to stress and impaired cardiovascular function in mice lacking corticotropinreleasing hormone receptor-2. Nature Genetics, 24(4), 403-409.

Crawley, J., \& Goodwin, F. K. (1980). Preliminary report of a simple animal behavior model for the anxiolytic effects of benzodiazepines. Pharmacology Biochemistry and Behavior, 13(2), 167-170.

Crestani, F., Keist, R., Fritschy, J. M., Benke, D., Vogt, K., Prut, L., Bluthmann, H., Mohler, H., \& Rudolph, U. (2002). Trace fear conditioning involves hippocampal alpha5 GABA(A) receptors. Proceedings of the National Academy of Sciences of the United States of America, 99(13), 8980-8985.

Crusio, W. E. (2001). Genetic dissection of mouse exploratory behaviour. Behavioral Brain Research, 125(1-2), 127-132.

Davis, M. (1997). Neurobiology of fear. Journal of Neuropsychiatry, 9(3), 382-402.

Davis, M., Walker, D. L., \& Lee, Y. (1997). Roles of the amygdala and bed nucleus of the stria terminalis in fear and anxiety measured with the acoustic startle reflex. Possible relevance to PTSD. Annals of the New York Academy of Sciences, 821, 305-331.

De Souza, E. B., \& Grigoriadis, D. E. (2000). Multiple brain corticotropin-releasing factor receptors and binding protein. In R. Quirion, A. Björklund \& T. Hökfelt (Eds.), Handbook of chemical neuroanatomy (Vol. 16, pp. 477-508). Amsterdam: Elsevier.

Denenberg, V. H. (1969). Open-field bheavior in the rat: what does it mean? Annals of the New York Academy of Sciences, 159(3), 852-859.

Dielenberg, R. A., Carrive, P., \& McGregor, I. S. (2001). The cardiovascular and behavioral response to cat odor in rats. unconditioned and conditioned effects. Brain Research, 897, 228237.

Dielenberg, R. A., Leman, S., \& Carrive, P. (2004). Effect of dorsal periaqueductal gray lesions on cardiovascular and behavioral responses to cat odor exposure in rats. Behavioral Brain Research, 153(2), 487-496. 
Dielenberg, R. A., \& McGregor, I. S. (1999). Habituation of the hiding response to cat odor in rats (Rattus norvegicus). Journal of Comparative Psychology, 113(4), 376-387.

Dielenberg, R. A., \& McGregor, I. S. (2001). Defensive behavior in rats towards predatory odors: a review. Neuroscience and Biobehavioral Reviews, 25(7-8), 597-609.

Dirks, A., Groenink, L., Bouwknecht, J. A., Hijzen, T. H., Van Der Gugten, J., Ronken, E., Verbeek, J. S., Veening, J. G., Dederen, P. J., Korosi, A., Schoolderman, L. F., Roubos, E. W., \& Olivier, B. (2002). Overexpression of corticotropin-releasing hormone in transgenic mice and chronic stress-like autonomic and physiological alterations. European Journal of Neuroscience, 16(9), 1751-1760.

Dulawa, S. C., Holick, K. A., Gundersen, B., \& Hen, R. (2004). Effects of chronic fluoxetine in animal models of anxiety and depression. Neuropsychopharmacology, 29(7), 1321-1330.

Eckart, K., Radulovic, J., Radulovic, M., Jahn, O., Blank, T., Stiedl, O., \& Spiess, J. (1999). Actions of CRF and its analogs. Current Medicinal Chemistry, 6, 1035-1053.

Esler, M. D., Thompson, J. M., Kaye, D. M., Turner, A. G., Jennings, G. L., Cox, H. S., Lambert, G. W., \& Seals, D. R. (1995). Effects of aging on the responsiveness of the human cardiac sympathetic nerves to stressors. Circulation, 91(2), 351-358.

Falls, W. A., Carlson, S., Turner, J. G., \& Willott, J. F. (1997). Fear-potentiated startle in two strains of inbred mice. Behavioral Neuroscience, 111, 855-861.

Fanselow, M. S. (1990). Factors governing one-trial contextual conditioning. Animal Learning \& Behavior, 18(3), 264-270.

Fanselow, M. S., Kim, J. J., Yipp, J., \& De Oca, B. (1994). Differential effects of the Nmethyl-D-aspartate antagonist DL-2-amino-5-phosphonovalerate on acquisition of fear of auditory and contextual cues. Behavioral Neuroscience, 108(2), 235-240.

Fendt, M., \& Fanselow, M. S. (1999). The neuroanatomical and neurochemical basis of conditioned fear. Neuroscience and Biobehavioral Reviews, 23(5), 743-760. 
File, S. E., Zangrossi, H., Jr., Sanders, F. L., \& Mabbutt, P. S. (1993). Dissociation between behavioral and corticosterone responses on repeated exposures to cat odor. Physiology and Behavior, 54(6), 1109-1111.

Fisher, L. A. (1989). Corticotropin-releasing factor: endocrine and autonomic integration of responses to stress. Trends in Pharmacological Sciences, 10(5), 189-193.

Fisher, L. A., Jessen, G., \& Brown, M. R. (1983). Corticotropin-releasing factor (CRF): mechanism to elevate mean arterial pressure and heart rate. Regulatory Peptides, 5(2), 153161.

Fleshler, M. (1965). Adequate acoustic stimulus for startle reaction in the rat. Journal of Comparative Physiology and Psychology, 60(2), 200-207.

Folkow, B. (2001). Mental stress and its importance for cardiovascular disorders; physiological aspects, "from-mice-to-man". Scandinavian Cardiovascular Journal, 35(3), 163-172.

Frankland, P. W., Cestari, V., Filipkowski, R. K., McDonald, R. J., \& Silva, A. J. (1998). The dorsal hippocampus is essential for context discrimination but not for contextual conditioning. Behavioral Neuroscience, 112(4), 863-874.

Goldstein, L. E., Rasmusson, A. M., Bunney, B. S., \& Roth, R. H. (1996). Role of the amygdala in the coordination of behavioral, neuroendocrine, and prefrontal cortical monoamine responses to psychological stress in the rat. Journal of Neuroscience, 16(15), 4787-4798.

Grippo, A. J., \& Johnson, A. K. (2002). Biological mechanisms in the relationship between depression and heart disease. Neuroscience and Biobehavioral Reviews, 26(8), 941-962.

Groenink, L., Pattij, T., De Jongh, R., Van der Gugten, J., Oosting, R. S., Dirks, A., \& Olivier, B. (2003). 5-HT1A receptor knockout mice and mice overexpressing corticotropinreleasing hormone in models of anxiety. European Journal of Pharmacology, 463(1-3), 185197. 
Guyton, A. C., Coleman, T. G., \& Granger, H. J. (1972). Circulation: overall regulation. Annual Reviews of Physiology, 38, 13-46.

Hamann, S. (2001). Cognitive and neural mechanisms of emotional memory. Trends in Cognitive Science, 5(9), 394-400.

Hebb, A. L., Zacharko, R. M., Dominguez, H., Trudel, F., Laforest, S., \& Drolet, G. (2002). Odor-induced variation in anxiety-like behavior in mice is associated with discrete and differential effects on mesocorticolimbic cholecystokinin mRNA expression. Neuropsychopharmacology, 27(5), 744-755.

Heinrichs, S. C., Menzaghi, F., Merlo Pich, E., Britton, K. T., \& Koob, G. F. (1995). The role of CRF in behavioral aspects of stress. Annals of the New York Academy of Sciences, 771, 92104.

Heinrichs, S. C., Stenzel-Poore, M. P., Gold, L. H., Battenberg, E., Bloom, F. E., Koob, G. F., Vale, W. W., \& Pich, E. M. (1996). Learning impairment in transgenic mice with central overexpression of corticotropin-releasing factor. Neuroscience, 74(2), 303-311.

Hillhouse, E. W., \& Karteris, E. (2002). Expression of multiple corticotropin-releasing hormone receptors in the human heart. Journal of Clinical Endocrinology and Metabolism, 87(6), 2992; author reply 2992-2993.

Holmes, A., Wrenn, C. C., Harris, A. P., Thayer, K. E., \& Crawley, J. N. (2002). Behavioral profiles of inbred strains on novel olfactory, spatial and emotional tests for reference memory in mice. Genes Brain and Behavior, 1(1), 55-69.

Hotsenpiller, G., \& Williams, J. L. (1997). A synthetic predator odor (TMT) enhances conditioned analgesia and fear when paired with a benzodiazepine receptor inverse agonist (FG-7142). Psychobiology, 25(1), 83-88.

Hsu, S. Y., \& Hsueh, A. J. (2001). Human stresscopin and stresscopin-related peptide are selective ligands for the type 2 corticotropin-releasing hormone receptor. Nature Medicine, 7(5), 605-611. 
Huerta, P. T., Sun, L. D., Wilson, M. A., \& Tonegawa, S. (2000). Formation of temporal memory requires NMDA receptors within CA1 pyramidal neurons. Neuron, 25(2), 473-480.

Ishii, T., Kuwaki, T., Masuda, Y., \& Fukuda, Y. (2001). Postnatal development of blood pressure and baroreflex in mice. Autonomic Neuroscience, 94(1-2), 34-41.

Iwata, J., \& LeDoux, J. E. (1988). Dissociation of associative and nonassociative concomitants of classical fear conditioning in the freely behaving rat. Behavioral Neuroscience, 102(1), 66-76.

Jahn, O., Radulovic, J., Stiedl, O., Tezval, H., Eckart, K., \& Spiess, J. (2005). Corticotropinreleasing factor binding protein- a ligand trap? Mini-Rev Med Chem, (in press).

Just, A., Faulhaber, J., \& Ehmke, H. (2000). Autonomic cardiovascular control in conscious mice. American Journal of Physiology-Regulatory Integrative and Comparative Physiology, 279(6), R2214-2221.

Kapp, B. S., Gallagher, M., Underwood, M. D., McNall, C. L., \& Whitehorn, D. (1982). Cardiovascular responses elicited by electrical stimulation of the amygdala central nucleus in the rabbit. Brain Research, 234(2), 251-262.

Kasckow, J. W., Baker, D., \& Geracioti, T. D., Jr. (2001). Corticotropin-releasing hormone in depression and post-traumatic stress disorder. Peptides, 22(5), 845-851.

Kim, J. J., DeCola, J. P., Landeira-Fernandez, J., \& Fanselow, M. S. (1991). N-methyl-Daspartate receptor antagonist APV blocks acquisition but not expression of fear conditioning. Behavioral Neuroscience, 105(1), 126-133.

Kimura, Y., Takahashi, K., Totsune, K., Muramatsu, Y., Kaneko, C., Darnel, A. D., Suzuki, T., Ebina, M., Nukiwa, T., \& Sasano, H. (2002). Expression of urocortin and corticotropinreleasing factor receptor subtypes in the human heart. Journal of Clinical Endocrinology and Metabolism, 87(1), 340-346. 
Kinney, J. W., Starosta, G., Holmes, A., Wrenn, C. C., Yang, R. J., Harris, A. P., Long, K. C., \& Crawley, J. N. (2002). Deficits in trace cued fear conditioning in galanin-treated rats and galanin-overexpressing transgenic mice. Learning and Memory, 9(4), 178-190.

Kishimoto, T., Radulovic, J., Radulovic, M., Lin, C. R., Schrick, C., Hooshmand, F., Hermanson, O., Rosenfeld, M. G., \& Spiess, J. (2000). Deletion of crhr2 reveals an anxiolytic role for corticotropin-releasing hormone receptor-2. Nature Genetics, 24(4), 415-419.

Koch, M. (1999). The neurobiology of startle. Progress in Neurobiology, 59, 107-128.

Koob, G. F., \& Heinrichs, S. C. (1999). A role for corticotropin releasing factor and urocortin in behavioral responses to stressors. Brain Research, 848(1-2), 141-152.

Koolhaas, J. M., Korte, S. M., De Boer, S. F., Van Der Vegt, B. J., Van Reenen, C. G., Hopster, H., De Jong, I. C., Ruis, M. A., \& Blokhuis, H. J. (1999). Coping styles in animals: current status in behavior and stress-physiology. Neuroscience and Biobehavioral Reviews, 23(7), 925-935.

Korte, S. M. (2001). Corticosteroids in relation to fear, anxiety and psychopathology. Neuroscience and Biobehavioral Reviews, 25(2), 117-142.

Kramer, K., \& Kinter, L. B. (2003). Evaluation and applications of radiotelemetry in small laboratory animals. Physiol Genomics, 13(3), 197-205.

Kramer, K., van Acker, S. A., Voss, H. P., Grimbergen, J. A., van der Vijgh, W. J., \& Bast, A. (1993). Use of telemetry to record electrocardiogram and heart rate in freely moving mice. Journal of Pharmacological and Toxicological Methods, 30(4), 209-215.

Kramer, K., van de Weerd, H., Mulder, A., Van Heijningen, C., Baumans, V., Remie, R., Voss, H. P., \& van Zutphen, B. F. M. (2004). Effect of conditioning on the increase of heart rate and body temperature provoked by handling in the mouse. Atla-Alternatives to Laboratory Animals, 32, 177-181.

Kumada, M., Terui, N., \& Kuwaki, T. (1990). Arterial baroreceptor reflex: its central and peripheral neural mechanisms. Progress in Neurobiology, 35(5), 331-361. 
Kurtz, T. W., Griffin, K. A., Bidani, A. K., Davisson, R. L., \& Hall, J. E. (2005).

Recommendations for blood pressure measurement in animals: summary of an AHA scientific statement from the Council on High Blood Pressure Research, Professional and Public Education Subcommittee. Arteriosclerosis, Thrombosis, and Vascular Biology, 25(3), 478-479.

LeDoux, J. E. (1993). Emotional memory systems in the brain. Behavioural Brain Research, $58,69-79$.

LeDoux, J. E. (1996). The emotional brain. New York: Simon \& Schuster (Touchstone).

LeDoux, J. E. (2002). Synaptic self- how our brains become who we are. New York: Penguin.

LeDoux, J. E., Iwata, J., Cicchetti, P., \& Reis, D. J. (1988). Different projections of the central amygdaloid nucleus mediate autonomic and behavioral correlates of conditioned fear. Journal of Neuroscience, 8(7), 2517-2529.

Loewy, A. D. (1990). Central autonomic pathways. In K. M. Spyer (Ed.), Central regulation of autonomic functions (pp. 88-103). New York: Oxford University Press.

Lovenberg, T. W., Chalmers, D. T., Liu, C., \& De Souza, E. B. (1995). CRF2 alpha and CRF2 beta receptor mRNAs are differentially distributed between the rat central nervous system and peripheral tissues. Endocrinology, 136(9), 4139-4142.

Matthies, H., Schroeder, H., Becker, A., Loh, H., Hollt, V., \& Krug, M. (2000). Lack of expression of long-term potentiation in the dentate gyrus but not in the CA1 region of the hippocampus of mu-opioid receptor-deficient mice. Neuropharmacology, 39(6), 952-960.

McEchron, M. D., Bouwmeester, H., Tseng, W., Weiss, C., \& Disterhoft, J. F. (1998). Hippocampectomy disrupts auditory trace fear conditioning and contextual fear conditioning in the rat. Hippocampus, 8(6), 638-646.

McNish, K. A., Gewirtz, J. C., \& Davis, M. (2000). Disruption of contextual freezing, but not contextual blocking of fear-potentiated startle, after lesions of the dorsal hippocampus. Behavioral Neuroscience, 114(1), 64-76. 
Milanovic, S., Radulovic, J., Laban, O., Stiedl, O., Henn, F., \& Spiess, J. (1998). Production of the Fos protein after contextual fear conditioning of C57BL/6N mice. Brain Research, 784(1-2), 37-47.

Mills, P. A., Huetteman, D. A., Brockway, B. P., Zwiers, L. M., Gelsema, A. J., Schwartz, R. S., \& Kramer, K. (2000). A new method for measurement of blood pressure, heart rate, and activity in the mouse by radiotelemetry. Journal of Applied Physiology, 88(5), 1537-1544.

Morris, R. G., Anderson, E., Lynch, G. S., \& Baudry, M. (1986). Selective impairment of learning and blockade of long-term potentiation by an N-methyl-D-aspartate receptor antagonist, AP5. Nature, 319(6056), 774-776.

Morrow, B. A., Redmond, A. J., Roth, R. H., \& Elsworth, J. D. (2000). The predator odor, TMT, displays a unique, stress-like pattern of dopaminergic and endocrinological activation in the rat. Brain Research, 864(1), 146-151.

Munck, A., Guyre, P. M., \& Holbrook, N. J. (1984). Physiological functions of glucocorticoids in stress and their relation to pharmacological actions. Endocrine Reviews, $5(1), 25-44$.

Nemeroff, C. B., Widerlov, E., Bissette, G., Walleus, H., Karlsson, I., Eklund, K., Kilts, C. D., Loosen, P. T., \& Vale, W. (1984). Elevated concentrations of CSF corticotropin-releasing factor-like immunoreactivity in depressed patients. Science, 226(4680), 1342-1344.

Nijsen, M. J., Croiset, G., Diamant, M., Stam, R., Delsing, D., de Wied, D., \& Wiegant, V. M. (1998). Conditioned fear-induced tachycardia in the rat: vagal involvement. European Journal of Pharmacology, 350(2-3), 211-222.

Overton, J. M., \& Fisher, L. A. (1991). Differentiated hemodynamic responses to central versus peripheral administration of corticotropin-releasing factor in conscious rats. $J$ Auton Nerv Syst, 35(1), 43-51.

Owens, M. J., \& Nemeroff, C. B. (1991). Physiology and pharmacology of corticotropinreleasing factor. Pharmacological Reviews, 43(4), 425-473. 
Parkes, D. G., Weisinger, R. S., \& May, C. N. (2001). Cardiovascular actions of CRH and urocortin: an update. Peptides, 22(5), 821-827.

Paylor, R., Tracy, R., Wehner, J., \& Rudy, J. W. (1994). DBA/2 and C57BL/6 mice differ in contextual fear but not auditory fear conditioning. Behavioral Neuroscience, 108(4), 810-817.

Peotta, V. A., Vasquez, E. C., \& Meyrelles, S. S. (2001). Cardiovascular neural reflexes in LNAME-induced hypertension in mice. Hypertension, 38(3 Pt 2), 555-559.

Pilz, P. K. D., \& Leaton, R. N. (1999). Short-term and long-term habituation of the acoustic startle response as a function of stimulus rise time in rats. Psychobiology, 27(3), 402-414.

Plappert, C. F., \& Pilz, P. K. (2001). The acoustic startle response as an effective model for elucidating the effect of genes on the neural mechanism of behavior in mice. Behavioural Brain Research, 125(1-2), 183-188.

Primus, R. J., Yevich, E., Baltazar, C., \& Gallager, D. W. (1997). Autoradiographic localization of CRF1 and CRF2 binding sites in adult rat brain. Neuropsychopharmacology, 17(5), 308-316.

Quigley, K. S., \& Berntson, G. G. (1990). Autonomic origins of cardiac responses to nonsignal stimuli in the rat. Behavioral Neuroscience, 104(5), 751-762.

Quinn, J. J., Oommen, S. S., Morrison, G. E., \& Fanselow, M. S. (2002). Post-training excitotoxic lesions of the dorsal hippocampus attenuate forward trace, backward trace, and delay fear conditioning in a temporally specific manner. Hippocampus, 12(4), 495-504.

Radulovic, J., Kammermeier, J., \& Spiess, J. (1998). Generalization of fear responses in C57BL/6N mice subjected to one-trial foreground contextual fear conditioning. Behav Brain Res, 95(2), 179-189.

Ramos, A., \& Mormede, P. (1998). Stress and emotionality: a multidimensional and genetic approach. Neuroscience and Biobehavioral Reviews, 22(1), 33-57.

Rasmusson, A. M., \& Charney, D. S. (1997). Animal models of relevance to PTSD. Annals of the New York Academy of Sciences, 821, 332-351. 
Reyes, T. M., Lewis, K., Perrin, M. H., Kunitake, K. S., Vaughan, J., Arias, C. A., Hogenesch, J. B., Gulyas, J., Rivier, J., Vale, W. W., \& Sawchenko, P. E. (2001). Urocortin II: a member of the corticotropin-releasing factor (CRF) neuropeptide family that is selectively bound by type 2 CRF receptors. Proceedings of the National Academy of Sciences of the United States of America, 98(5), 2843-2848.

Richter, R. M., \& Mulvany, M. J. (1995). Comparison of hCRF and oCRF effects on cardiovascular responses after central, peripheral, and in vitro application. Peptides, 16(5), 843-849.

Roose, S. P. (2001). Depression, anxiety, and the cardiovascular system: the psychiatrist's perspective. Journal of Clinical Psychiatry, 62 Suppl 8, 19-22; discussion 23.

Roose, S. P., \& Spatz, E. (1999). Treatment of depression in patients with heart disease. Journal of Clinical Psychiatry, 60 Suppl 20, 34-37.

Roozendaal, B., Koolhaas, J. M., \& Bohus, B. (1991). Attenuated cardiovascular, neuroendocrine, and behavioral responses after a single footshock in central amygdaloid lesioned male rats. Physiology and Behavior, 50(4), 771-775.

Roozendaal, B., Koolhaas, J. M., \& Bohus, B. G. (1992). Central amygdaloid involvement in neuroendocrine correlates of conditioned stress responses. Journal of Neuroendocrinology, 4(4), 483-489.

Rosen, J. B., \& Schulkin, J. (1998). From normal fear to pathological anxiety. Psychological Review, 105(2), 325-350.

Rosengren, A., Tibblin, G., \& Wilhelmsen, L. (1991). Self-perceived psychological stress and incidence of coronary artery disease in middle-aged men. American Journal of Cardiology, 68(11), 1171-1175.

Ruberman, W., Weinblatt, E., Goldberg, J. D., \& Chaudhary, B. S. (1984). Psychosocial influences on mortality after myocardial infarction. New England Journal of Medicine, 311(9), 552-559. 
Sanders, M. J., Wiltgen, B. J., \& Fanselow, M. S. (2003). The place of the hippocampus in fear conditioning. European Journal of Pharmacology, 463(1-3), 217-223.

Shekhar, A., Sajdyk, T. J., Gehlert, D. R., \& Rainnie, D. G. (2003). The amygdala, panic disorder, and cardiovascular responses. Annals of the New York Academy of Sciences, 985, 308-325.

Shnerson, A., \& Pujol, R. (1982). Age-related changes in the C57BL/6J mouse cochlea. I. physiological findings. Developmental Brain Research, 2, 65-75.

Shors, T. J., Townsend, D. A., Zhao, M., Kozorovitskiy, Y., \& Gould, E. (2002).

Neurogenesis may relate to some but not all types of hippocampal-dependent learning. Hippocampus, 12(5), 578-584.

Smith, G. W., Aubry, J. M., Dellu, F., Contarino, A., Bilezikjian, L. M., Gold, L. H., Chen, R., Marchuk, Y., Hauser, C., Bentley, C. A., Sawchenko, P. E., Koob, G. F., Vale, W., \& Lee, K. F. (1998). Corticotropin releasing factor receptor 1-deficient mice display decreased anxiety, impaired stress response, and aberrant neuroendocrine development. Neuron, 20(6), 1093-1102.

Soufer, R., Bremner, J. D., Arrighi, J. A., Cohen, I., Zaret, B. L., Burg, M. M., \& GoldmanRakic, P. (1998). Cerebral cortical hyperactivation in response to mental stress in patients with coronary artery disease. Proceedings of the National Academy of Sciences of the United States of America, 95(11), 6454-6459.

Spiess, J., Rivier, J., Rivier, C., \& Vale, W. (1981). Primary structure of corticotropinreleasing factor from ovine hypothalamus. Proceedings of the National Academy of Sciences of the United States of America, 78(10), 6517-6521.

Stein, P. K., Bosner, M. S., Kleiger, R. E., \& Conger, B. M. (1994). Heart rate variability: a measure of cardiac autonomic tone. American Heart Journal, 127(5), 1376-1381.

Stenzel-Poore, M. P., Cameron, V. A., Vaughan, J., Sawchenko, P. E., \& Vale, W. (1992). Development of Cushing's syndrome in corticotropin-releasing factor transgenic mice. Endocrinology, 130(6), 3378-3386. 
Stenzel-Poore, M. P., Heinrichs, S. C., Rivest, S., Koob, G. F., \& Vale, W. W. (1994). Overproduction of corticotropin-releasing factor in transgenic mice: a genetic model of anxiogenic behavior. Journal of Neuroscience, 14(5 Pt 1), 2579-2584.

Stiedl, O., Birkenfeld, K., Palve, M., \& Spiess, J. (2000). Impairment of conditioned contextual fear of C57BL/6J mice by intracerebral injections of the NMDA receptor antagonist APV. Behavioral Brain Research, 116(2), 157-168.

Stiedl, O., \& Meyer, M. (2002). Fractal dynamics of heart beat interval fluctuations in corticotropin-releasing factor receptor subtype 2 deficient mice. Integrative Physiological and Behavioral Science, 37(4), 311-345.

Stiedl, O., \& Meyer, M. (2003). Cardiac dynamics in corticotropin-releasing factor receptor subtype-2 deficient mice. Neuropeptides, 37(1), 3-16.

Stiedl, O., Meyer, M., Jahn, O., Ogren, S. O., \& Spiess, J. (2005). Corticotropin-Releasing Factor Receptor 1 and Central Heart Rate Regulation in Mice during Expression of Conditioned Fear. Journal of Pharmacology and Experimental Therapeutics, 312(3), 905916.

Stiedl, O., Meyer, M., Kishimoto, T., Rosenfeld, M. G., \& Spiess, J. (2003). Stress-mediated heart rate dynamics after deletion of the gene encoding corticotropin-releasing factor receptor 2. European Journal of Neuroscience, 17(10), 2231-2235.

Stiedl, O., Palve, M., Radulovic, J., Birkenfeld, K., \& Spiess, J. (1999a). Differential impairment of auditory and contextual fear conditioning by protein synthesis inhibition in C57BL/6N mice. Behavioral Neuroscience, 113(3), 496-506.

Stiedl, O., Radulovic, J., Lohmann, R., Birkenfeld, K., Palve, M., Kammermeier, J., Sananbenesi, F., \& Spiess, J. (1999b). Strain and substrain differences in context- and tonedependent fear conditioning of inbred mice. Behavioral Brain Research, 104(1-2), 1-12.

Stiedl, O., Radulovic, J., \& Spiess, J. (1997). Behavioral, physiological and molecular changes related to the expression of conditioned fear in mice. In G. Lüer \& U. Lass (Eds.), erinnern und Behalten (pp. 61-78). Göttingen. 
Stiedl, O., \& Spiess, J. (1997). Effect of tone-dependent fear conditioning on heart rate and behavior of C57BL/6N mice. Behavioral Neuroscience, 111(4), 703-711.

Takahashi, L. K. (2001). Role of CRF(1) and CRF(2) receptors in fear and anxiety. Neuroscience and Biobehavioral Reviews, 25(7-8), 627-636.

Ter Horst, G. J. (2000). Emotions and heart-activity control. In G. J. Ter Horst (Ed.), The nervous system and the heart (pp. 55-115). Totowa: Humana Press.

Tezval, H., Jahn, O., Todorovic, C., Sasse, A., Eckart, K., \& Spiess, J. (2004). Cortagine, a specific agonist of corticotropin-releasing factor receptor subtype 1, is anxiogenic and antidepressive in the mouse model. Proceedings of the National Academy of Sciences of the United States of America, 101(25), 9468-9473.

Thompson, R. F. (2001). Das Gehirn. Von der Nervenzelle zur Verhaltenssteuerung. Berlin: Spektrum.

Timpl, P., Spanagel, R., Sillaber, I., Kresse, A., Reul, J. M., Stalla, G. K., Blanquet, V., Steckler, T., Holsboer, F., \& Wurst, W. (1998). Impaired stress response and reduced anxiety in mice lacking a functional corticotropin-releasing hormone receptor 1. Nature Genetics, 19(2), 162-166.

Tornatzky, W., \& Miczek, K. A. (1994). Behavioral and autonomic responses to intermittent social stress: differential protection by clonidine and metoprolol. Psychopharmacology, 116(3), 346-356.

Tovote, P. (2001). Die Modulation der Herzfrequenzdynamik von Mäusen durch Neuropeptid $Y$. Georg-August-Universität, Göttingen.

Tovote, P., Meyer, M., Pilz, P. K., Ronnenberg, A., Ogren, S. O., Spiess, J., \& Stiedl, O. (2005). Dissociation of temporal dynamics of heart rate and blood pressure responses elicited by conditioned fear but not acoustic startle. Behavioral Neuroscience, 119(1), 55-65. 
Tulppo, M. P., Makikallio, T. H., Seppanen, T., Airaksinen, J. K., \& Huikuri, H. V. (1998). Heart rate dynamics during accentuated sympathovagal interaction. American Journal of Physiology, 274(3 Pt 2), H810-816.

Vale, W., Spiess, J., Rivier, C., \& Rivier, J. (1981). Characterization of a 41-residue ovine hypothalamic peptide that stimulates secretion of corticotropin and beta-endorphin. Science, 213(4514), 1394-1397.

van den Buuse, M., Van Acker, S. A., Fluttert, M., \& De Kloet, E. R. (2001). Blood pressure, heart rate, and behavioral responses to psychological "novelty" stress in freely moving rats. Psychophysiology, 38(3), 490-499.

Van Vliet, B. N., Chafe, L. L., \& Montani, J. P. (2003). Characteristics of 24 h telemetered blood pressure in eNOS-knockout and C57Bl/6J control mice. Journal of Physiology, 549(Pt 1), 313-325.

Wallace, K. J., \& Rosen, J. B. (2000). Predator odor as an unconditioned fear stimulus in rats: elicitation of freezing by trimethylthiazoline, a component of fox feces. Behavioral Neuroscience, 114(5), 912-922.

Wilkinson, D. J., Thompson, J. M., Lambert, G. W., Jennings, G. L., Schwarz, R. G., Jefferys, D., Turner, A. G., \& Esler, M. D. (1998). Sympathetic activity in patients with panic disorder at rest, under laboratory mental stress, and during panic attacks. Archives of General Psychiatry, 55(6), 511-520.

Wuttke, W. (2000). Endokrinologie. In R. F. Schmidt, G. Thews \& F. Lang (Eds.), Physiologie des Menschen (pp. 392-398). Berlin: Springer.

Yang, M., Augustsson, H., Markham, C. M., Hubbard, D. T., Webster, D., Wall, P. M., Blanchard, R. J., \& Blanchard, D. C. (2004). The rat exposure test: a model of mouse defensive behaviors. Physiology and Behavior, 81(3), 465-473.

Zangrossi, H., Jr., \& File, S. E. (1994). Habituation and generalization of phobic responses to cat odor. Brain Research Bulletin, 33(2), 189-194. 
Zipes, D. P., \& Wellens, H. J. (1998). Sudden cardiac death. Circulation, 98(21), 2334-2351. 


\section{Lebenslauf}

1975

1981

1982-1985

1985-1994

1994

$1995-2002$

2001-2002

2003
Geburt in Gelsenkirchen als Sohn von Sabine und Rainer Tovote

Grundschule Feldhausen

Grundschule Büttendorf

Wittekind-Gymnasium Lübbecke, Abschluss mit Abitur

Zivildienst

Georg-August-Universität Göttingen

Studium der Biologie, Abschluss mit Diplom und Studium der Biologie und der Chemie für das Lehramt an Gymnasien, Abschluss mit erstem Staatsexamen

Max-Planck-Institut für Experimentelle Medizin Göttingen

Diplomand in der Abteilung Molekulare Neuroendokrinologie Titel der Diplomarbeit: „Die Modulation der Herzfrequenzdynamik von Mäusen durch Neuropeptid Y“،

Max-Planck- Institut für Experimentelle Medizin Göttingen

Doktorand in der Abteilung Molekulare Neuroendokrinologie Titel der Dissertation: „Neuroautonome Regulation und deren emotionale Modulation bei Mäusen“ 


\section{Daten der vorliegenden Arbeit wurden veröffentlicht in:}

\section{Originalpublikationen}

1. Tovote P., Meyer, M., Beck-Sickinger, A.G., S. von Hörsten, S., Ögren, S.O., Spiess, J. \& Stiedl, O. (2004) Central NPY receptor-mediated alteration of heart rate during expression of conditioned auditory fear in mice. Regulatory Peptides, 120, 205-214.

2. Stiedl O., Tovote, P., Ögren, S.O. \& Meyer M. (2004) Behavioral and autonomic dynamics during contextual fear conditioning in mice. Autonomic Neuroscience: Basic and Clinical, $115,15-27$.

3. Tovote P., Meyer, M., Pilz, P., Ronnenberg, A., Ögren, S.O., Spiess, J. \& Stiedl, O. (2005) Dissociation of temporal dynamics of heart rate and blood pressure responses elicited by conditioned fear but not acoustic startle. Behavioral Neuroscience, 119(1), 55-65.

4. Misane P., Tovote, P., Spiess, J., Ögren, S.O. \& Stiedl, O. (2005) Time-dependent involvement of the dorsal hippocampus in trace fear conditioning in mice. Hippocampus (in press).

\section{Eingereichte Manuskripte}

1. Tovote, P., Meyer, M., Ronnenberg, A., Ögren, S.O., Spiess, J. \& Stiedl, O. (2005) Heart rate dynamics in CRFR1-deficient and CRF-transgenic mice during acute emotional challenge. Neuroscience (review submitted).

III. Abstracts für Kongressbeiträge

1. Stiedl O., Tovote, P., Meyer, M., Beck-Sickinger, A.G., von Hörsten, S., \& Spiess, J. (2002) NPY-induced bradycardia and attenuated conditioned tachycardia during retention of conditioned auditory fear in mice. Abstracts of the 32nd Meeting of the Society for Neuroscience, Orlando, FL, USA, 84.6.

2. Koch M., Tovote, P., Ronnenberg, A., Ögren, S.O., Stiedl, O. \& Spiess, J. (2003) Effects of 5-HT $\mathrm{H}_{2 \mathrm{C}}$ receptor activation on exploratory behavior and autonomic function of mice. In: Proceedings of the 29th Göttingen Neurobiology Conference and 5th Conference of the German Neuroscience Society, N. Elsner \& H. Zimmermann (eds.), Thieme Verlag, Stuttgart, pp. 706-707.

3. Tovote, P., Koch, M., Ronnenberg, A., Meyer, M., Stiedl, O. \& Spiess, J. (2003) Blood pressure responses in the fear-conditioned mouse. In: Proceedings of the 29th Göttingen Neurobiology Conference and 5th Conference of the German Neuroscience Society, $N$. Elsner \& H. Zimmermann (eds.), Thieme Verlag, Stuttgart, p. 874.

4. Stiedl, O., Meyer, M., Tovote, P., Ronnenberg, A. \& Spiess, J. (2003) Stress-mediated heart rate dynamics in CRF receptor 1- and 2-deficient and CRF-overexpressing mice. Abstracts of the 33rd Meeting of the Society for Neuroscience, New Orleans, LA, USA, 538.2 . 
5. Tovote, P., M. Meyer, A. Ronnenberg, J. Spiess \& O. Stiedl (2003) Temporal dynamics of heart rate and blood pressure responses in mice subjected to fear conditioning and auditory startle. Abstracts of the 33rd Meeting of the Society for Neuroscience, New Orleans, LA, USA, 624.3.

6. Tovote, P., I. Misane, J. Spiess, S.O. Ögren \& O. Stiedl (2004) Time-dependent involvement of the dorsal hippocampus in trace fear conditioning in mice. Abstract for the 34th Meeting of the Society for Neuroscience, San Diego, USA, 773.4.

7. Stiedl, O., Misane, I., Tovote, P., Ronnenberg, A., Spiess, J. \& Ögren, S.O. (2004) Involvement of NMDA receptors in the dorsal hippocampus in passive avoidance learning in mice. Abstract for the 34th Meeting of the Society for Neuroscience, San Diego, USA, 773.12 .

8. Tovote, P., Misane, I., Ronnenberg, A., Meyer, M., Ögren, S.O., Spiess, J. \& Stiedl, O. (2005) Involvement of the dorsal hippocampus in trace fear conditioning in mice: a timedependent process. In: Proceedings of the 30th Göttingen Neurobiology Conference and 6th Conference of the German Neuroscience Society, Göttingen, Germany, Thieme Verlag, Stuttgart (in press).

IV. Abstracts für zukünftige Kongressbeiträge

1. Tovote, P., M. Meyer, A. Ronnenberg, S. O. Ögren, O. Stiedl and J. Spiess (2005) Heart rate dynamics and behavioral responses during acute emotional challenge in CRF receptor 1-deficient and CRF-overexpressing mice. Abstract for the 87th Annual Meeting of the Endocrine Society, San Diego, USA. 


\section{Dank}

Mein herzlichster Dank gilt Dr. Oliver Stiedl für die hervorragende, grundlegende und weiterführende wissentschaftliche Ausbildung in seiner Arbeitsgruppe, die Betreuung dieser Dissertation und für die fruchtbare Zusammenarbeit bei den Forschungsprojekten und Publikationen.

Ich danke Prof. Dr. Dr. Joachim Spiess für die Anstellung in der Abteilung für Molekulare Neuroendokrinologie, für die Betreuung der Doktorarbeit, der Forschungsprojekte und für die generöse Unterstützung meiner wissentschaftlichen Entwicklung.

Ich bedanke mich bei Prof. Dr. Rüdiger Hardeland für die Betreuung dieser Dissertation am Zoologischen Institut und für die kompetenten Ratschläge und konstruktiven Anmerkungen zu meiner Arbeit.

Mein Dank gilt Prof. Dr. Andreas Stumpner für die Übernahme des Korreferats, die sehr gute Ausbildung an der Universität und für die stets aufmunternde Unterstützung.

Ich danke Prof. Dr. Michael Meyer für seine fundierten Ratschläge und kritischen Kommentare zu meiner Arbeit und für die Kooperation bei den Publikationen.

Herzlichen Dank an Dr. Peter Pilz für die Kooperation bei dem Behavioral Neuroscience Manuskript.

Mein besonderer Dank gilt Anja Ronnenberg für die tägliche Hilfe nicht nur bei der Laborarbeit, für das Korrekturlesen und freundschaftliche Unterstützung.

Vielen Dank an Lothar Demel, Thomas Liepold, Lars van Werven, Frank Thörel, Harry Scherer, Dr. Olaf Jahn, Dr. Hossein Tezval und Dr. Jelena Radulovic für die nette Zusammenarbeit und Unterstüzung in der Abteilung.

Muchas gracias a las barakistas: Nils, Matti und Tilli

Ich danke meiner Familie: Sabine, Rainer und Alisa Tovote und Christina Libsig-Seer für aufmunternde Gespräche und seelischen Beistand

Mein größter Dank gebührt Dir, Katrin. Aber das ist eine andere Geschichte... 